17 INSTITUTO DE QuímICA

\title{
Determinação de Macro e Microelementos em Adoçantes Dietéticos por ICP OES.
}

\author{
Darilena Monteiro Porfírio
}

Dissertação apresentada como parte dos requisitos para obtenção do grau de Mestrado em Química na Área de Química Analítica.

Orientadora:

Profa. Dra. Elisabeth de Oliveira 


\section{"Determinação macro e microelementos em adoçantes dietéticos por ICP OES"}

\section{DARILENA MONTEIRO PORFÍRIO}

Dissertação de Mestrado submetida ao Instituto de Química da Universidade de São Paulo como parte dos requisitos necessários à obtenção do grau de Mestre em Química - Área: Química Analítica.

Aprovada por:

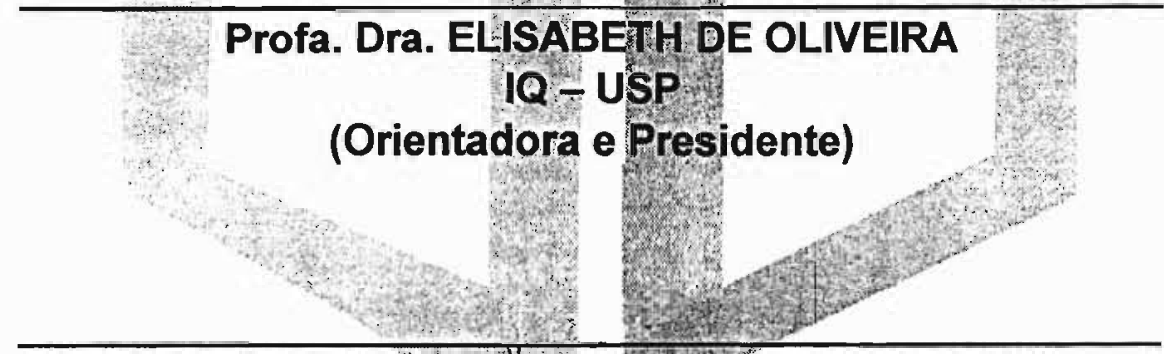

Profa. Dra. MARINAVRANEO MAGGI TAVARES

IQ. USP

Profa. Dra. SOLANGE CADORE

IQ - UNICAMP

SÃO PAULO

16 DE JUNHO DE 2004.

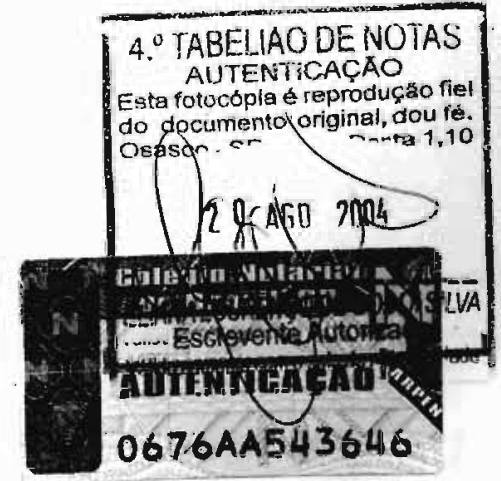


Esta dedicatória é inspirada na AVE MARIA DAS MULHERES de Silvana Duboc

e não tem a intenção de excluir o universo masculino que amo e me dedico, quero neste momento homenagear, agradecer e lembrar, das mulheres que influenciam e deixam marcas nas vidas todos que as cercam.

Àquelas que foram escolhidas para dar a vida.

E mulheres de todas as espécies.

De todos os credos, raças e nacionalidades,

Todas aquelas nas quais a vida está envolvida em sorrisos, lágrimas, tristezas e felicidades.

Às que trabalham o dia inteiro,

Às mães, com seus filhos doentes,

Às meninas carentes,

Às que ainda estão dentro de um ventre.

Às adolescentes inexperientes,

Às velhinhas esquecidas, sem abrigo, sem família, carinho e amigos

Às mulheres guerreiras a vida inteira,

Às mães que não têm como dar a seus filhos, o pão e a educação.

À todas que eu já conheci.

Às amigas,

Às inimigas,

Às irmãs e às freiras,

Às que perderam a fé,

Às escritoras e as doutoras,

Às artistas e professoras,

Às governantes e as menos importantes, também às ignorantes,

$E$ a todas que estão gestantes,

À que foi traída,

Às que são humilhadas,

Às que foram contaminadas,

$E$ todas as mulheres que se sentem culpadas

por não conseguir fazer sempre o melhor.

$E$ todas nós. 
À Deus

e suas bênçãos presentes em todos

os momentos de minha vida.

\begin{abstract}
À
Claudio e D'arc, meus pais que

me ensinaram a realizar sonhos.
\end{abstract}

Á

Rogilson, Danillo e Diogo, meus amores e sonhos concretizados.

Minhas irmãs Lucilena, Claudilena e Milena, sempre presentes apesar da distância.

À minha orientadora Profa. Elisabeth de Oliveira, pela amizade, segurança e pelas lições que foram ensinadas em todos estes anos. 


\section{Agradecimentos}

À minha orientadora, Dra. Elisabeth de Oliveira, pela amizade, paciência, compreensão e orientação em temas científicos e pessoais;

Ao IQ-USP pelo apoio material;

Aos Docentes do IQ-USP pela formação e exemplo a ser seguido;

Aos colegas do LEAA pela convivência agradável;

À ASTRATOM pela realização das análises comparativas por ICP MS;

Aos Técnicos Renato, Roberto, Débora e Wilson(in memorium) pelos préstimos;

Aos funcionários da Biblioteca do Conjunto das Químicas IQ-USP, pelo auxílio e eficiência;

Aos funcionários da Secretaria de Pós-graduação pelo atendimento e cordialidade;

E todas as pessoas que direta ou indiretamente, contribuíram para a realização deste trabalho. 
Índice

Dedicatória

Agradecimentos

Lista de Figuras

Lista de Tabelas

Abreviaturas

xiii

Resumo

Xv

Abstract

$x v i$

Objetivo Geral

xvii

Objetivo Específico

xviii

Capítulo 1

xviii

1. INTRODUÇÃO.

Capítulo 2

2. ADOÇANTES DIETÉTICOS E EDULCORANTES. 5

2.1 EDULCORANTES. 6

2.1.1 Sacarina. 6

$\begin{array}{lll}\text { 2.1.2 Ciclamato. } & 7\end{array}$

2.1.3 Aspartame. 9

2.1.4 Esteviosídeo. 10

2.1.5 Acesulfame-K. 11

2.1.6 Sucralose. 12

Capítulo $3 \quad 16$

3. LEGISLAÇÃO BRASILEIRA SOBRE ADOÇANTES DIETÉTICOS. 16 Capítulo $4 \quad 19$

4. BIODISPONIBILIDADE E INTERAÇÕES DOS ELEMENTOS DE INTERESSE NA NUTRIÇÃO.

4.1 MACROELEMENTOS (Macrominerais). 19

4.2.1 Cálcio. 20

4.2.2 Magnésio. 20

4.2.3 Potássio. 21

4.2.4 Sódio. 21

4.2 MICROELEMENTOS ( Microminerais ou Traço) 23 
4.2.1 Alumínio. 25

4.2.2 Arsênio. 25

4.2.3 Cádmio. 26

4.2.4 Cobre. 28

4.2.5 Chumbo. 25

4.2.6 Cromo. 26

$\begin{array}{lll}4.2 .7 & \text { Estanho. } 29\end{array}$

$\begin{array}{lll}4.2 .8 \text { Ferro. } & 29\end{array}$

4.2.9 Manganês 30

4.2.10 Mercúrio. 31

4.2.11 Níquel. 31

4.2.12 Selênio. 32

4.2.13 Vanádio. 32

4.2.14 Zinco. 32

4.3 LEGISLAÇÃO BRASILEIRA SOBRE OS ELEMENTOS NA NUTRIÇÃO.

4.4 LEGISLAÇÃO BRASILEIRA DE CONTAMINANTES INORGÂNICOS EM ALIMENTOS. 34

$\begin{array}{ll}\text { Capitulo } 5 & 37\end{array}$

5. DADOS MERCADOLÓGICOS. 37

5.1 AMOSTRAGEM. 38

Capitulo 6

6. REVISÃO BIBLIOGRÁFICA DA METODOLOGIA ANAIÍTICA 41

6.1 PREPARAÇÃO DAS AMOSTRAS. 41

6.1.1 Amostras Líquidas. 42

6.1.2 Amostras Sólidas. 43

6.2 PROCEDIMENTO DE DISSOLUÇÃO. 44

6.2.1 Métodos por Via Seca. 44

6.2.2 Métodos por Via Úmida. $\quad 46$

6.3 ESCOLHA DA TÉCNICA. 46

6.4 ANÁLISE POR ICP OES. $\quad 47$

6.4.1 Fonte de Excitação. 48

6.4.2 Detecção. 53 
6.4.3 Interferências.

6.5 PROCEDIMENTOS DE CALIBRAÇÃO.

7. PROCEDIMIENTOS E MÉTODOS.

7.1 EQUIPAMENTOS.

7.2 REAGENTES.

7.3 DISSOLUÇÃO DAS AMOSTRAS DE ADOÇANTES DIETÉTICOS.

7.3.1 Análise Sem o Tratamento Prévio da Amostra.

7.3.2 Resíduo de Cinzas.

7.3.3 Dissolução a frio.

7.3.4 Extração em Microondas.

Capítulo 8

8. RESULTADOS E DISCUSSÕES. 66

8.1 PARÂMETROS INSTRUMENTAIS DO ICP OES. 68

8.1.1 Avaliação da Determinação em Múltiplos Comprimentos de Onda. 77 Capítulo 9

9. RESULTADOS.

9.1 AVALIAÇÃO DA TÉCNICA E EXIGÊNCIA DA LEGISLAÇÃO. 93

9.2 AVALIAÇÃO DOS ELEMENTOS MAIORES. 95 Sem tratamento Prévio versus Resíduo de Cinzas.

9.3 AVALIAÇÃO DOS ELEMENTOS TRAÇO:

Sem tratamento Prévio versus Extração em Microondas de alta pressão.

9.4 DETERMINAÇÃO DE METAIS EM AMOSTRAS DE ADOÇANTES EM PÓ.

9.5 DETERMINAÇÃO DE METAIS EM AMOSTRAS DE ADOÇANTES LIQUIDO.

9.6 IDR DE NUTRIENTES E O CONSUMO DE ADOÇANTES DIETÉTICOS.

9.7 ANÁLISE HIERÁRQUICA DAS AMOSTRAS DE ADOÇANTES DIETÉTICOS. 
CONCLUSOES

TRABALHOS FUTUROS.

REFERÊNCIA BIBLIOGRÁFICA.

ANEXO I: Minerais na Composição do Corpo Humano.

ANEXO II: Definição de Caloria.

ANEXO III: Estudo Fatorial 22 para otimização dos parâmetros de Análise por ICP OES.

ANEXO IV: Tabelas dos Parâmetros das Regressões lineares para as determinações em Múltiplos Comprimentos de Onda.

ANEXO V: Estudo dos Perfis e das Interferências espectrais e de Matriz.

\section{Lista de Figuras}

FIGURA 1: Fórmula estrutural da Sacarina na forma ácida.

FIGURA 2: Fórmula estrutural da Sacarina na forma de seus sais de sódio e de cálcio.

FIGURA 3: Fórmula estrutural do Ciclamato na forma ácida.

FIGURA 4: Fórmula estrutural do Ciclamato na forma de seus sais de sódio e de cálcio.

FIGURA 5: Fórmula estrutural do Aspartame.

FIGURA 6: Fórmula estrutural do Esteviosídeo.

FIGURA 7: Fórmula Estrutural do Acesulfame-K.

FIGURA 8: Fórmula Estrutural da Sucralose.

FIGURA 9: Distribuição dos Produtos Light e diet no Brasil no ano de 200237

FIGURA 10: Distribuição dos edulcorantes utilizados na composição dos Adoçantes dietéticos no mercado brasileiro no ano de 2002.

FIGURA 11: Distribuição das Amostras de adoçantes dietéticos em pó. $\quad 39$

FIGURA 12: Distribuição das Amostras de adoçantes dietéticos líquido. $\quad 40$

FIGURA 13: Codificação das amostras de adoçantes dietéticos coletadas. $\quad 40$

FIGURA 14: Esquema Resumido de como um resultado analítico pode ser obtido por Espectrometria de Emissão Atômica. 
FIGURA 15: Esquema dos processos que ocorrem no sistema de Introdução de amostra e na fonte de excitação.

FIGURA 16: Esquema do posicionamento da zona de observação nas vistas Radial e Axial.

FIGURA 17: Esquema Detalhado da Fonte de Plasma com Vista Axial.

FIGURA 18: Montagem do nebulizador, da câmara de nebulização e da tocha axial.

FIGURA 19: Representação do Círculo de Rowland e sua semelhança com as placas fotográficas.

FIGURA 20: Circulo de Rowland e o esquema das ópticas, fendas e fotodinodos de detecção simultânea.

FIGURA 21: Espectro obtido para o estudo realizado por Mermet das intensidades relativas das linhas atômicas e iônicas do Magnésio.

FIGURA 22: Comparação entre as funções de calibração típica, a adição de padrão monoelementar e multielementar e os efeitos que podem ser verificados.

FIGURA 23: Método de aquecimento para obtenção do Residuo de Cinzas. 63

FIGURA 24: Programa de aquecimento para dissolução em Microondas Fechado.

FIGURA 25: Comparação dos métodos de dissolução quanto ao número de amostras por ciclo de preparação.

FIGURA 26: Comparação dos métodos de dissolução quanto ao tempo de preparação de amostras por ciclo.

FIGURA 27: Comparação dos métodos de dissolução quanto a freqüência analítica.

FIGURA 28: Curvas Analíticas do Alumínio (394 nm).

FIGURA 29: Curvas Analíticas do Arsênio (193,759nm).

FIGURA 30: Curvas Analíticas do Cádmio (226,502 nm).

FIGURA 31: Curvas Analíticas do Cromo (205,552 nm).

FIGURA 32: Curvas Analíticas do Cobre $(224,700 \mathrm{~nm})$.

FIGURA 33: Curvas Analíticas do Ferro $(261,187 \mathrm{~nm})$.

FIGURA 34: Curvas Analíticas do Mercúrio (194,227nm). 
FIGURA 35: Curvas Analíticas do Manganês (257,610nm). 72

FIGURA 36: Curvas Analíticas do Níquel (221,648 nm). 72

FIGURA 37: Curvas Analíticas do Selênio (203,985 nm). 73

FIGURA 38: Curvas Analíticas do Zinco $(213,856 \mathrm{~nm})$. 73

FIGURA 39: Curvas Analíticas do Chumbo $(217,000 \mathrm{~nm})$. 73

FIGURA 40: Determinação de Carbono Residual para a amostra SACY-L2 para os métodos de preparação de amostras: Resíduo de Cinzas, Microondas e sem o tratamento prévio.

FIGURA 41: Curvas Analíticas e Perfis espectrais de múltiplos comprimentos de onda do Alumínio.

FIGURA 42: Curvas Analíticas e Perfis espectrais de múltiplos comprimentos de onda do Arsênio.

FIGURA 43: Curvas Analíticas e Perfis espectrais de múltiplos comprimentos de onda do Cálcio.

FIGURA 44: : Curvas Analíticas e Perfis espectrais de múltiplos comprimentos de onda do Cádmio.

FIGURA 45: Curvas Analíticas e Perfis espectrais de múltiplos comprimentos de onda do Cromo.

FIGURA 46: Curvas Analíticas e Perfis espectrais de múltiplos comprimentos de onda do Cobre.

FIGURA 47: Curvas Analíticas e Perfis espectrais de múltiplos comprimentos de onda do Ferro.

FIGURA 48: Curvas Analiticas e Perfis espectrais de múltiplos comprimentos de onda do Mercúrio.

FIGURA 49: Curvas Analíticas e Perfis espectrais de múltiplos comprimentos de onda do Manganês.

FIGURA 50: Curvas Analíticas e Perfis espectrais de múltiplos comprimentos de onda do Níquel.

FIGURA 51: Curvas Analíticas e Perfis espectrais de múltiplos comprimentos de onda do Chumbo.

FIGURA 52: Curvas Analíticas e Perfis espectrais de múltiplos comprimentos de onda do Selênio.

FIGURA 53: Curvas Analíticas e Perfis espectrais do Vanádio. 
FIGURA 54: Linhas analíticas adequadas a determinação sem o tratamento prévio das amostras.

FIGURA 55: Linhas analíticas adequadas a determinação sem o tratamento prévio das amostras.

FIGURA 56A: Comparação dos resultados dos macroelementos para amostra SACY-L7 sem tratamento prévio, com o Resíduo de cinzas e com o ICP MS.

FIGURA 56B: Comparação dos resultados dos microelementos para amostra SACY-L7 sem tratamento prévio, com o tratamento em microondas de alta pressão e com o ICP MS.

FIGURA 56C: Comparação dos resultados dos microelementos para amostra SACY-L7sem tratamento prévio, com o tratamento em microondas de alta pressão e com o ICP MS.

FIGURA 57A: Comparação dos resultados dos macroelementos para amostra ASP-P9 sem tratamento prévio, com o Resíduo de cinzas e com o ICP MS.

FIGURA 57B: Comparação dos resultados dos microelementos para amostra ASP-P9 sem tratamento prévio, com o tratamento em microondas de alta pressão e com o ICP MS.

FIGURA 57C: Comparação dos resultados dos microelementos para amostra ASP-P9 sem tratamento prévio, com o tratamento em microondas de alta pressão e com o ICP MS.

FIGURA 58A: Comparação dos resultados dos macroelementos para amostra SUC-P1 sem tratamento prévio, com o Resíduo de cinzas e com o ICP MS

FIGURA 58B: Comparação dos resultados dos microelementos para amostra SUC-P1 sem tratamento prévio, com o tratamento em microondas de alta pressão e com o ICP MS.

FIGURA 58C: Comparação dos resultados dos microelementos para amostra SUC-P1 sem tratamento prévio, com o tratamento em microondas de alta pressão e com o ICP MS.

FIGURA 59A: Comparação dos resultados dos macroelementos para amostra SACY-P2 sem tratamento prévio, com o Resíduo de cinzas e 100 com o ICP MS. 
FIGURA 59B: Comparaçăo dos resultados dos microelementos para amostra SACY-P2 sem tratamento prévio, com o tratamento em microondas de alta pressão e com o ICP MS.

FIGURA 60A: Comparação dos resultados dos macroelementos para amostra ASP-L1 sem tratamento prévio, com o Resíduo de cinzas e com o ICP MS.

FIGURA 60B: Comparação dos resultados dos microelementos para amostra ASP-L1 1 sem tratamento prévio, com o tratamento em microondas de alta pressão e com o ICP MS.

FIGURA 60C: Comparação dos resultados dos microelementos para amostra ASP-L1 sem tratamento prévio, com o tratamento em microondas de alta pressão e com o ICP MS.

FIGURA 61A: Comparação dos resultados dos macroelementos para amostra STE-P1 sem tratamento prévio, com o Resíduo de cinzas e com o ICP MS.

FIGURA 61B: Comparação dos resultados dos microelementos para amostra STE-P1 sem tratamento prévio, com o tratamento em microondas de alta pressão e com o ICP MS.

FIGURA 61C: Comparação dos resultados dos microelementos para amostra STE-P1 sem tratamento prévio, com o tratamento em microondas de alta pressão e com o ICP MS.

FIGURA 62: Somatório da concentração de metais tóxicos das amostras de adoçante dietético em pó.

FIGURA 63: Somatório da concentração de metais tóxicos das amostras de adoçante dietético líquido.

FIGURA 64: Concentração de Arsênio presente nas amostras de adoçante dietético em pó em comparação com o limite da legislação.

FIGURA 65: Concentração de Cromo presente nas amostras de adoçante dietético em pó em comparação com o limite da legislação.

FIGURA 66: Concentração de Níquel presente nas amostras de adoçante dietético líquido em comparação com o limite da legislação.

FIGURA 67: Análise Hierárquica das amostras de Adoçantes Dietéticos. 
Lista de Tabelas

TABELA 1: Principais características dos Edulcorantes.

TABELA 2: Tabela com a composição dos adoçantes quanto aos edulcorantes utilizados, quantidade de adoçante $\theta$ equivalência em medidas casuais em relação ao açúcar, fabricante, calorias e Ingestão Máxima Diária.

TABELA 3: Limites Máximos de Edulcorantes em Alimentos e Bebidas dietéticas.

TABELA 4: Ingestão Diária Recomendada (IDR) para Adultos

TABELA 5: Ingestão Diária Recomendada (IDR) para Lactentes $\theta$ Crianças.

TABELA 6: Ingestão Diária Recomendada (IDR) para Gestantes e Lactantes.

TABELA 7: Resumo do Limite Máximo para Contaminantes inorgânicos encontrados no Decreto $n^{\circ} 55.871$.

TABELA 8: Resumo do Limite Máximo para Contaminantes inorgânicos encontrados na Portaria ${ }^{\circ}{ }^{\circ} 685$.

TABELA 9: Vantagens e desvantagens da análise por ICP OES frente a outras técnicas espectrais.

TABELA 10: Programa de Dissolução Ácida em Microondas de Alta Pressão para amostras de adoçante dietético.

TABELA 11: Parâmetros instrumentais de operação usual para o ICP OES.

TABELA 12: Parâmetros instrumentais de operação para o ICP OES. 76

TABELA 13: Desvio Padrão Relativo Aceitável para a determinação em função da concentração do elemento de interesse.

TABELA 14: Comparação do Limite de quantificação da técnica de análise por ICP OES para Alimentos Sólidos e a exigência da legislação brasileira.

TABELA 15: Comparação do Limite de quantificação da técnica de análise por ICP OES para Alimentos Líquidos e a exigência da legislação brasileira. 
TABELA 16: Resultados da determinação de $\mathrm{Na}, \mathrm{Mg}, \mathrm{Al}, \mathrm{K}, \mathrm{Ca}, \mathrm{V}, \mathrm{Mn}$, $\mathrm{Fe}, \mathrm{Ni}, \mathrm{Cu}, \mathrm{Zn}, \mathrm{As}, \mathrm{Cd}$ e $\mathrm{Cr}$ em amostras de Adoçante dietético em pó com o edulcorante Aspartame.

TABELA 17: Resultados da determinação de $\mathrm{Na}, \mathrm{Mg}, \mathrm{Al}, \mathrm{K}, \mathrm{Ca}, \mathrm{V}, \mathrm{Mn}$, $\mathrm{Fe}, \mathrm{Ni}, \mathrm{Cu}, \mathrm{Zn}, \mathrm{As}, \mathrm{Cd}$ e $\mathrm{Cr}$ em amostras de Adoçante dietético em pó com o edulcorante Aspartame.

TABELA 18: Resultados da determinação de $\mathrm{Na}, \mathrm{Mg}, \mathrm{Al}, \mathrm{K}, \mathrm{Ca}, \mathrm{V}, \mathrm{Mn}$, $\mathrm{Fe}, \mathrm{Ni}, \mathrm{Cu}, \mathrm{Zn}, \mathrm{As}, \mathrm{e} \mathrm{Cr}$ em amostras de Adoçante dietético em pó com os edulcorantes Sacarina e 106 Ciclamato.

TABELA 19: Resultados da determinação de $\mathrm{Na}, \mathrm{Mg}, \mathrm{Al}, \mathrm{K}, \mathrm{Ca}, \mathrm{V}, \mathrm{Mn}$, $\mathrm{Fe}, \mathrm{Ni}, \mathrm{Cu}, \mathrm{Zn}, \mathrm{As}, \mathrm{Cd}$ e $\mathrm{Cr}$ em amostras de Adoçante dietético em pó com os edulcorantes Stévia e Sucralose. 107

TABELA 20: Resultados da determinação de $\mathrm{Na}, \mathrm{Mg}, \mathrm{Al}, \mathrm{K}, \mathrm{Ca}, \mathrm{V}$, $\mathrm{Cr}, \mathrm{Mn}, \mathrm{Fe}, \mathrm{Ni}, \mathrm{Cu}, \mathrm{Zn}, \mathrm{Pb}$ e Cd na amostra de Adoçante dietético líquido com o edulcorante Aspartame.

TABELA 21: Resultados da determinação de $\mathrm{Na}, \mathrm{Mg}, \mathrm{Al}, \mathrm{K}, \mathrm{Ca}, \mathrm{V}, \mathrm{Cr}$, $\mathrm{Mn}, \mathrm{Fe}, \mathrm{Ni}, \mathrm{Cu}, \mathrm{Zn}, \mathrm{Pb}$ e $\mathrm{Cd}$ em amostras de Adoçante dietético líquido com os edulcorantes Sacarina e 113 Ciclamato.

TABELA 22: Resultados da determinação de $\mathrm{Na}, \mathrm{Mg}, \mathrm{Al}, \mathrm{K}, \mathrm{Ca}, \mathrm{V}, \mathrm{Cr}$, $\mathrm{Mn}, \mathrm{Fe}, \mathrm{Ni}, \mathrm{Cu}, \mathrm{Zn}, \mathrm{Pb}$ e $\mathrm{Cd}$ em amostras de Adoçante dietético líquido com os edulcorantes Sacarina e 114 Ciclamato.

TABELA 23: Valores máximos de $\mathrm{Na}, \mathrm{Ca}, \mathrm{Mg}, \mathrm{Mn}, \mathrm{Fe}$ e $\mathrm{Cu}$ por $10 \mathrm{~g}$ de adoçante dietético em pó e a porcentagem em relação a IDR destes nutrientes.

TABELA 24: Valores máximos de $\mathrm{Na}, \mathrm{Ca}, \mathrm{Mg}, \mathrm{Mn}, \mathrm{Fe}$ e Cu por $10 \mathrm{~g}$ de adoçante dietético em pó e a porcentagem em relação a IDR destes nutrientes. 


\section{Abreviaturas}

ICP OES - Inductively Coupled Plasma Atomic Emission Spectrometry.

EEA - Espectrometria de Emissão Atômica.

CCD - Charge Coupled Device.

SVS - Secretaria de Vigilância Sanitária

IDR - Ingestão Diária Recomendada.

FDA - Food and Drug Administration.

DMDR - Dose Máxima Diária Recomendada.

DINAL - Divisão Nacional de Alimentos.

MS - Ministério da Saúde.

OMS - Organização Mundial de Saúde.

MA - Ministério da Agricultura e do Abastecimento.

IARC - International Agency for Research on Cancer.

ESADDI - Ingestão Alimentar Estimada Adequada e Segura.

HSDB - Hazardous Substances Data Bank.

TGI - Trato Gastrointestinal.

ABIA - Associação Brasileira das Industrias de Alimentação.

ABIAD - Associação Brasileira da Industria de Alimentos Dietéticos.

BG - Background ou Fundo.

MRC - Material de Referência Certificado.

MIP - Microwave Inductively Plasma.

DCP -Discharge Coupled Plasma.

RF - Radio Frequência.

PI - Padrão Interno.

ETL - Equilíbrio Térmico Local.

BIPM - Bureau Internacional de Pesos e Medidas.

LD - Limite de Detecção.

LQ - Limite de Quantificação.

BEC - Blank Equivalent Concentration.

$\mathrm{RSD}_{\mathbf{R}}$ - Desvio Padrão Relativo.

ICP MS - Inductively Coupled Plasma Atomic Mass Spectrometry. 


\section{Resumo}

Neste estudo foi determinado o conteúdo de metais em adoçantes dietéticos de mesa, consumidos por um número crescente de pessoas preocupadas em manter a forma física e restringir o nível calórico da dieta havendo ou não recomendação médica.

Foram coletadas 26 amostras de adoçantes dietéticos distribuídos no mercado de São Paulo, em uma grande variedade de apresentações, produtos, composições e marcas. Como a composição é dependente da produção, esta análise é indispensável ao controle da qualidade e relevante à saúde do consumidor.

A Espectrometria de Emissão Óptica com Fonte de Plasma Indutivamente Acoplado (ICP OES) com vista axial, mostrou-se adequada determinação dos macronutrientes $\mathrm{Na}$, $\mathrm{K}, \mathrm{Ca}, \mathrm{Mg}$ e dos microelementos essenciais $\mathrm{Fe}, \mathrm{Cu}, \mathrm{Zn}, \mathrm{Cr}, \mathrm{Mn}$ e Se, dos potencialmente tóxicos $\mathrm{Al}, \mathrm{Ni}, \mathrm{As}, \mathrm{Cd}$ e $\mathrm{Pb}$ em adoçantes sólidos e líquidos, atendendo as exigências da legislação brasileira. Assim, foi realizado um estudo comparativo entre as determinações utilizando as metodologias clássicas de pré-tratamento da amostra, como o resíduo de cinzas, a dissolução ácida com aquecimento por microondas com o procedimento sem tratamento prévio das amostras, visando facilitar a análise, uma vez que esta é a etapa que mais consome tempo e esforços.

A determinação simultânea do espectro favoreceu a análise, uma vez que 74 comprimentos de onda puderam ser selecionados sem aumento no tempo ou no custo de análise, auxiliando na seleção de 36 linhas analíticas mais adequadas (livre de interferências) à determinação sem tratamento prévio da amostra.

Nenhuma amostra de adoçante excedeu o valor recomendado para o somatório dos contaminantes inorgânicos (Aspartame $<10 \mu \mathrm{g} \mathrm{g}^{-1}$ e Sacarina $<20 \mu \mathrm{g} \mathrm{g}^{-1}$ ). No entanto, 6 marcas de adoçantes em pó excederam o valor limite da legislação para As $\left(1,0 \mu \mathrm{g} \mathrm{g}^{-1}\right)$, excederam o valor para $\mathrm{Cr}$ total $(0,1 \mu \mathrm{g} \mathrm{g})$ e 2 marcas de adoçante líquido excederam o valor para $\mathrm{Ni}\left(0,1 \mu \mathrm{g} \mathrm{g}^{-1}\right)$. Mostrando que os adoçantes em pó apresentam $\left(\approx 5 \mu \mathrm{g} \mathrm{g}^{-1}\right)$ níveis maiores de metais potencialmente tóxicos que os adoçantes líquidos $\left(\approx 2,0 \mu \mathrm{g} \mathrm{mL} \mathrm{m}^{-1}\right.$. 


\section{ABSTRACT}

The metal content in artificial sweetener usually consumed by a growing population concerned to keep body shape and to restrict the diet caloric content, by medical recommendation or not, was measured.

The samples were 26 artificial sweeteners available at São Paulo's market, under different forms, and several suppliers, with various sweetener composition, and brands. Because the composition depends on manufacture factors, this analysis is mandatory for quality control and relevant for the user health.

Inductively coupled plasma atomic emission with axial view has demonstrated to be an appropriated technique to determine the macronutrient content, such as $\mathrm{Na}, \mathrm{K}, \mathrm{Ca}, \mathrm{Mg}$ and essential microelements such as $\mathrm{Fe}, \mathrm{Cu}, \mathrm{Zn}, \mathrm{Cr}, \mathrm{Mn}$ and $\mathrm{Se}$, besides the potentially toxic elements such as $\mathrm{Al}, \mathrm{Ni}, \mathrm{As}, \mathrm{Cd}$ and $\mathrm{Pb}$ in solid and liquid sweeteners in accordance with to the Brazilian regulation. It was also performed a comparative study of the sample preparation methodology, using classical sample pretreatment, such as burning to ashes, and acid dissolution with microwave heating and a procedure without prior sample treatment (dissolution and/or convenient dilution), aiming at facilitating the analysis of dietetic sweetener because this step is the most time and labor consuming.

The analysis was simplified using the simultaneous spectra acquisition, once 74 wavelengths were selected without time or cost increase, and helping the identification of 36 appropriate analytical lines (free from interferences) to apply to the samples determination without prior treatment.

None sweetener exceeded the recommended value of inorganic contaminant (for aspartame samples the value was below $10 \mu \mathrm{g} \mathrm{g}^{-1}$ and for saccharine samples that was below $\left.20 \mu \mathrm{g} \mathrm{g}^{-1}\right)$. However, 6 brands of artificial sweetener in powder exceeded the legislation limit value for As $\left(1.0 \mu \mathrm{g} \mathrm{g}^{-1}\right)$, and other 7 brands exceeded the $\mathrm{Cr}$ recommended maximum value $\left(0.1 \mu \mathrm{g} \mathrm{g}^{-1}\right)$. Other 2 brands of liquid sweetener exceeded the Ni recommended maximum value. Therefore, for all samples, the artificial sweetener in powder presented higher levels of potentially toxic metals $\left(\approx 5 \mu \mathrm{g} \mathrm{g}^{-1}\right)$ than those in a liquid presentation $\left(\approx 2.0 \mu \mathrm{g} \mathrm{mL}^{-1}\right)$. 


\section{Objetivo Geral}

Analisar algumas marcas de adoçantes dietéticos presentes no mercado brasileiro e determinar a presença de elementos essenciais ou não, contaminantes e potencialmente tóxicos, por Espectrometria de Emissão Óptica com fonte de Plasma Indutivamente Acoplado (ICP OES) para o controle nutricional e toxicológico.

\section{Objetivo Específico}

Determinar as curvas analíticas de trabalho, o limite de detecção, os comprimentos de onda e os demais parâmetros de trabalho do Espectrômetro de Emissão Atômica com detecção Óptica.

Estudar a viabilidade de realizar determinações por ICP OES sem o tratamento prévio das amostras de adoçantes comparando os procedimentos de diluição e/ou dissolução, de dissolução ácida com aquecimento por microondas e o resíduo de cinzas.

Corrigir possiveis interferências espectrais ou de matriz no decorrer da análise realizada para o procedimento sem o tratamento prévio da amostra.

Apresentar resultados confiáveis sobre a composição elementar dos adoçantes dietéticos comercializados em São Paulo. 


\section{Capítulo 1}

\section{INTRODUÇÃO}

Os elementos químicos estão presentes na nutrição humana, por isso é necessário um estudo da distribuição destes na dieta alimentar, assim sua forma, distribuição e interação deve ser monitorada.

Segundo MIYAGISHIMA et al. para garantir a segurança alimentar estão envolvidos muitos setores particulares, desde a produção (agrícola ou industrial) até o consumo. O governo, indústria e consumidor são três pilares principais que influenciam a cadeia alimentícia e cada um tem responsabilidades distintas ${ }^{1}$.

O governo deve manter departamentos ou agências relacionadas à segurança alimentar que contemple a agricultura, a produção e o comércio, estendendo-se por outras atividades que possam afetar a produção e o consumo de alimentos (a educação, finanças e o meio ambiente). O governo deve estabelecer padrões, relações de saúde ou códigos e assegurar execução destes pelo devido setor. Deve ajudar o consumidor a obter informações corretas sobre o consumo dos alimentos, assim as autoridades de saúde devem colaborar com as autoridades de educação, para garantir informação adequada sobre segurança alimentar a todos os consumidores.

A indústria alimentícia, independente do tamariho ou origem, tem a responsabilidade fundamental de produzir alimentos seguros ao consumo. Isto pode ser alcançado, em parte, por meio de códigos de boas práticas na produção e manipulação de alimentos, de leis pertinentes e regulamentos fixados pelo governo. A indústria deveria colaborar com o governo e informar as autoridades e os consumidores, assumindo um papel central no que se refere à qualidade 
nutricional do produto, educar os consumidores por meio de anúncios e rótulos que obedecem a regulamentos, mantendo a confiabilidade e a credibilidade na indústria de alimentos.

O consumidor, quando finalmente escolhe um produto, deve estar preparado para consumí-lo. Deve mostrar-se bastante consciente quando compra, prepara e consome um determinado alimento, pois se o consumidor faz mal-uso de um alimento, os esforços de todos os outros setores envolvidos, desde a produção até o prato, foram em vão. Todo consumidor deveria ser vigilante e capaz de evitar alimentos que foram produzidos ou preparados sem oferecer garantida segurança. Para tanto, uma ampla discussão deve ser gerada para fornecer subsídios a melhorias na regulamentação, na produção e na escolha de produtos alimentícios.

Posto isso, a produção de adoçantes dietéticos de mesa é parte de um processo de inovação tecnológica, processo este dinâmico quanto à criação, difusão e comercialização de produtos alimentícios, que transforma e modifica mercados.

Segundo PALAEZ o desenvolvimento de tecnologias de síntese de edulcorantes alternativos à sacarose - cuja hegemonia marcou historicamente a civilização ocidental - permitiu não apenas uma crescente segmentação deste tipo de mercado, como também proporcionou um espaço de concorrência entre empresas de diferentes ramos (químico, farmacêutico e alimentício) ${ }^{2}$.

Se, por um lado, a evolução do mercado de produtos alimentares "light" pode chegar a uma estagnação, por outro lado a difusão de substâncias sintéticas representam uma mudança no cenário de síntese e comercialização de novos produtos alimentares. Isto quer dizer que este tipo de tecnologia pode ter 
implicações mais profundas e duráveis no sistema agroalimentar, que uma simples resposta ao excesso de consumo calórico de camadas da população.

Os adoçantes dietéticos de mesa são consumidos por grande parte da população, mas seu principal emprego é como coadjuvantes no controle do Diabetes Mellitus, podendo ser até totalmente abolido da alimentação do diabético, porém têm sua expressão quanto ao convívio social destes indivíduos, como substitutos da sacarose, conferindo sabor e conforto que estão associados a nossa cultura. A substituição da sacarose pelos adoçantes dietéticos facilita a terapia nutricional instituída ao paciente. Assim, neste estudo pretende-se monitorar a qualidade dos adoçantes dietéticos consumidos no estado de São Paulo quanto os elementos nutrientes, contaminantes e possivelmente tóxicos.

Deve-se então, compreender que papel alguns elementos químicos desempenham no metabolismo humano, como estes se fazem necessários a nossa nutrição, como agem no metabolismo de enzimas, no balanço de íons, na pressão osmótica e que funções reguladoras possuem e como alguns deles em determinadas concentrações são tóxicos.

Faz-se necessária à escolha de uma técnica analítica adequada, assim alguns fatores devem ser considerados, tais como o número de elementos a ser analisado e o número de elementos abrangidos pela técnica, os limites de detecção e de quantificação, a suscetibilidade a efeitos de matriz e a converiência da técrica para a matriz de interesse. A utilidade de uma técrica deve ser avaliada de maneira ampla, considerando uma determinação multielementar simultânea, a sensibilidade e os limites de detecção que não são os mesmos para todos os elementos. Assim a determinação requer um compromisso na condição experimental, que afeta a exatidão e a precisão de pelo 
menos alguns elementos, e que, dependem da concentração do elemento de interesse e dos concomitantes da matriz.

A ICP OES é uma poderosa técnica de análise multicomponente ${ }^{3}$. O plasma é fonte de alta temperatura que minimiza efeitos de matriz e produz sensibilidade adequada à maioria dos metais e alguns não-metais, em diversas ordens de grandeza de concentração (de $\%$ a $\mathrm{mg} \mathrm{L}^{-1}$ ). Também proporciona linhas muito intensas para quase todos os elementos presentes na amostra. Muitos sistemas de detecção não são otimizados para a exploração completa da enorme quantidade de informação produzida por uma fonte de plasma. Um detector ideal em EEA deve combinar a conveniência de uma eletrônica adequada e a capacidade de detecção multicanal das antigas placas fotográficas, como é o caso dos charge coupled device (CCD) ${ }^{4}$. Este trabalho propõe uma metodologia de dissolução simplificada para a determinação multielementar que atenda à legislação vigente, visando o controle de alimentos para fins especiais como adoçantes dietéticos líquidos e em pó, comercializados no estado de São Paulo. 


\section{Capítulo 2}

\section{ADOÇANTES DIETÉTICOS E EDULCORANTES:}

De acordo com a legislação brasileira em vigor, Portaria da Secretaria de Vigilância Sanitária (SVS) n³8 de 13/01/98, Adoçantes de Mesa são os produtos especificamente formulados para conferir o sabor doce aos alimentos e bebidas. Este regulamento tem como objetivo fixar a identidade e as características mínimas de qualidade, que devem obedecer os adoçantes de mesa e aplica-se a produtos que venham a substituir os açúcares quanto a propriedades de conferir o sabor doce aos alimentos e bebidas formulados para dietas com restrição de sacarose, frutose e glicose, para atender pessoas sujeitas a restrições de ingestão destes açúcares, os quais também devem atender aos dispositivos do Regulamento Técnico para Alimentos para Fins Especiais ${ }^{5}$.

O CODEX ALIMENTARIUS classificou os substitutos da sacarose em dois grupos $^{6}$ :

Edulcorantes Intensos ou (Não-Nutritivos): fornecem somente doçura acentuada, não desempenham nenhuma outra função tecnológica no produto final. São pouco calóricos e são utilizados em quantidades muito pequenas.

Agentes de Corpo: fornecem energia e textura aos adoçantes, geralmente contêm o mesmo valor calórico da sacarose e são utilizados em quantidades que facilitem medição e o consumo do adoçante dietético.

Os adoçantes podem conter e ser formulados à base de edulcorantes naturais e ou artificiais e seus respectivos veículos permitidos na legislação, tais como: água, álcool etilico, amidos, amido modificado, dextrinas, dextrose, frutooligossacarideos, frutose, glicerina ou glicerol, isomalte, lactose, maltitol e seu 
xarope, maltodextrina, manitol, polidextrose, polietileno glicol, propileno glicol, sacarose, sorbitol pó ou em solução.

Os edulcorantes são substâncias artificiais ou naturais geralmente centenas de vezes mais doces que o açúcar de cana, responsáveis pelo sabor doce no adoçante, e não são calóricos. Exceção feita ao Aspartame, embora seu poder de adoçamento deixe suas calorias despreziveis. Os edulcorantes aprovados no Brasil para uso em adoçantes dietéticos são: sacarina, ciclamato, aspartame, esteviosídeo, acessulfame-K e sucralose.

\subsection{Edulcorantes}

\subsubsection{SACARINA}

A sacarina $\left(\mathbf{C}_{7} \mathrm{H}_{4} \mathrm{OSO}_{2} \mathbf{N H}\right)$ foi descoberta em 1878 por IRA REMESEN e C. FAHIBERG quando estudavam as oxidações das sulfamidas, na Universidade Jonh Hopkins - NY. Foi aprovada no Brasil como edulcorante em $1965^{7}$. As figuras 1 e 2 mostram a fórmula estrutural da sacarina.<smiles>O=C1NS(=O)(=O)c2ccccc21</smiles>

\section{1,1-dióxido-3-oxo-2,3 dihidro-1,2 benzoisotiazol}

Figura 1 : Fórmula estrutural da Sacarina na forma ácida.<smiles>O=C1[N-]S(=O)(=O)c2ccccc21</smiles><smiles>O=C1[N-]c2ccccc2S1(=O)=O</smiles>

Figura 2: Fórmula estrutural da Sacarina na forma de seus sais de sódio e de cálcio. 
A sacarina é uma substância não-calórica, cerca de 300 a 700 vezes mais doce que a sacarose. Apresenta sabor residual amargo em altas concentrações. É o único edulcorante estável sob aquecimento e em meio ácido. A Ingestão Diária Recomendada (IDR) para a sacarina é de $2,5 \mathrm{mg} / \mathrm{Kg}$ de massa corpórea. Em humanos a sacarina é rapidamente absorvida e excretada na urina, a segurança de seu uso é investigada há 50 anos e seu uso é permitido em 90 países ${ }^{8}$.

A sacarina ocupa atualmente a primeira posição no "ranking" dos edulcorantes intensos. Apesar de sua descoberta ter ocorrido nos EUA, esta substância foi produzida inicialmente na Alemanha. Sua produção nos EUA começou em 1901, sendo o primeiro produto fabricado pela empresa Monsanto. Durante os anos 70 , a sua inocuidade foi questionada por suspeitas de causar câncer. Depois de diversas verificações a sacarina foi ratificada pelo FDA (Food and Drug Administration) dos EUA e continua sendo consumida mundialmente, sendo a China seu maior consumidor.

Atualmente são utilizados dois processos industriais para a produção da sacarina. O método mais comum é descontínuo e utiliza como matéria-prima o tolueno e o ácido clorossulfônico e na etapa final utiliza-se como agente oxidante uma mistura sulfocrômica a quente ${ }^{9}$.

\subsubsection{Ciclamato}

O ciclamato $\left(\mathrm{C}_{6} \mathrm{H}_{13} \mathrm{NO}_{3} \mathrm{~S}\right)$ foi descoberto em 1937, por Michael Sveda, sua patente tornou-se propriedade dos laboratórios Abbot, que o introduziram no mercado americano depois de aprovado como edulcorante pelo FDA, em 1949 e no Brasil em $1965^{7}$. As Figuras 3 e 4 mostram a fórmula estrutural da ciclamato. 
O processo de fabricação de ciclamatos parte da ciclohexamina e do ácido sulfâmico em duas etapas. Na primeira etapa é feita a sulfonação da ciclohexamina utilizando acido sulfâmico, sal de ácido sulfâmico ou trióxido de enxofre e o excesso de amina é eliminado por evaporação a pressão reduzida. Então, é feita a adição de hidróxido de sódio ou de cálcio para a síntese do respectivo sal ${ }^{9}$.

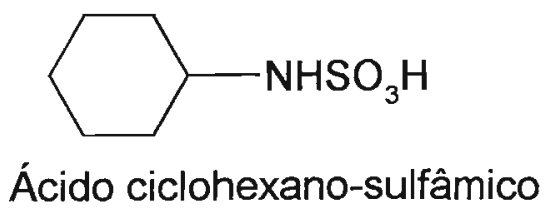

Figura 3: Fórmula estrutural do ciclamato na forma ácida.

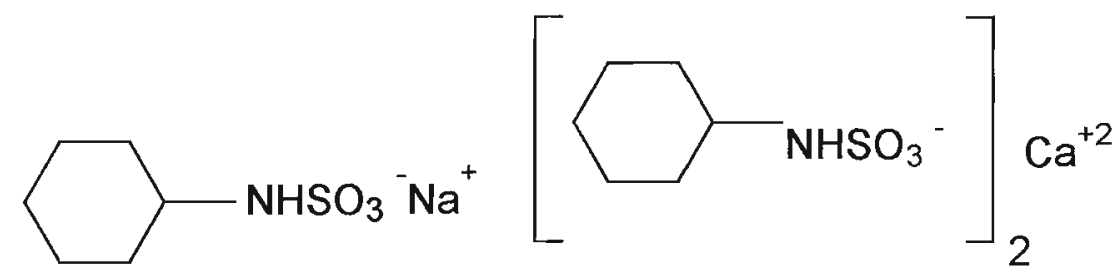

Figura 4: Fórmula estrutural do ciclamato na forma de seus sais de sódio e de cálcio.

O ciclamato é uma substância não-calórica, cerca de 30 vezes mais doce que a sacarose. É estável durante prolongados períodos de aquecimento. A IDR para o ciclamato é de 0,1 a $11 \mathrm{mg} / \mathrm{Kg}$ de massa corpórea ${ }^{8}$.

O ciclamato dominou o mercado norte-americano de edulcorantes durante os anos 60. Contudo em 1970 a sua comercialização foi proibida nos EUA por uma suspeita que a ciclohexamina, produto de sua hidrólise, seria um potencial agente causador do câncer; após vários estudos verificou-se que nem o ciclamato nem a ciclohexamina são cancerígenos ou genotóxico. O FDA reaprovou seu uso nos EUA.

Atualmente os ciclamatos são permitidos para o uso em alimentos de baixa caloria em mais de 40 países. 


\subsubsection{ASPARTAME}

$\mathrm{O}$ aspartame $\left(\mathbf{C}_{\mathbf{1 4}} \mathbf{H}_{\mathbf{1 8}} \mathbf{N}_{\mathbf{2}} \mathbf{O}_{\mathbf{5}}\right)$ foi descoberto acidentalmente em 1965 por Jim Schalatter nos laboratórios da SEARLE. Na época de sua aprovação pesavam sobre a sacarina as suspeitas sobre possíveis efeitos cancerígenos e o ciclamato estava proibido nos EUA. O aspartame foi liberado no Brasil em $1981^{7}$. A figura 5 mostra a fórmula estrutural do aspartame.

O aspartame é um dipeptídeo formado pelo ácido L-aspártico e pela Lfenilalanina metil éster 200 vezes mais doce que a sacarose.<smiles>COC(=O)C(Cc1ccccc1)NC(=O)C(N)CC(=O)O</smiles>

éster metílico do $\alpha$ - $\beta$-aspartil-L-fenilalanina

Figura 5: Fórmula estrutural do Aspartame.

A estabilidade do aspartame em produtos secos é boa, sendo comparada à do produto puro, mas em solução a estabilidade diminui com o tempo, com a temperatura, com o $\mathrm{pH}$ e com a umidade ${ }^{8}$.

Muitas sínteses químicas são relatadas, mas as vias industriais mais significativas envolvem a desidratação do ácido aspártico para formar o anidrido do ácido, seguido da sua reação com a fenilalanina ou com o éster metílico para obter o aspartame ${ }^{9}$. 
A decomposição do aspartame produz seu dipeptídeo aspartilfenilalanina e/ou a dicetopiperazina e a cinética é normalmente de primeira ordem. A $25^{\circ} \mathrm{C}$ a estabilidade máxima observada é em pH 4,3.

Quando metabolizado o aspartame produz aspartato, metanol e fenilalanina, que podem ser metabolizados ou excretados. A IDR para o aspartame é de 40 $\mathrm{mg} / \mathrm{Kg}$ de massa corpórea.

\subsubsection{ESTEVIOSÍDEO}

O esteviosídeo é quimicamente classificado como um glicosídeo, que em função de sua estrutura tridimensional, apresenta glicóforos capazes de sensibilizar as papilas gustativas da língua produzindo sabor doce. É extraído das folhas da Stevia rebaudiana Bertoni. Já era utilizada pelos índios guaranis. Em 1900, Ovídio Rebaudi, um químico paraguaio, estudou suas características, isolando um princípio amargo (com características de digestivo) e um princípio extremamente doce. Na década de 70 a estévia foi levada para o Japão, onde foi estudada sob aspectos químicos, toxicológicos e de desenvolvimento de processos de extração ${ }^{10}$. A figuras 6 mostra a fórmula estrutural do esteviosídeo.

O perfil de sabor é semelhante ao da sacarose, porém mais persistente e residual de mentol. Adoça de 110 a 300 vezes mais que a sacarose. Apresenta sinergia com aspartame, acessulfame-K e ciclamato, mas não com sacarina. É não cariogênico e indicado para diabéticos. É resistente a algumas temperaturas associadas às faixas de $\mathrm{pH}$. A maioria dos estudos toxicológicos do esteviosídeo e dos extratos de estévia foram realizados no Japão e a conclusão é que, os glicosídeos não são tóxicos ao homem e outras espécies animais. No Brasil, a Universidade Estadual de Maringá os estudou sob o aspecto de produção, sendo que em 1987 a Divisão Nacional de Alimentos - DINAL licenciou o uso de esteviosídeo em alimentos. A IDR é de $5,5 \mathrm{mg} / \mathrm{kg}$ peso/dia ${ }^{11}$. 


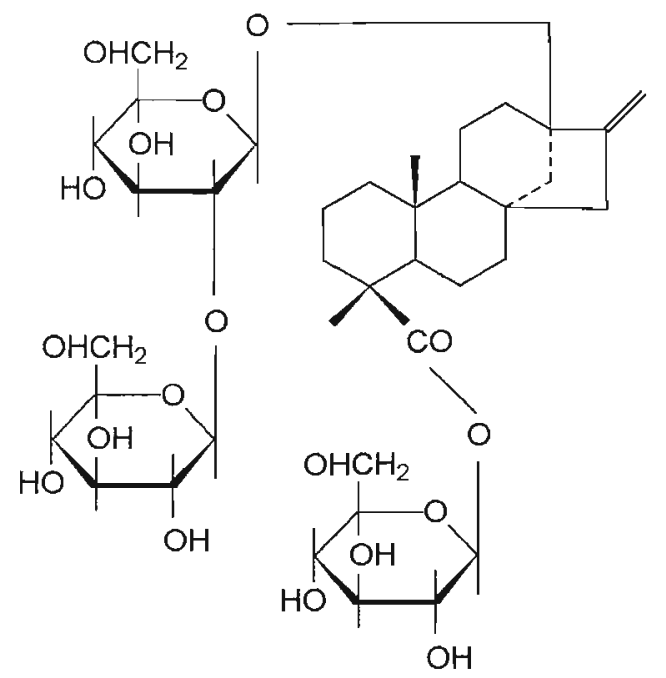

Figura 6: Fórmula estrutural do Esteviosídeo.

\subsubsection{Acessulfame-K}

Foi descoberto por KARL CLAUSS e HENRY JENSEN, em 1967 na Alemanha, acidentalmente quando trabalhavam no desenvolvimento de novos produtos, e encontraram um composto de sabor doce ${ }^{12}$. Apresenta estrutura semelhante à sacarina, sendo um sal de potássio da sulfonamida cíclica, obtido de derivados de ácido acetoacético. Apresenta estabilidade em várias condições de temperatura e $\mathrm{pH}^{13}$. Sua doçura é rapidamente perceptível, com decréscimo lento, não persistente. É cerca de 180 a 200 vezes mais doce que a sacarose. É não calórico, não cariogênico e indicado para diabéticos, possui sinergismo com aspartame, frutose e sorbitol, sua IDR é de $15 \mathrm{mg} / \mathrm{kg}$ peso/dia. A figuras 7 mostra a fórmula estrutural do acessulfame-K.

Não é metabolizado pelo homem, sendo que $99 \%$ da dose é eliminada de forma inalterada. Foi estudado por 15 anos e mais de 90 estudos comprovaram não apresentar efeitos tóxicos, carcinogênicos, mutagênicos ou teratogênicos ${ }^{14,15}$. 


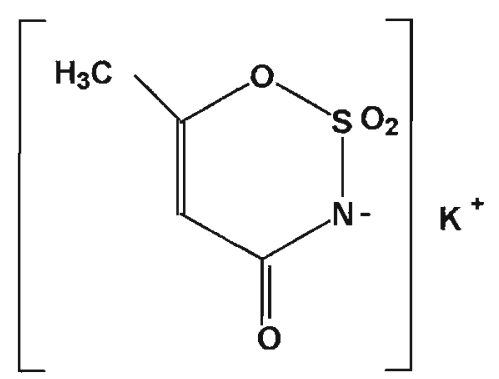

Figura 7: Fórmula Estrutural do Acessulfame-K.

\subsubsection{SUCRALOSE}

Descoberta em 1976 por pesquisadores da TATE \& LYLE Specialty Sweeteners, na Inglaterra ${ }^{16}$. É o composto 4,1',4"-triclorogalactosacarose, obtido por cloração seletiva dos grupos hidroxílicos das posições 4 e 6 da sacarose. É 400 a 800 vezes mais doce que a sacarose, seu dulçor é dependente de pH e temperatura, apresentando boa estabilidade ${ }^{17}$. A figuras 8 mostra a fórmula estrutural da sucralose. Perfil de sabor de percepção rápida e com persistência maior que a sacarose. É não calórica, não cariogênica e é indicada para diabéticos. A IDR é de $15 \mathrm{mg} / \mathrm{kg}$ peso/dia ${ }^{18}$. Suas ligações carbono-cloro são estáveis e não hidrolisadas durante a digestão, sendo rapidamente excretada nas fezes. Estudada por 15 anos, foram realizados por volta de 140 estudos em animais e humanos, concluindo que não apresenta efeitos teratogênicos, toxicidade ou carcinogenicidade ${ }^{18}$.

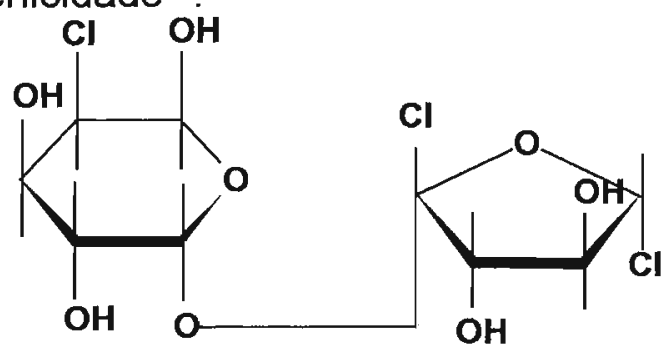

Figura 8:Fórmula Estrutural da Sucralose.

A tabela 1 apresenta os principais edulcorantes permitidos no Brasil. A tabela 2 mostra alguns dos produtos comercializados, os fabricantes, os edulcorantes, a quantidade de calorias por dose e a Dose Máxima Diária Recomendada (DMDR). 


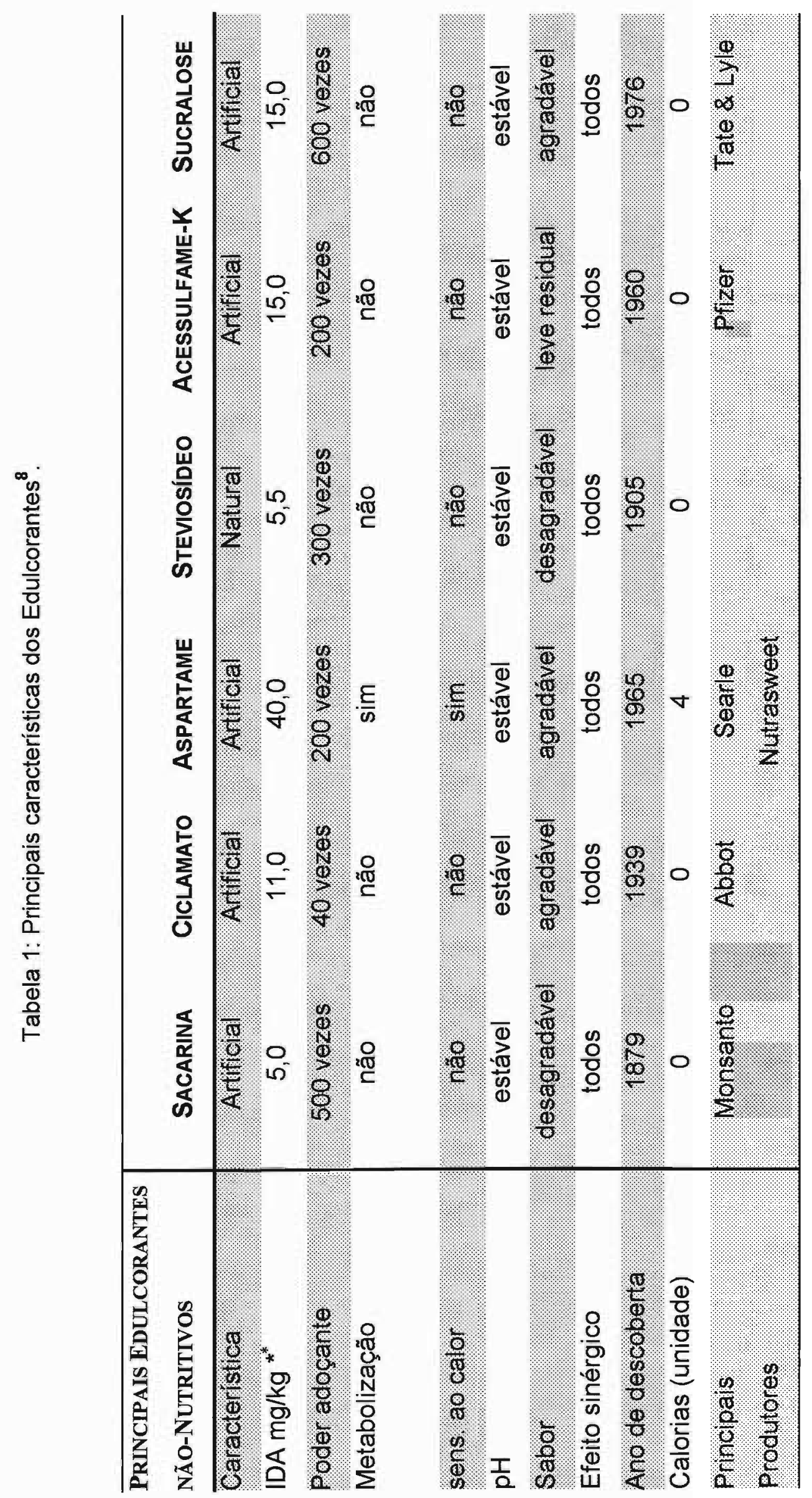

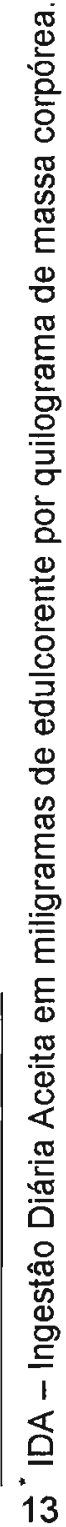




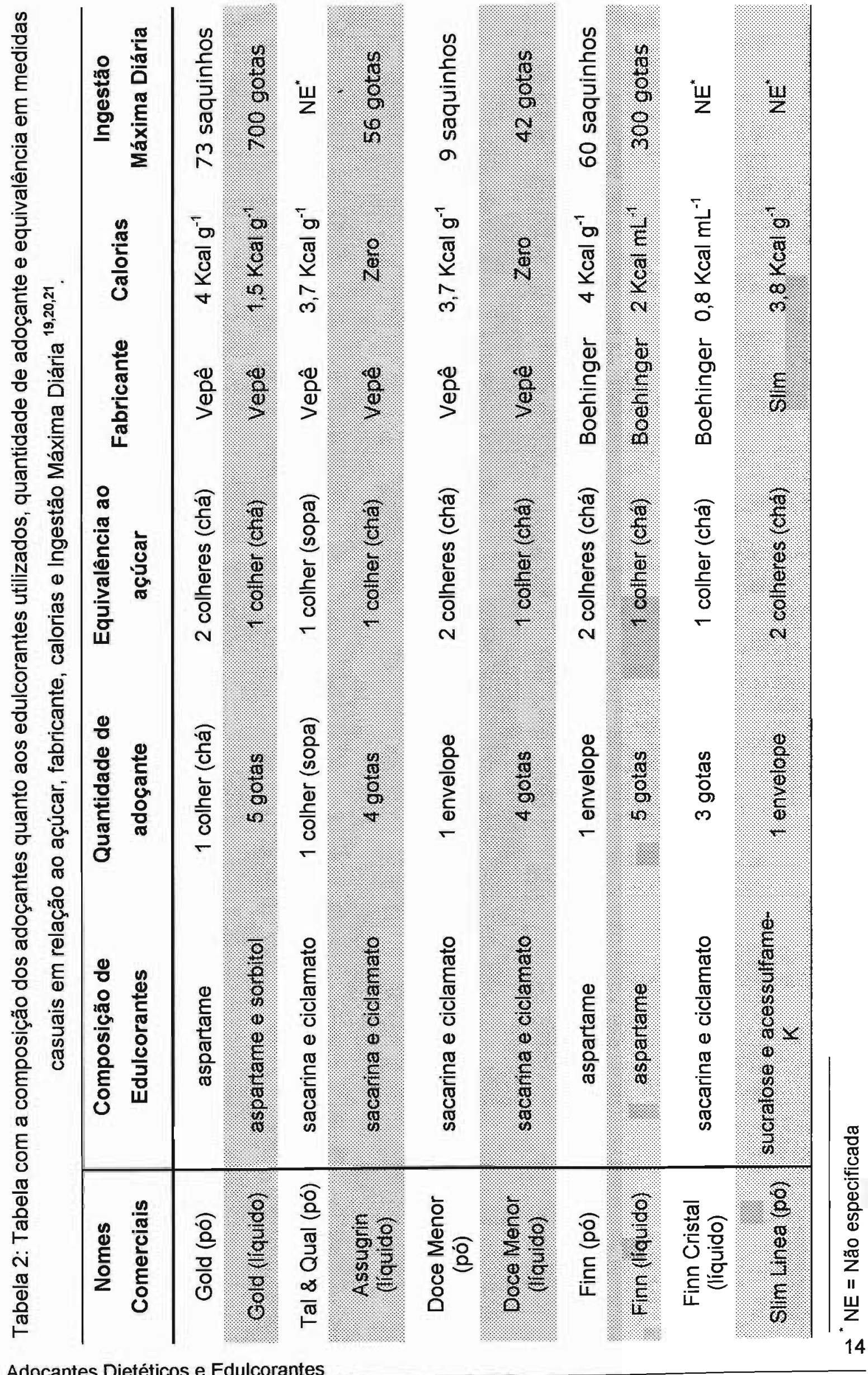




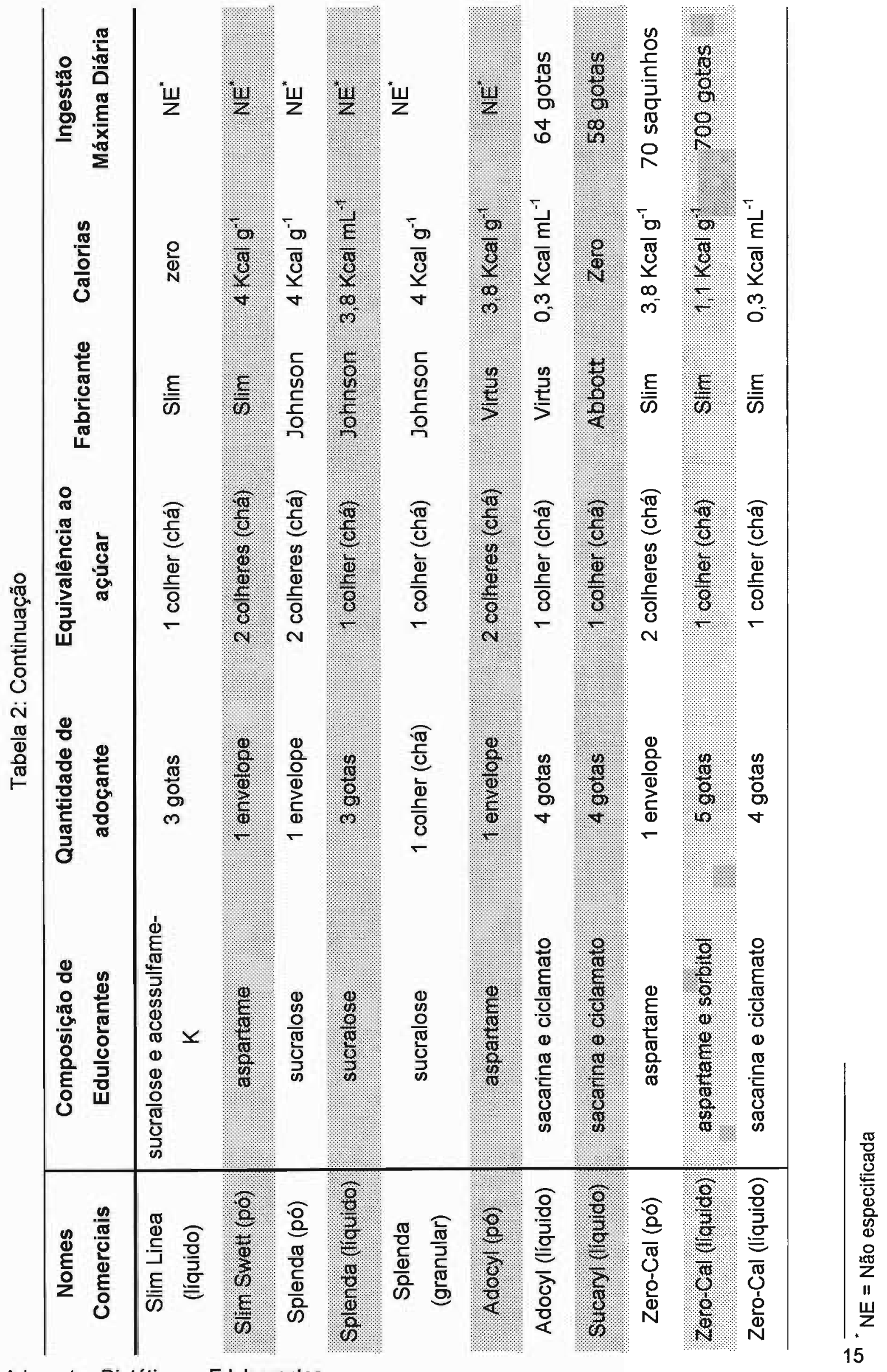




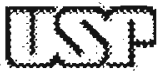

\section{Capítulo 3}

\section{LEGISLAÇÃO BRASILEIRA SOBRE ADOÇANTES DIETÉTICOS}

A legislação brasileira que definiu Edulcorante remonta a 1965, com o decreto $n^{0} 55.871$ de 26/03/1965 (D.O.U.-29/05/1965) (2) $^{22}$ que em seu artigo $4^{0}$, Alínea VIII: estabelece "Edulcorante: a substância orgânica artificial, não glicídica, capaz de conferir sabor doce aos alimentos". Pode ser empregado na formulação de produtos dietéticos a Sacarina sódica e o Ciclamato de sódio e cálcio.

Em 1969 definiu-se "Alimento Dietético: todo alimento elaborado para regimes alimentares especiais destinados a ser ingerido por pessoas sãs". Decreto-Lei $n^{\circ} .986$ de 21/10/1969 Art. $2^{\circ}$, Alínea V (D.O.U. -21/10/1969) ${ }^{23}$.

A partir de 1977 foi definido o "Produto dietético: produto tecnicamente elaborado para atender as necessidades dietéticas de pessoas em condições fisiologicamente especiais", pela Alínea XVII do art. $2^{\circ}$. Decreto no. 74.170 de 10/06/74 (D.O.U. $-11 / 06 / 1974)^{24}$, a qual dispõe sobre o controle sanitário do comércio de drogas, medicamentos, insumos farmacêuticos e correlatos pela Lei $n^{\circ}$. 6.360 de 23/09/76 Art. $3^{\circ}$. Item I (D.O.U. $\left.-24 / 09 / 1976\right)^{25}$.

O Comunicado no. 08/81 da Divisão Nacional de Alimentos (DINAL) de $13 / 10 / 1981^{26}$ e o Processo $n^{\circ}$. 11.782/1980 da Secretaria Nacional de Vigilância Sanitária (SNVS) permitiu o uso do Aspartame como aditivo edulcorante de emprego restrito em alimentos dietéticos ${ }^{27}$.

A Portaria no. 14 da DINAL, de 10/09/1986 (D. O.U. -12/09/1986) autorizou o emprego do esteviosídeo como edulcorante natural em alimentos e bebidas dietéticas $^{28}$. A Portaria $n^{0}$. 1 da SNVS de 07/01/1988 (D.O.U. - 10/01/1988) determinou que os edulcorantes até então registrados na Divisão de 
Medicamentos, passariam a ser registrados na DINAL ${ }^{29}$. Este fato permitiu uma enorme expansão deste mercado, pois agora havia uma maior liberdade na formulação e na utilização de ingredientes, o que permitiu uma maior variedade e outras opções de produtos dietéticos. A Tabela 3 mostra os limites máximos de edulcorantes em alimentos e bebidas dietéticas

A Portaria $n^{\circ} .23$ da SNVS de 04/04/1988 (D.O.U. - 07/04/1988) aprovou normas sobre alimentos dietéticos e considerou "alimentos dietéticos ou alimentos de regime ou alimento para usos dietéticos especiais ou alimentos para dietas especiais, os alimentos ou bebidas especialmente elaboradas e formuladas quer pela escolha adequada de seus ingredientes, quer pela substituição, adição ou supressão parcial ou total de um ou mais de seus componentes de forma que sua composição atenda a necessidades dietéticas específicas, de pessoas com exigências metabólicas, fisiológicas ou físicas particulares"30.

A portaria no. 25 da SNVS, de 04/04/1988 (D.O.U. - 07/04/1988) normatizou o uso dos "Adoçantes dietéticos", quanto à denominação e rotulagem ${ }^{31}$. Trata-se de produtos à base de edulcorantes, com ou sem a adição de açúcar, apresentando-se nas formas sólida e em solução.

A resolução no. 113 da SNAD de 07/11/1988 (D.O.U. $-21 / 11 / 1988)^{32}$ reviu a tabela I Anexa ao Decreto 55.871/65 que incluiu a Classe Edulcorantes e fixou os seguintes limites máximos. Em 1996 houve a introdução do conceito de "alimentos para fins especiais" englobando modificados dietéticos destinados a grupos populacionais específicos (Portaria SVS n. 234 de 21/05/1996) ${ }^{33}$. 
Tabela 3: Limites Máximos de Edulcorantes em Alimentos e Bebidas Dietéticas

\begin{tabular}{|c|c|c|}
\hline Edulcorantes Artificiais & Uso & Limites Máximos \\
\hline Aspartane & Alimentos Dietetices & $\begin{array}{l}75 \mathrm{mg} / \mathrm{loOg} \\
75 \mathrm{mg} / 100 \mathrm{ml}\end{array}$ \\
\hline Ciclamato & $\begin{array}{l}\text { Alimentos Dietéticos } \\
\text { Bebidas Dietéticas }\end{array}$ & $\begin{array}{l}130 \mathrm{mg} / 100 \mathrm{~g} \\
130 \mathrm{mg} / 100 \mathrm{~mL}\end{array}$ \\
\hline Sacarina & Alimentos Dietelicos & 30 mong/1001011. \\
\hline Edulcorantes Naturais & Uso & Limites Máximos \\
\hline Esteviosideo & Alimentos Dieteficos & $60 \mathrm{mg} / 100 \mathrm{ml}$. \\
\hline
\end{tabular}

Em 1997 houve a adequação jurídica dos "alimentos para fins especiais" incluindo os adoçantes e sendo definitivamente aprovado como alimento pela Portaria do Ministério da Saúde (MS) $1.549 / 97{ }^{34}$.Chegando à legislação atual com a Portaria 29 de 13/01/1998, onde foi aprovado o Regulamento Técnico referente a Alimentos para Fins Especiais foram fixadas a identidade e as características mínimas de qualidade que devem obedecer estes produtos ${ }^{16,35,36}$. 
Capítulo 4

\section{BIODISPONIBILIDADE E INTERAÇÕES DOS ELEMENTOS DE INTERESSE NA NUTRIÇÃO.}

A consideração de essencialidade de um elemento é estabelecida pela Organização Mundial de Saúde (OMS). Um elemento é considerado essencial para um organismo quando a redução de sua exposição a um nivel menor que um certo limite resulta consistentemente em uma redução em uma função fisiologicamente importante ${ }^{37,38}$.

\subsection{MACROELEMENTOS (Macrominerais)}

Macroelementos são definidos arbitrariamente como essenciais com níveis recomendados de 100 mg/dia ou mais; por sua abundância percentual no corpo humano $\mathrm{Ca}(1,5$ a $2,2 \%), \mathrm{P}(0,8-1,2 \%) \mathrm{K}(0,35 \%), \mathrm{S}(0,25 \%), \mathrm{Na}(0,15 \%) \mathrm{Cl}$ $(0,15 \%)$ e $M g(0,05 \%)$ (Anexol),

A) MACRONUTRIENTES (MACROELEMENTOS) ESSENCIAIS: $\mathrm{Ca}, \mathrm{P}, \mathrm{Na}, \mathrm{K}$, $\mathrm{Cl}, \mathrm{Mg}, \mathrm{S}$ (necessários em quantidade de $100 \mathrm{mg} / \mathrm{dia}$ ou mais). O sódio juntamente com $\mathrm{Ca}, \mathrm{Mg}$ e $\mathrm{K}$ são os elementos mais importantes dos fluídos intra e extra celulares, são importantes na movimentação de soluções entre os vários compartimentos corpóreos devido ao efeito osmótico, ajudam na manutenção do equilíbrio iônico e exercem funções como atividades enzimáticas ou como coenzimas. O sódio e o potássio são contra-íons e estimulam impulsos nervosos, enquanto que o cálcio e o hidrogênio possuem efeitos depressores sobre tecidos nervosos. 


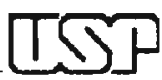

\subsubsection{CÁLCIO}

É um elemento essencial à vida humana - constitui ossos e dentes na sua maioria ( 1,5 a $2 \%$ massa corpórea) e em menor quantidade está presente no sangue, fluidos intra e extracelulares e tecidos moles. É imprescindível nos processos metabólicos, regula as contrações cardíacas, age como mensageiro em canais específicos iniciando atividades celulares, influencia a diferenciação e a divisão celular, ajuda a controlar os mecanismos de coagulação sanguínea regulando o fibrogênio e a fibrina, o equilibrio iônico, a condução nervosa e as junções sinápticas ${ }^{38}$.

O cálcio é absorvido somente se estiver na forma solúvel e não deve ser precipitado por outros constituintes da dieta. Maiores níveis de cálcio são recomendados na adolescência, gestação e lactação (ver tabelas 4, 5 e 6) (4) $^{\mathbf{4}} \mathrm{A}$ deficiência de cálcio pode causar deformidades ósseas, hipertensão, tetânia e a toxicidade é conhecida em crianças que recebem suplementação mineral podendo ocasionar hipercalcemia, causando excesso de calcificação nos ossos e tecidos moles; pode causar também excessiva excreção urinária, gerando cálculos renais ${ }^{45}$.

\subsubsection{MAgnésio}

O magnésio é antagonista do cálcio e essencial a todo processo bioquímico no corpo, incluindo o metabolismo do DNA e RNA. É predominantemente intracelular e sua concentração plasmática é 7 vezes menor que a concentração intra celular ${ }^{38}$. 


\subsubsection{POTÁSSIO}

É um dos minerais mais importantes de nosso corpo e é indispensável à dieta, constitui $5 \%$ do conteúdo mineral do corpo humano. Está distribuído em todos os fluidos e tecidos corpóreos e é um elemento essencialmente intracelular. Juntamente com o sódio e o cloreto é responsável por funções fisiológicas importante como: a manutenção do balanço hídrico, equilíbrio ácido-base e osmótico, na transmissão nervosa, nos batimentos cardíacos, na síntese do DNA, RNA e proteínas e na contração muscular.

A "bomba" $\mathrm{Na} / \mathrm{K} / \mathrm{Ca}$ / ATPase é um sistema regulador do volume sanguíneo de potencial de membrana, no transporte de glicose e de alguns aminoácidos (alanina, prolina, tirosina e triptofano). O potássio é facimente absorvido pelo TGI e excretado pela urina, fezes e suor ${ }^{38,44}$.

\subsubsection{Sódıo}

O sódio é o principal eletrólito do líquido extra celular, totalmente absorvido pela dieta, absorvido pelo TGI e é responsável pela manutenção do volume extra celular circulante e da circulação. O organismo regula e pode conservar o sódio diminuindo o débito urinário, caso a dieta seja livre do mesmo.

A alimentação usual do brasileiro contém 2800 a 5000 mg de sódio; este é utilizado não apenas para conferir sabor, mas como conservante pela indústria alimentícia, a qual demonstra uma tendência a aumentar a quantidade de sal em alimentos processados, tendência esta que se contrapõe ao consumo doméstico, que vem sendo gradativamente diminuído. Assim, há uma grande preocupação com o aumento exagerado da ingestão de sódio ${ }^{38,44}$, 
Tabela 4: Ingestão Diária Recomendada (IDR) para Adultos

\begin{tabular}{l|l|l}
\hline NUTRIENTE & UNIDADE & IDR \\
\hline Cálcio & $\mathrm{mg}$ & 800 \\
Fósforo & $\mathrm{mg}$ & 800 \\
Magnésio & $\mathrm{mg}$ & 300 \\
Ferro & $\mathrm{mg}$ & 14 \\
Zinco & $\mathrm{mg}$ & 15 \\
Cobre & $\mathrm{mg}$ & 3 \\
lodo & $\mu \mathrm{g}$ & 150 \\
Selênio & $\mu \mathrm{g}$ & 70 \\
Molibdênio & $\mu \mathrm{g}$ & 250 \\
Cromo & $\mu \mathrm{g}$ & 200 \\
Manganês & $\mathrm{mg}$ & 5 \\
\hline
\end{tabular}

Tabela 5: Ingestão Diária Recomendada (IDR) para Lactentes e Crianças

\begin{tabular}{|c|c|c|c|c|c|c|}
\hline \multirow[t]{2}{*}{ NUTRIENTE } & \multirow[t]{2}{*}{ UNIDADE } & \multirow{2}{*}{$\frac{\text { LACTENTE - Idade(anos) }}{0-0,5}$} & \multicolumn{4}{|c|}{ CRIANÇAS - Idade (anos) } \\
\hline & & & $0,5-1,0$ & $1-3$ & $4-6$ & $7-10$ \\
\hline Cálcio & $\mathrm{mg}$ & 400 & 600 & 800 & 800 & 800 \\
\hline Fósforo & $\mathrm{mg}$ & 300 & 500 & 800 & 800 & 800 \\
\hline Magnésio & $\mathrm{mg}$ & 40 & 60 & 80 & 120 & 170 \\
\hline Ferro & $\mathrm{mg}$ & 6 & 10 & 10 & 10 & 10 \\
\hline Zinco & $\mathrm{mg}$ & 5 & 5 & 10 & 10 & 10 \\
\hline Cobre & $\mathrm{mg}$ & $0,4-0,6$ & $0,6-0,7$ & $0,7-1,0$ & $1,0-1,5$ & $1-2$ \\
\hline lodo & $\mu g$ & 40 & 50 & 70 & 90 & 120 \\
\hline Selênio & $\mu g$ & 10 & 15 & 20 & 20 & 30 \\
\hline Molibdênio & $\mu g$ & $15-30$ & $20-40$ & $25-50$ & $30-75$ & $50-150$ \\
\hline Cromo & $\mu \mathrm{g}$ & $10-40$ & $20-60$ & $20-80$ & $30-120$ & $50-200$ \\
\hline Manganês & $\mathrm{mg}$ & $0,3-0,6$ & $0,6-1,0$ & $1,0-1,5$ & $1,5-2,0$ & 2 \\
\hline
\end{tabular}


Tabela 6: Ingestão Diária Recomendada (IDR) para Gestantes e Lactantes

\begin{tabular}{|c|c|c|c|c|}
\hline \multirow[t]{2}{*}{ NUTRIENTE } & \multirow[t]{2}{*}{ UNIDADE } & IDR & \multicolumn{2}{|c|}{ IDR para Lactantes } \\
\hline & & $\begin{array}{l}\text { Para } \\
\text { Gestantes }\end{array}$ & $\begin{array}{l}\text { Primeiros } 6 \\
\text { meses }\end{array}$ & $\begin{array}{l}\text { Segundos } 6 \\
\text { meses }\end{array}$ \\
\hline Cálcio & $\mathrm{mg}$ & 1.200 & 1.200 & 1.200 \\
\hline Fósforo & $\mathrm{mg}$ & 1.200 & 1.200 & 1.200 \\
\hline Magnésio & mg & 300 & 355 & 340 \\
\hline Ferro & mg & 30 & 15 & 15 \\
\hline Zinco & $\mathrm{mg}$ & 15 & 19 & 16 \\
\hline Cobre & $\mathrm{mg}$ & $1,5-3,0$ & $1,5-3,0$ & $1,5-3,0$ \\
\hline lodo & $\mu g$ & 175 & 200 & 200 \\
\hline Selênio & $\mu g$ & 65 & 75 & 75 \\
\hline Molibdênio & $\mu \mathrm{g}$ & $75-250$ & $75-250$ & $75-250$ \\
\hline Cromo & $\mu \mathrm{g}$ & $50-200$ & $50-200$ & $50-200$ \\
\hline Manganês & $\mathrm{mg}$ & $2-5$ & $2-5$ & $2-5$ \\
\hline
\end{tabular}

\subsection{MICROELEMENTOS (Microminerais ou traço)}

Microelementos são elementos arbitrariamente definidos por suas concentrações que não excedem $250 \mu \mathrm{g} \mathrm{g}^{-1}$ de matriz (tecidos, alimentos ou água potável): $\mathrm{Fe}, \mathrm{Zn}, \mathrm{Cu}, \mathrm{Co}, \mathrm{F}, \mathrm{Cr}, \mathrm{Mn}, \mathrm{Mo}, \mathrm{Se}, \mathrm{V}$.

Segundo sua importância biológica os microelementos podem ser divididos em:

A)- ESSENCIAIS: apresentam função biológica conhecida

Seguindo a definição da OMS, para considerar que um elemento é essencial para um organismo, este deve estar presente em uma concentração razoavelmente constante nos tecidos saudáveis do organismo; sua deficiência na dieta deve conduzir ao desenvolvimento de anormalidades estruturais ou 
fisiológicas; a adição do elemento nas dietas deficientes deve evitar o desenvolvimento das anormalidades ou fazê-las desaparecer; as anormalidades produzidas pela deficiência devem ser acomparıhadas de mudanças bioquínicas especificas que cessam ao desaparecer a deficiência ${ }^{37}$.

B) - POSSIVELMENTE ESSENCIAIS: os dados de que se dispõe não são suficientes para demonstrar que cumprem as condições de essencialidade.

C) - CONTAMINANTES OU NÃO-ESSENCIAIS: são aqueles que são detectados em alguma quantidade no organismo, sem nenhuma função metabólica.

D) - POTENCIALMENTE TÓXICOS: são os elementos que podem ser tóxicos se ingeridos em quantidades relativamente grandes ou por períodos de tempo prolongado, ou quando o organismo é exposto a ele. Os principais elementos potencialmente tóxicos são: Mercúrio, Chumbo, Arsênio, Cádmio, Níquel e Aluminio.

Pode-se apresentar também uma classificação nutricional dos elementos:

MICRONUTRIENTES ESSENCIAIS OU OLIGOELEMENTOS: $\mathrm{Fe}, \mathrm{Cu}, \mathrm{F}, \mathrm{Co}, \mathrm{Zn}$, Cr, Mn, I, Mo, Se (necessários em quantidades não superiores a 1 mg/dia).

MICRONUTRIENTES POSSIVELMENTE ESSENCIAIS: Si, V.

ELEMENTOS CONTAMINANTES: $\mathrm{Pb}, \mathrm{Cd}, \mathrm{Hg}, \mathrm{As}, \mathrm{Ba}, \mathrm{Sr}, \mathrm{B}, \mathrm{Al}, \mathrm{Li}, \mathrm{Be}, \mathrm{Rb}$ e $\mathrm{Sn}$.

A maioria dos elementos chega ao organismo através da alimentação e é de relevante importância compreender os fatores que governam as respostas, a deficiência ou o excesso de elementos na nutrição. Assim, a abordagem multidisciplinar para a avaliação do risco relacionado aos elementos, macro ou micro nutrientes, que irão influenciar a saúde, é necessária quando considerados aspectos fisiológicos, ambientais ou sociais que causam modificações nas dietas e conseqüentemente no sangue e nos tecidos humanos. 


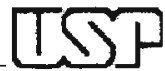

\subsubsection{Alumínio}

Não existe evidência confirmada que o alumínio possua alguma função essencial a animais e aos seres humanos. A consideração principal com respeito ao alumínio e à saúde é seu potencial de toxicidade se a exposição for excessiva $^{39,40}$. Os aspectos toxicológicos do alumínio consumido oralmente são pouco definidos, pois o elemento é pobremente absorvido pelo intestino; as quantidades baixas absorvidas das dietas normais são excretadas por rins saudáveis de modo que nenhum acúmulo ocorra. Ingestões médias com variação de 3 a 14 mg de alumínio/dia têm sido relatadas ${ }^{37}$.

\subsubsection{ARSẾNIO}

O arsênio encontra-se nas formas trivalente e pentavalente nos alimentos, água e, no meio ambiente. Está amplamente distribuído geologicamente e solos não expostos podem conter de 0,1 a $40 \mathrm{mg} \mathrm{Kg}^{-1}$ de arsênio ${ }^{37}$.

Os compostos de arsênio são mais conhecidos por sua ação tóxica, mas seus efeitos farmacológicos também são documentados. Menos descrita é a evidência de aumento na função essencial por baixas ingestões de arsênio na dieta de animais. Algumas alterações bioquímicas acompanhando os sinais de deficiência de arsênio têm sido descritas, tais como:velocidade de crescimento reduzida e prejuizo na capacidade reprodutiva de animais. Os efeitos biológicos do arsênio dependem da forma quimica na qual o elemento se apresenta. Assim, a maioria dos alimentos de origem terrestre contém menos de $1 \mu \mathrm{g} \mathrm{g}^{-1}$ de peso seco, enquanto nos alimentos de origem marinha encontram-se até $80 \mu \mathrm{g} \mathrm{g}^{-1}$. Baseado em estudos de dietas de diversos países, a ingestão diária de arsênio por adulto varia entre 200 e $100 \mu \mathrm{g} / \mathrm{dia}^{41}$. Como contaminantes em alimentos os 
arsenatos e os organoarseniacais pentavalentes são mais significativos que os arsenitos em concentração e em freqüência de ocorrência ${ }^{42}$.

Devido o arsênio inorgânico ser conhecido como cancerígeno existem recomendações para limitar a exposição humana ao elemento, assim há uma recomendação provisória para adultos de $15 \mu \mathrm{g} \mathrm{Kg}{ }^{-1}$ de massa corpórea por semana. Se uma necessidade humana para arsênio existir, um valor facilmente alcançável para a maioria das dietas é de $20 \mu \mathrm{g} / \mathrm{dia}^{37,42,43}$.

\subsubsection{CÁDMIO}

O cádmio não é encontrado na natureza no seu estado elementar, seu uso industrial extensivo tem causado uma contaminação generalizada do ambiente (solo, água e vegetação) e como conseqüência o suprimento alimentar humano.

BENNETT modelando as vias de exposição humana a metais pesados mostrou que $80 \%$ do cádmio absorvido é proveniente de alimentos e da água, mas esta é uma exposição menos aguda que refletem uma ação tóxica sobre os rins e sobre o esqueleto. Riscos maiores são provocados por inalação, que resulta em lesões pulmonares ${ }^{46}$,

A retenção de cádmio nos tecidos está relacionada à síntese de cádmiometalotioneína, um complexo de cádmio-proteína de baixa massa molecular. 0 cádmio se acumula em todos os órgãos, mas preferencialmente nos rins com a idade e com o aumento da carga de cádmio corpóreo. Indivíduos com nefropatias severas de cádmio podem apresentar cálculos renais e perdas excessivas de cálcio. Com a exposição crônica ao cádmio pode haver alterações no metabolismo de fósforo e de cálcio que podem causar osteoporose e osteomalacia $^{47}$. 
A FAO/OMS determinam que a ingestão máxima semanal tolerável de cádmio é de $7 \mu \mathrm{g} \mathrm{Kg}^{-1}$ de massa corpórea. As concentrações na maioria dos alimentos são menores que $0,15 \mathrm{mg} \mathrm{Kg}^{-1}$, exceção a mariscos e rins bovino (1-2 $\mathrm{mg} \mathrm{Kg}^{-1}$ e $0,5 \mathrm{mg} \mathrm{Kg}^{-1}$, respectivamente); em vegetais e cereais os teores de cádmio são influenciados pelo solo, pela geologia ou pela poluição industrial urbana ou industrial ${ }^{37,48}$.

\subsubsection{COBRe}

O cobre é um elemento essencial amplamente distribuído nos tecidos biológicos, encontrado na forma de metaloproteínas que funcionam como enzimas, que são responsáveis por uma variedade de reações metabólicas, como a respiração celular (citocromo oxidadase e superóxido dismutase) e a utilização de energia, na síntese de proteínas complexas de tecidos conjuntivos do esqueleto e dos vasos sanguíneos e em uma variedade de compostos neuroativos envolvidos na função do sistema nervoso (dopamina $\beta$ monoxigenase $)^{49}$.

A ingestão típica de cobre por adultos está na faixa de 1 a $1,5 \mathrm{mg} / \mathrm{dia}$. As formas solúveis de cobre são absorvidas pelo intestino com uma eficiência que varia normalmente de 40 a $60 \%$; esta eficiência pode reduzir se forem consideradas algumas substâncias que reduzem a biodisponibilidade do cobre*, tais como: ácido ascórbico, cálcio, fósforo, cádmio, penicilina, tiomolibdatos, fitato, lignina, ferro, chumbo, sacarose, frutose e zinco. O fator que aumenta a eficiência na absorção de cobre é a baixa oferta de cobre na dieta. Baseado no limite máximo de variação de segurança de ingestões médias da população foi

\footnotetext{
* evidéncia derivada de estudos em animais; a relevância em humanos ainda não foi esclarecida.
} 
estabelecido que para adultos, $12 \mathrm{mg} /$ dia para homens e $10 \mathrm{mg} / \mathrm{dia}$ para mulheres como a quantidade de cobre considerada tolerável, ou seja, não parece ter efeito prejudicial à saúde ${ }^{37}$.

\subsubsection{Chumво}

Os efeitos tóxicos do chumbo envolvem vários órgãos e são conseqüência de uma variedade de defeitos bioquímicos. O chumbo afeta o sistema nervoso, particularmente de crianças e bebês, mas os efeitos mais sensíveis na população adulta são a hipertensão e a anemia. A anemia do chumbo resulta em dois efeitos básicos: o ciclo de vida do eritrócito é diminuído e há prejuízo na síntese do heme $e^{37,38,44}$.

O chumbo é classificado como carcinogênico pela International Agency for Research on Cancer (IARC). A toxicidade severa do chumbo causa esterelidade, aborto, mortalidade e morbidade neonatal. Em adultos, a ingestão média de chumbo é de 20 a $514 \mu \mathrm{g}$ por dia e em crianças e bebês de 2 a $24 \mu \mathrm{g} \mathrm{Kg}^{-1}$ de massa corpórea por semana ${ }^{37}$.

\subsubsection{CROMO}

O cromo é um nutriente essencial que potencializa a ação da insulina e assim influencia o metabolismo de carboidratos, lipídeos e proteínas. Entretanto, a relação entre o cromo e a função da insulina ainda não foi elucidada. O cromo pode ter uma função bioquímica que afeta o receptor da insulina,

O cromo trivalente apresenta toxicidade baixa, enquanto que o cromo hexavalente em doses orais de $50 \mu \mathrm{g} \mathrm{g} \mathrm{g}^{-1}$ de dieta induz a depressão do crescimento, dano hepático e renal em animais experimentais ${ }^{50}$. 
A natureza não tóxica do cromo III em alimentos sugere que o limite tolerável desta espécie é relativamente alta, entre 125 e $200 \mu \mathrm{g} / \mathrm{dia}$, e que o limite máximo para suplementação não deva exceder $250 \mu \mathrm{g} / \mathrm{dia}^{37,51}$.

\subsubsection{ESTANHO}

O estanho não possui função bioquímica conhecida, pois estudos recentes foram invalidados e não estabeleceram conclusivamente a essencialidade do estanho. Sinais de exposições crônicas e ingestões excessivas de estanho incluem depressão de crescimento e anemia. O estanho também interfere na atividade de várias enzimas e no metabolismo do $\mathrm{Zn}, \mathrm{Cu}$ e $\mathrm{Ca}$ e altera as concentrações teciduais de vários outros elementos ${ }^{37,38,44}$.

\subsubsection{FERRO}

O ferro é um dos minerais mais estudados na nutrição humana; é muito bem conservado pelo organismo, cerca de $90 \%$ é recuperado e reutilizado exaustivamente. A maioria do ferro corporal é ligado à hemoglobina do sangue $\theta$ à mioglobina do músculo, outra parte é ligada a enzimas (citocromo, catalase, e metaloproteínas). O ferro não funcional está armazenado no fígado, no baço na medula óssea e na circulação sanguínea, na forma de proteínas (transferrina, ferritina, e hemossiderina) ${ }^{38,44}$,

O ferro exerce função estrutural no grupo heme da hemoglogina, responsável pelo transporte de oxigênio e gás carbônico no sangue. Além disso, funciona como cofator de diversas enzimas não heme, influencia processos metabólicos na síntese de purinas, carnitina, colágeno, neurotransmissores (serotonina, dopamina, norepinefrina) e na conversão de $\beta$-caroteno na forma ativa da vitamina A. A deficiência de ferro é a mais comum de todas as deficiências minerais nos humanos e os grupos mais atingidos são as crianças 
menores de 2 anos, meninas adolescentes, mulheres grávidas e idosos. 0 principal sintoma da deficiência de ferro é a anemia (microcítica e hipocrômica), que causa desde palidez, fraqueza e fadiga a taquicardia, falta de ar e sintomas de má oxigenação tecidual.

As necessidades diárias individuais variam de acordo coma estimativa de perdas de $10 \mathrm{mg} / \mathrm{dia}$ para homens adultos a $14 \mathrm{mg} / \mathrm{dia}$ para mulheres e de 6-10 mg/dia para crianças (ver tabelas 4,5 e 6$)^{45}$.

\subsubsection{MANGANÊS}

O manganês encontra-se entre os elementos traços essenciais, e age como ativador e como um constituinte de diversas enzimas (hidrolases, cinases, descarboxilases, glicosiltransferases, arginase, piruvatocarboxilase, glucamina sintetase, manganês superóxido dismutase e tranferases), mas a maioria das enzimas também podem ser ativada por outros metais, especialmente o magnésio. Os sinais de deficiência de manganês têm sido estudados, mas a essencialidade do manganês ainda foi recentemente estabelecida. A toxicidade oral do manganês em humanos é considerada mínima, a forma mais comum de toxicidade por manganês é resultado da inalação crônica ${ }^{52}$.

Os alimentos constituem a fonte primária de manganês para a população em geral, apesar de sua absorção ser relativamente baixa (3 a 5\%). Mesmo sendo considerado um elemento essencial, não há um valor de ingestão diária recomendada, mas o US National Research Council estabelece níveis para Ingestão Alimentar Estimada Adequada e Segura (ESADDI). A dose de referência de manganês em alimentos é de $0,14 \mathrm{mg} \mathrm{kg}^{-1} /$ dia (USEPA 2000). O Hazardous Substances Data Bank (HSDB, 2000) refere o valor de IDAI para manganês total de $2,5-5,0 \mathrm{mg} / \mathrm{dia}^{53}$. 


\subsubsection{MERCÚRIO}

O mercúrio pode ser encontrado na forma elementar $\left(\mathrm{Hg}^{\circ}\right)$ inorgânica ou nos estados de oxidação +1 e +2 em compostos inorgânicos e orgânicos. A absorção gastrointestinal é menor para compostos inorgânicos e maior para compostos orgânicos. Os rins retêm as maiores concentrações de mercúrio após a exposição aos seus compostos ou vapores, enquanto que o mercúrio orgânico tem maior afinidade pelo cérebro. Os maiores riscos à saúde humana surgem dos efeitos neurotóxicos.

A FAO/OMS recomenda que a ingestão de mercúrio total não deve exceder $5 \mu \mathrm{g} / \mathrm{semana}$ por quilograma de massa corpórea e não mais que 3,5 $\mu \mathrm{g} / \mathrm{semana/}$ $\mathrm{kg}$ de massa corpórea de metil mercúrio. Tipicamente $84 \%$ da ingestão total de mercúrio inorgânico é proveniente da dieta e de 20 a $85 \%$ do metil-mercúrio é proveniente de peixes e frutos do $\operatorname{mar}^{37}$.

\subsubsection{Níquel}

Há uma discussão epidemiológica da deficiência de níquel que aguarda esclarecimentos dos efeitos da deficiência e da exposição excessiva do níquel em humanos. Entretanto, alguns sinais são relacionados à deficiência do níquel como a diminuição do crescimento e da hematopoiese. A sensibilidade ao níquel pela população em geral não é conhecida, mas concentrações séricas acima de 1,0 $\mu \mathrm{g}$ $\mathrm{L}^{-1}$ de níquel indicam exposição excessiva e sabe-se que a absorção de níquel varia entre 8 a $50 \%$ do valor ingerido ${ }^{38,44}$. 


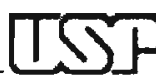

\subsubsection{SELÊNIO}

O selênio é um não-metal relativamente raro e sua essencialidade para humanos foi demonstrada, pois sua incorporação à enzima glutationa peroxidase (GPX) é vital na proteção de membranas celulares e sub-celulares contra agentes oxidantes solúveis ${ }^{37,38,44}$.

A toxicidade crônica de selênio em humanos é caracterizada pela perda de cabelo e pela mudança na morfologia das unhas. Os efeitos deletérios do selênio não foram claramente estabelecidos, mas supöe-se que ele aumente a suscetibilidade de certas proteinas à denaturação pelo calor ${ }^{37}$,

A recomendação da ingestão diária de selênio é apresentada na tabela 6.

\subsubsection{VANÁDIO}

Só recentemente foi considerado essencial à vida humana. Tem uma ação de simular a Insulina, favorecendo a entrada de glicose nas células musculares e pode ajudar o corpo a produzir os glóbulos vermelhos ${ }^{37}$.

\subsubsection{ZiNco}

Talvez seja o mais importante mineral de nossa alimentação, necessário para mais de 200 atividades enzimáticas no nosso organismo. É o principal protetor do sistema imunológico estimulando a produção dos leucócitos e sendo imprescindível na regulagem da informação genética. Também é essencial para a estrutura e funcionamento das membranas celulares, além de ser antioxidante. Tem sido usado no tratamento da artrite e pode ajudar a prevenir os efeitos degenerativos do envelhecimento ${ }^{38}$. 


\subsection{Legislação Brasileira sobre os elementos na Nutrição.}

A PORTARIA No 33, DE 13 DE JANEIRO DE 1998 da Secretária de Vigilância Sanitária, do Ministério da Saúde ${ }^{44}$, baseada na resolução Mercosul GMC N¹8/94, considera a necessidade de adotar a Ingestão Diária Recomendada (IDR) de vitaminas, minerais e proteínas a ser utilizada como parâmetro de ingestão desses nutrientes por indivíduos e diferentes grupos populacionais, visando o aperfeiçoamento das ações de controle sanitário na área de alimentos para a proteção da saúde da população em geral. É apresentado nas tabelas 4, 5 e 6 um resumo da IDR para os elementos relevantes ao trabalho.

\subsection{Legislação Brasileira de Contaminantes Inorgânicos em alimentos,}

O Decreto $n^{\circ} 50.040$, de 24 de janeiro de 1961 dispõe sobre as Normas Técnicas Especiais Reguladoras do emprego de aditivos químicos a alimentos. $\mathrm{O}$ artigo $3^{\circ}$ considerava "aditivos incidentais" as substâncias estranhas que podiam ser encontradas nos alimentos como decorrência das fases de elaboração, preparo, acondicionamento ou estocagem. E estabelecia limites máximos para estes aditivos incidentais ${ }^{\mathbf{5 4}}$.

O Decreto $n^{\circ} 55.871$, de 26 de março de 1965 modifica o Decreto $n^{\circ} 50.040$, referente a normas reguladoras do emprego de aditivos para alimentos. Pela primeira vez apresenta em seu anexo um limite de tolerância máximo para contaminantes inorgânicos, alguns dos quais ainda vigoram, pois não houve alteração na legislação atual ${ }^{55}$.

Como a legislação brasileira não prevê um limite de tolerância máximo de contaminantes inorgânicos serão apresentados limites referentes aos outros 
alimentos, ou seja aos alimentos não especificados e pertencentes à categoria " outros alimentos".

Na Portaria $n^{\circ} 685$, de 27 de agosto de 1998 a Vigilância Sanitária do Ministério da Saúde, considera a necessidade de constante aperfeiçoamento das ações de controle sanitário na área de alimentos visando a proteção à saúde da população e que é indispensável o estabelecimento de regulamentos técnicos sobre contaminantes em alimentos, com vistas a minimizar os riscos à saúde humana ${ }^{56}$.

No Art. $1^{\circ}$ aprova o Regulamento Técnico: "Princípios Gerais para o Estabelecimento de Níveis Máximos de Contaminantes Químicos em Alimentos" e seu Anexo: "Limites máximos de tolerância para contaminantes inorgânicos". Nos casos dos alimentos não contemplados no presente Regulamento, permanecem vigentes os limites máximos de tolerância para contaminantes inorgânicos já previstos na legislação nacional. Os níveis máximos de contaminantes em alimentos serão considerados na avaliação de impacto à saúde do consumidor. 
Tabela 7: Resumo do Limite Máximo de Tolerância para Contaminantes inorgânicos encontrados no Decreto $n^{\circ} 55.871$

\begin{tabular}{|c|c|c|}
\hline $\begin{array}{l}\text { Contaminante } \\
\text { Inorgânicos }\end{array}$ & $\begin{array}{l}\text { Alimentos em que podem ser } \\
\text { encontrados }\end{array}$ & $\begin{array}{c}\text { Limite Máximo de } \\
\text { Tolerância } \\
\text { LMT }\left(\mu g^{-1}\right) \\
\end{array}$ \\
\hline Antimônio & Outros alimentos & 2,00 \\
\hline Arsênio & Outros alimentos & 1,00 \\
\hline Cádmio & Outros alimentos & 1,00 \\
\hline Cobre & Outros alimentos & 30,00 \\
\hline Cromo & Qualquer alimento & 0,10 \\
\hline Estanho & Qualquer alimento & 250,00 \\
\hline Mercúrio & Outros alimentos & 0,01 \\
\hline Níquel & Outros alimentos & 5,00 \\
\hline \multirow[t]{2}{*}{ Selênio } & Alimentos sólidos & 0,30 \\
\hline & Alimentos líquidos & 0,05 \\
\hline Zinco & Outros alimentos & 50,00 \\
\hline Chumbo & Outros alimentos & 0,80 \\
\hline
\end{tabular}


Tabela 8: Resumo do Limite Máximo de Tolerância para Contaminantes inorgânicos encontrados na Portaria $n^{\circ} 685$.

\begin{tabular}{|c|c|c|}
\hline $\begin{array}{l}\text { Contaminante } \\
\text { Inorgânicos }\end{array}$ & $\begin{array}{l}\text { Alimentos em que podem } \\
\text { ser encontrados }\end{array}$ & $\begin{array}{c}\text { Limite Máximo de } \\
\text { Tolerância } \\
\left(\mathrm{mg} \mathrm{Kg}^{-1}\right)\end{array}$ \\
\hline \multirow[t]{2}{*}{ ARSÊNIO } & Açúcares & 1,0 \\
\hline & Mel & 1,0 \\
\hline \multirow[t]{2}{*}{ COBRE } & Lactose & 2,0 \\
\hline & Mel & 10 \\
\hline ESTANHO & $\begin{array}{c}\text { Sucos de frutas cítricas } \\
\text { (enlatados) }\end{array}$ & 150 \\
\hline \multirow[t]{3}{*}{ CHUMBO } & Dextrose (glucose) & 2,0 \\
\hline & $\begin{array}{l}\text { Alimentos para fins especiais, } \\
\text { para lactentes e crianças até } \\
\text { três anos. }\end{array}$ & 0,2 \\
\hline & $\begin{array}{c}\text { Partes comestíveis } \\
\text { cefalópodes }\end{array}$ & 2,0 \\
\hline CÁDMIO & Peixes e produtos da pesca & 1,0 \\
\hline \multirow[t]{2}{*}{ MERCÚRIO } & Peixes e produtos da pesca & 0,5 \\
\hline & Peixes predadores & 1,0 \\
\hline
\end{tabular}




\section{Capítulo 5}

\section{DADOS MERCADOLÓGICOS}

Para a Associação Brasileira das Indústrias de Alimentação - ABIA, após a estabilização econômica do País ocorreram mudanças estruturais, e a economia mecheu com os hábitos da população e com o consumo dos produtos "diet" $\Theta$ "light" principalmente a partir de 1995, apesar dessas categorias existirem desde $1990^{57}$

A ABIA informa que o mercado de produtos "diet/light" que movimenta anualmente US\$2,5 bilhões, cresceu mais de $870 \%$ nos últimos 10 anos e apresenta índices de crescimento da ordem de no mínimo $10 \%$ ao ano. Na figura 9, vê-se que os adoçantes de mesa são uma grande parcela deste mercado, compondo $21 \%$ das vendas de produtos dietéticos em geral, atrás apenas dos refrigerantes ${ }^{57}$.

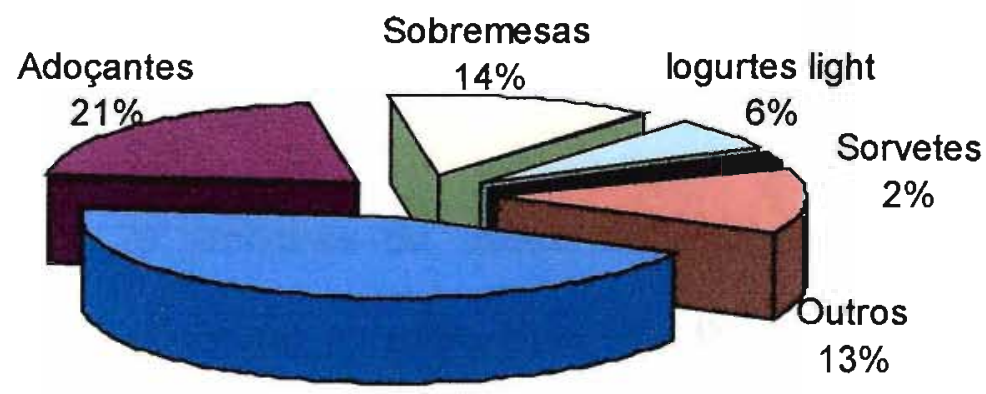

Refrigerantes

$44 \%$

Figura 9: Distribuição dos Produtos Light e Diet no Brasil no ano de 2002.

Para fazer um comparativo, em 1998, essa indústria movimentou US $\$ 1$ bilhão. Com base nesse histórico, a Associação Brasileira da Indústria de Alimentos Dietéticos ABIAD prevê para 2005 a cifra de US\$ 7 bilhões. 
Dentre os adoçantes dietéticos de mesa a associação da sacarina com o ciclamato é mais consumida, pois seu custo médio é de $U \$ 2 / \mathrm{Kg}$ enquanto o aspartame custa U\$ 50/Kg e o esteviosídeo U\$ 120/Kg. Não é apenas o custo explica esta preferência, mas também a possibilidade de produzir formulações diversas com outros edulcorantes, que tem efeito sinérgico com a sacarina e com ciclamato $^{58}$.

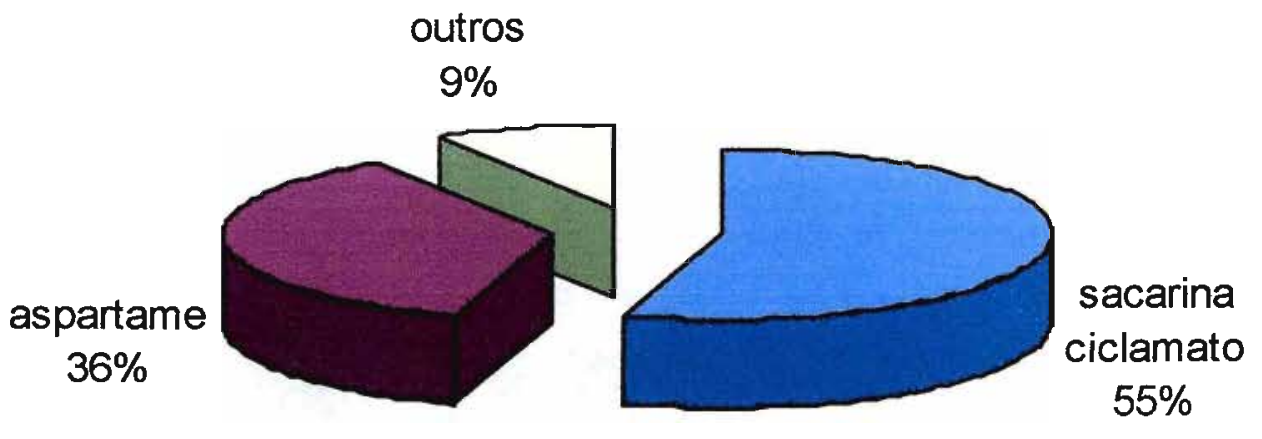

Figura 10: Distribuição dos edulcorantes utilizados na composição dos adoçantes dietéticos no mercado brasileiro no ano de 2002.

\subsection{Amostragem}

Foram coletadas 26 amostras de adoçantes dietéticos de mesa de 13 marcas encontradas no mercado do estado de São Paulo. As amostras foram coletadas em diversos estabelecimentos no período de janeiro a junho de 2000 , como supermercados e farmácias de grande circulação, de maneira aleatória $\theta$ em triplicata.

As amostras foram divididas em grupos, considerando sua composição e a sua forma de apresentação, como visto nas figuras 11 e 12. 


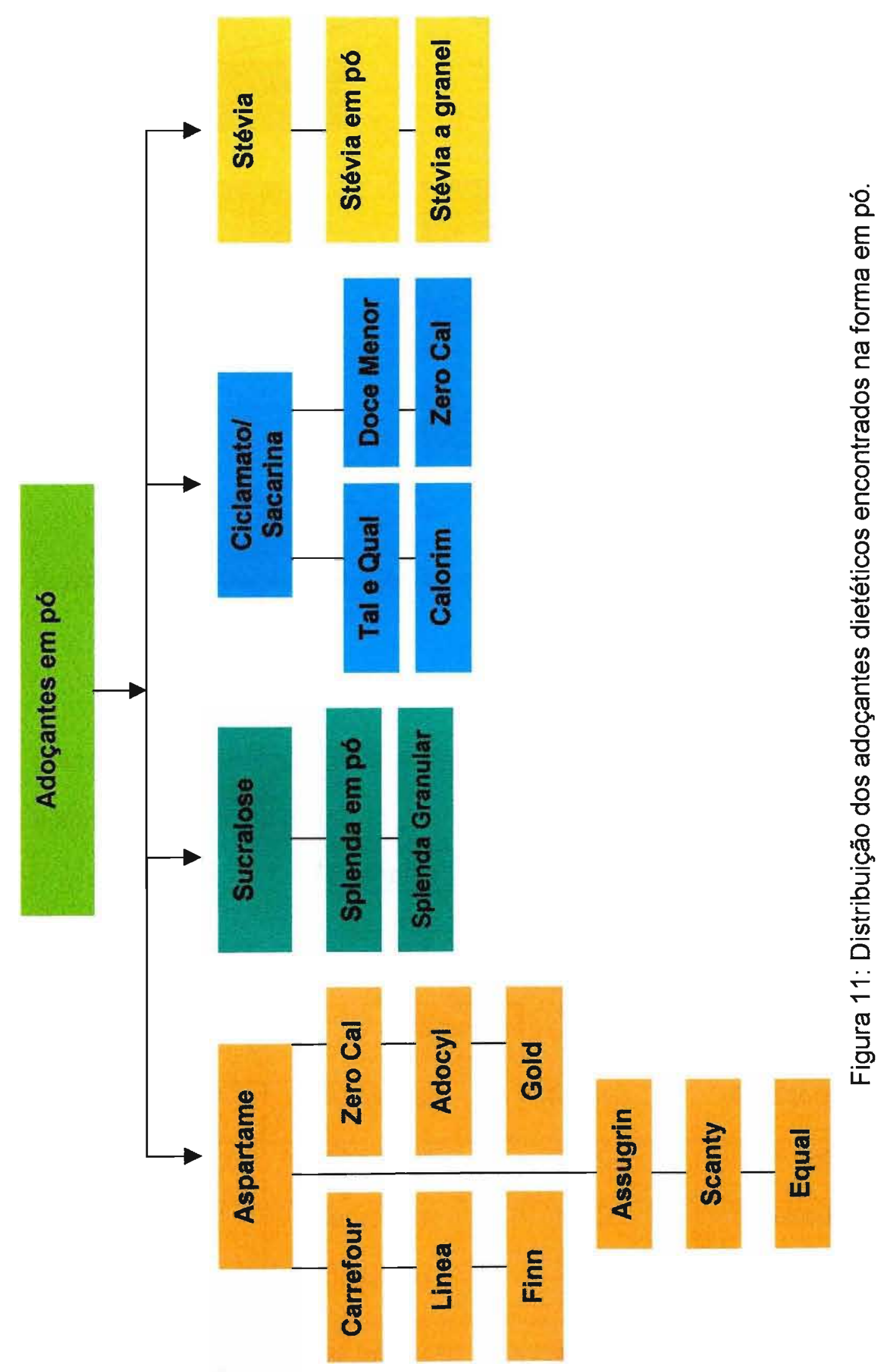




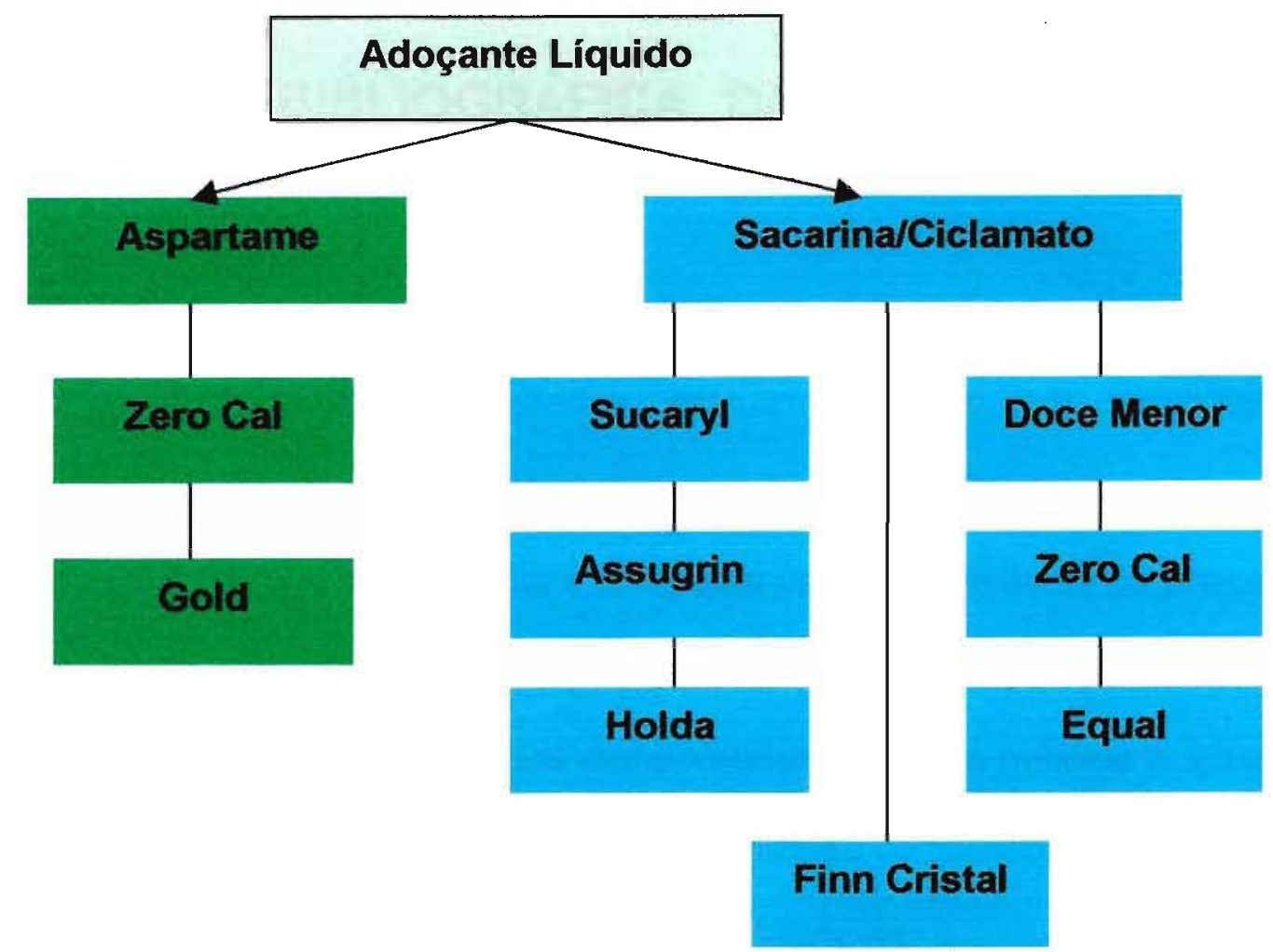

Figura 12: Distribuição dos adoçantes dietéticos encontrados na forma líquida.

As amostras foram codificadas (figura 13) segundo seu edulcorante principal (Aspartame, Sacarina/Ciclamato, Stévia e Sucralose) e sua apresentação (líquido e em pó), por exemplo;

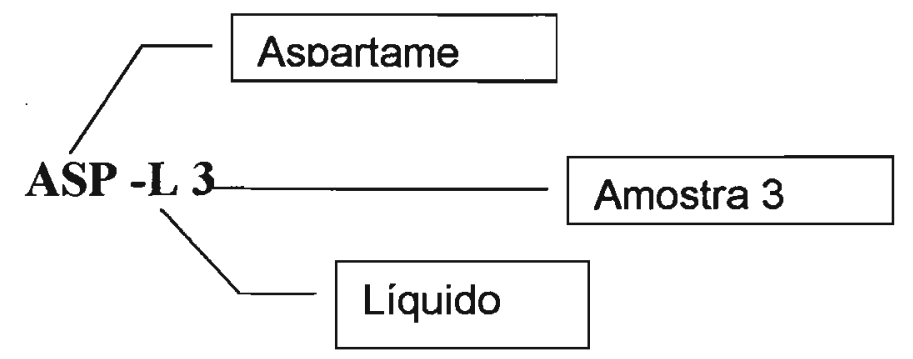

\begin{tabular}{|c|c|c|c|}
\hline Código & Edulcorante & Código & Edulcorante \\
\hline ASP & Aspartame & SUC & Sucralose \\
\hline SACY & Sacarina / & STE & Stévia \\
& Ciclamato & & \\
& & & \\
\hline
\end{tabular}

Figura 13: Codificação das amostras de adoçantes dietéticos coletadas. 


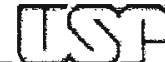

\section{Capítulo 6}

\section{REVISÃO BIBLIOGRÁFICA DA METODOLOGIÂ ANALÍTICA POR ICP OES.}

Entende-se como metodologia analítica o conjunto de procedimentos, parâmetros e ferramentas utilizados em uma análise em particular. Na Espectrometria de Emissão Atômica com fonte de Plasma Indutivamente Acoplado (ICP OES) a metodologia é composta pelo procedimento de preparação das amostras, seleção dos parâmetros instrumentais, aquisição de sinal e introdução da amostra, seleção dos comprimentos de onda máximo e ajustes de fundo (BG) e a calibração. Em alguns casos, deve-se considerar a otimização dos parâmetros instrumentais e a correção de interferências.

Neste capítulo são mostrados artigos recentes pertinentes a cada uma das etapa que compõem a metodologia analítica.

\subsection{Preparação das Amostras}

As determinações elementares por métodos espectroscópicos necessitam de etapas de preparação de amostras, sejam elas mais simples ou mais complexas estas são geralmente as etapas que mais consomem tempo de análise e se não é estabelecida de forma criteriosa é responsável por erros importantes na análise ${ }^{59}$. Em geral, a amostra deve ser convertida a uma forma adequada e conveniente ao procedimento da análise. Isto é, particularmente, verdade para as amostras sólidas onde para satisfazer limitações do sistema de introdução, as amostras devem ser solubilizadas. 
HOEINING e KERSABIEC em uma revisão discutem diversos métodos de dissolução, alguns problemas analíticos e as possibilidades recentes sobre as etapas de pré-tratamento de amostras, como mostradas a seguir ${ }^{60}$.

Para vários tipos de amostra os métodos de dissolução não representam uma dificuldade, mas podem aparecer problemas como volatilização/ perdas ou a formação de resíduos insolúveis. Nos casos onde observam-se recuperações inadequadas os processos de solubilização devem ser reconsiderados. Infelizmente, não há um caminho fácil para tomar decisões e não existe um consenso para todos os tipos de amostras.

\subsubsection{AMOSTRAS LÍQUIDAS}

Pelas baixas concentrações do elemento de interesse em amostras líquidas, umm alerta deve ser feito, sobre a possibilidade de contaminação por adição de compostos químicos com grau de pureza incerto (ácidos, tampões espectroscópicos, modificadores químicos, etc...) ou pela desmineralização insuficiente da água utilizada nas diluições ou por escolha ou descontaminação inadequada dos equipamentos volumétricos, ou ainda, pela manipulação da amostra durante a amostragem ou o pré-tratamento.

O risco de contaminação aumenta com a diminuição da concentração do elemento de interesse presente na amostra. Assim, todo o material de laboratório utilizado deve ser lavado com ácido nítrico de 1 a $10 \%$ e, em seguida lavado com água desmineralizada e desionizada. 
Para minimizar as perdas do elemento de interesse por adsorção de íons metálicos, as amostras podem ser armazenadas por curtos períodos de tempo em refrigerador e por longos períodos no "freezer".

As amostras líquidas geralmente podem ser introduzidas para análise com ou sem tratamento prévio. Em relação à análise espectroscópica, não há precaução em particular a ser tomada. Se a concentração medida satisfaz aos principais critérios do método espectroscópico que são a sensibilidade e o intervalo linear de análise e,além disso a possibilidade de interferências está sob controle, a análise em solução pode ser realizada automaticamente, em qualquer sistema moderno de análise espectral.

Soluções não aquosas ou com alto teor de orgânicos podem algumas vezes ser analisadas diretamente, mas em outras podem sofrer variações significativas com a viscosidade.

\subsubsection{AMOSTRAS SóLIDAS}

Em muitos casos, a preparação das amostras sólidas envolve diversas etapas: amostragem, classificação, sub-amostragem, mineralização ou solubilização. Alguns desses procedimentos representam as maiores fontes de contaminação, e há que se ter cuidados especiais com todo o material de laboratório e com os reagentes.

Em alguns casos as amostras podem ser analisadas diretamente em suspensão, eliminando a etapa de dissolução. Esta possibilidade é por muitas vezes comum para a análise por ICP OES ${ }^{\mathbf{6 1 , 6 2 , 6 3}}$.

É evidente que a preparação é mais uma etapa de grande importância para a qualidade dos resultados analíticos e, assim alguns princípios devem ser respeitados. 


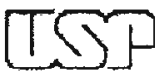

a) A consulta prévia à literatura, com o real objetivo da análise, pois o procedimento mais completo nem sempre é o melhor.

b) O uso de água e reagente de alta pureza sempre em quantidades reduzidas.

c) Limitar o volume dos frascos para minimizar a área de contato com as soluções.

d) Descontaminar todos os equipamentos volumétricos que irão entrar em contato com a amostra.

e) Simplificar a manipulação da amostra, filtração, transferências são às vezes desnecessárias.

f) Avaliar o procedimento pela resposta do branco analítico, estudando possibilidades de contaminação.

g) Verificar a recuperação quando o procedimento usa Material de Referência Certificado (MRC) de composição semelhante à amostra quando este existe e está disponível ${ }^{59,64}$.

\subsection{Procedimento de Dissolução}

\subsubsection{MÉtodos POR ViA SECA}

O resíduo de cinzas é geralmente usado para eliminar a matéria orgânica das amostras. Neste procedimento eleva-se a temperatura à pressão atmosférica. A amostra é pesada em cadinho e aquecida por diversas horas de 400 a $550^{\circ} \mathrm{C}$, em forno tipo mufla. A porção inorgânica associada à matriz é transformada em óxidos e carbonatos, que são dissolvidos em ácido apropriado. Este método é simples e pode ser aplicado a uma grande variedade de tipos de amostras, ao mesmo tempo. 
Comparando com os procedimentos de via úmida. há uma grande vantagem neste procedimento, pois grandes quantidades de amostra podem ser calcinadas e dissolvidas em pequenas quantidades de ácido, o que permite uma grande préconcentração de elementos traços na solução final, desde que estes não sejam interferentes potenciais à determinação.

Perdas por volatilização são relacionadas com a temperatura aplicada, e este é um procedimento proibitivo a elementos voláteis como $\mathrm{Hg}$, As e Se. Outros voláteis permitem temperaturas entre 400 e $450^{\circ} \mathrm{C}$.

\subsubsection{MÉTODOS POR VIA ÚMIDA}

Dentro dos procedimentos de Via Úmida dois tipos de procedimento podem ser adotados: a solubilização total e a mobilização seletiva (extração parcial). Conseqüentemente podem ser escolhidos e adaptados seguindo critérios bem definidos

A decomposição total da amostra de alimento é realizada na presença de HF combinada com outros ácidos. Este procedimento permite a solubilização de todos os elementos presentes na amostra (exceto o silício, que é volatilizado durante o aquecimento). Para avaliação de um ataque total o uso do MRC é de suma importância.

Um ataque forte geralmente usa mistura de ácidos fortes, exceto HF, que se adaptam melhor à rotina de um laboratório; o ataque ácido forte é satisfatório em muitos casos na comparação com o ataque total, testando a recuperação para a sua validação, dependendo da composição da matriz da amostra. 
Ataques moderados, a princípio, são usados para simular a transferência de elementos de ambientes, como a assimilação de elementos traços biodisponíveis. Atualmente, não há um consenso para esta metodologia.

A maioria dos métodos de dissolução por via úmida (decomposição total ou ataque forte) envolve o uso de um ou de alguns ou da combinação de todos os 5 ácidos $\left(\mathrm{HNO}_{3}, \mathrm{H}_{2} \mathrm{SO}_{4}, \mathrm{HClO}_{4}, \mathrm{HCl} \text { e } \mathrm{HF}\right)^{60}$.

\subsection{Escolha da Técnica}

O emprego do ICP OES na determinação dos elementos de interesse nutricional e toxicológico é demonstrado em diversos artigos que avaliam de forma rápida e confiável a segurança alimentar de diversos produtos.

CAROLI et al. determinaram 12 elementos tóxicos e essenciais em mel, que foi analisado como parâmetro de qualidade ambiental e em um estudo nutricional do alimento ${ }^{65}$.

THIEL e DANZER fizeram a determinação direta de 15 elementos em vinho com calibração com simulação de matriz, visando o estudo de autenticidade das amostras analisadas ${ }^{63}$.

MORGANO et al. utilizaram dois métodos de preparação de amostra para comparar a determinação de minerais em sucos de uva comercializados, prontos para o consumo ${ }^{6 \hat{6}}$.

Assim, guardando os devidos cuidados, a determinação por ICP OES mostra-se vantajosa quando comparada a outras técnicas, uma vez que a agilidade e o volume de informação obtido sằo numerosos. 


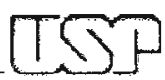

Como visto na tabela 9 na análise por ICP OES diversos tipos de líquidos orgânicos podem ser introduzidos diretamente ${ }^{67}$, o que torna a técnica vantajosa para a determinação em amostras que já se encontram nesta forma. Mas neste trabalho foi necessário verificar se a técnica analítica era adequada à determinação de modo que os limites de quantificação atendessem a legislação brasileira para elementos potencialmente tóxicos nas diluições ou dissoluções aplicadas na metodologia analítica.

Tabela 9: Vantagens e desvantagens da análise por ICP OES frente a outras técnicas espectrais.

\begin{tabular}{l|c}
\hline \multicolumn{1}{c|}{ Vantagens } & Desvantagens \\
\hline Análise qualitativa ou quantitativa. & Interferências Espectrais \\
Menor interferência de matriz. & \\
Determinação Multilementar simultânea. & \\
Não há necessidade de fontes de radiação. & \\
Possibilidade da introdução de amostras & \\
líquidas sem prévio tratamento. & \\
\hline
\end{tabular}

\subsection{Análise por ICP OES}

A Espectrometria de Emissão Atômica (EEA) é utilizada em análises multielementares de vários tipos de amostras, utilizando os mais diferentes sistemas de introdução de amostra, fonte de excitação, dispersão da radiação e análise de dados experimentais (figura 14) para obtenção de resultados analíticos. 


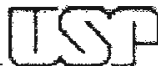

A utilização de plasmas induzidos como fonte de excitação em emissão atômica foi idealizada na década de 60, por GREENFIELD ${ }^{68}$ e FASSEL ${ }^{67}$. Posteriormente seu mecanismo foi descrito por GREENFIELD juntamente com uma extensa revisão do surgimento à aplicação dos tipos de plasma como fonte espectroscópica ${ }^{69-71}$.

\subsubsection{FONTE DE EXCITAÇÃO}

Foi descrito por GREENFIELD, que a fonte de excitação (o plasma) é necessária à volatilização, atomização e excitação dos átomos presentes na amostra, para posterior emissão de radiação eletromagnética de comprimento de onda característico ${ }^{\mathbf{6 8 , 7 2}}$ (figura15); ou seja, a fonte de excitação precisa ser capaz de remover a água (ou outro solvente) de uma amostra líquida (desolvatação), quebrar as partículas da amostra em moléculas (vaporização, dissociação), quebrar as moléculas em átomos (atomização) e fornecer energia para os átomos (excitação) $^{\text {69-72. }}$. 


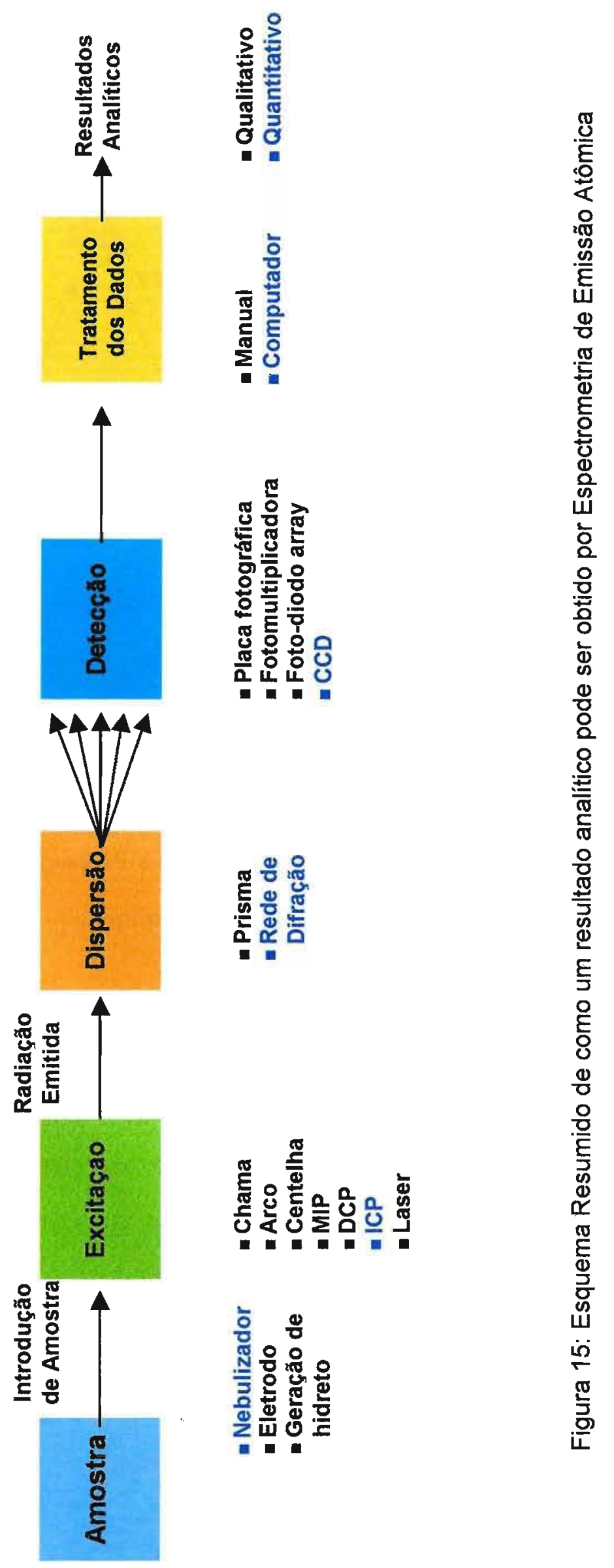


Fonte de Excitação -

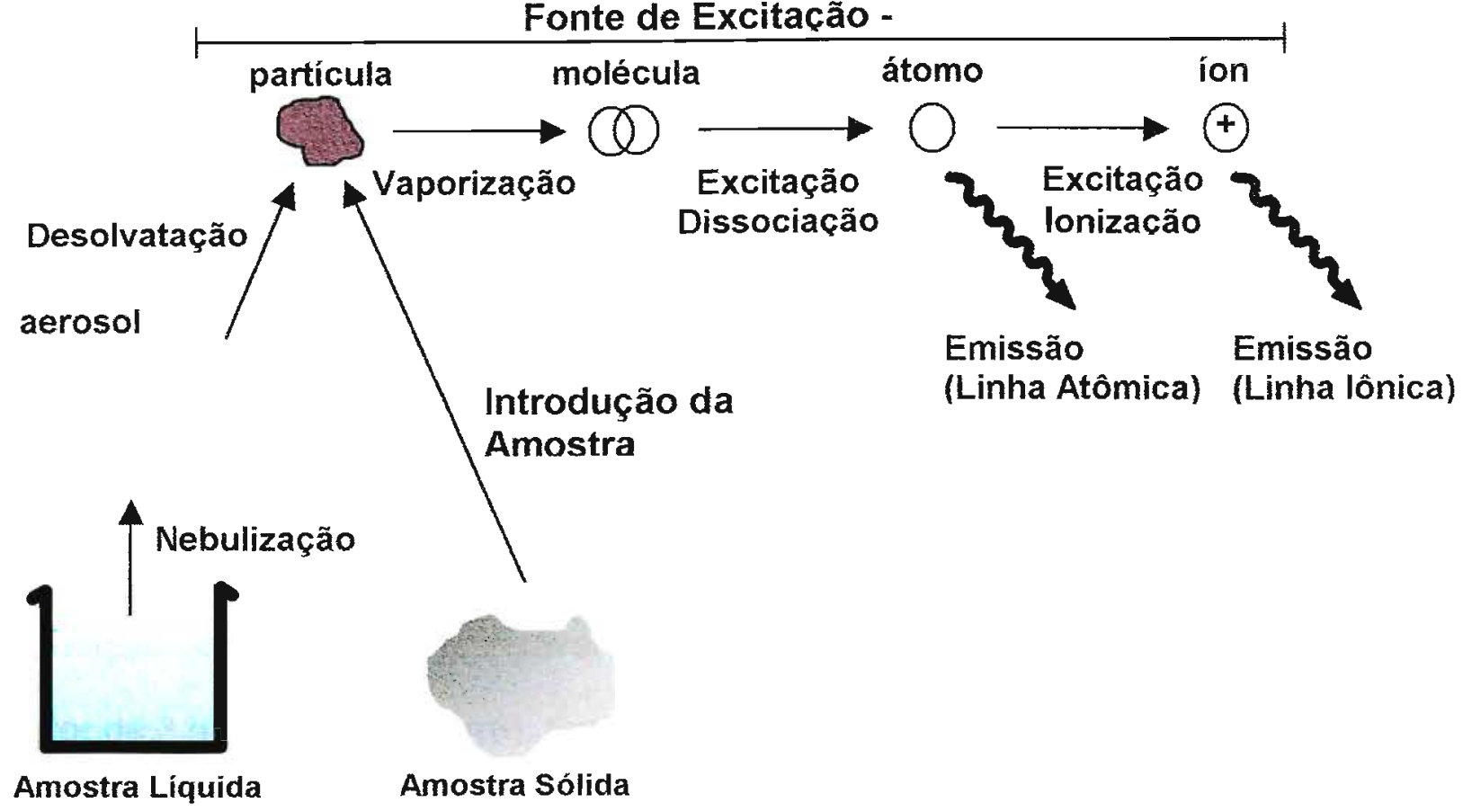

Figura 15: Esquema dos processos que ocorrem no sistema de Introdução de amostra e na fonte de excitação.

Nos últimos anos, a instrumentação analítica, para determinação de metais, tem sofrido avanços consideráveis. A técnica de Espectrometria de Emissão Óptica em Plasma Indutivamente Acoplado (ICP OES) tem sido utilizada amplamente devido a uma série de vantagens que oferece, tais como: análise multielementar simultânea, sensibilidade e precisão, rapidez, bem como ampla faixa dinâmica. 


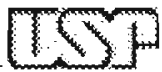

Entre as diversas implementações nos instrumentos de ICP OES cita-se o posicionamento da tocha inicialmente radial e atualmente a axial (figura 16). Os sistemas de espelhos para transmissão da radiação deram lugar às atuais fibras ópticas e às fotomultiplicadoras e fotodinodos que compõem os diferentes canais da detecção simultânea da radiação, onde as características, o modo de utilização, de otimização e de aquisição de sinal são distintos e merecedores de discussão.

Segundo MOORE a fonte de plasma com vista axial, comparativamente a vista radial, apresenta maior sensibilidade e eficiência, uma vez que a zona de observação do plasma se estende de $5 \mathrm{~mm}$ a $35 \mathrm{~mm}$, assim o aumento de radiação detectada é responsável pela melhora nos limites de detecção em um fator de 3 a 8 vezes (figura16). Entretanto, deve-se considerar que na observação radial havia uma escolha mais refinada da radiação por meio da seleção da altura de observação, e na observação axial tem-se uma soma de todas as radiações provenientes de todas as interações ocorridas no canal central do plasma ${ }^{72}$. Assim DENNAUD et al recomendam um cuidado maior no estudo de interferências para a determinação com vista axial, pois quando a análise é realizada por ICP OES com vista radial a escolha da altura de observação é feita reduzindo as interferências, a níveis aceitáveis, e com a vista axial, o efeito de matriz é a média dos efeitos em todo o canal central do plasma ${ }^{73,74}$. Conseqüentemente, o efeito de matriz no sinal de emissão no sistema com vista axial é mais facilmente percebido e mais complexo no caso de aplicações práticas. A figura 17 mostra a interface e a zona analítica em detalhe. A figura 18 mostra o sistema de nebulização (nebulizador, câmara de nebulização) e o posicionamento da tocha axial no equipamento. 
VISTA RADIAL

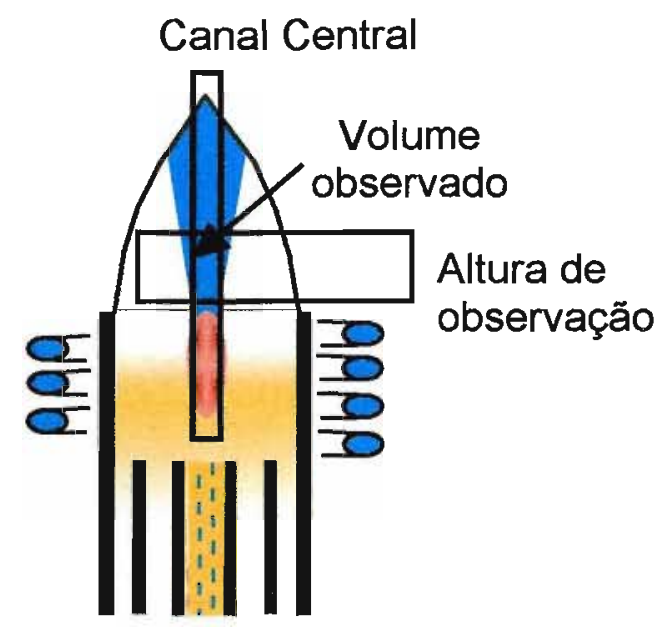

VISTA AXIAL

profundidade

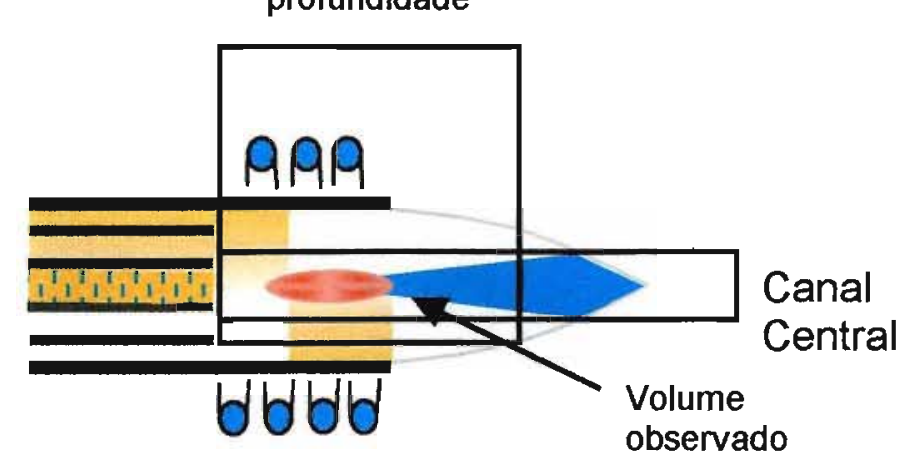

Figura 16: Esquema do posicionamento da zona de observação nas vistas Radial e Axial.

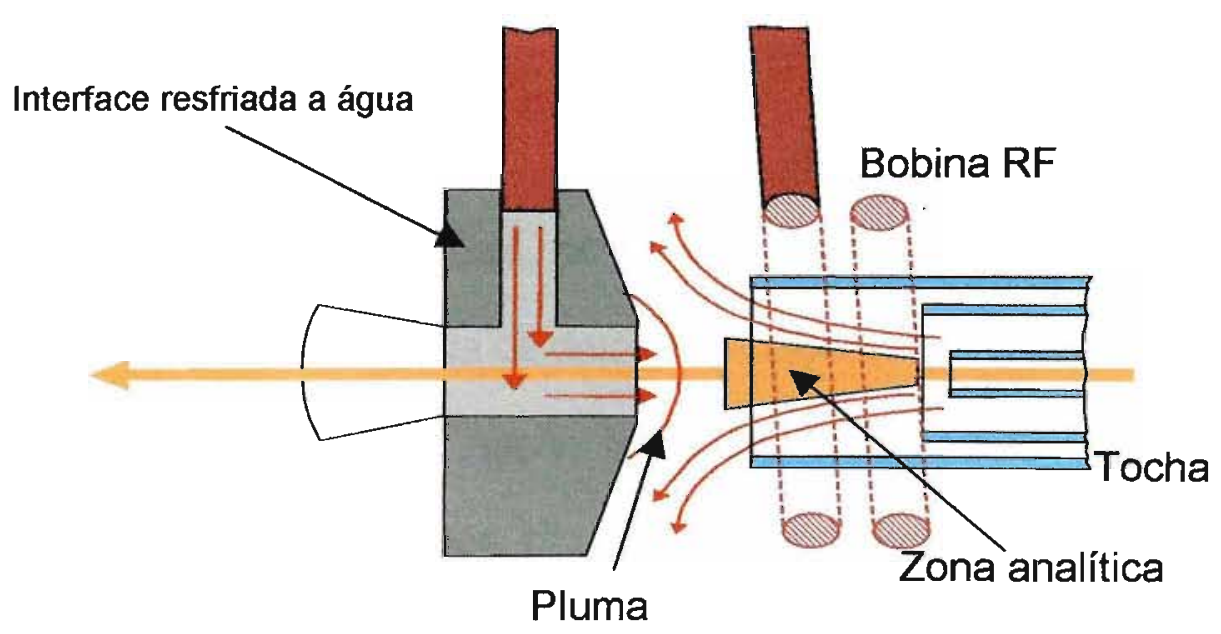

Figura 17: Esquema Detalhado da Fonte de Plasma com Vista Axial 


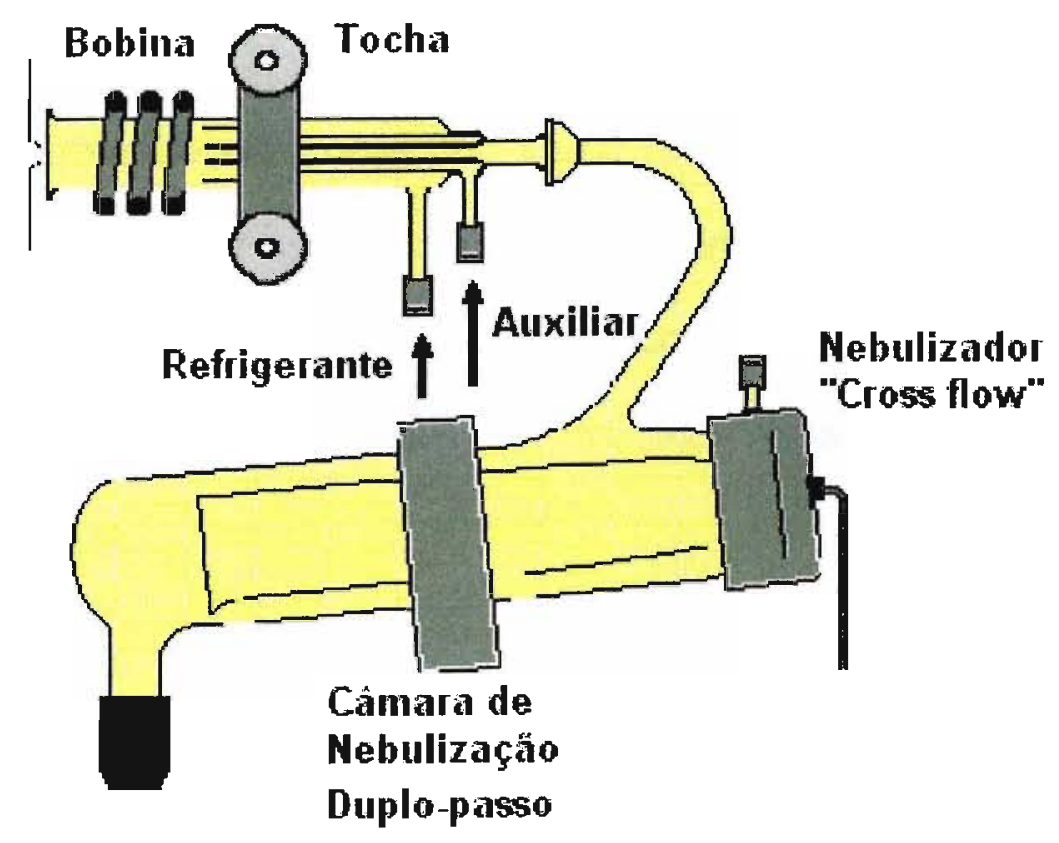

Figura 18: Montagem do nebulizador, da câmara de nebulização e da tocha axial.

\subsubsection{Deteç̧Ão}

Segundo PIMENTEL et al. um detector ideal em EEA combina a conveniência de uma eletrônica adequada e a capacidade de detecção multicanal das antigas placas fotográficas ${ }^{4}$. Às vezes, um sistema de detecção chega próximo às características ideais, como é o caso dos CCD. Combinado a uma óptica Echelle, bem desenhada os detectores CCD exibem um largo intervalo com alta resolução. Esta é a combinação ótima, de um moderno sistema de deteç̧ão, com uma ótica sofisticada que promove determinações multielementares bem sucedidas com alguns poucos casos de interferências reportados na literatura. Sistemas de alta resolução são necessários para calibrações tradicionalmente univariadas onde muita informação espectral é ignorada e apenas um ou dois comprimentos de onda são observados para cada elemento e a escolha é feita 
pelo comprimento de onda com intensidades relativas mais altas e livre de interferentes.

No caso do espectrômetro com detecção CCD, há dispositivos montados no círculo de Rowland para medir as radiações mais importantes do espectro em um plano (figuras 19,20 ). O computador é usado para controlar o instrumento e para análise dos resultados, assim, podem ser medidos e avaliados espectros inteiros ${ }^{74}$

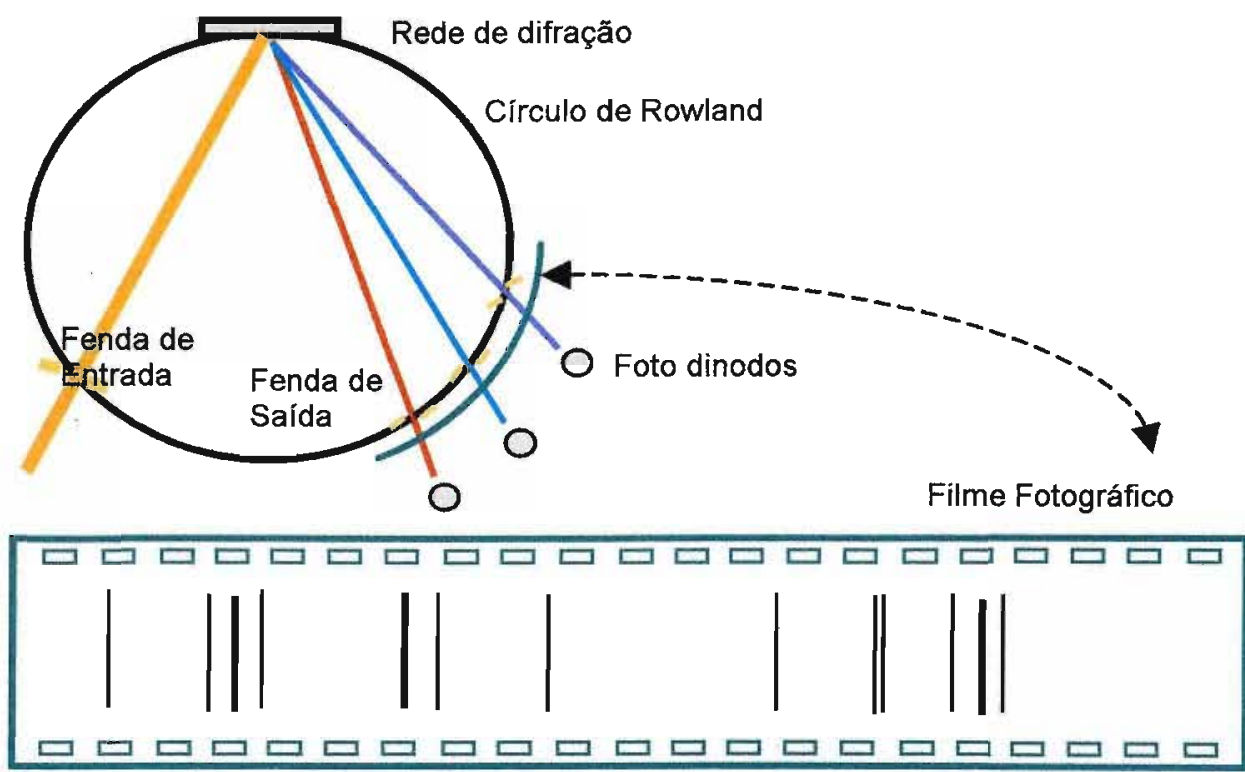

Figura 19: Representação do Círculo de Rowlande sua semelhança com as placas fotográficas. 


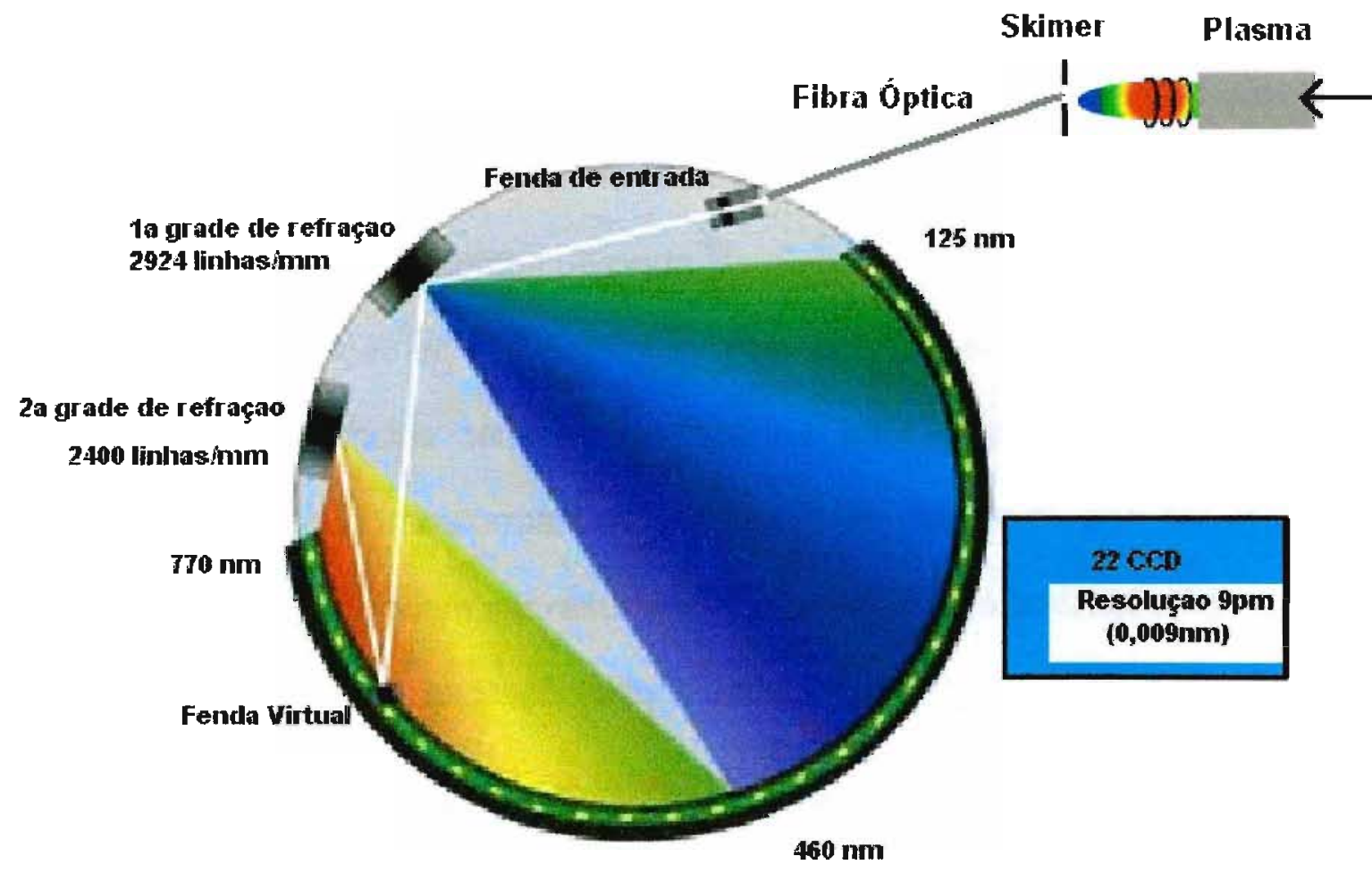

Figura 20: Círculo de Rowland e o esquema das ópticas, fendas e fotodinodos de detecção simultânea.

\subsubsection{INTERFERÊNCIAS}

A análise por ICP OES com vista axial apresenta grande sensibilidade, eficiência e rapidez, esta atende a demanda crescente da análise elementar numa ampla faixa linear de concentração. No caso de análise de matrizes orgânicas complexas ou concomitantes facilmente ionizáveis, a medida pode sofrer uma influência considerável: podem ocorrer interferências por efeito de matriz, principalmente no caso da análise sem o tratamento prévio da amostra ${ }^{3,75}$.

Com a melhora na capacidade dos computadores de armazenar uma grande quantidade de dados, pode-se utilizar toda informação espectral minimizando problemas de sobreposição de espectros com a aplicação de diversos métodos de tratamentos de dados que vêm aparecendo na literatura para o tratamento do 


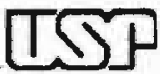

sinal analítico, como a correção de fundo (BG) simultânea ${ }^{76}$, a utilização de Padrão Interno $(\mathrm{PI})^{\mathbf{7 7}, \mathbf{7 8}}$, a correção de sinal por razão entre intensidades de várias linhas analíticas de um mesmo elemento ${ }^{78-80}$ e por fim, a determinação utilizando múltiplos comprimentos de onda ${ }^{81}$.

Desde a introdução do ICP como fonte de emissão, testes de diagnóstico e estudos de interferências têm sido aplicados para tentar compreender os processos básicos que transformam as espécies inseridas no plasma em fótons e íons. Estes processos podem ser resumidos nas etapas de atomização(figura 14), geração de átomos livres, excitação e ionização.

As interferências podem ocorrer por ineficiência nos processos de transferência de energia do plasma para amostra. Também podem ocorrer por mudanças no sistema de introdução e de nebulização da amostra. Na literatura encontramos alguns procedimentos que tentam auxiliar na elucidação destes processos.

MERMET recomenda a medida experimental das razões de intensidade das linhas iônica e atômica (Mgll / Mgl), que serve não apenas para avaliar o Equilíbrio Térmico Local (ETL), mas reflete a ineficiência nos processos de atomização, exitação e ionização do plasma $^{82}$, uma vez que muitas linhas atômicas modificam sua sensibilidade relativa por mudanças nos parâmetros de operação, em contraste com as linhas iônicas. Estas foram denominadas de linhas Soft e Hard, respectivamente. Contudo, a medida da razão de intensidade das linhas iônica e atômica permite a determinação do ETL e a otimização dos parâmetros do plasma. Além disso, é possível avaliar se qualquer mudança no sinal é conseqüência de variações nas propriedades do plasma, que é útil no 
estudo de efeitos de interferência, em particular no caso dos elementos facilmente ionizáveis presentes na matriz.

Sendo assim, razão $\mathrm{Mg}$ II / Mg I é um parâmetro adequado para avaliar as condições do operação de ICP OES com configurações axial e radial, na figura 21 vê-se um exemplo do espectro obtido para o estudo realizado por Mermet das intensidades relativas das linhas atômicas e iônicas do Magnésio. Quanto maior essa razão, tanto menor a possibilidade de ocorrência de interferências matriciais.

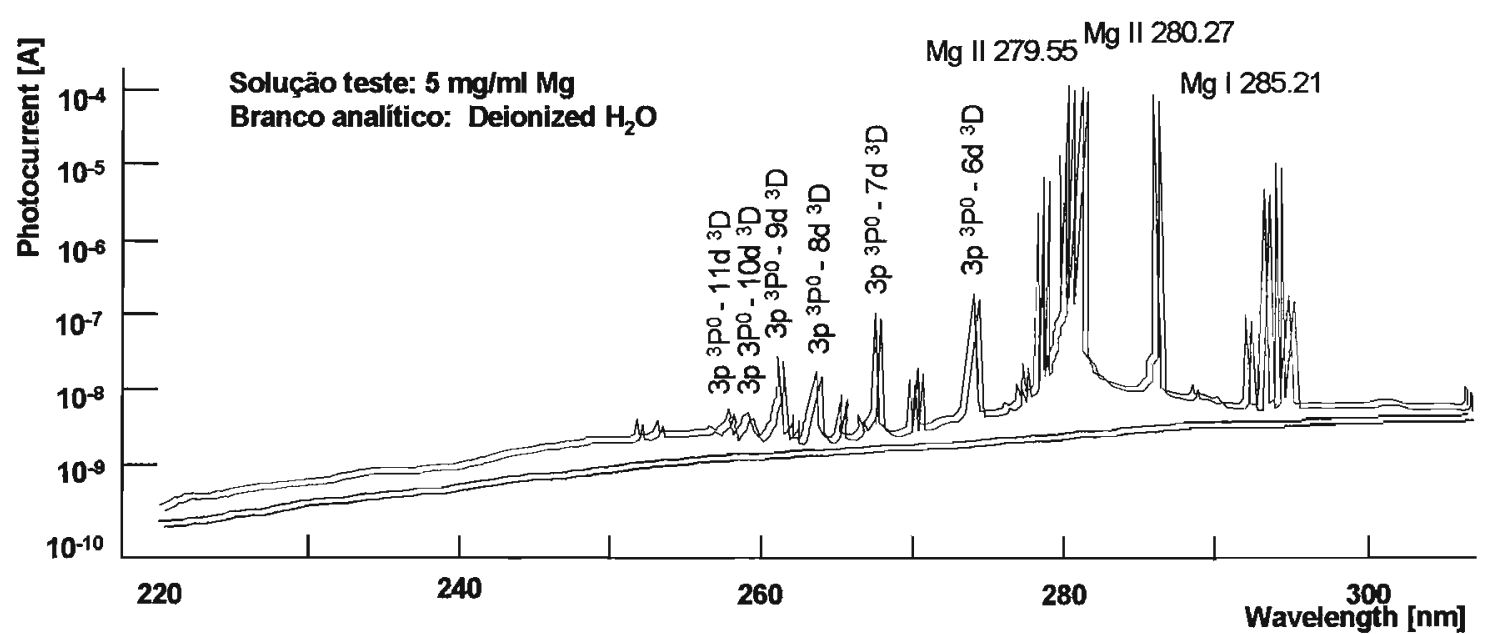

Figura 21: Espectro obtido para o estudo realizado por Mermet das intensidades relativas das linhas atômicas e iônicas do Magnésio

Então, alguns cuidados práticos devem ser adotados e são indispensáveis para obter o melhor desempenho instrumental, evitando ou minimizando os problemas citados anteriormente, tais como o ajuste óptico com uma solução de referência adequada (Tuning solution), o ajuste do eixo XYZ da óptica em relação ao canal central do plasma, a utilização de uma solução de $Y\left(1000 \mu \mathrm{g} \mathrm{mL}^{-1}\right)$ para a verificação das zonas de excitação iônica e atômica, os testes da influência da potência e dos fluxos de gás (auxiliar, refrigerante e do nebulizador) na condição ótima de análise ${ }^{82}$. 


\subsection{Procedimentos de Calibração}

Segundo a nova versão do Vocabulário de Termos Fundamentais e Gerais de Metrologia baseada na $2^{a}$ edição/1993 do documento elaborado pelo Bureau Internacional de Pesos e Medidas - BIPM, pela Comissão Internacional de Eletrotécnica - IEC, pela Federação Internacional de Química Clínica - IFCC, pela Organização Internacional de Normalização - ISO, pela União Internacional de Química Pura e Aplicada - IUPAC e pela União Internacional de Física Pura e Aplicada - IUFAP, com a devida adaptação ao nosso idioma, publicado na Portaria INMETRO $n^{\circ}$ 029, de 10 de março de 1995, o procedimento de Calibração é "um conjunto de operações que estabelece, sob condições especificadas, a relação entre os valores indicados por um instrumento de medição ou sistema de medição ou valores representados por uma medida materializada ou um material de referência, e os valores correspondentes das grandezas estabelecidos por padrões." ${ }^{83}$.

Sendo assim, o processo de quantificação depende de que a amostra forneça para uma dada concentração a mesma resposta que um padrão de mesma concentração daria. Este efeito se dá porque os métodos instrumentais são, na maioria das vezes, relativos. Mas algumas matrizes propiciam diferenças importantes no sinal do elemento de interesse, expressas nas relações de calibração, comprometendo os resultados quantitativos ${ }^{84,85}$,

Estes efeitos são facilmente identificados comparando-se a curva analítica (padrões aquosos), com uma curva de adição de padrão monoelementar (amostra+padrão monoelementar) e com uma curva de adição de padrão multielementar (amostra+padrão multielementar) ${ }^{86}$, assim três efeitos podem ser vistos (como na figura 22): 
- Igualdade entre as inclinações das funções da curva analítica típica e a adição de padrão, onde não há efeitos de matriz alterando o resultado da medida. Presença de uma matriz simples e de simples interpretação.

- Diferença na inclinação das funções da curva analítica típica e a adição de padrão, onde o efeito de matriz é demonstrado pelo aumento ou pela supressão do sinal analítico em presença da amostra. Presença de matriz complexa.

- Igualdade entre as inclinações das funções de calibração da curva analítica típica e a adição de padrão, com diferenças entre as intersecções do eixo do sinal para as funções de calibração por adição de padrão mono e multielementar, o que demonstra presença de interferências espectrais. Presença de matriz complexa e interferência espectral.

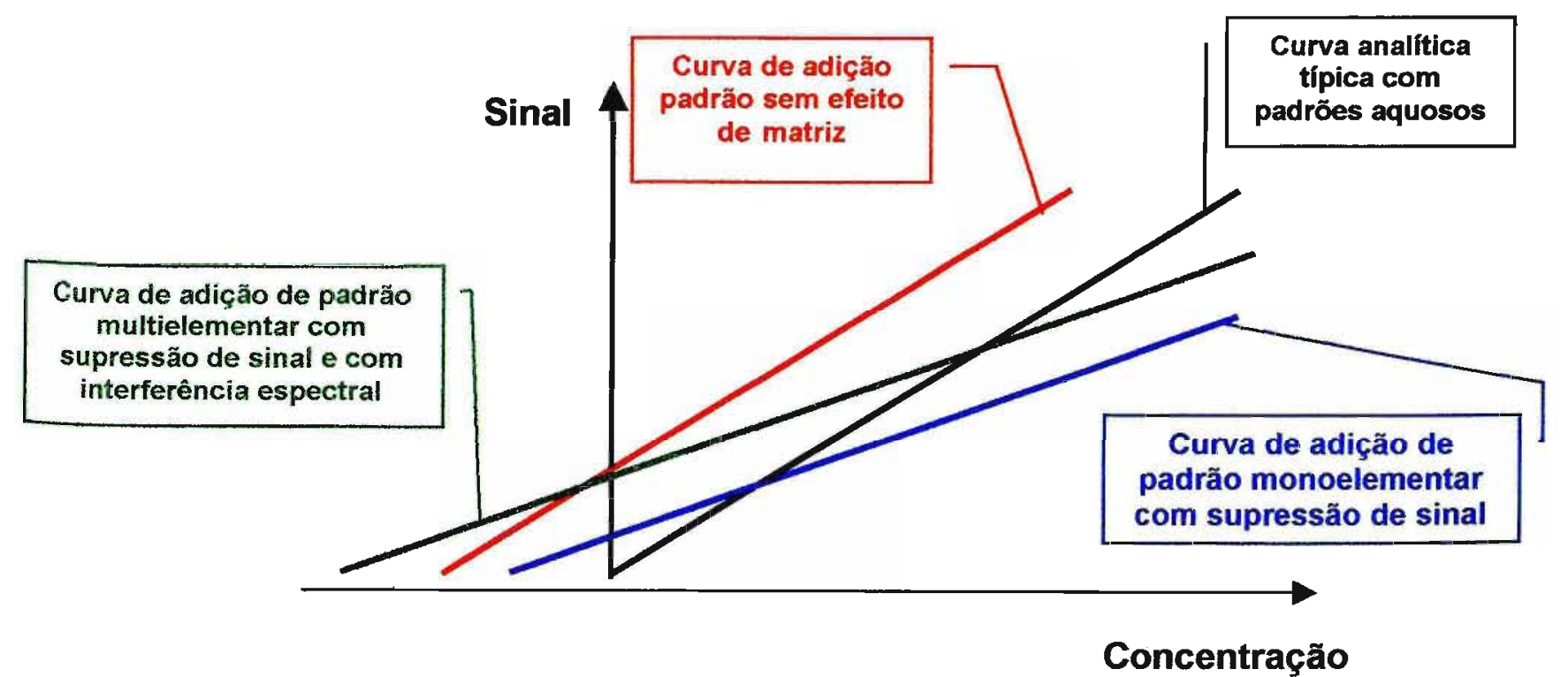

Fgura 22: Comparação entre as funções de calibração típica, a adição de padrão monoelementar e multielementar e os efeitos que podem ser verificados 
Outra maneira de verificar a presença de efeitos de interferência espectral ou de matriz é a análise das curvas analíticas de adição de padrão com a determinação de múltiplos comprimentos de onda simultâneos, pois as sensibilidade das linhas analíticas podem ser distintas, mas a concentração do branco de adição é única e se houver discordância neste valor é porque há algum efeito modificando o sinal analítico, que pode estar relacionada a algum tipo de interferência.

Assim, o procedimento de determinação em múltiplos comprimentos de onda pode ser utilizado para a seleção da melhor linha analítica (mais sensível, sem intereferências e mais adequada à análise monoelementar) ou para a determinação em múltiplas linhas analíticas, eliminando interferências espectrais e de matriz melhorando a precisão da determinação. Este procedimento foi adotado neste trabalho e seus resultados são apresentados nos capítulos subsequentes. 


\section{Capítulo 7}

\section{Procedimentos e Métodos}

\subsection{Equipamentos:}

Mufla Programável EDGCON 3P-7000Microondas de alta pressão ETHOS Milli-Q Gradient.

Destilador de ácido em Quartzo (Marconi).

Espectrômetro de Emissão Atômica CIROS ${ }^{\mathrm{CCD}}$ Spectro Co.

Espectrômetro de Emissăo Atômica com detecção de Massas.

ULTRAMASS-7000. Varian Inc.

\subsection{Reagentes}

Foram utilizadas soluções estoque certificadas SPEX CERTIPEP mono elementares $1 \mathrm{~g} \mathrm{~L}^{-1}$ ou preparadas a partir de ampolas MERCK.Tanto nas soluções de referência como nas amostras utilizou-se água destilada, purificada em resina de troca iônica e ultra-purificada em sistema Milli-Q.

Os reagentes utilizados nas análises, de grau analítico, estão relacionados a seguir: ácido nítrico $\left(\mathrm{HNO}_{3} \mathrm{MERCK} 68 \%\right)$ bi-destilado e peróxido de hirogênio $\left(\mathrm{H}_{2} \mathrm{O}_{2} \mathrm{CRQ} 29\right.$ a $\left.32 \%\right)$.

Foram feitos brancos analíticos em triplicata, contendo todos os reagentes $\theta$ passando por todos os procedimentos aplicados à amostra para verificar a qualidade dos reagentes e a validade dos procedimentos de dissolução. 


\subsection{Dissolução das Amostras de Adoçantes Dietéticos.}

Na literatura são mostrados diversos métodos de tratamento e solubilização das amostras, que envolvem várias etapas e consomem tempo, esforço e reagentes. Como a determinação por ICP OES é simultânea e multielementar, a freqüência analítica é grandemente comprometida pela preparação das soluções teste, neste trabalho propôs-se um método mais simples e rápido, sem tratamento prévio da amostra, além de uma diluição conveniente; e para validar este procedimento foram comparados os resultados de cinzas nitradas ${ }^{87,88}$ para os macrominerais, e para os microminerais foram avaliados os métodos de dissolução em microondas e por dissolução a frio,

\subsubsection{Análise Sem o Tratamento Prévio da Amostra:}

Os adoçantes sólidos foram dissolvidos na proporção de $1 \mathrm{~g}$ de amostra a um volume final de $50 \mathrm{~mL}$ em água Milli-Q. A diluição escolhida leva em consideração o consumo do produto, pois a maioria das marcas analisadas acondiciona as doses individuais em envelopes de 0,8 a 1,0g, e não é incomum um consumo de 1 a 2 envelopes de adoçante por $50 \mathrm{~mL}$ de bebida. Sendo assim, a intenção é que a análise reproduza o consumo normal de um indivíduo.

Para as amostras de adoçantes dietéticos líquidos fez-se uma análise dos rótulos dos produtos onde há informação da composição porcentual do mesmo e o conteúdo de edulcorante varia entre 3,8 e 4,8\%; assim para manter a mesma proporção em massa dos adoçantes em pó, as amostras foram diluídas na proporção $25 \mathrm{~mL}$ de amostra para $50 \mathrm{~mL}$ de volume final, com água Milli-Q. 


\subsubsection{Resíduo de CInzas:}

Pesou-se $1 \mathrm{~g}$ de amostra em cadinho de porcelana limpo e tarado. Utilizando uma mufla de aquecimento programável e taxa de aquecimento de $1^{\circ} \mathrm{C} \mathrm{min}^{-1}$ realizou-se procedimento de aquecimento mostrado na figura 23 . Este procedimento não foi realizado para as amostras de adoçantes dietéticos líquidos, pois verificou-se valores de umidade médio de $87 \%$.

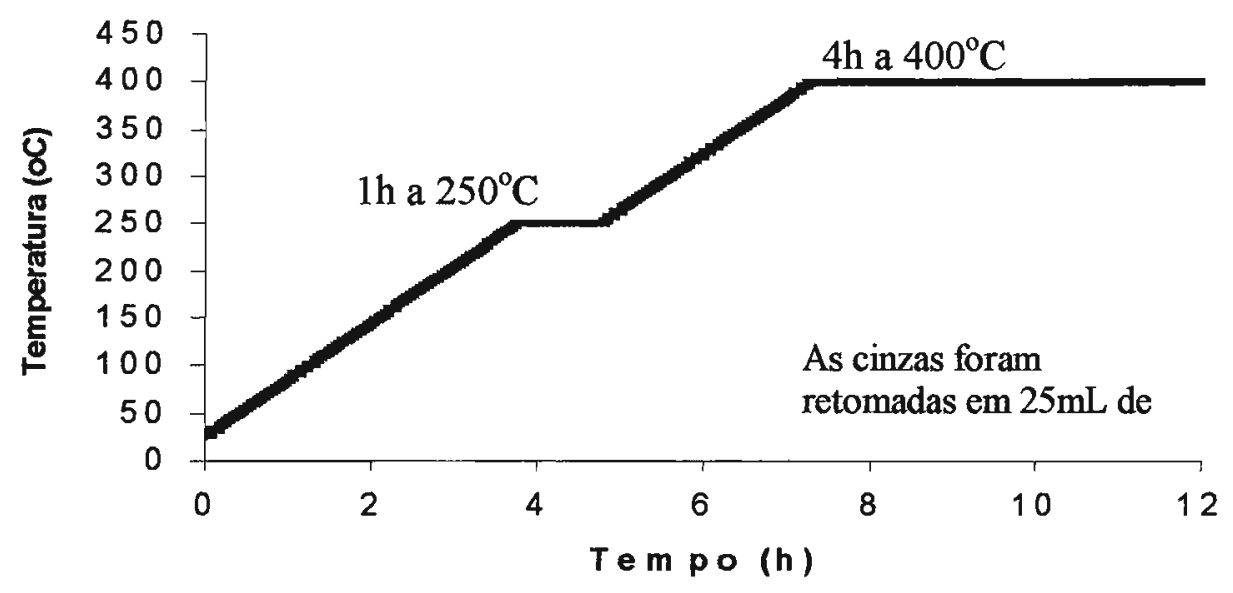

Figura 23: Método de aquecimento para obtenção do Resíduo de Cinzas.

Se a amostra não produzir cinzas brancas, esta deve ser tratada com $1 \mathrm{~mL}$ de $\mathrm{HNO}_{3}$ concentrado, seco em chapa de aquecimento e retornar a mufla a $480^{\circ} \mathrm{C}$ por 12 horas. Ao final, a amostra deve ser retomada em $25 \mathrm{~mL}$ de $\mathrm{HNO}_{3}(5 \% \mathrm{v} / \mathrm{v})$. Determinaram-se os brancos e as amostras em triplicata. Este procedimento, além de demorado era limitado pelo número de cadinhos (30) por ciclo de aquecimento, possibilitando a decomposição de 3 brancos e 9 amostras por ciclo. 


\subsubsection{DISSOLUÇÃo A FRIO.}

Este procedimento foi realizado para 6 amostras de adoçante em pó e/ou granulado.Pesou-se $1 \mathrm{~g}$ de amostra, transferiu-se a tubos rosqueados (polipropileno) graduados e descontaminados em $\mathrm{HNO}_{3}$ 1\% por 24 horas, adicionou-se $5 \mathrm{~mL}$ de $\mathrm{HNO}_{3}$ (65\% Sub-destilado) por 18 horas. Näo havendo nenhuma formação de precipitado ajustou-se a volume final de $25 \mathrm{~mL}$. Este procedimento é conveniente, pois pode-se preparar um número bastante grande de amostras, limitado apenas pelo espaço disponível na capela.

\subsubsection{EXTRAÇÃO EM MICROONDAS.}

Realizou-se a análise de 6 amostras em triplicata, com os respectivos testes de adição e recuperação para comparação da exatidão das metodologias de preparo de amostras. A capacidade de dissolução é de 8 vasos por ciclo de operação,o que possibilitou a dissolução de 2 brancos e 2 amostras em triplicata, por ciclo de dissolução ${ }^{89}$.

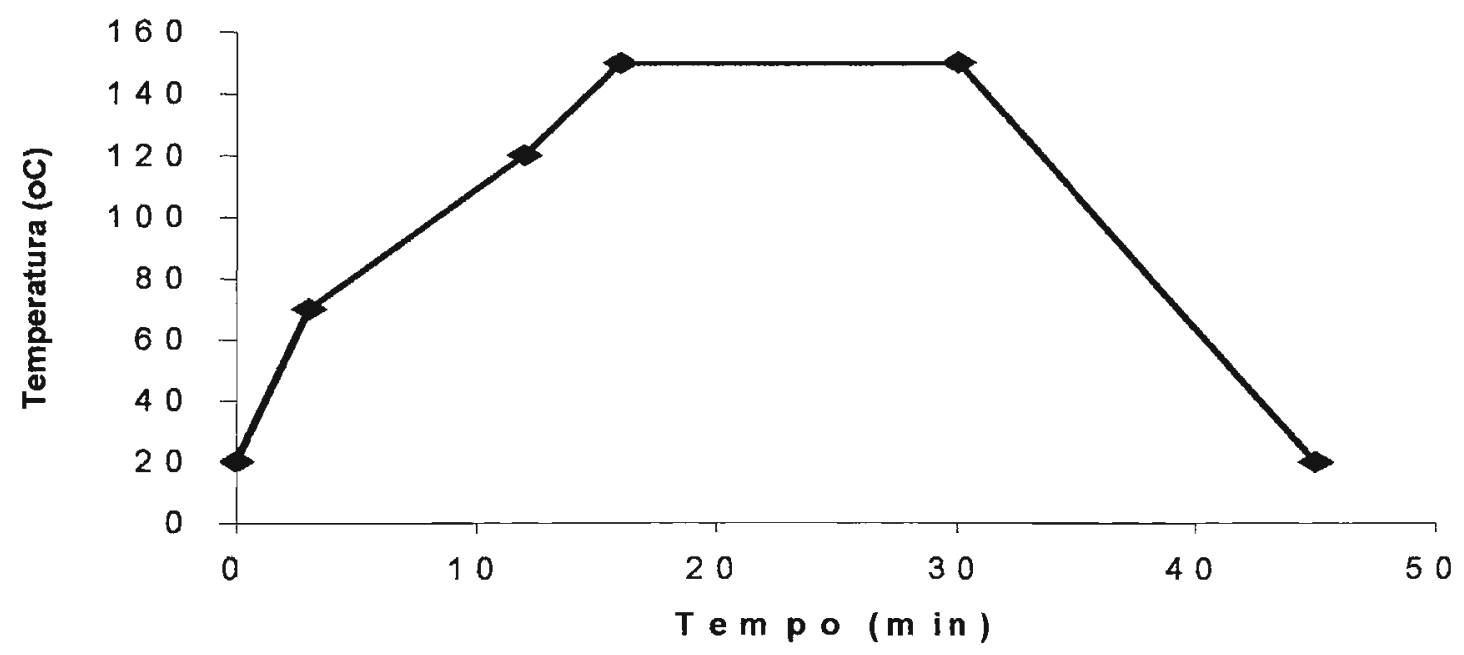

Figura 24: Programa de aquecimento para dissolução em Microondas Fechado 
Tabela 10: Programa de Dissolução Ácida em Microondas de Alta Pressão para amostras de adoçante dietético.

\begin{tabular}{c|c|c}
\hline Massa de amostra (mg) & \multicolumn{2}{c}{$\begin{array}{c}0,5 \mathrm{~g} \text { da amostra sólida } \\
\text { ou } 5 \mathrm{~mL} \text { da amostra líquida. }\end{array}$} \\
\hline Reagentes & \multicolumn{2}{c}{$8 \mathrm{~mL} \mathrm{HNO}+3 \mathrm{~mL}_{2} \mathrm{O}_{2}$} \\
\hline Etapas de dissolução & 10 & 20 \\
\hline 1 & 10 & 70 \\
\hline 2 & 10 & 120 \\
\hline 3 & 10 & 140 \\
\hline 4 & 5 & 140 \\
\hline 5 & & 25 \\
\hline Volume final $(\mathrm{mL})$ & \multicolumn{2}{|c}{25} \\
\hline
\end{tabular}




\section{Capítulo 8}

\section{Resultados e Discussões}

Para simplificar a análise utilizou-se o procedimento de determinação sem o tratamento prévio da amostra, pois observou-se que todos os produtos analisados são solúveis em água, mas existem aditivos e conservantes de formulação bastante distinta o que implica em uma matriz complexa com alto teor de orgânicos.

Comparando os procedimentos de dissolução quanto ao tempo de preparação por ciclo, o número de amostras por ciclo e a sua freqüência analítica mostra-se uma ampla vantagem para a análise sem o tratamento prévio caso esta metodologia apresente resultados equivalentes aos métodos já estabelecidos, o resíduo de cinzas e a dissolução em microondas de alta pressão (figuras 25,26 e 27).

Os resultados com a dissolução à frio não se mostraram adequados, uma vez que havia à formação de um precipitado branco atribuído à formação de glucose e galactose pela hidrólise ácida da lactose, principal agente de corpo do adoçante dietético em pó.

O resíduo de cinzas apresentou brancos analíticos elevados, impossibilitando a avaliação de baixas concentrações elementares. Os brancos elevados podem ser conseqüência do longo tempo de exposição na mufla. 


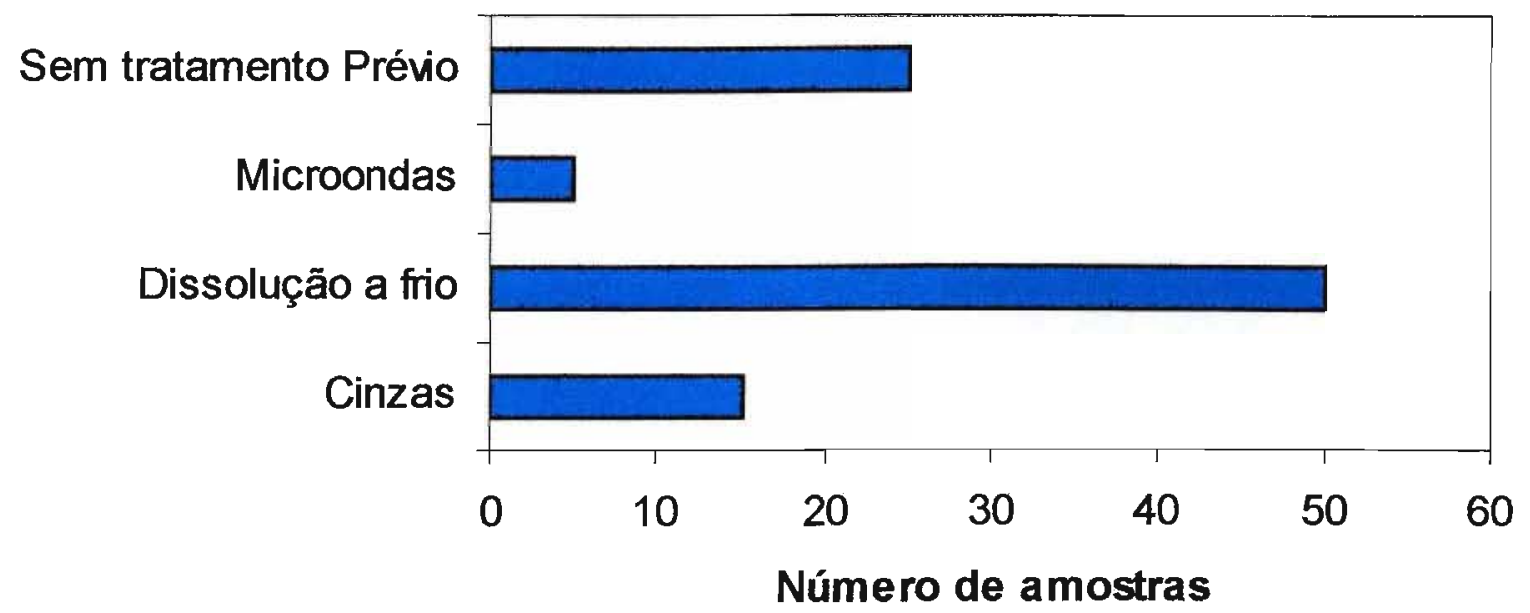

Figura 25: Comparação dos métodos de dissolução quanto ao número de amostras por ciclo de preparação.

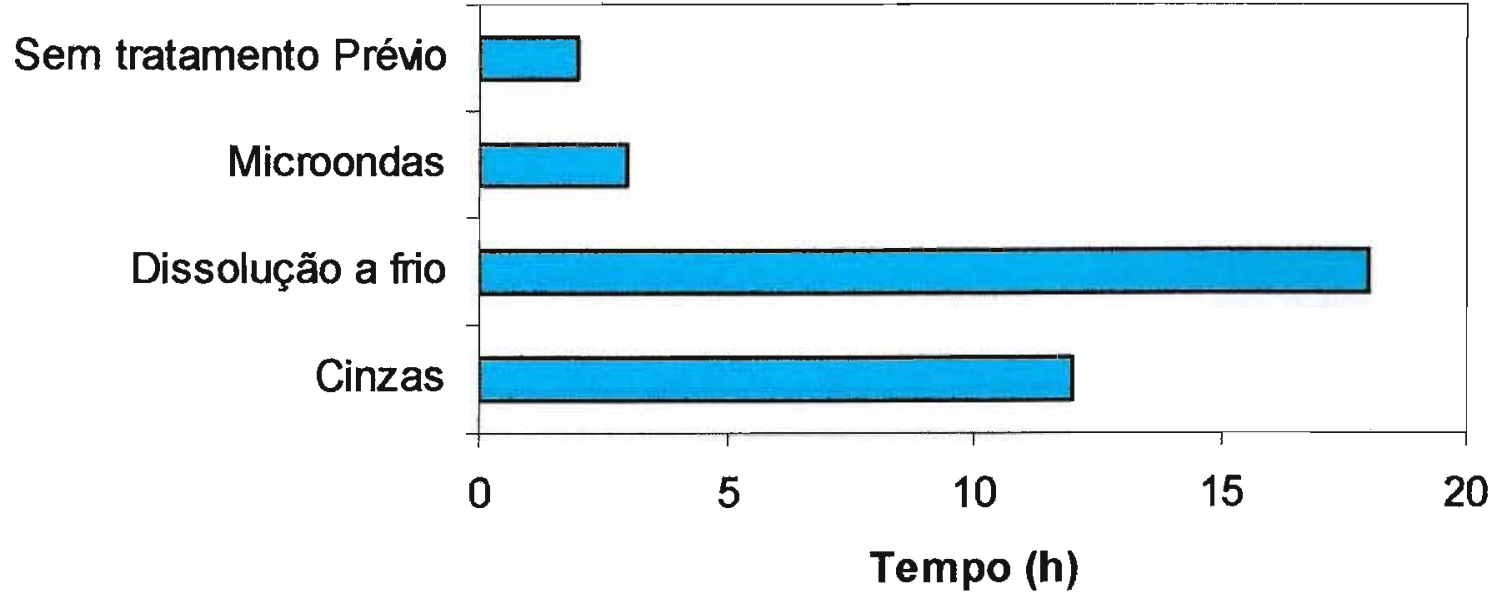

Figura 26: Comparação dos métodos de dissolução quanto ao tempo de preparação de amostras por ciclo.

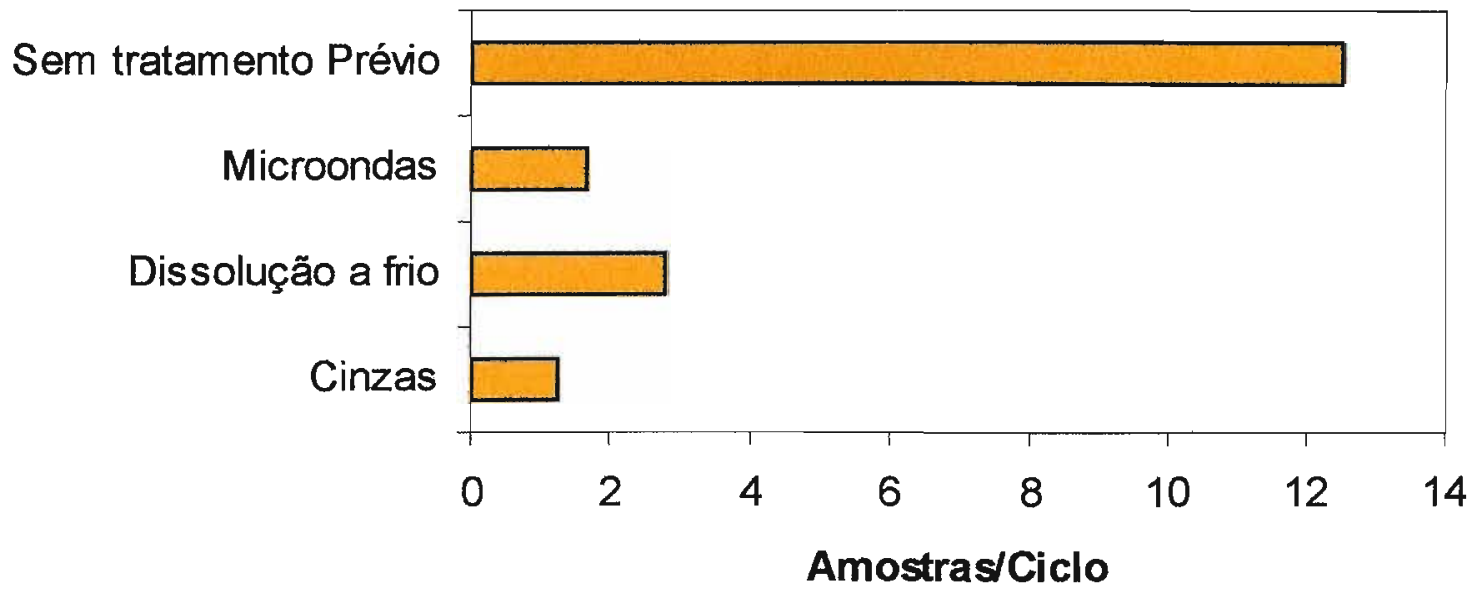

Figura 27: Comparação dos métodos de dissolução quanto a freqüência analítica 


\subsection{Parâmetros Instrumentais do ICP OES:}

Estudos preliminares nas condições operacionais usuais do ICP OES (Tabela 11), mostraram que para todas as linhas analíticas investigadas houve alteração do sinal de intensidade da amostra relativamente à solução aquosa de padrão. Nas figuras de 28 a 39 verifica-se o estudo da alteração no sinal analítico quando comparamos a curva analítica em meio aquoso e a curva de adição de padrão para os elementos de interesse. Verifica-se que quase todos os elementos analisados sofrem efeito de supressão de sinal em presença da matriz e que apenas o As, Se e Zn demonstraram um comportamento de adição padrão com inclinação semelhante à curva analítica aquosa.

Tabela 11: Parâmetros instrumentais de operação usual para o ICP OES *

\begin{tabular}{c|c}
\hline Espectrômetro Simultâneo & CIROS $^{\text {CCD }}$ \\
\hline Potência & $1400 \mathrm{~W}$ \\
Freqüência & $27,12 \mathrm{MHz}$ \\
Fluxo de Ar refrigerante & $12 \mathrm{~L} \mathrm{~min}^{-1}$ \\
Fluxo de Ar auxiliar & $1,2 \mathrm{~L} \mathrm{~min}^{-1}$ \\
Fluxo de Ar de arraste & $1,0 \mathrm{~mL} \mathrm{~min}^{-1}$ \\
Introdução de Amostra & $2 \mathrm{~mL} \mathrm{~min}^{-1}$ \\
\hline
\end{tabular}

\footnotetext{
* Verificar no anexo III o estudo fatorial do ajuste dos parâmetros operacionais.
} 
Inicialmente, imaginou-se que este efeito de supressão do sinal analítico (verificado pelas diferentes inclinações das curvas analíticas) fora devido à introdução da amostra sem o prévio tratamento e que a matriz carbonácea era a responsável por estes efeitos.

A natureza e a causa do efeito de matriz é bastante discutida mas, no caso da análise por ICP OES, vários autores ${ }^{90}$ reportam um tipo de efeito de matriz típico causado por espécies concomitantes com matrizes orgânicas ou com elementos facilmente ionizáveis, que podem contribuir modificando a intensidade da linha analítica, quando se considera uma matriz complexa, o que seria perfeitamente aceitável, pois a natureza das amostras de adoçante dietético é complexa. Esta modificação no sinal analítico poderia ser causada por alterações físicas no meio, como viscosidade e tensão superficial, que provocariam mudanças na taxa de inserção de amostra no plasma91. 


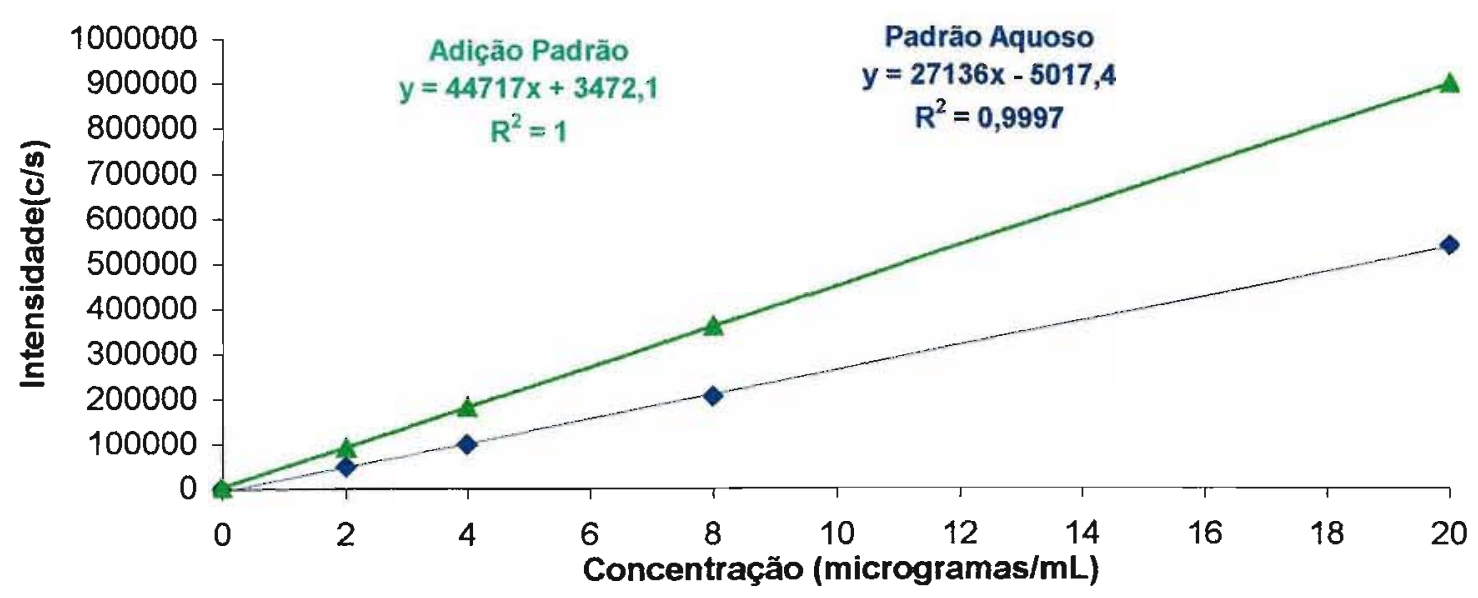

Figura 28: Curvas Analíticas do Aluminio (394 nm)

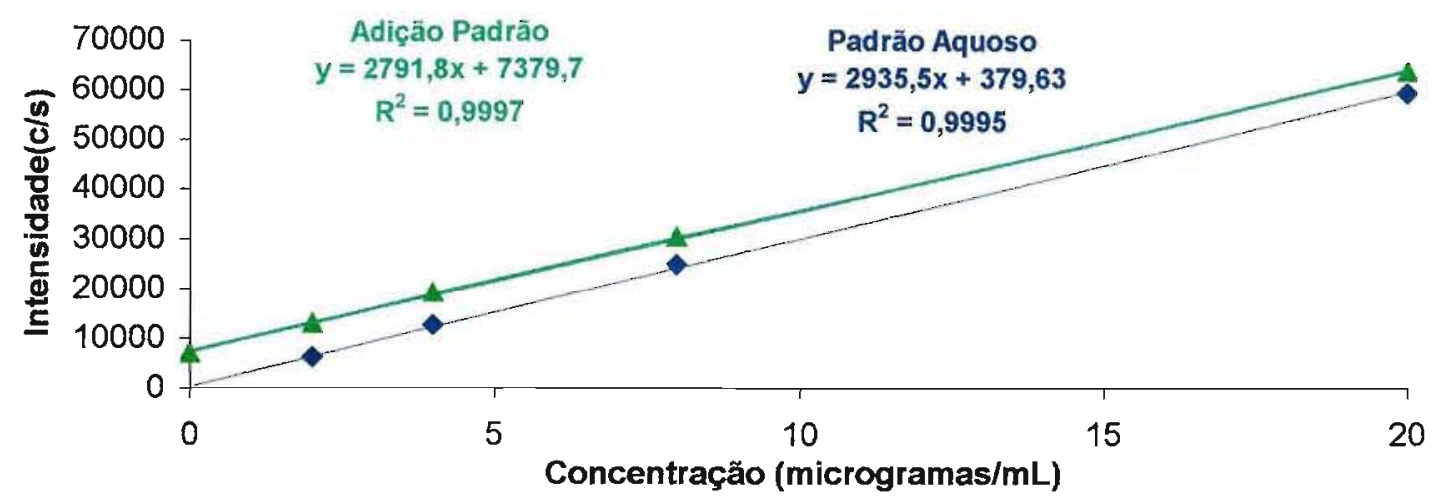

Figura 29: Curvas Analíticas do Arsênio (193,759nm)

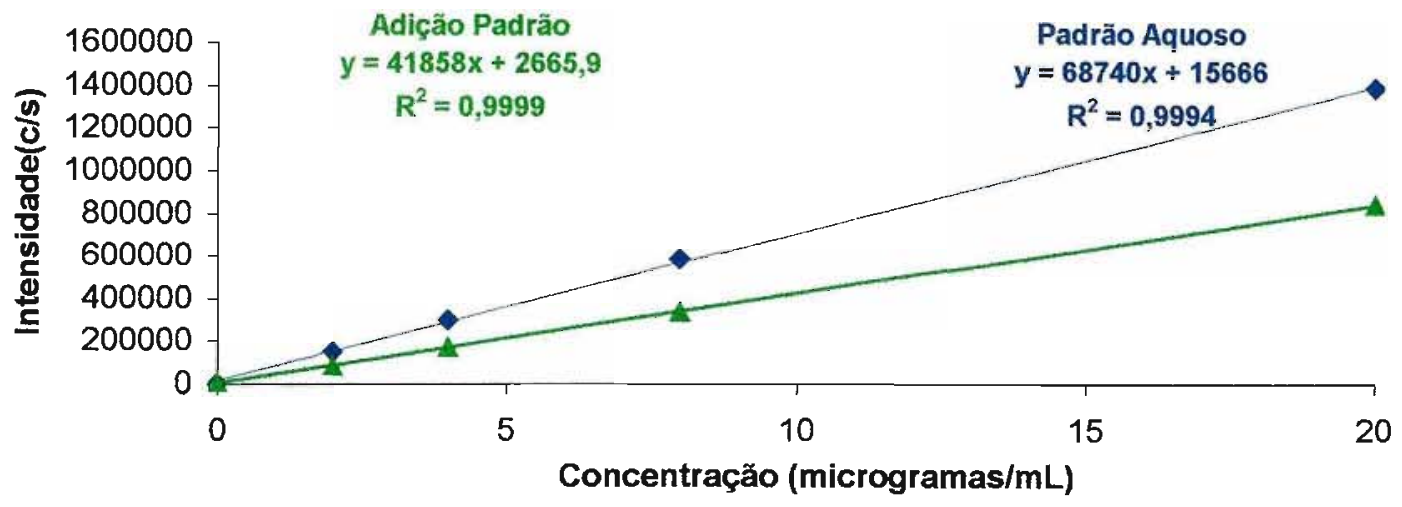

Figura 30: Curvas Analíticas do Cádmio (226,502 nm) 

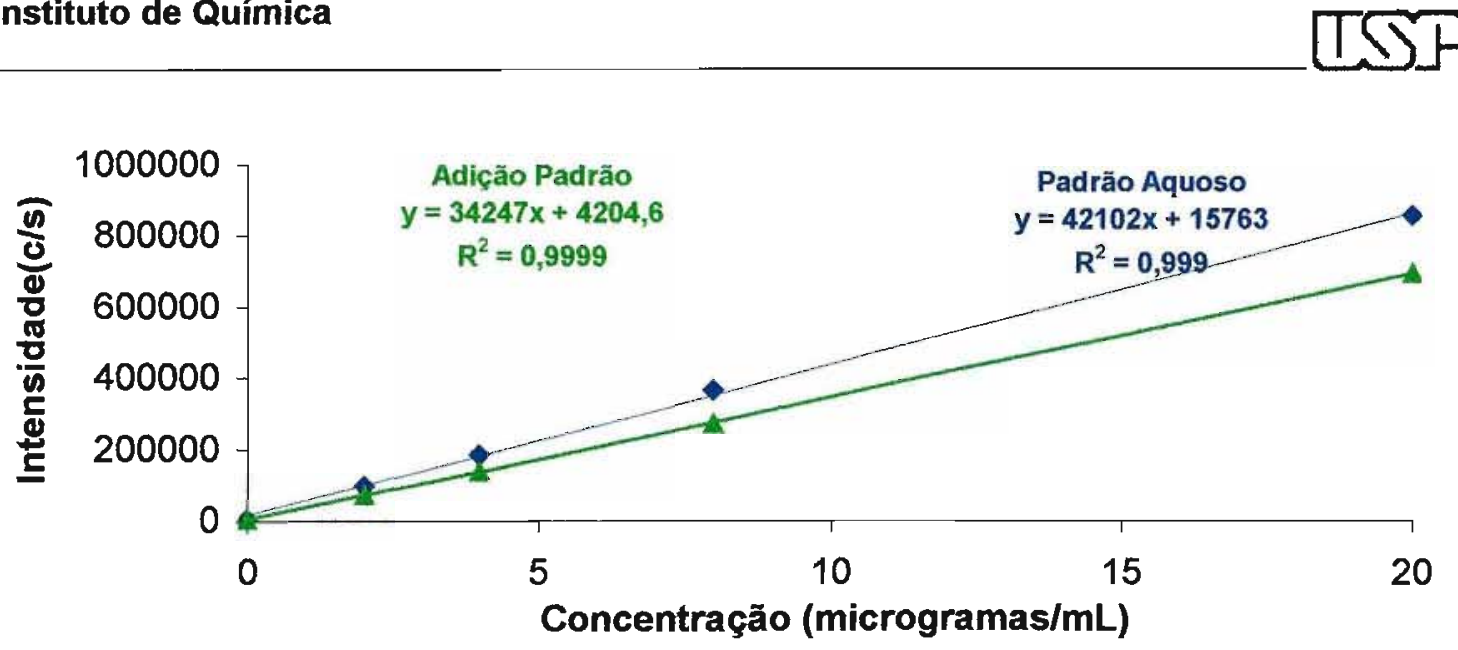

Figura 31:Curvas Analíticas do Cromo (205,552 nm).

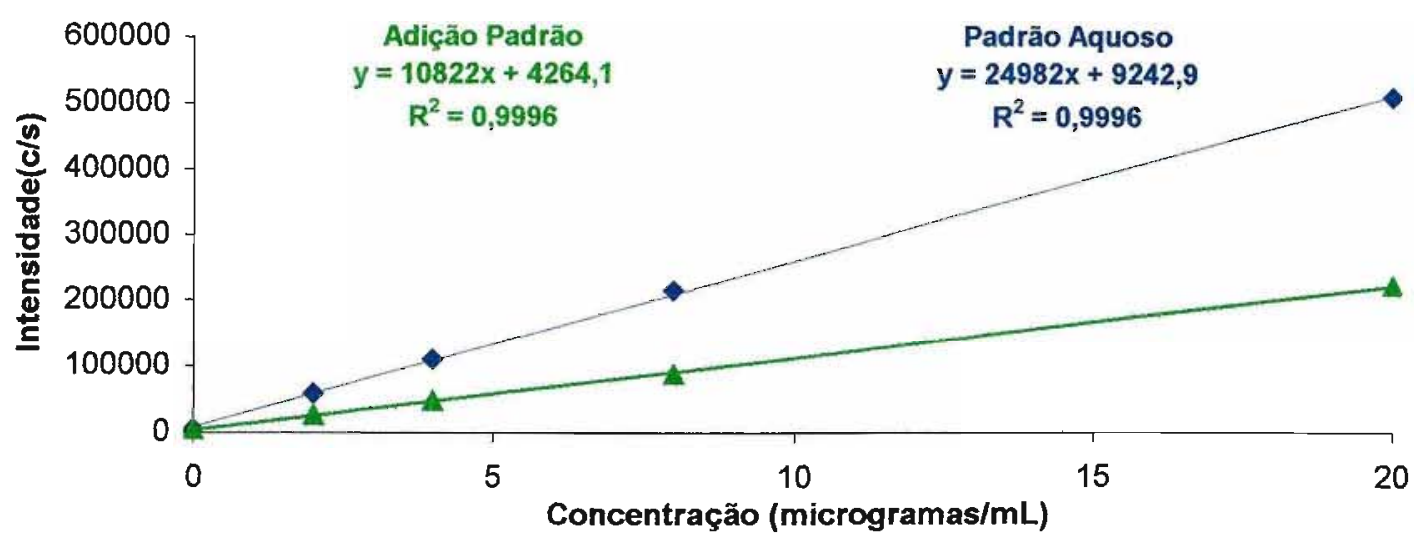

Figura 32:Curvas Analíticas do Cobre $(224,700 \mathrm{~nm})$,

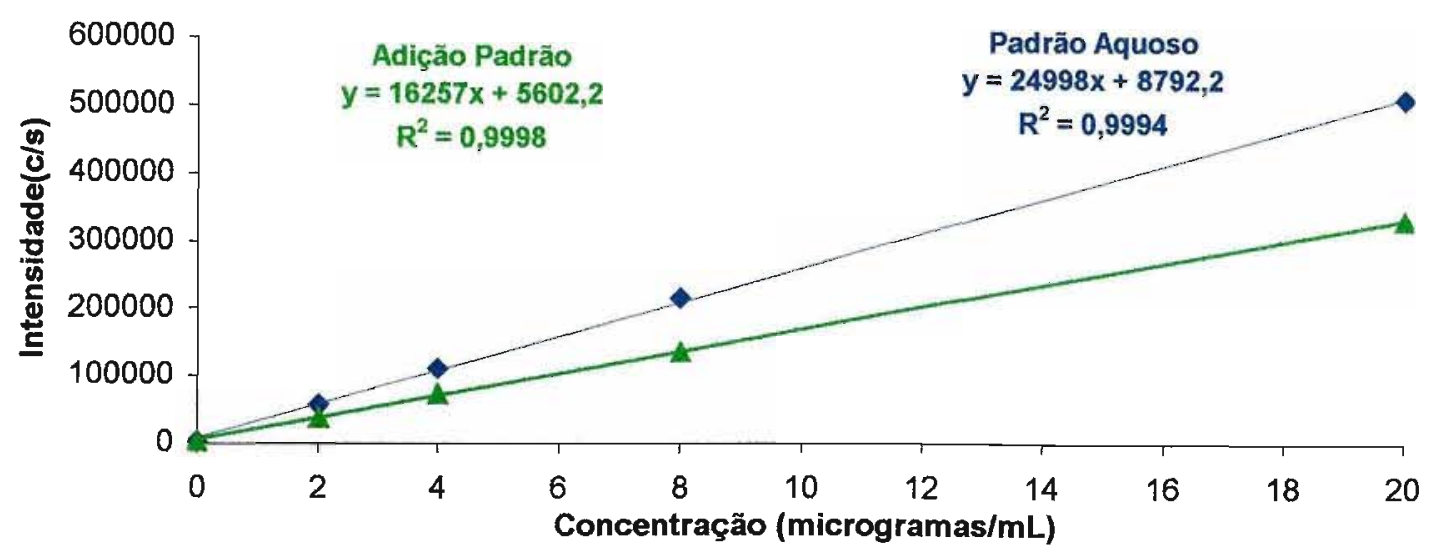

Figura 33:Curvas Analíticas do Ferro $(261,187 \mathrm{~nm})$. 


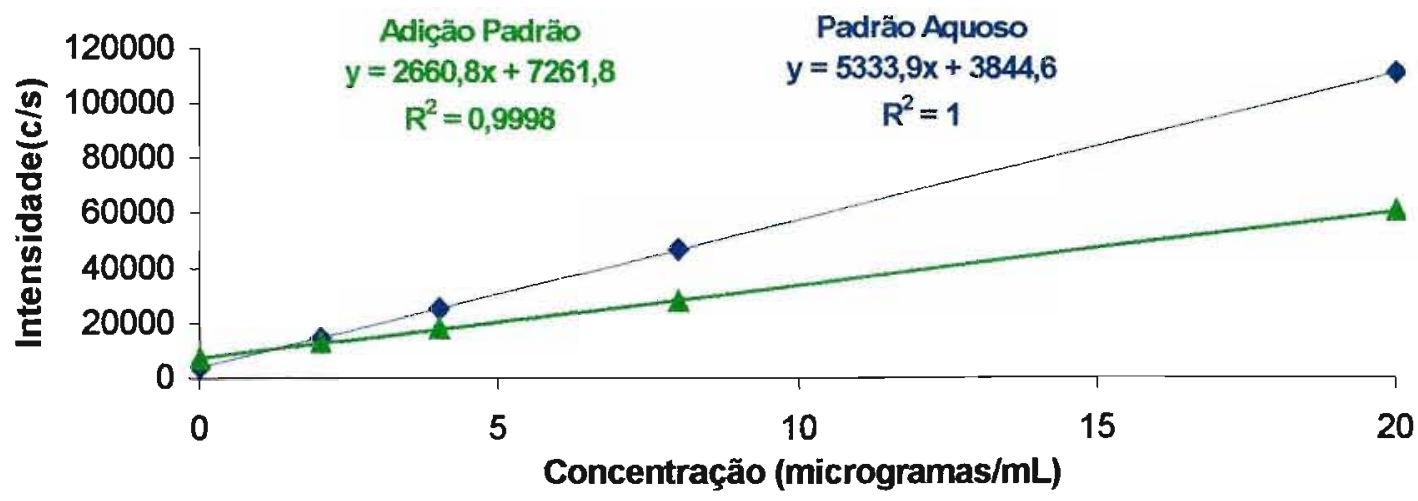

Figura 34: Curvas Analíticas do Mercúrio (194,227nm).

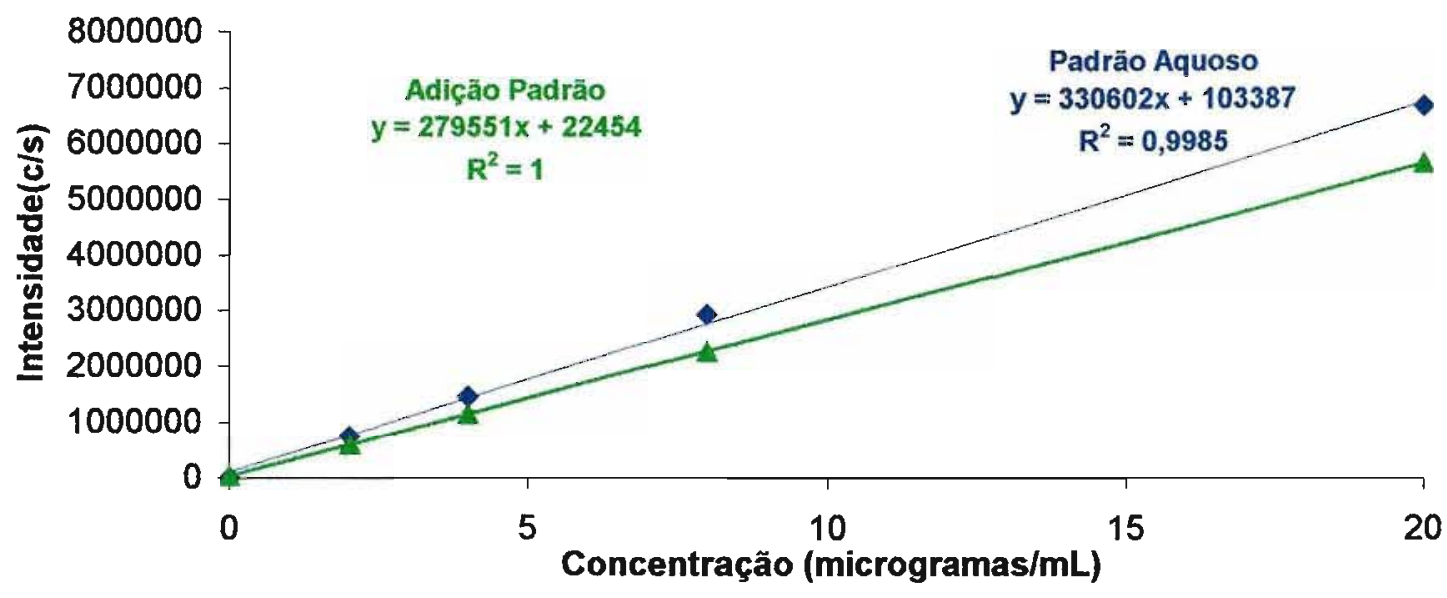

Figura 35: Curvas Analíticas do Manganês (257,610nm).

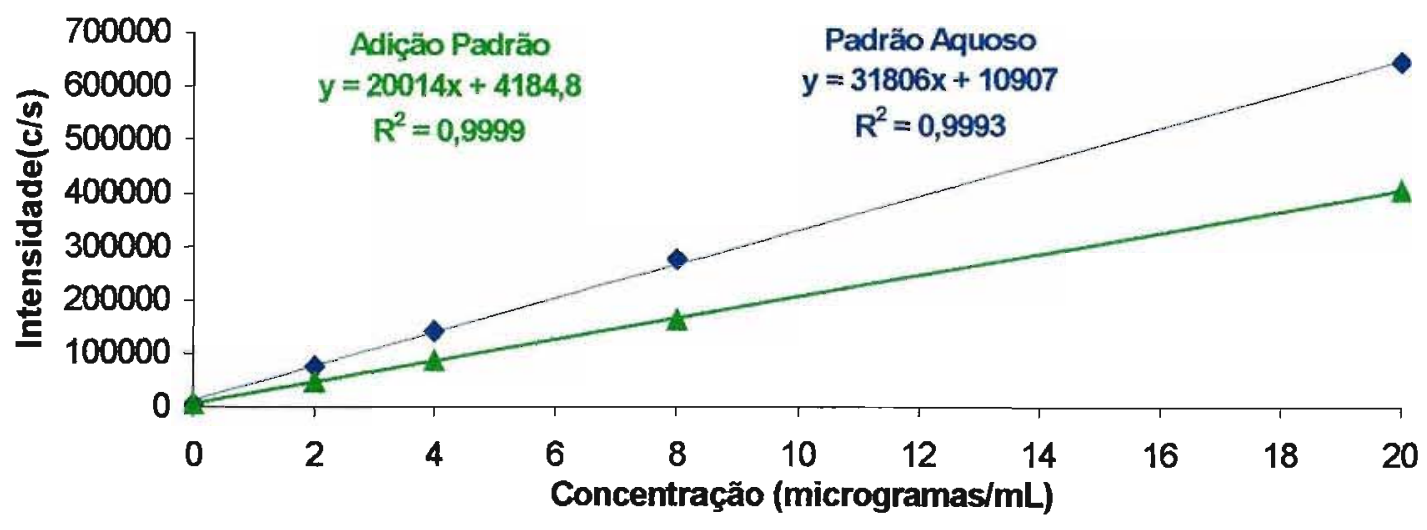

Figura 36: Curvas Analíticas do Níquel $(221,648 \mathrm{~nm})$. 


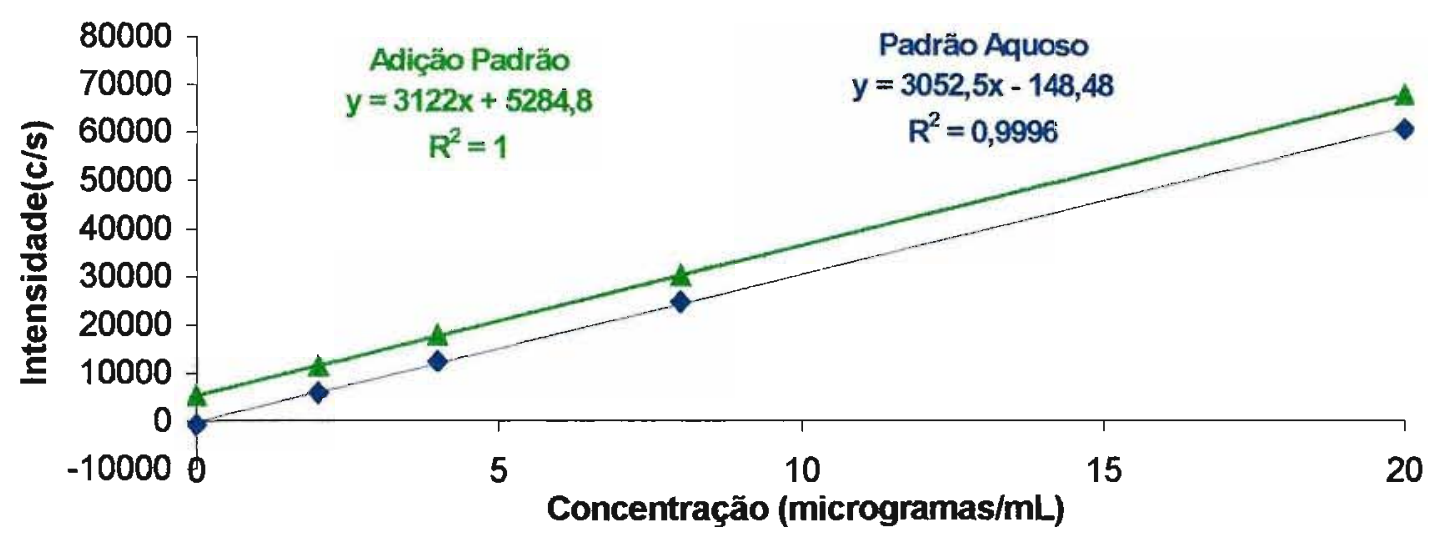

Figura 37: Curvas Analiticas do Selênio $(203,985 \mathrm{~nm})$.

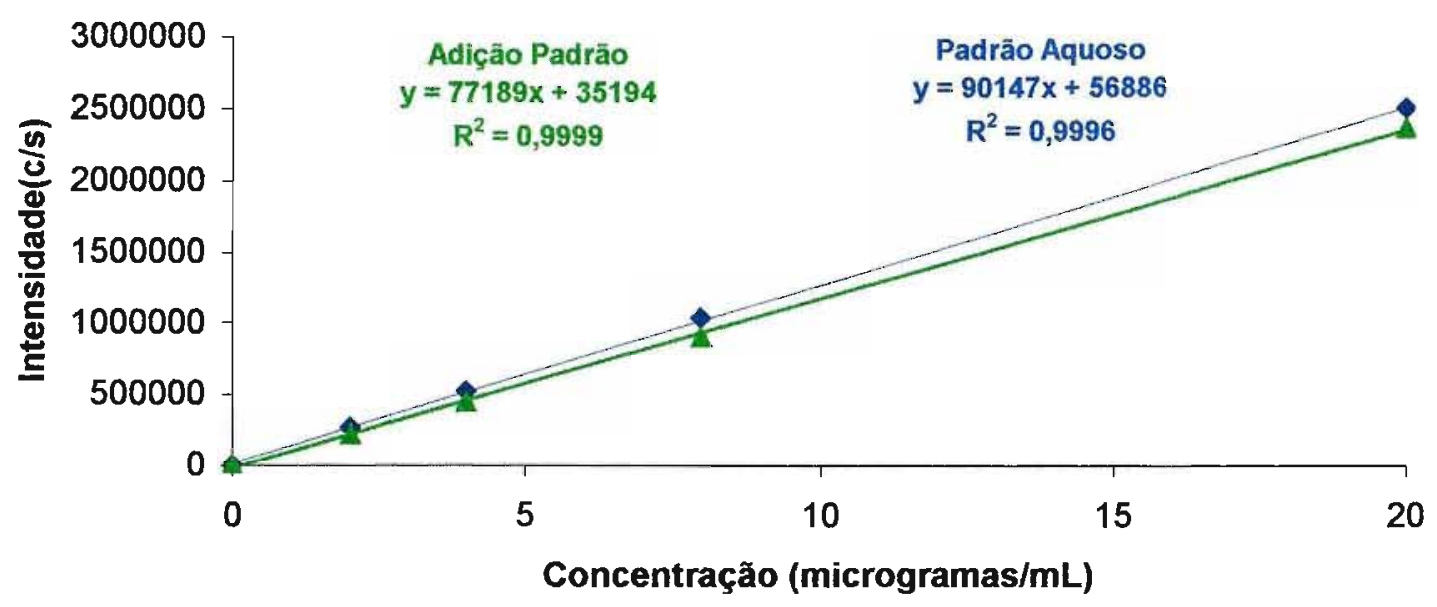

Figura 38: Curvas Analíticas do Zinco $(213,856 \mathrm{~nm})$.

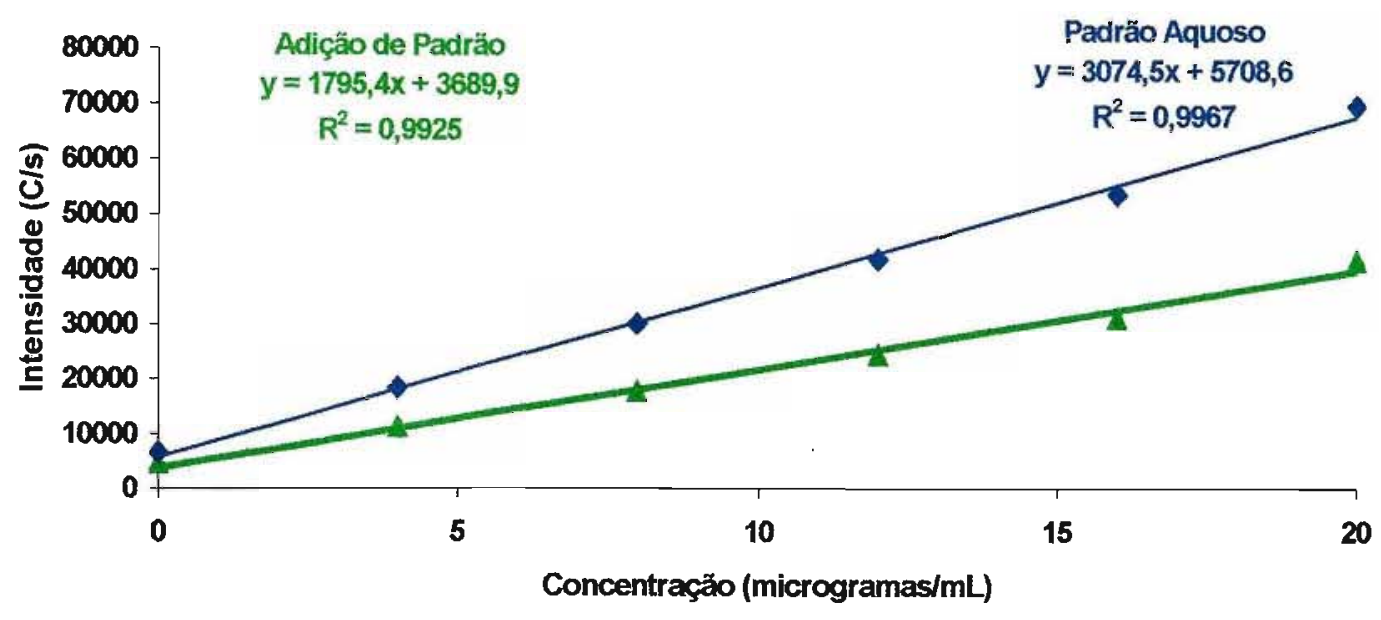

Figura 39: Curvas Analíticas do Chumbo (217,000 nm). 
Para investigar se o efeito de supressão de sinal verificado na análise sem o tratamento prévio da amostra fora devido à matriz ou à otimização dos parâmetros analíticos (Potência, Pressão do Nebulizador, Vazão da Bomba e Distância axial da tocha) foram realizados alguns testes para melhor compreender estes efeitos e tentar minimizar tanto quanto possivel este tipo de interferência.

Se os efeitos observados fossem devido à matriz carbonácea da formulação dos adoçantes, estes efeitos não seriam verificados, quando efetuada a dissolução ácida em microondas ou o resíduo de cinzas com destruição da fração orgânica. Foi feita a determinação do carbono residual segundo GOUVEIA et al. e verificou-se a média de $7,4 \%$ de carbono residual para o procedimento em microondas e a média de 0,99\% para a determinação do resíduo de cinzas e, ainda assim, houve modificações no sinal analítico para a determinação elementar ${ }^{92}$.

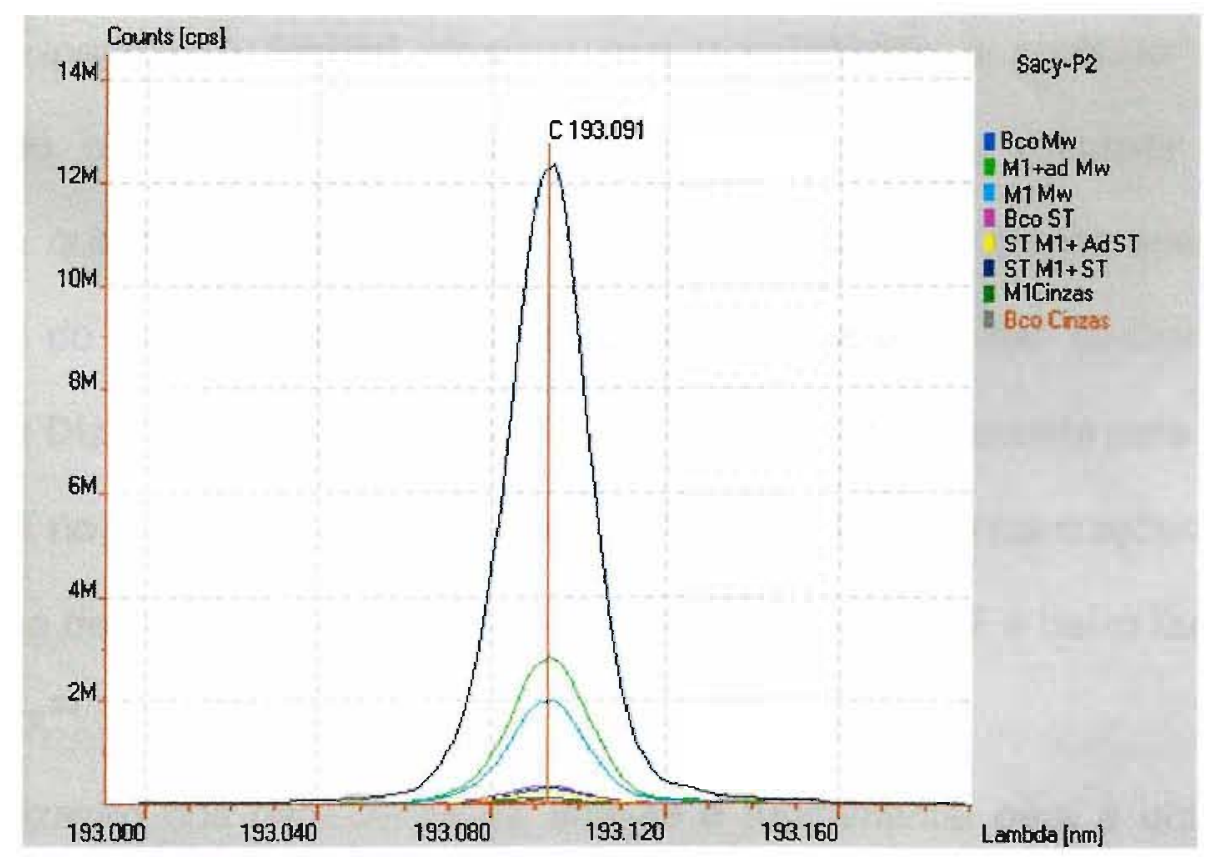

Figura 40: Determinação de Carbono Residual para a amostra SACY-L2 para os métodos de preparação de amostras: Resíduo de Cinzas, Microondas e sem o tratamento prévio. 
Verificou-se que os vários perfis espectrais, para os elementos de interesse tratados pelos diferentes métodos de dissolução, não mostraram mudanças expressivas pela destruição da matriz carbonácea (fig. 40 e anexo V).

Após esta constatação foram realizados testes nas condições de operação, que deveriam ser feitos de modo a produzir o máximo de informação útil no menor tempo possível; assim, propôs-se um experimento fatorial $2^{2}$ com ponto central, onde avaliou-se as razões de intensidade das linhas iônica e atômica do $\mathrm{Mg}$ (indicado no Anexo III) para verificar se qualquer mudança no sinal analítico é conseqüência de variações nas propriedades do plasma, para explicar os efeitos de interferência.

Com o experimento fatorial (anexo III) definiram-se as novas condições de operação, mostradas na tabela 12, minimizando as interferências de matriz para a determinação desejada.

O experimento fatorial mostrou que aumentando a potência de RF e diminuindo o fluxo do nebulizador há uma melhora na resposta $\mathrm{Mgll} / \mathrm{Mgl}$, indicando que nestas condições as linhas atômicas ficam menos suscetíveis a variações do sinal analítico com a presença da matriz. $E$ isso concorda com o estudo de DUBUISSON et al. que diz que a condição mais robusta para minimizar os efeitos no plasma causados por amostras com altas concentrações de sódio no sistema de introdução de amostra é a alta potência de RF e baixo fluxo de gás carregador $^{93}$.

A otimização dos parâmetros de análise é fundamental para a obtenção de resultados com a melhor exatidão e precisão possível. Para tanto, são realizados testes de varredura de diferentes linhas espectrais de cada elemento, buscando melhor sensibilidade, menores Limites de Detecção (LOD), Limites de 
Quantificação(LOQ) e os parâmetros de regressão para os elementos de interesse.

No Anexo IV têm-se as tabelas com os comprimentos de onda (nm), o Intervalo Linear, o limite de detecção $\left(\mu \mathrm{g} \cdot \mathrm{mL}^{-1}\right)$, o BEC (BlanK Equivalent Concentration), o coeficiente de correlação, o Erro Padrão e os coeficientes da regressão para os elementos de interesse nas condições de análise.

Tabela 12: Parâmetros instrumentais de operação para o ICP OES*

\begin{tabular}{c|c}
\hline Espectrômetro Simultâneo & CIROS $^{\text {CCD }}$ \\
\hline Prequencia & $1400 \mathrm{~W}$ \\
Fluxo de Ar refrigerante & $27,12 \mathrm{MHz}$ \\
Fluxo de Ar auxiliar & $12 \mathrm{~L} \mathrm{~min}^{-1}$ \\
Fluxo de Ar de arraste & $1,0 \mathrm{~L} \mathrm{~min}^{-1}$ \\
Introdução de Amostra & $0,8 \mathrm{~mL} \mathrm{~min}^{-1}$ \\
Nebulizador & $2 \mathrm{~mL} \mathrm{~min}^{-1}$ \\
Camâra de Nebulização & Cross-flow \\
\hline
\end{tabular}

Também, as interferências espectrais não podem ser completamente descartadas, uma vez que podem estar presentes concomitantes nas mais diversas concentrações que podem causar efeitos de sobreposição de sinal ou alteração no fundo (sobreposição de linhas, elevação do fundo, fundo estruturado e emissão de espécies moleculares) que prejudicam a exatidão da determinação.

\footnotetext{
* Verificar no anexo III o estudo fatorial do ajuste dos parâmetros operacionais.
} 
Assim, a determinação em múltiplas linhas analíticas de um mesmo elemento fornece informação suficiente para definir a qualidade do resultado expresso.

\subsubsection{AVAliaçÃo da determinaçÃo EM Múltiplos Comprimentos DE ONDA}

A determinação simultânea, no espectro de 125 a $770 \mathrm{~nm}$, propiciou não apenas a maior aquisição de sinal analítico pelo tempo*, com respeito a linha analítica e ao fundo (BG), mas a rapidez na determinação de múltiplas linhas analíticas do elemento de interesse e uma melhoria extraordinária nos resultados, uma vez que procedimentos matemáticos mais sofisticados tornam-se possiveis,

Assim, o recurso da determinação simultânea do espectro favorece a precisão da determinação, uma vez que vários comprimentos de onda podem ser selecionados, inclusive para um mesmo elemento (figuras 41 a 53) sem aumento no tempo ou no custo de análise. Em decorrência desta implementação há mais informação espectral disponível e pode-se fazer a deterninação na linha espectral mais sensível ou em todas as linhas analíticas com sensibilidade adequada e livre de interferência espectral. A vantagem nesta determinação em múltiplos comprimentos de onda é que se tem mais informação sobre os efeitos de matriz ou de interferência espectral e assim pode-se fazer a seleção de uma ou mais linhas adequadas a determinação e facilitar o procedimento de análise de uma matriz mais complexa, como é o caso dos adoçantes dietéticos, sem o tratamento prévio da matriz,

Os procedimentos de múltiplas linhas analíticas foram primeiramente utilizados na seleção de comprimentos de onda para determinações quantitativas, mas pode ser empregado na correção de efeitos de fundo contínuo ou

\footnotetext{
"Na determinação seqüencial o acréscimo de elemento ou de um novo comprimento de onda implica no aumento do tempo necessário à determinação.
} 
estruturado. Podem também corrigir efeitos de matriz, mas os resultados devem ser verificados com procedimentos de "matrix maching" (simulação de matriz) ou adição de padrão ${ }^{76}$.

Assim, comparou-se os resultados de adição e recuperação para as amostras de adoçante dietético sem o tratamento prévio e com a determinação de múltiplos comprimentos de onda. Nas figuras 54 e 55, apresentam-se as médias das recuperações obtidas para adições de $0,1,0,5$ e $1,0 \mu \mathrm{g} \mathrm{mL} \mathrm{L}^{-1}$ para as amostras de Sacy-P2, que mostrou ser uma das matrizes mais complexas.

Neste trabalho a seleção das linhas analíticas mais adequadas seguiu o que recomenda VAN VEEN, isto é, verificam-se os valores das recuperações obtidas, os coeficientes de correlação das curvas analíticas e das curvas de adição padrão, o erro padrão, o BEC e o LOD para cada uma das 74 linhas analíticas investigadas (tabelas no anexo IV).

Das 74 linhas analíticas investigadas, 36 mostraram-se adequadas a determinação e estão relacionadas nas figuras 54 e 55.

Segundo GILBERT os critérios de aceitação para a comparação entre métodos de análise ou para a validação de um novo método, quando não há valores de precisão estabelecidos, pode ser calculado segundo a equação de Horwitz, que foi obtida pelo estudo em colaboração de cerca de 3000 laboratórios $^{94}$. Na equação de Horwitz, tem-se o Desvio Padrão Relativo em função da faixa de concentração investigada independentemente da técnica analítica e do elemento de interesse a ser determinado.

$$
\operatorname{RSD}_{\mathrm{R}}=2^{(1-0,5 \log \mathrm{C})} \quad \text { Equação de Horwitz }
$$


Tabela 13: Desvio Padrão Relativo Aceitável para a determinação em função da concentração do elemento de interesse.

\begin{tabular}{c|c|c}
\hline Concentração & Unidade & RSDR \\
\hline 1 & $100 \%$ & 2,0 \\
\hline $10^{-1}$ & & 2,8 \\
\hline $10^{-2}$ & $1 \%$ & 4,0 \\
\hline $10^{-3}$ & & 5,6 \\
\hline $10^{-4}$ & & 8,0 \\
\hline $10^{-5}$ & & 11,0 \\
\hline $10^{-6}$ & $\mathrm{mg} \mathrm{kg}^{-1}$ & 16,0 \\
\hline $10^{-7}$ & & 23,0 \\
\hline $10^{-8}$ & & 32,0 \\
\hline $10^{-9}$ & $\mu g \mathrm{~kg}^{-1}$ & 45,0 \\
\hline
\end{tabular}

Sendo assim para o nível de concentração investigada é aceitável até $20 \%$ de desvio relativo para a determinação e, que foi obedecido para a grande maioria dos elementos e comprimentos de onda investigados. 


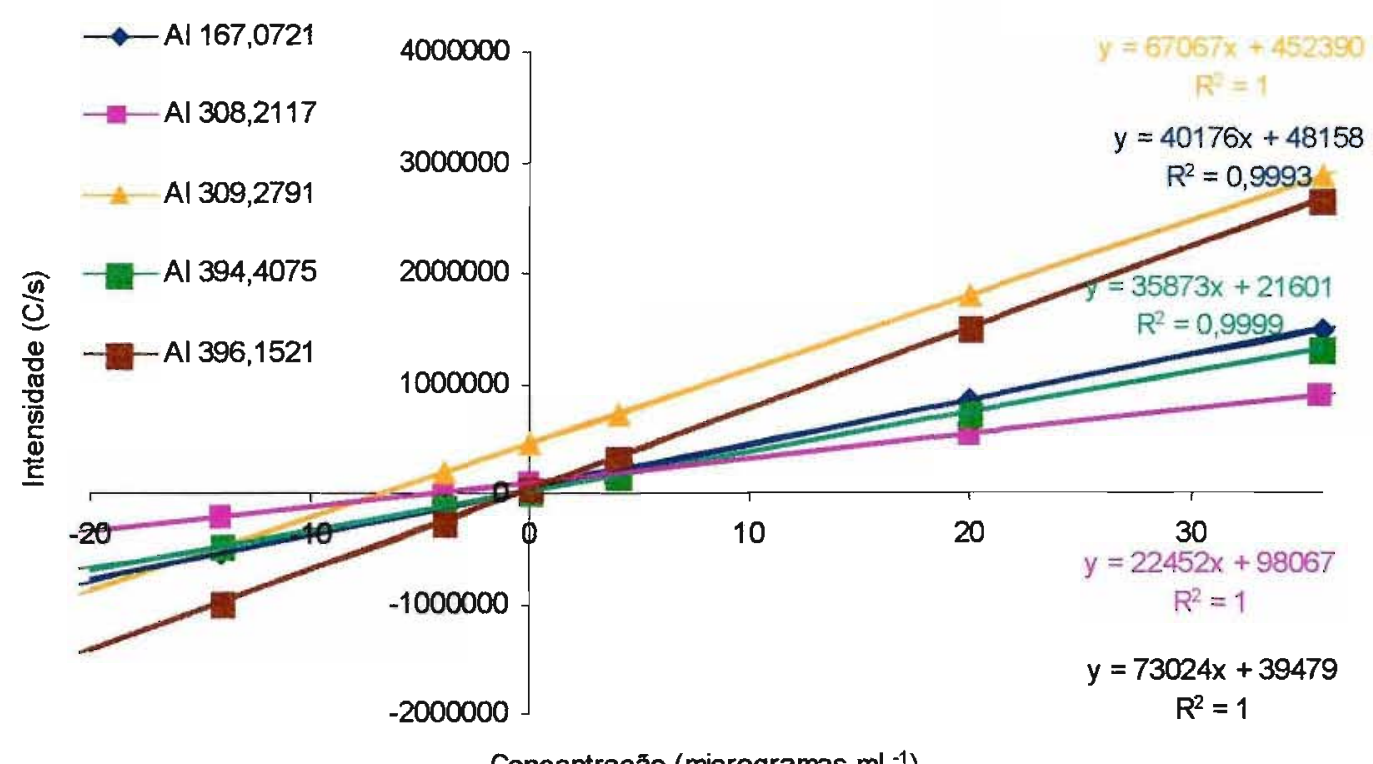

Concentraçăo (microgramas $\mathrm{mL}^{-1}$ )

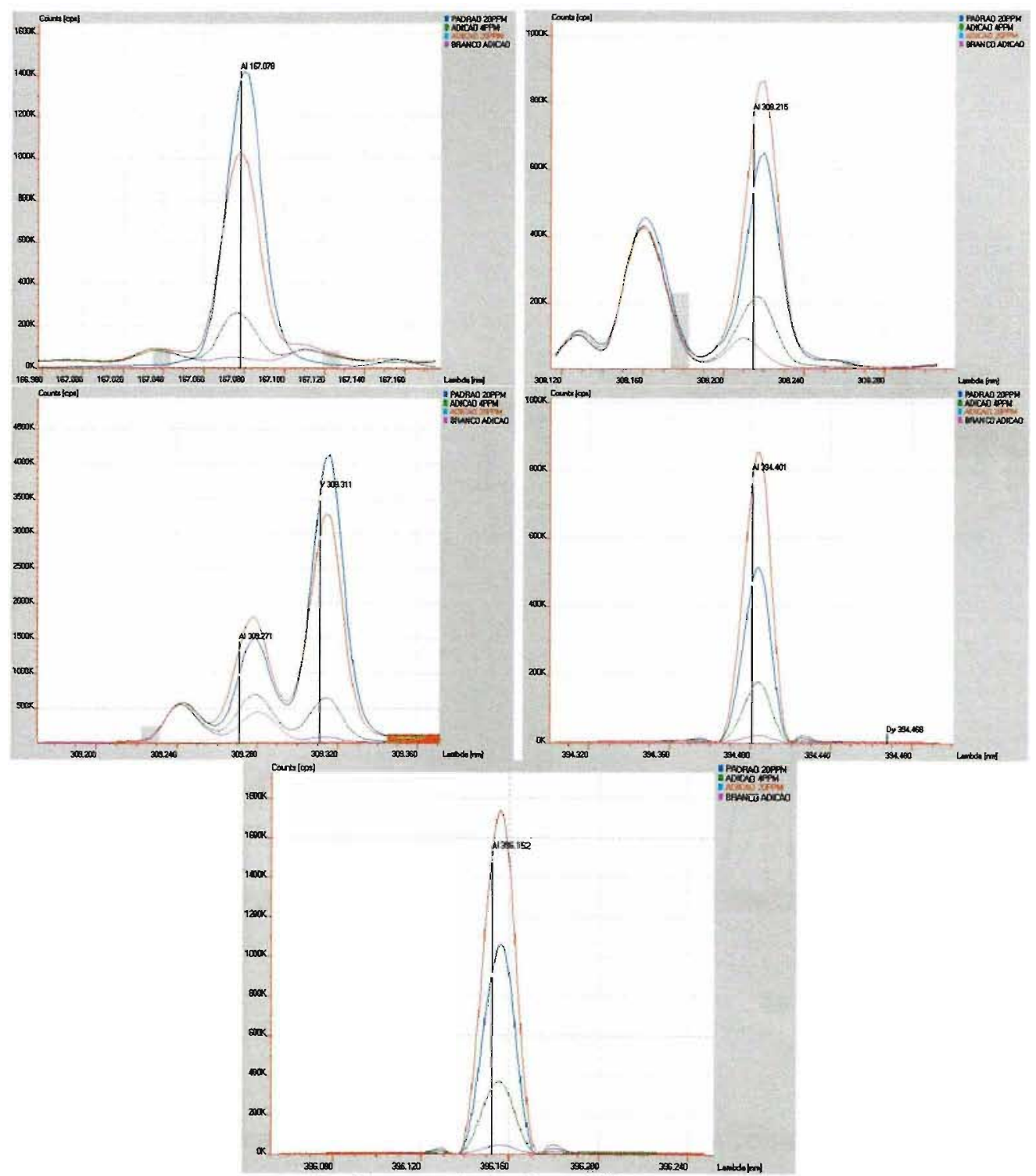

Figura 41: Curvas Analíticas e Perfis espectrais de múltiplos comprimentos de onda do Alumínio 

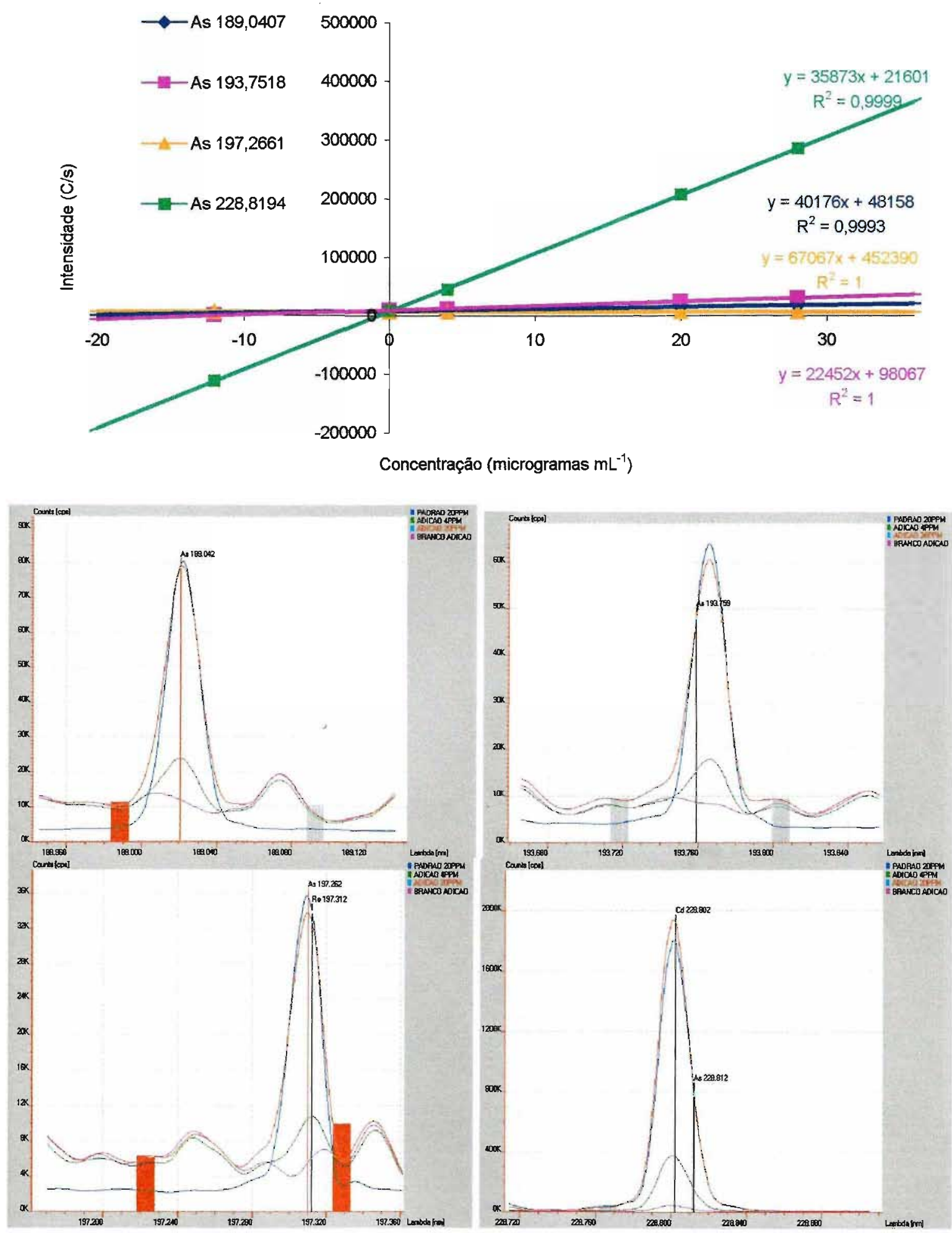

Figura 42: Curvas Analíticas e Perfis espectrais de múltiplos comprimentos de onda do Arsênio. 


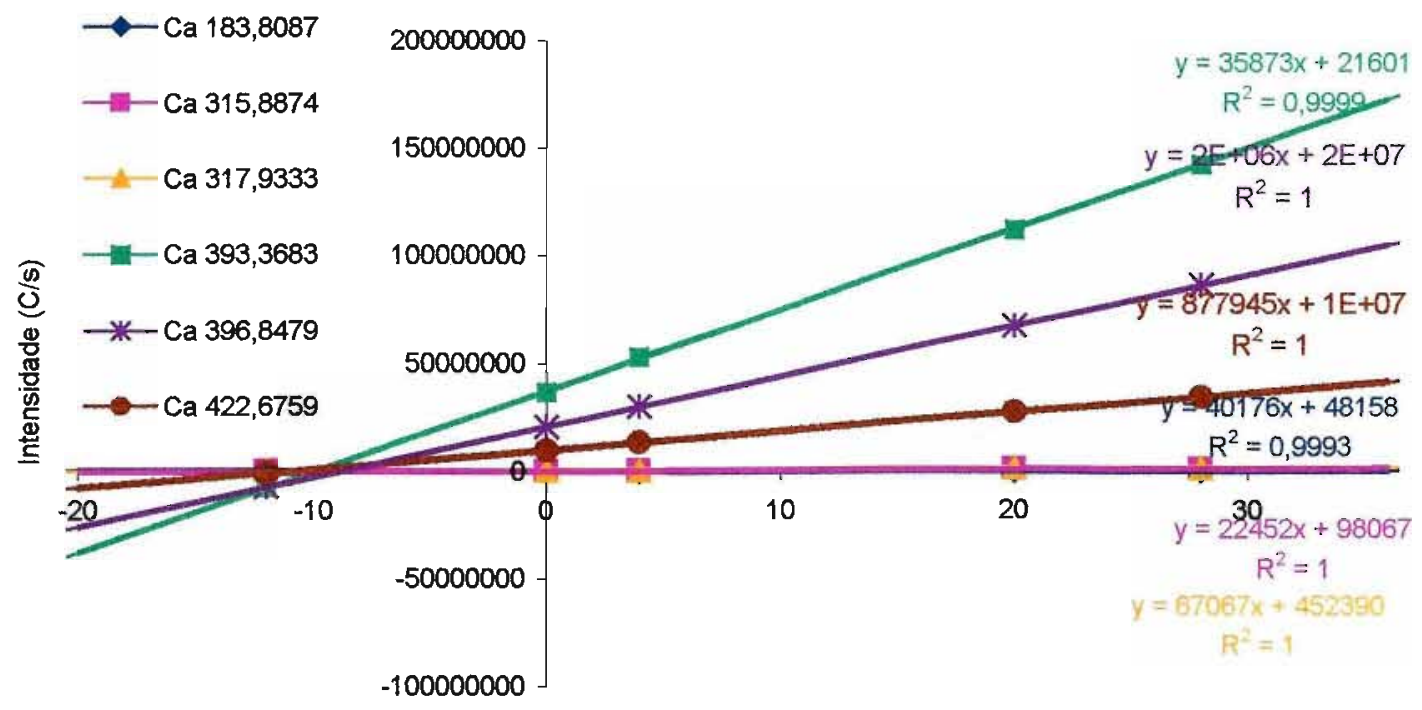

Concentraçăo (microgramas $\mathrm{mL}^{-1}$ )
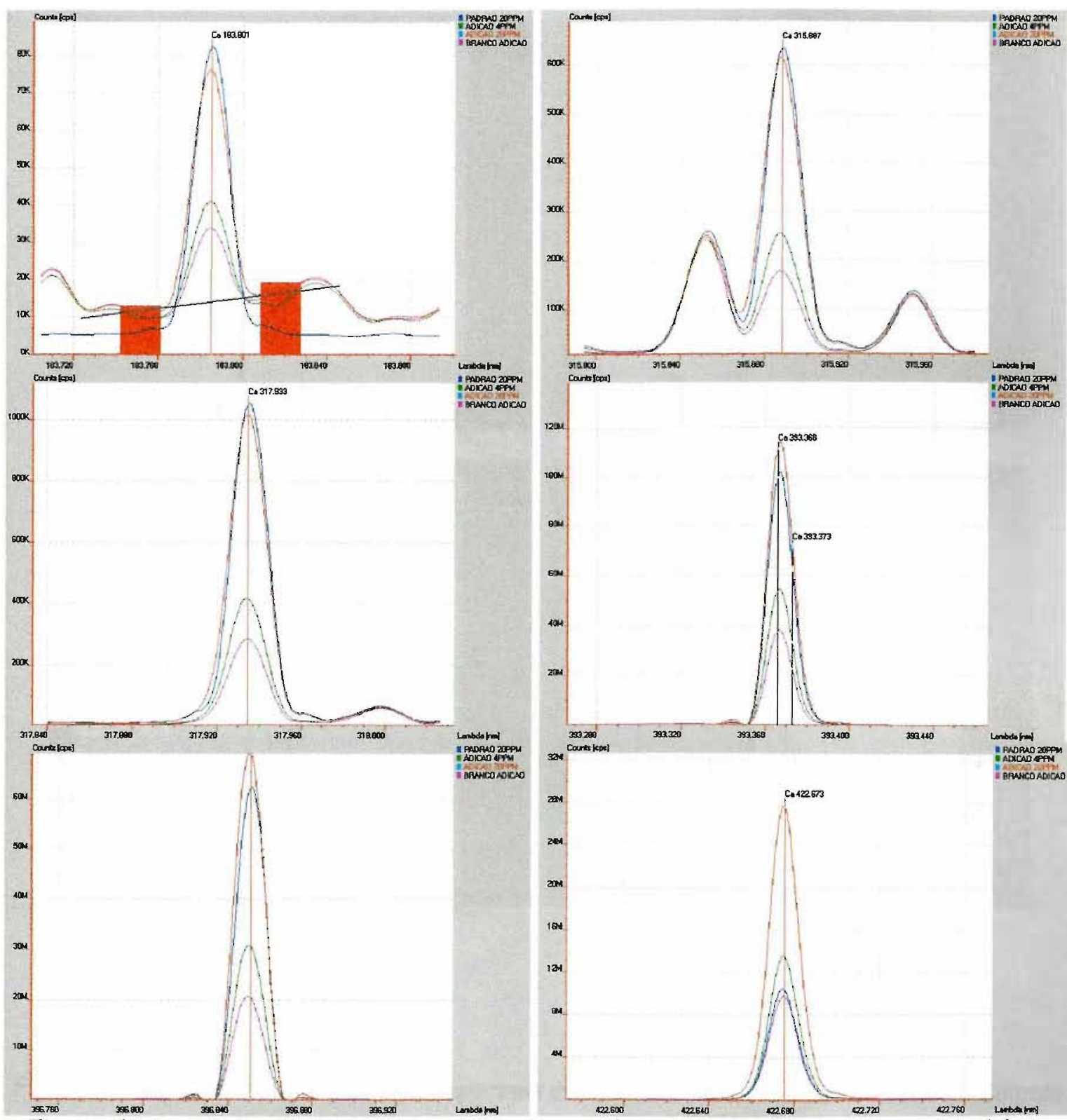

Figura 43: Curvas Analíticas e Perfis espectrais de múltiplos comprimentos de onda do Cálcio 

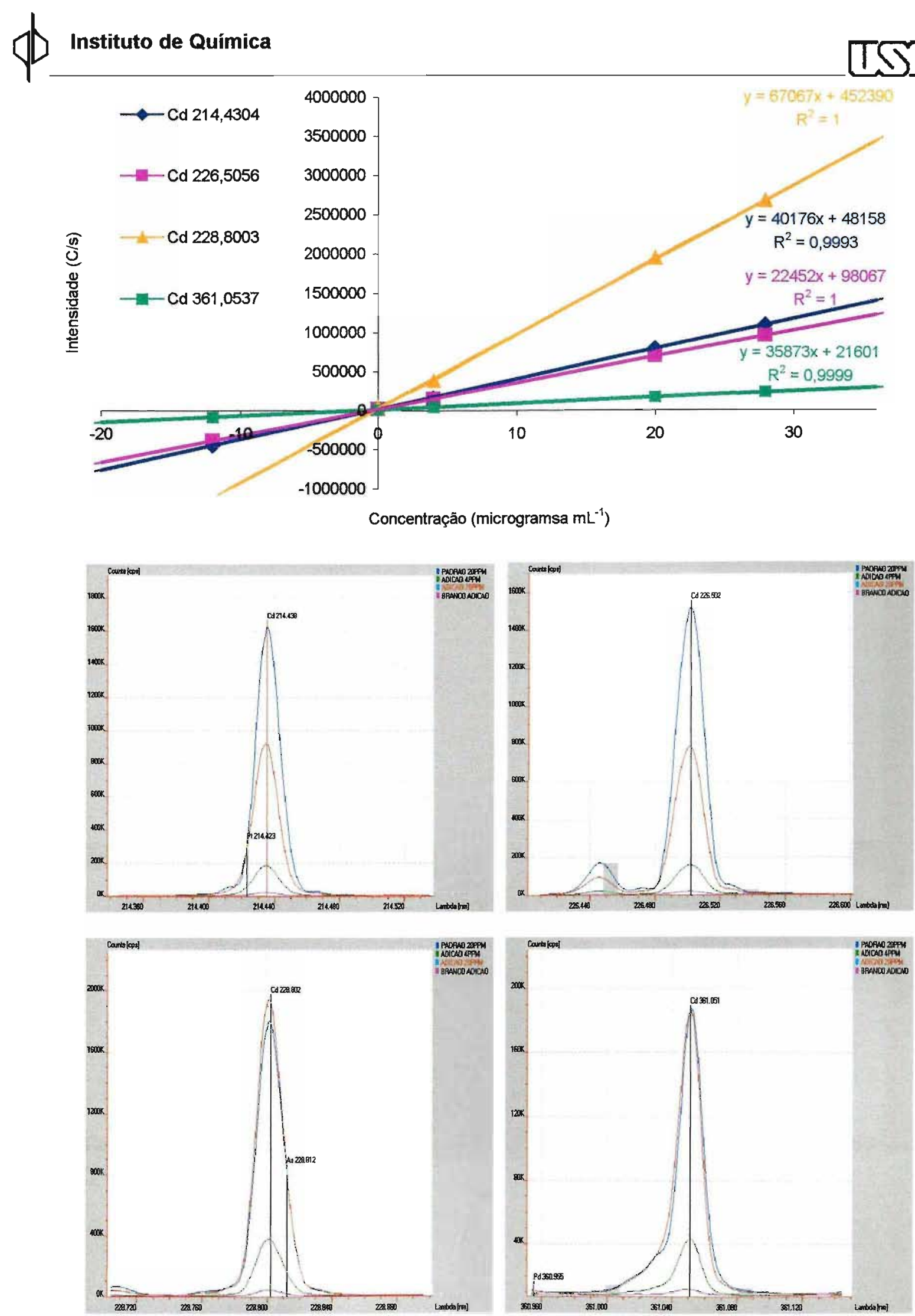

Figura 44: Curvas Analíticas e Perfis espectrais de múltiplos comprimentos de onda do Cádmio 
$\phi$ Instituto de Química

TSP
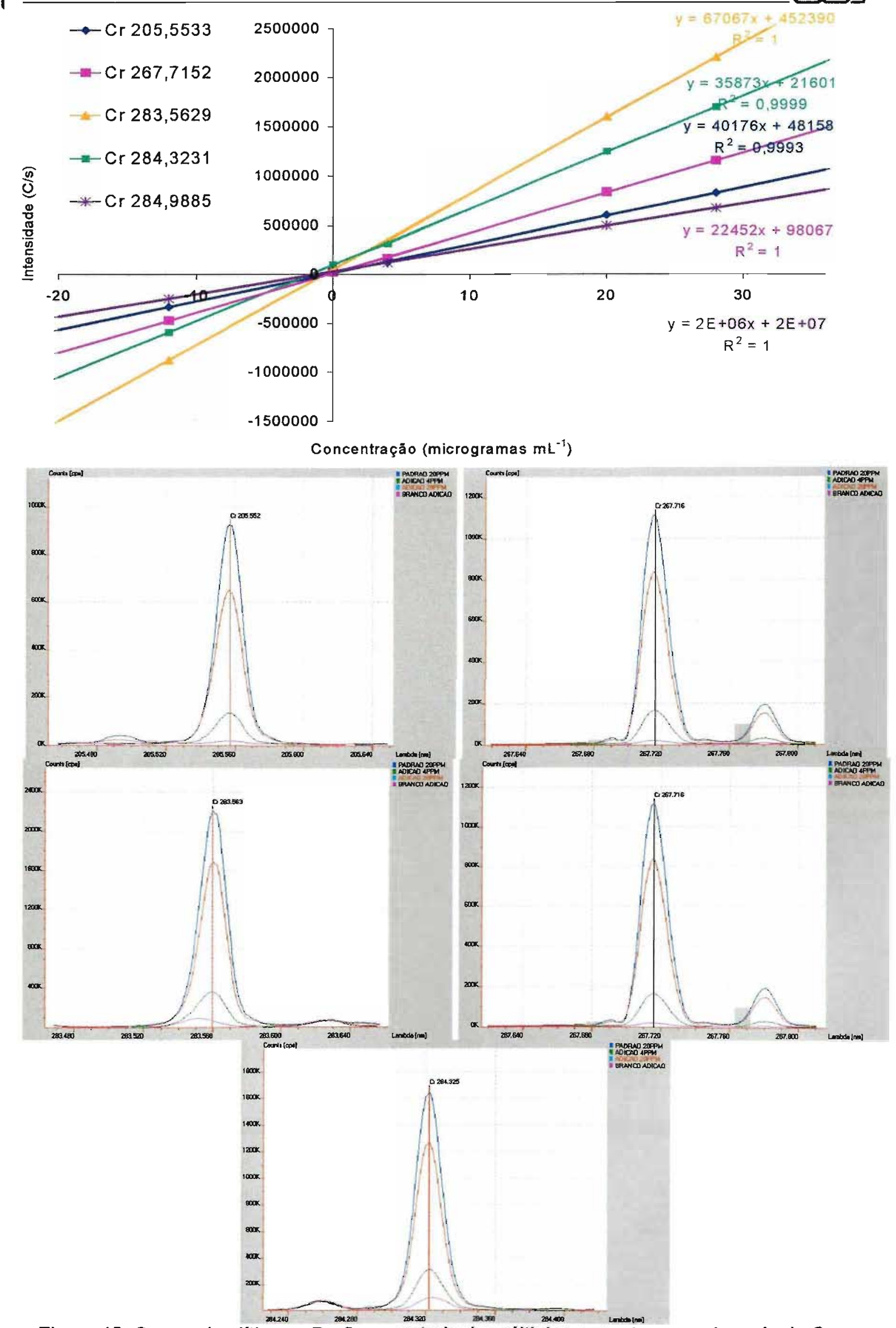

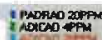

Figura 45: Curvas Analíticas e Perfis espectrais de múltiplos comprimentos de onda do Cromo 


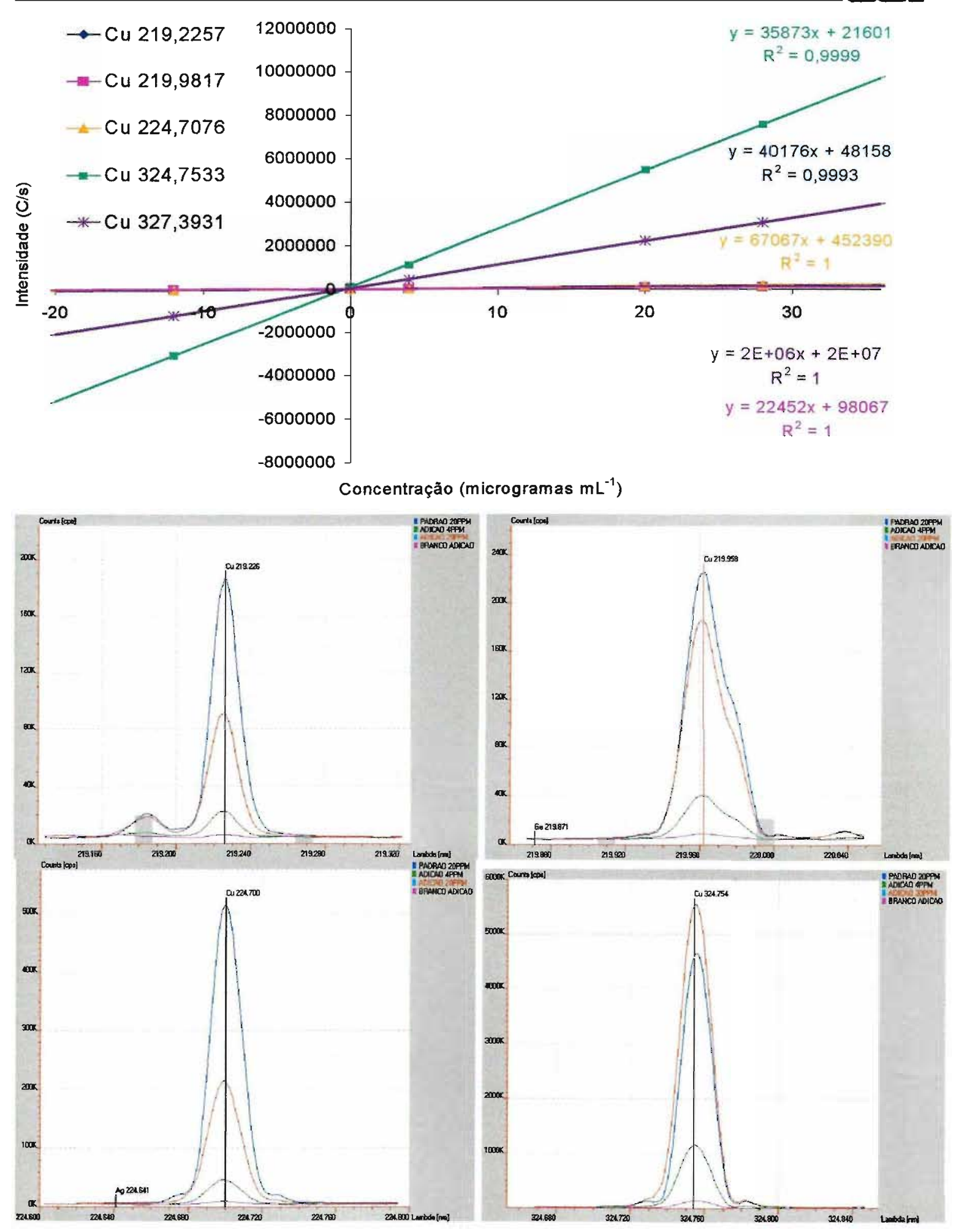

Figura 46: Curvas Analíticas e Perfis espectrais de múltiplos comprimentos de onda do Cobre. 
1

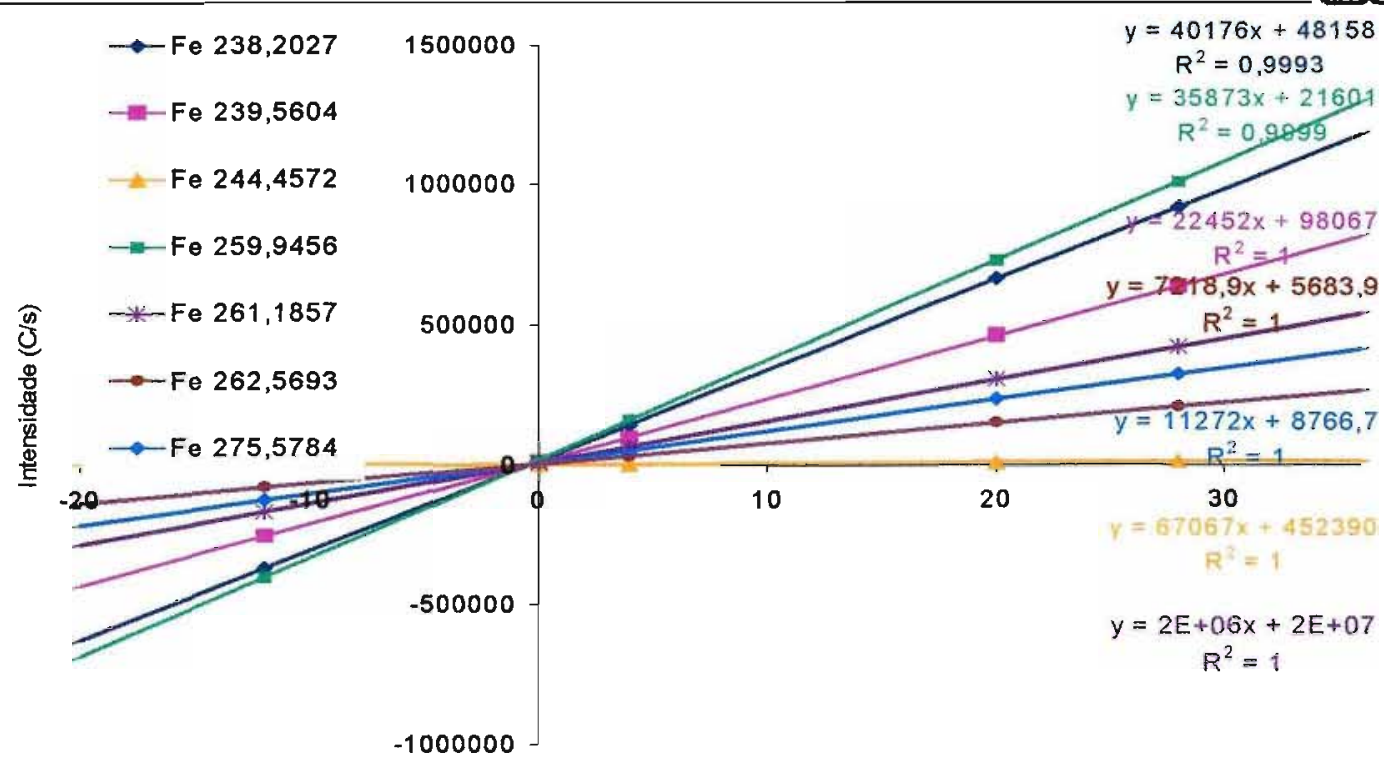

Concentraçāo (microgramas $\mathrm{mL}^{-1}$ )
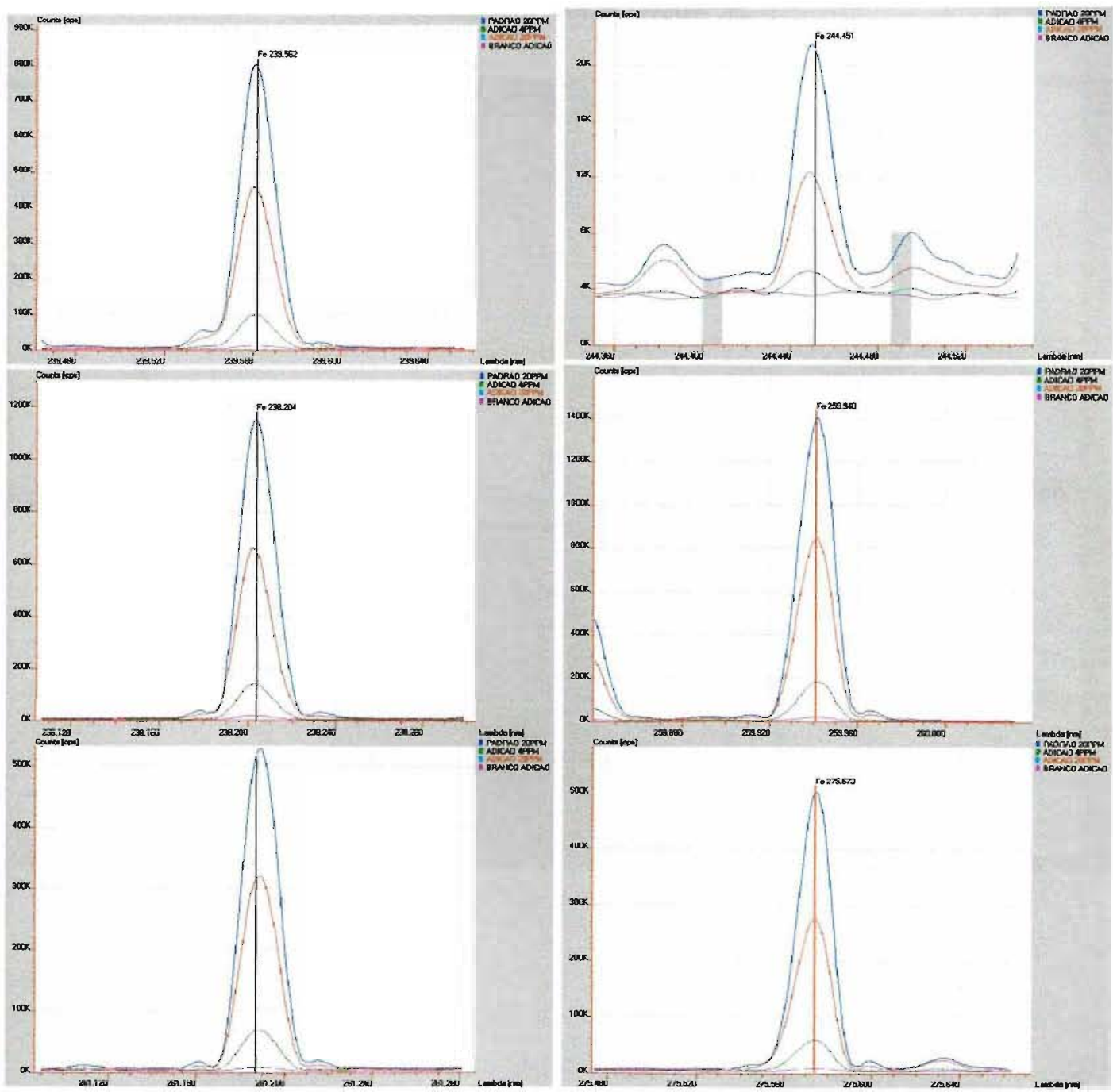

Figura 47: Curvas Analíticas e Perfis espectrais de múltiplos comprimentos de onda do Ferro 

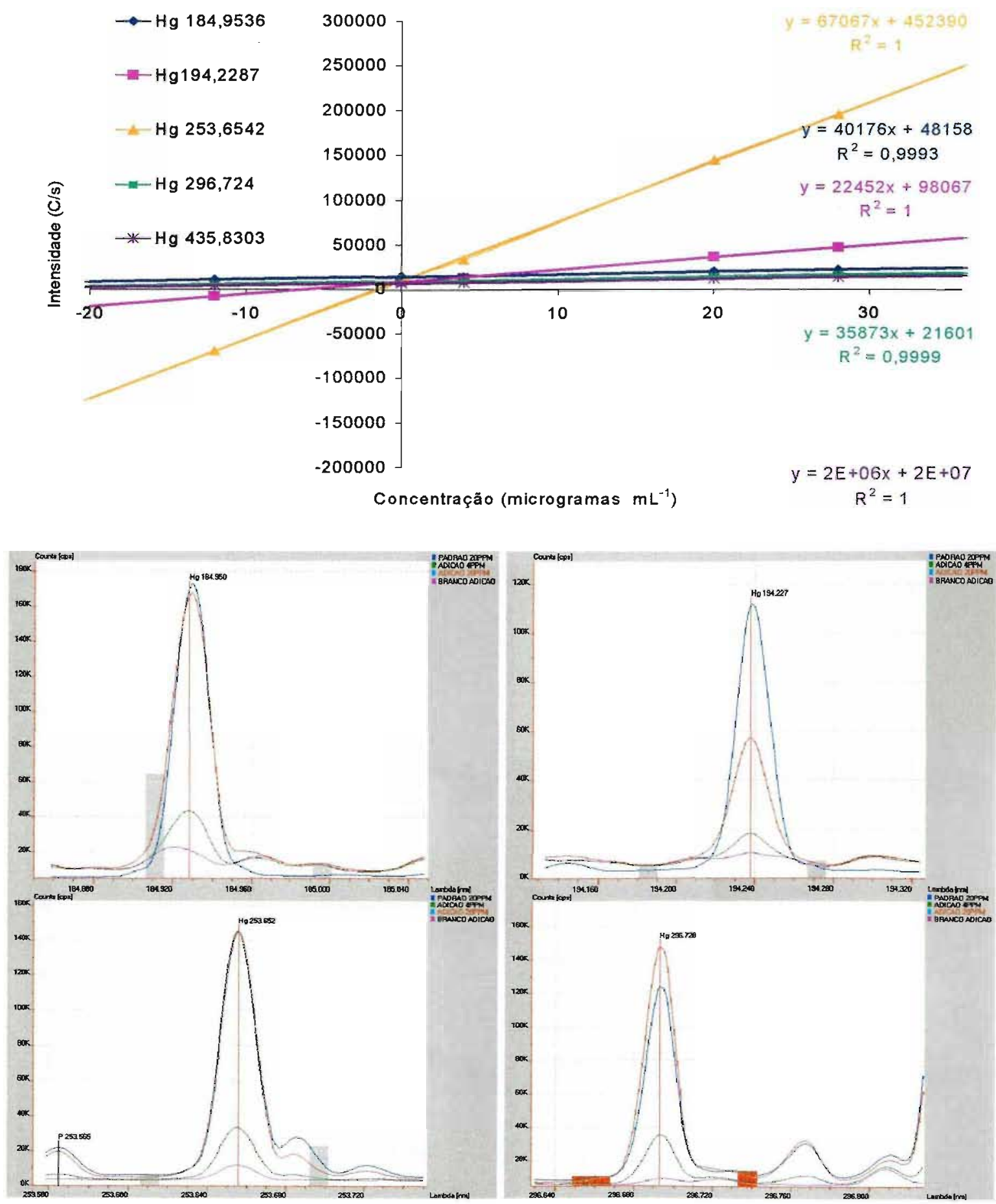

Figura 48: Curvas Analíticas e Perfis espectrais de múltiplos comprimentos de onda do Mercúrio 

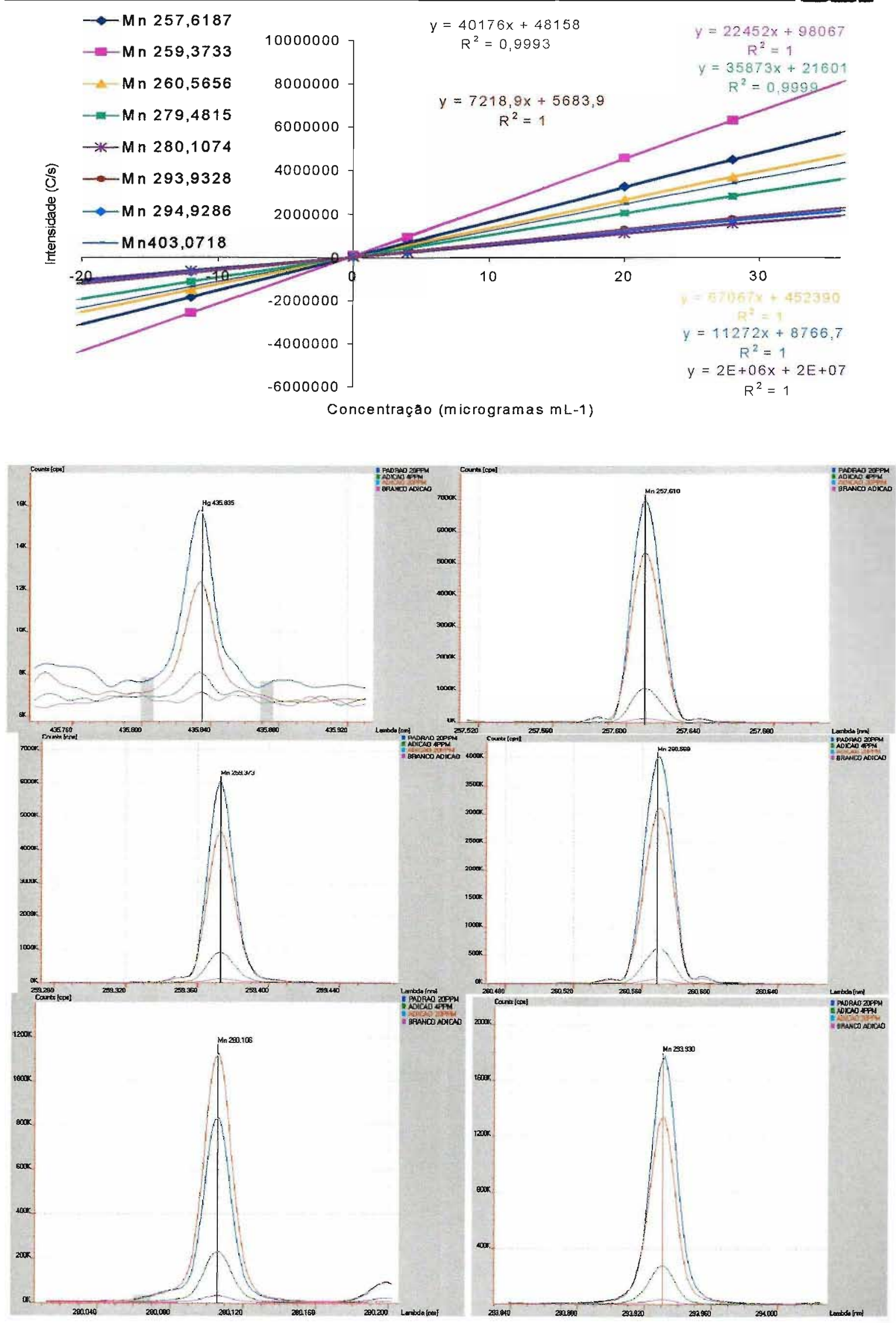

Figura 49: Curvas Analíticas e Perfis espectrais de múltiplos comprimentos de onda do Manganês 


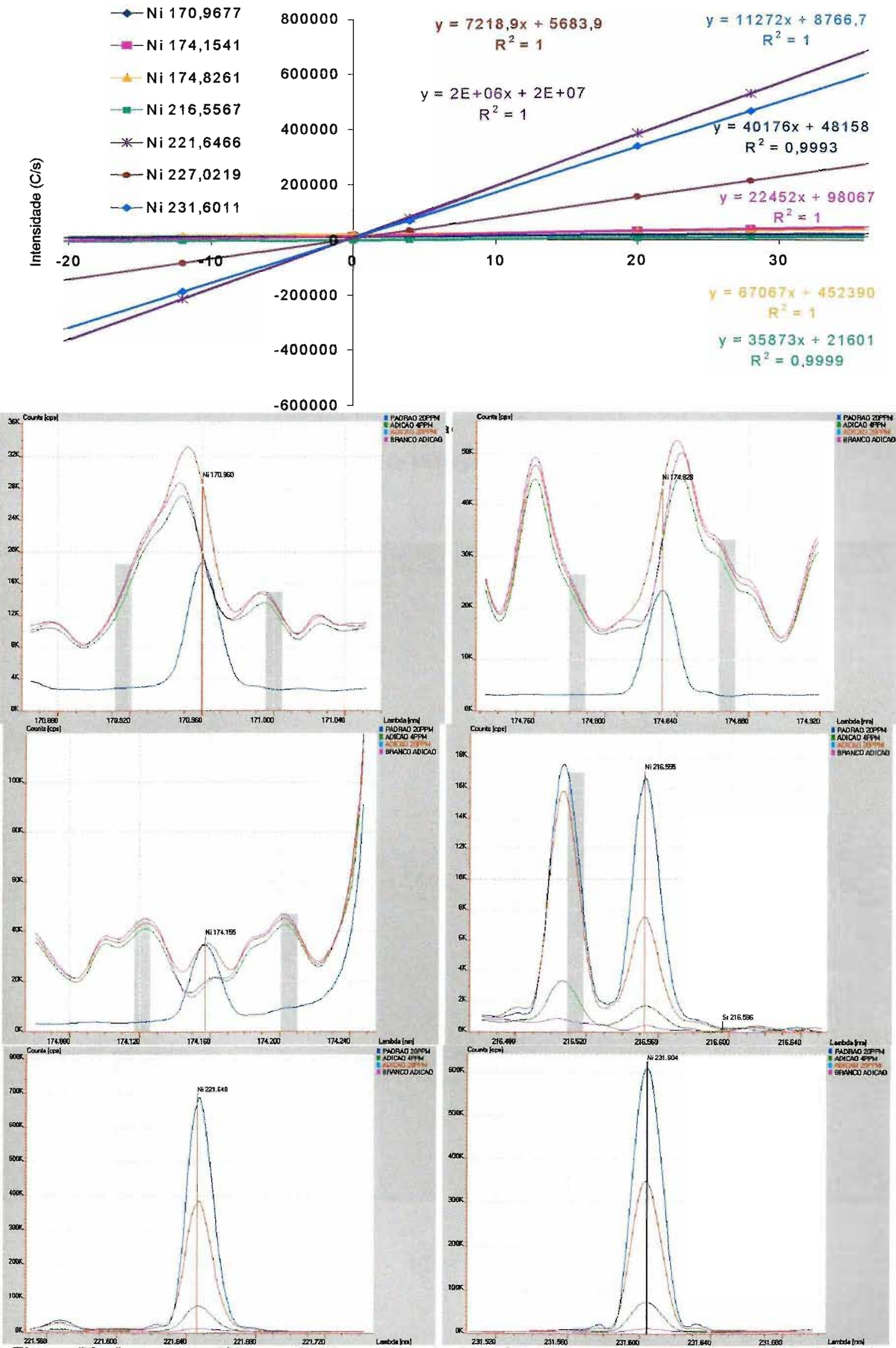

Figura 50: Curvas Analíticas e Perfis espectrais de múltiplos comprimentos de onda do Níquel. 

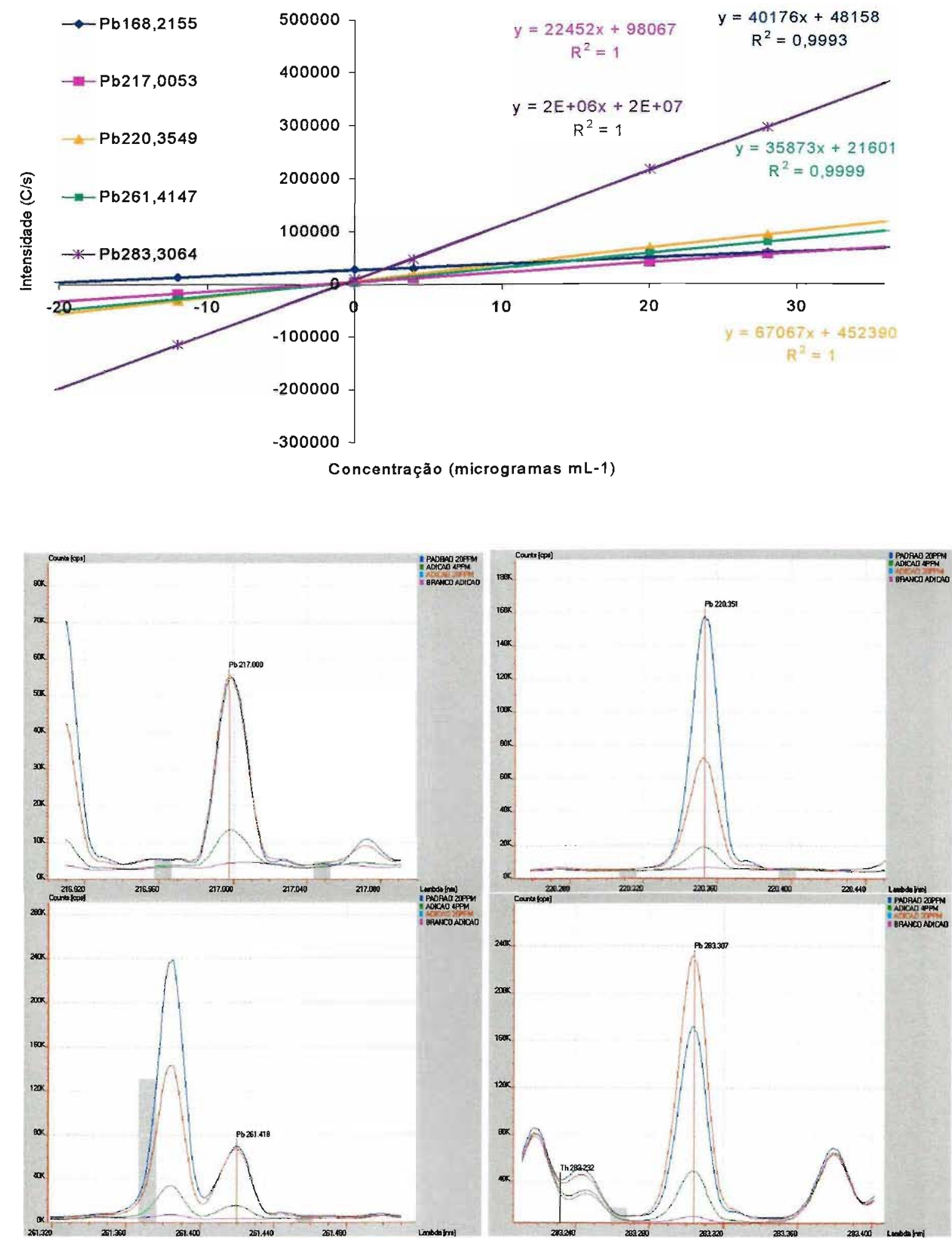

Figura 51: Curvas Analíticas e Perfis espectrais de múltiplos comprimentos de onda do Chumbo 


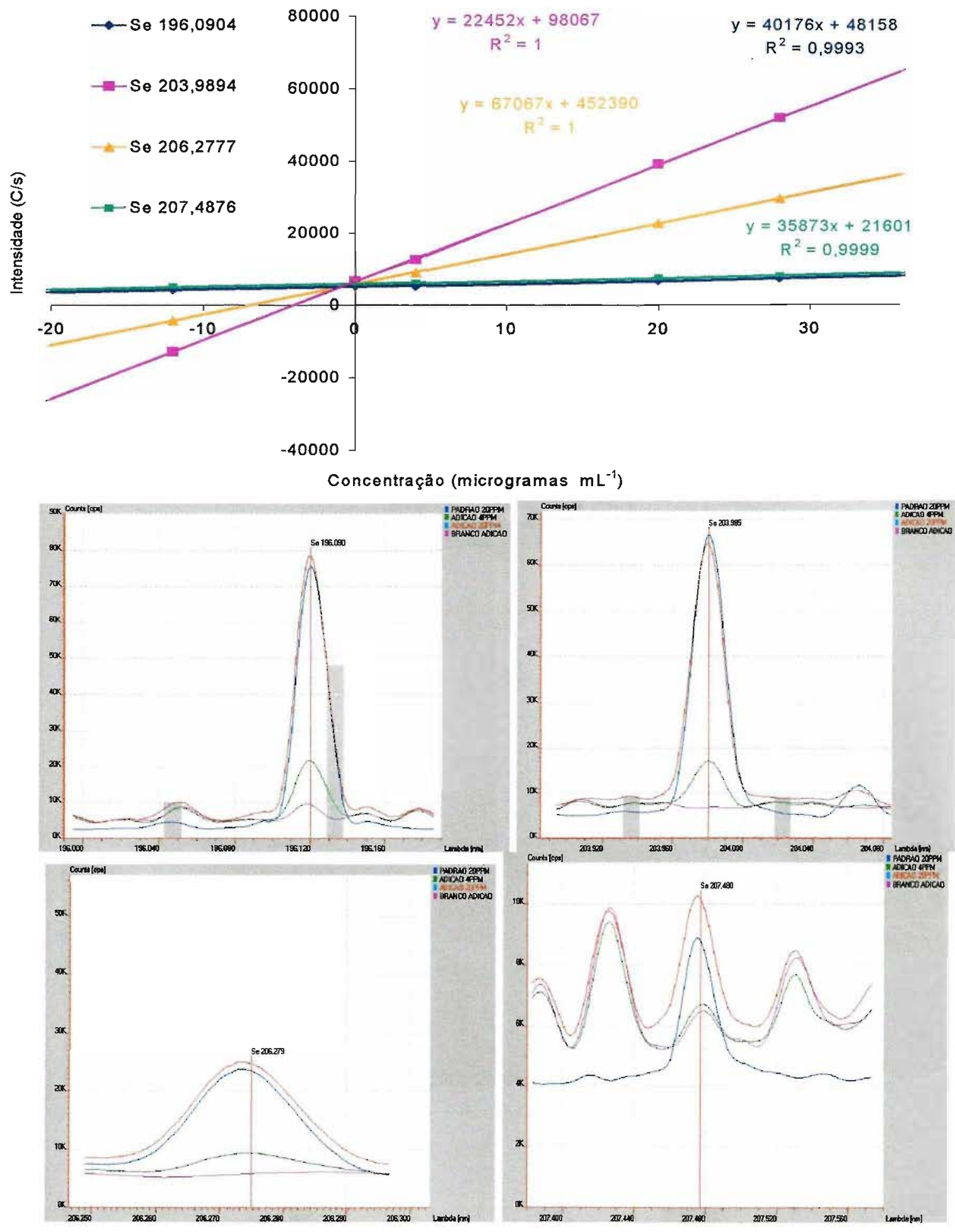

Figura 52: Curvas Analíticas e Perfis espectrais de múltiplos comprimentos de onda do Selênio 

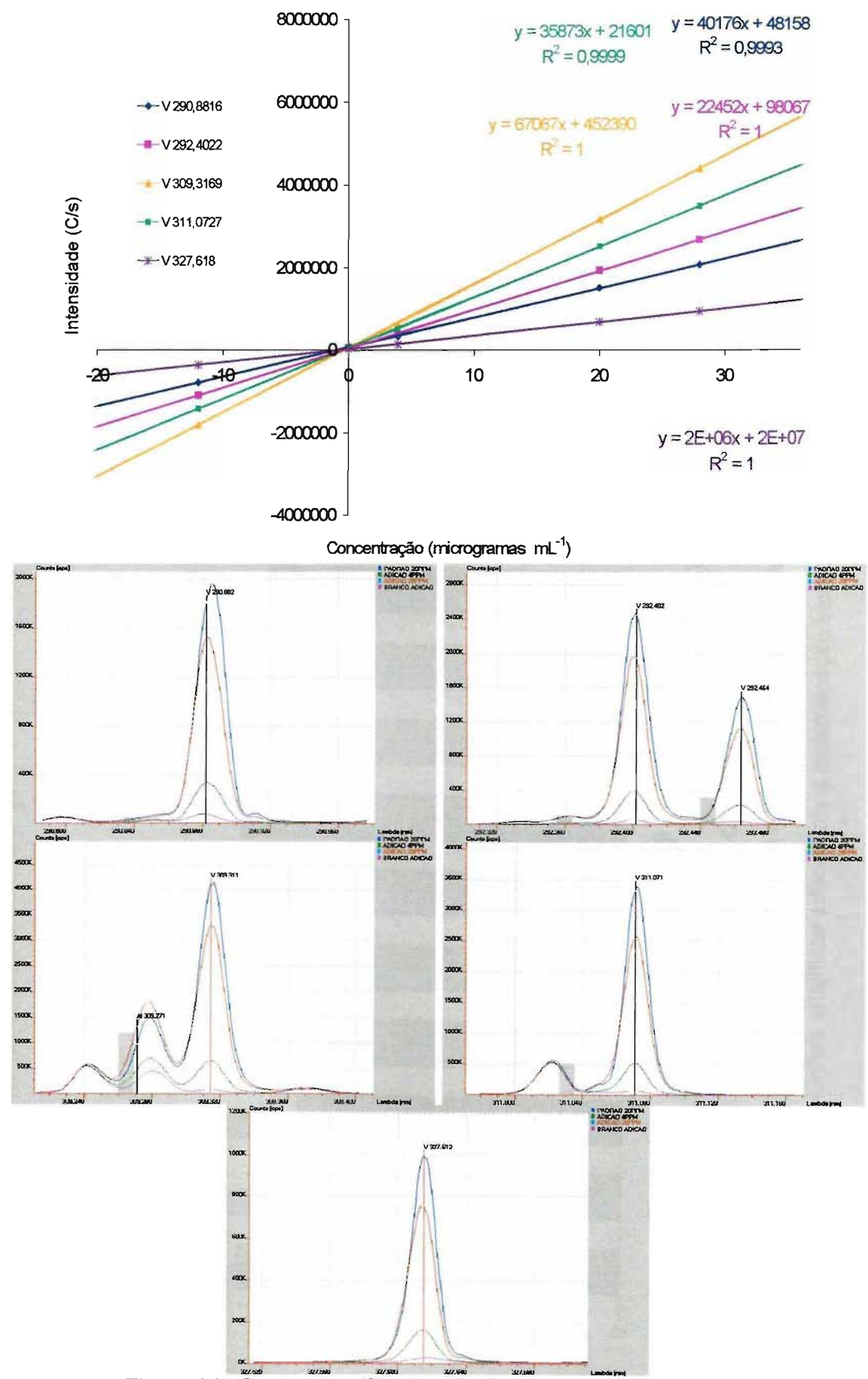

Figura 53: Curvas Analíticas e Perfis espectrais do Vanádio 


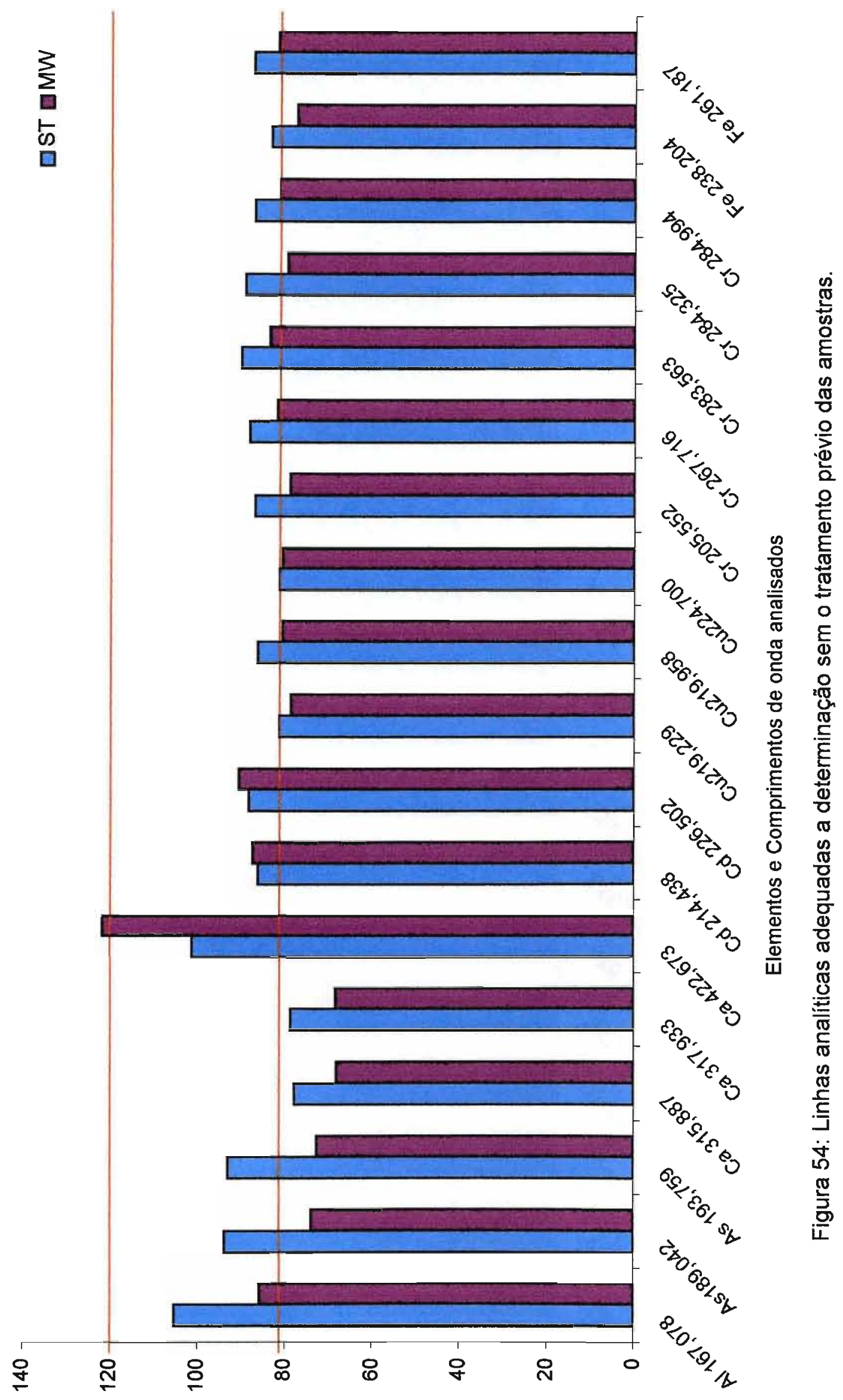




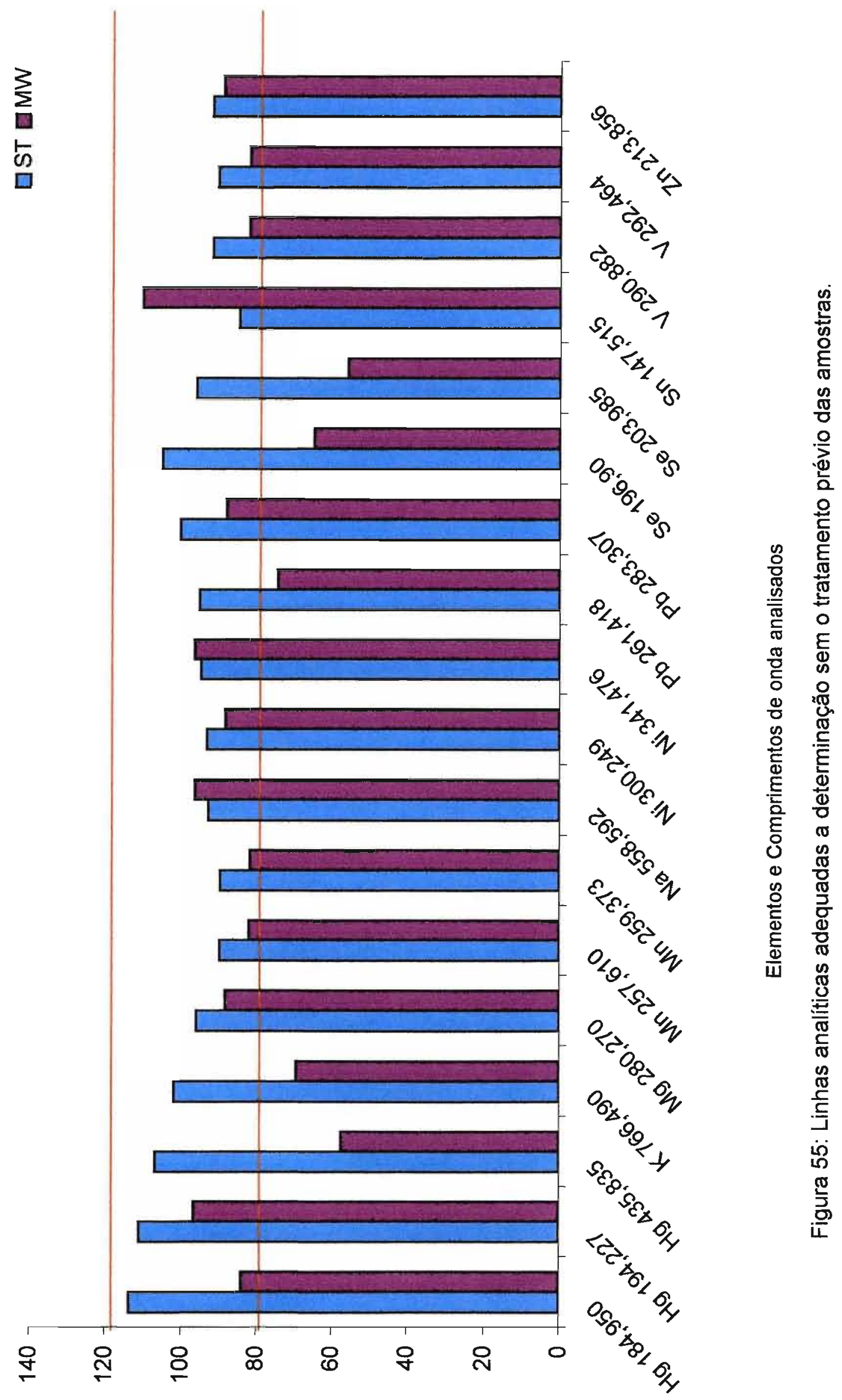


Capítulo 9

\section{RESULTADOS:}

\subsection{Avaliação da Técnica e a Exigência da Legislação Brasileira.}

As tabelas 14 e 15 mostram a viabilidade da determinação elementar nas amostras de adoçante dietético em função da diluição escolhida, lembrando que essa levou em consideração a forma de consumo dos adoçantes. Assim, foi possível a determinação dos seguintes elementos controlados pela legislação: $\mathrm{Al}$, $\mathrm{Sn}, \mathrm{Zn}, \mathrm{Cu}, \mathrm{Ni}, \mathrm{As}, \mathrm{Cd}$ e $\mathrm{Pb}$, em adoçantes sólidos, e $\mathrm{Zn}, \mathrm{Cu}, \mathrm{Ni}, \mathrm{Fe}, \mathrm{Pb}$ e $\mathrm{Cr}$ em adoçantes líquidos. Mas uma das vantagens da determinação sem o tratamento prévio da amostra é a rapidez e facilidade de preparar uma nova diluição ou dissolução mais conveniente a determinação.

Tabela 14: Comparação do limite de quantificação da técnica de análise por ICP OES para Alimentos Sólidos e a exigência da legislação brasileira.

\begin{tabular}{c|ccccc}
\hline Elementos & $\begin{array}{c}\text { LD } \\
\text { Instrumental } \\
\left(\mu \mathrm{g} \mathrm{mL}^{-1}\right)\end{array}$ & $\begin{array}{c}\text { LOQ } \\
\text { Intrumental } \\
\left(\mu \mathrm{g} \mathrm{mL}^{-1}\right)\end{array}$ & $\lambda(\mathrm{nm})$ & $\begin{array}{c}\text { LOQ } \\
\text { amostra } \\
\left(\mu \mathrm{g} \mathrm{g} \mathbf{~}^{-1}\right)\end{array}$ & $\begin{array}{c}\text { Limite } \\
\text { Legislação } \\
\left(\mu \mathbf{g ~ g}^{-1}\right)\end{array}$ \\
\hline $\mathrm{Al}$ & 0,0007 & 0,007 & 167,078 & 0,35 & $20,0^{* *}$ \\
$\mathrm{Sn}$ & 0,007 & 0,07 & 189,991 & 5,0 & 150,0 \\
$\mathrm{Zn}$ & 0,01 & 0,1 & 213,856 & 9,0 & 50,0 \\
$\mathrm{Cu}$ & 0,008 & 0,08 & 324,754 & 4,2 & 30,0 \\
$\mathrm{Ni}$ & 0,005 & 0,05 & 221,648 & 2,3 & 5,0 \\
$\mathrm{As}$ & 0,001 & 0,01 & 189,042 & 0,7 & 1,0 \\
$\mathrm{Cd}$ & 0,001 & 0,01 & 214,438 & 0,5 & 1,0 \\
$\mathrm{~Pb}$ & 0,05 & 0,5 & 261,418 & $\mathbf{2 , 5}$ & $\mathbf{1 , 0}$ \\
$\mathrm{Se}$ & 0,01 & 0,1 & 196,090 & $\mathbf{8 , 0}$ & $\mathbf{0 , 3 0}$ \\
$\mathrm{Cr}$ & 0,001 & 0,01 & 267,716 & $\mathbf{0 , 3 0}$ & $\mathbf{0 , 1 0}$ \\
$\mathrm{Hg}$ & 0,01 & 0,1 & 194,227 & $\mathbf{5 , 0}$ & $\mathbf{0 , 0 1}$ \\
\hline
\end{tabular}


Tabela 15: Comparação do Limite de quantificação da técnica de análise por ICP OES para Alimentos Líquidos e a exigência da legislação brasileira

\begin{tabular}{c|ccccc}
\hline Elementos & LD & LQ & & LQ & Limite \\
& Instrumental & Intrumental & $\lambda(\mathrm{nm})$ & amostra & Legislação \\
& $\left(\mu \mathrm{g} \mathrm{mL}^{-1}\right)$ & $\left(\mu \mathrm{g} \mathrm{mL}^{-1}\right)$ & & $\left(\mu \mathrm{g} \mathrm{m}^{-1}\right)$ & $\left(\mu \mathbf{g ~ g}^{-\mathbf{1}}\right)$ \\
\hline $\mathrm{Zn}$ & 0,01 & 0,1 & 213,856 & 0,4 & 5,0 \\
$\mathrm{Cu}$ & 0,008 & 0,08 & 324,754 & 0,20 & 2,0 \\
$\mathrm{Ni}$ & 0,005 & 0,05 & 221,648 & 0,10 & 0,10 \\
$\mathrm{Fe}$ & 0,005 & 0,05 & 259,940 & 0,1 & 5,0 \\
$\mathrm{Cd}$ & 0,001 & 0,01 & 214,438 & $\mathbf{0 , 2 0}$ & $\mathbf{0 , 0 1}$ \\
$\mathrm{Pb}$ & 0,05 & 0,5 & 261,418 & 0,1 & 0,5 \\
$\mathrm{Cr}$ & 0,001 & 0,01 & 267,716 & 0,03 & 0,05 \\
$\mathrm{As}$ & 0,001 & 0,01 & 196,090 & 0,3 & 1,0 \\
$\mathrm{Hg}$ & 0,01 & 0,1 & 194,227 & $\mathbf{0 , 2 5}$ & $\mathbf{0 , 0 1}$ \\
$\mathrm{Se}$ & 0,01 & 0,1 & 189,042 & $\mathbf{0 , 3 3}$ & $\mathbf{0 , 3 0}$ \\
\hline
\end{tabular}

Assim, verificou-se que a técnica de análise elementar por ICP OES atendia às necessidades da legislação brasileira para a determinação de $\mathrm{Al}, \mathrm{Sn}, \mathrm{Zn}, \mathrm{Cu}$, $\mathrm{Ni}$, As, $\mathrm{Cd}$ e $\mathrm{Pb}$ em adoçantes sólidos e $\mathrm{Zn}, \mathrm{Cu}$, Ni, $\mathrm{Fe}, \mathrm{Pb}$ e $\mathrm{Cr}$ em adoçantes líquidos.

Para a determinação de $\mathrm{Cr}$ nos adoçantes sólidos e de $\mathrm{Cr}$ e Se em adoçantes líquidos, a técnica não atende a legislação, mas pode-se monitorar a presença destes elementos uma vez que eles estão na mesma ordem de grandeza que os valores que a legislação exige. 
Para a determinação de $\mathrm{Se}, \mathrm{Pb}$ e $\mathrm{Hg}$ nos adoçantes sólidos e de $\mathrm{Cd}$ e $\mathrm{Hg}$ em adoçantes líquidos, a técnica não atende a legislação, e seria recomendável a determinação por outra técnica analítica mais sensivel, como ICP-MS.

\subsection{Avaliação dos Elementos Maiores:}

\section{Sem tratamento Prévio versus Resíduo de Cinzas.}

Para verificar se a análise sem o tratamento prévio da amostra para determinação dos elementos maiores ( $\mathrm{Na}, \mathrm{K}, \mathrm{Ca}, \mathrm{Mg}$ e $\mathrm{Fe}$ ) em amostras dos adoçantes dietéticos fora eficiente, fez-se a comparação desta metodologia com a determinação com tratamento por resíduo de cinzas, uma vez que este é o método recomendado pelas Normas Analíticas do Instituto Adolfo Lutz ${ }^{89}$. Foram testadas 6 amostras, de cada um dos tipos de matriz que compõem o adoçante dietético: SACY-L7, ASP-P9, SUC-P1, SACY-P2, ASP-L1, STE-P1, respectivamente.

O valor do resíduo de cinzas está adequado à legislação, < 4\%, mas apenas os elementos maiores $\mathrm{Na}, \mathrm{K}, \mathrm{Ca}$ e $\mathrm{Mg}$ puderam ser avaliados, pois neste procedimento os brancos analíticos foram bastante elevados, não permitindo a avaliação dos micronutrientes. Deve-se ressaltar, entretanto, que nem sempre este resíduo representa toda substância inorgânica presente na amostra, pois alguns sais podem sofrer redução ou volatilização neste aquecimento ${ }^{90}$.

Os resultados são mostrados nas figuras 56-A a 61-A. Foram comparadas as médias das determinações por resíduo de cinzas e sem o tratamento prévio da amostra e estas mostraram-se equivalentes quando aplicado o teste $t$ pareado para um nível de confiança de $95 \%$. 


\subsection{Avaliação dos Elementos traço:}

\section{Sem tratamento Prévio versus Extração em Microondas de alta pressão.}

Para verificar se a análise sem o tratamento prévio da amostra para determinação dos elementos traço (Al, $\mathrm{As}, \mathrm{Cd}, \mathrm{Cu}, \mathrm{Mn}, \mathrm{Mg}, \mathrm{Ni}, \mathrm{Pb}, \mathrm{Sn}, \mathrm{V}$, e Zn) em amostras dos adoçantes dietéticos fora adequada, fez-se a comparação desta metodologia com a determinação com extração em microondas de alta pressão, uma vez que método é aceito para a determinação de microconstituintes.

Os resultados são mostrados nas figuras 56-B a 61-B. Foram comparadas as médias das determinações por dissolução em microondas de alta pressão e sem o tratamento prévio da amostra, as quais mostraram-se equivalentes quando aplicado o teste t pareado para um nível de confiança de $95 \%$.

Os resultados mostrados nas figuras $56-\mathrm{C}$ a $61-\mathrm{C}$ correspondem a comparação das médias das determinaçōes por dissolução em microondas com determinação por ICP-MS e sem o tratamento prévio da amostra com determinação por ICP OES, as quais mostraram-se equivalentes quando aplicado o teste t pareado para um nível de confiança de $95 \%$, 


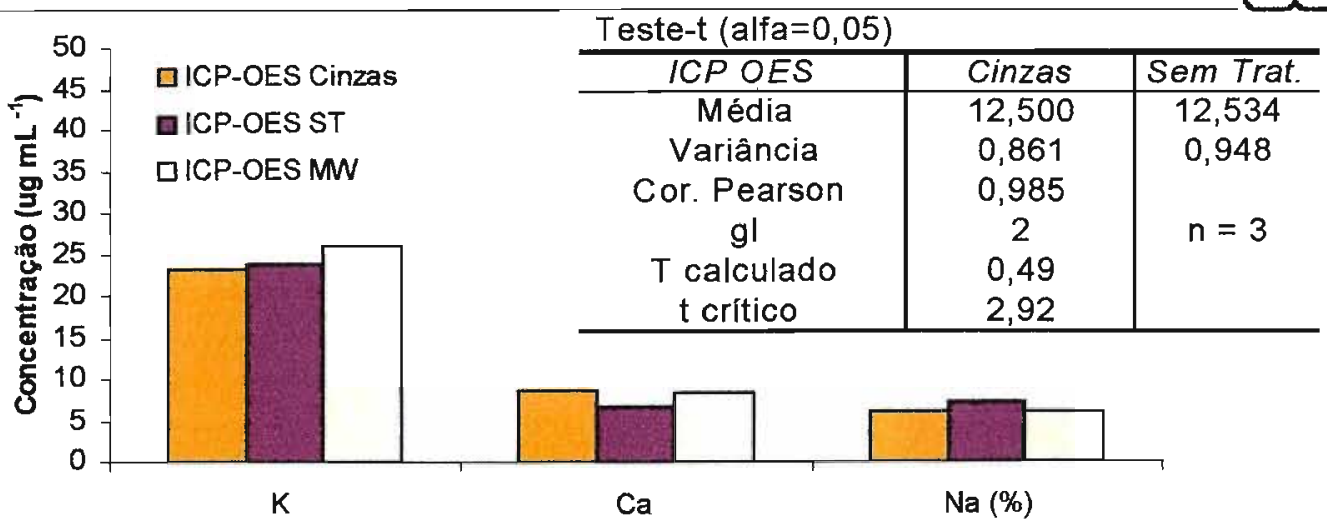

Figura 56-A: Comparação dos resultados dos macroelementos para amostra SACY-L7 sem tratamento prévio, com o Resíduo de cinzas e com o ICP-MS.

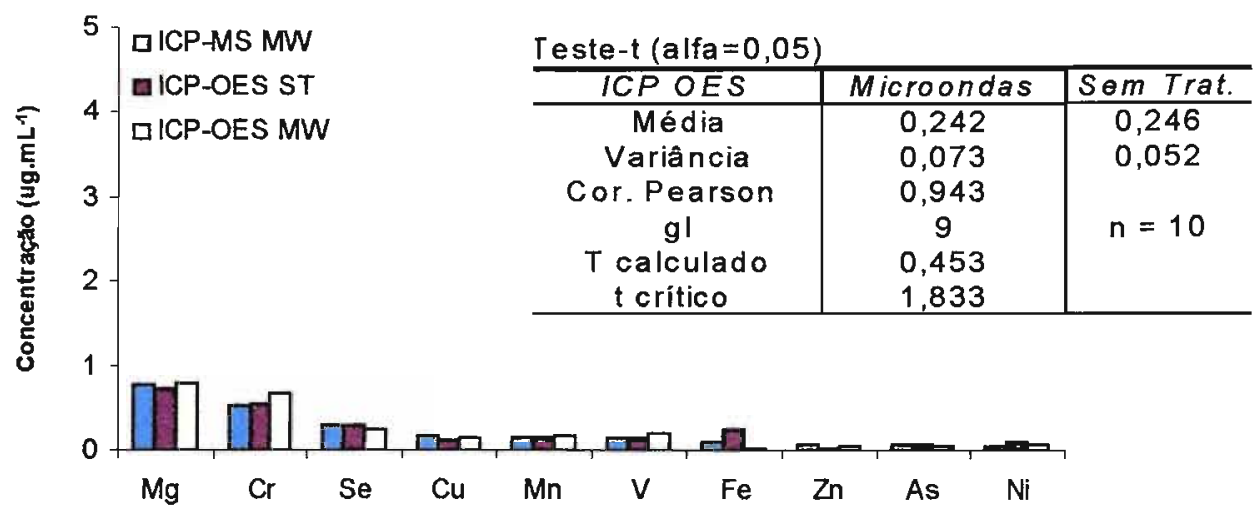

Figura 56-B: Comparação dos resultados dos microelementos para amostra SACY-L7 sem tratamento prévio, com o tratamento em microondas de alta pressão e com o ICP-MS.

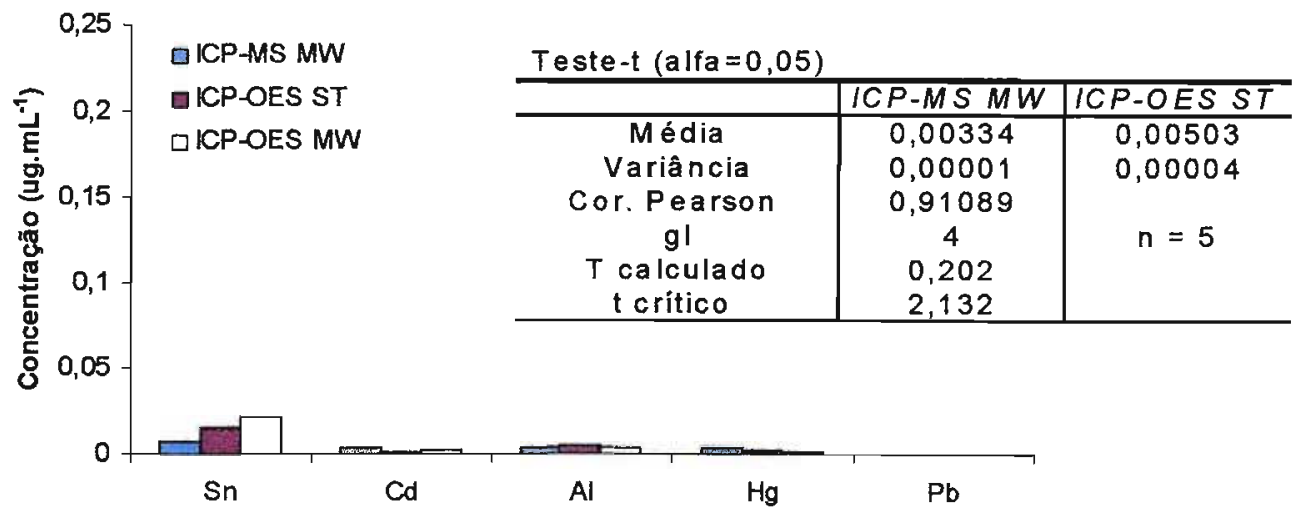

Figura 56-C: Comparação dos resultados dos microelementos para amostra SACY-L7 sem tratamento prévio, com o tratamento em microondas de alta pressão e com o ICP-MS. 


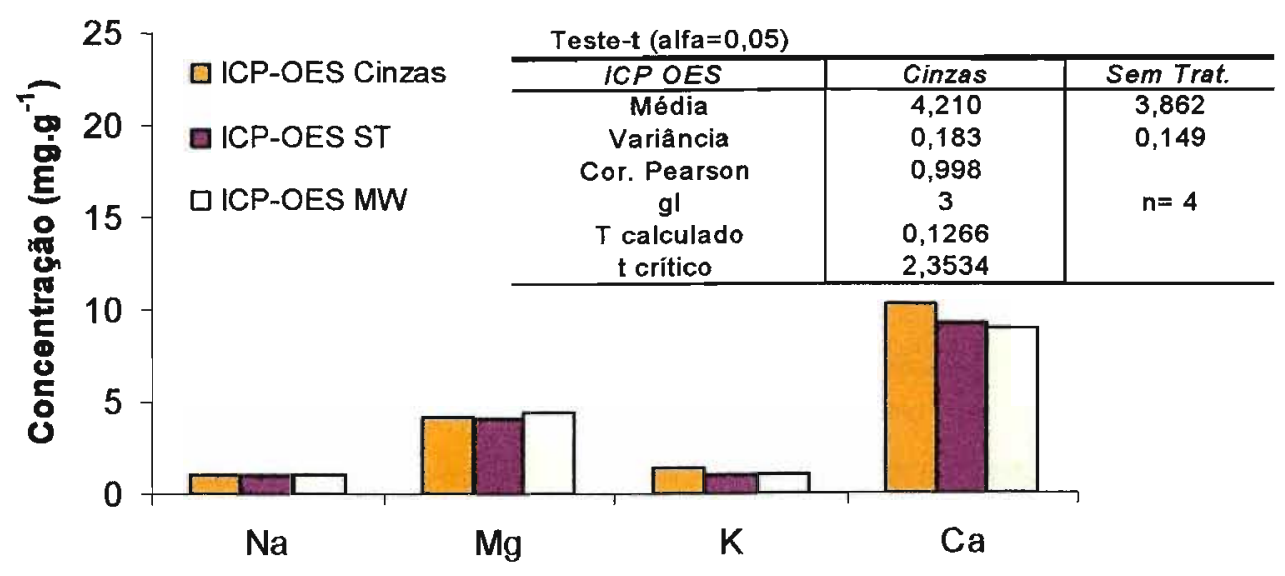

Figura 57-A: Comparação dos resultados dos macroelementos para amostra ASP-P9 sem tratamento prévio, com o Resíduo de cinzas e com o ICP-MS.

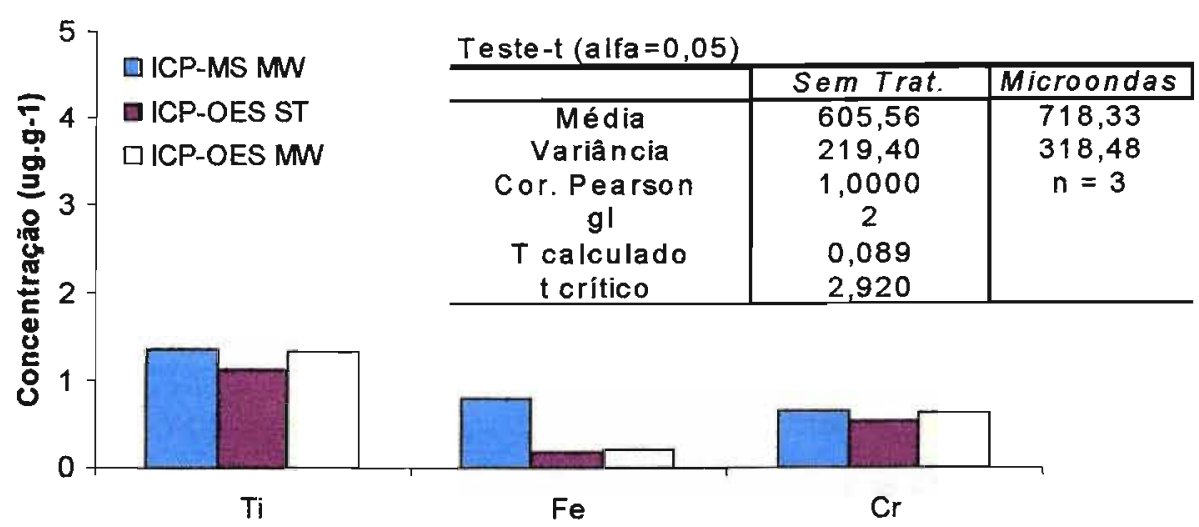

Figura 57-B: Comparação dos resultados dos microelementos para amostra ASP-P9 sem tratamento prévio, com o tratamento em microondas de alta pressão e com o ICP-MS.

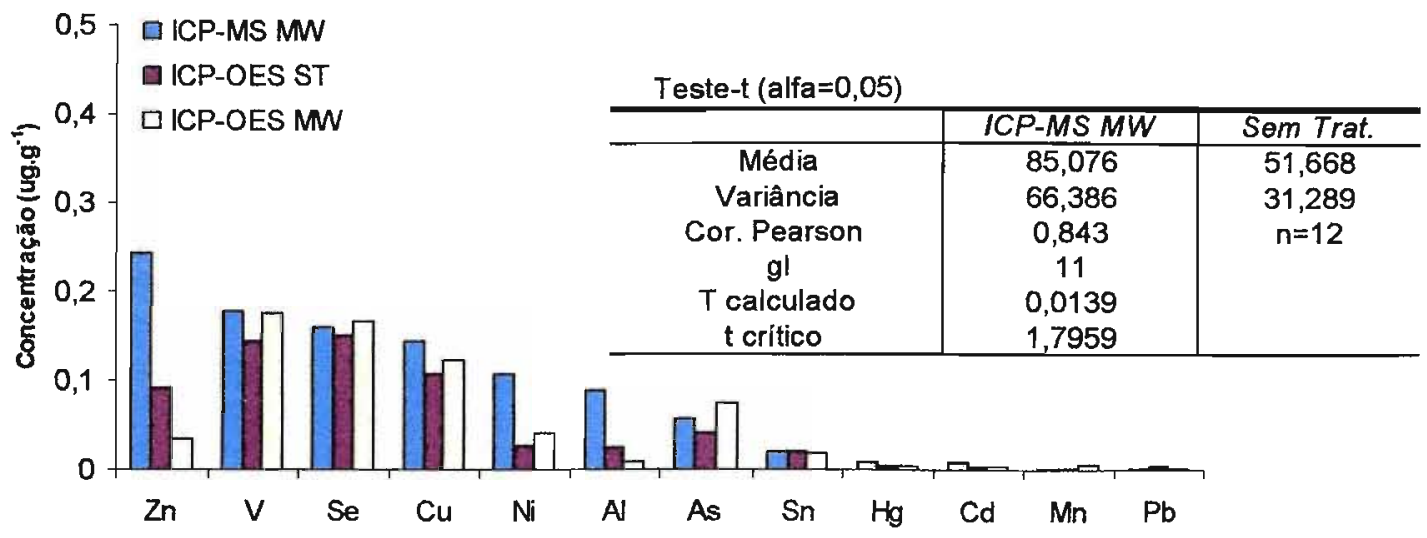

Figura 57-C: Comparação dos resultados dos microelementos para amostra ASP-P9 sem tratamento prévio, com o tratamento em microondas de alta pressão e com o ICP-MS. 


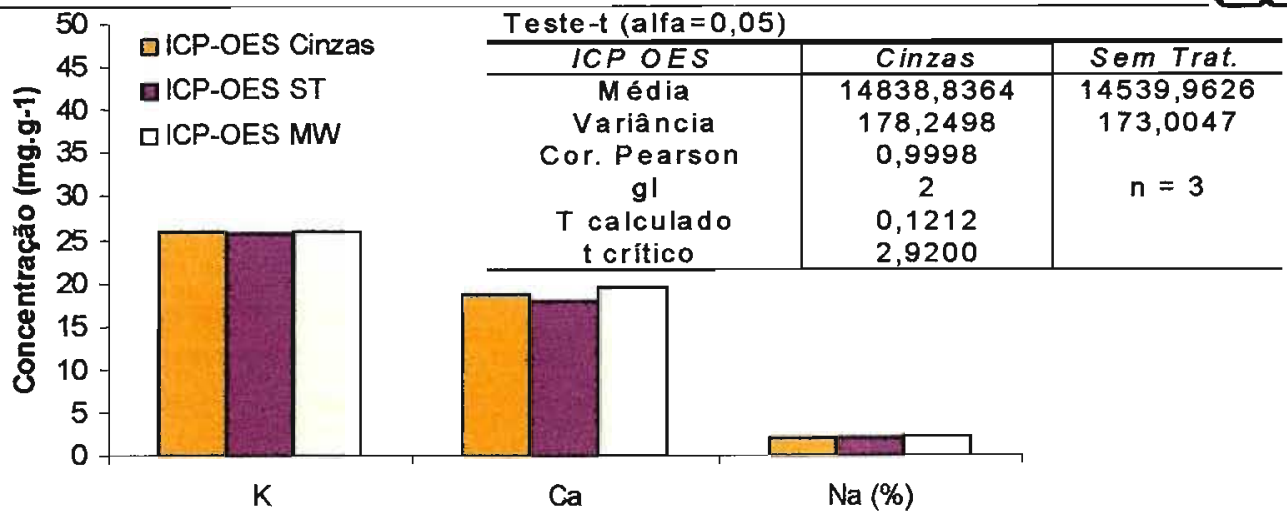

Figura 58-A: Comparação dos resultados dos macroelementos para amostra SUC-P1 sem tratamento prévio, com o Residuo de cinzas e com o ICP-MS.

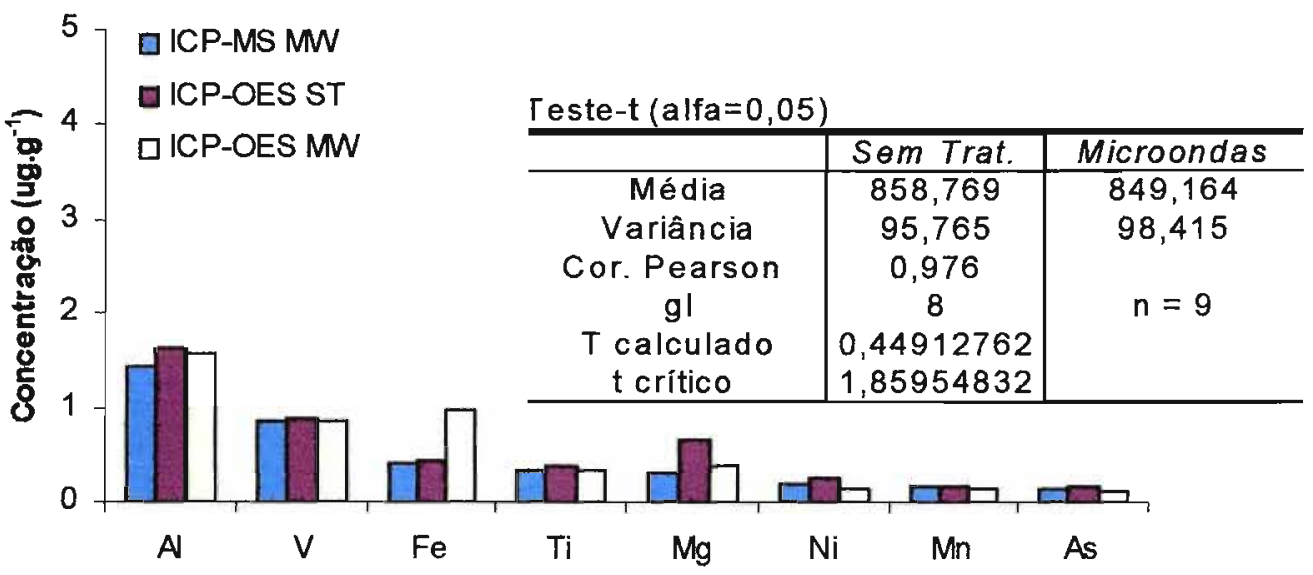

Figura 58-B: Comparação dos resultados dos microelementos para amostra SUC-P1 sem tratamento prévio, com o tratamento em microondas de alta pressão e com o ICP-MS.

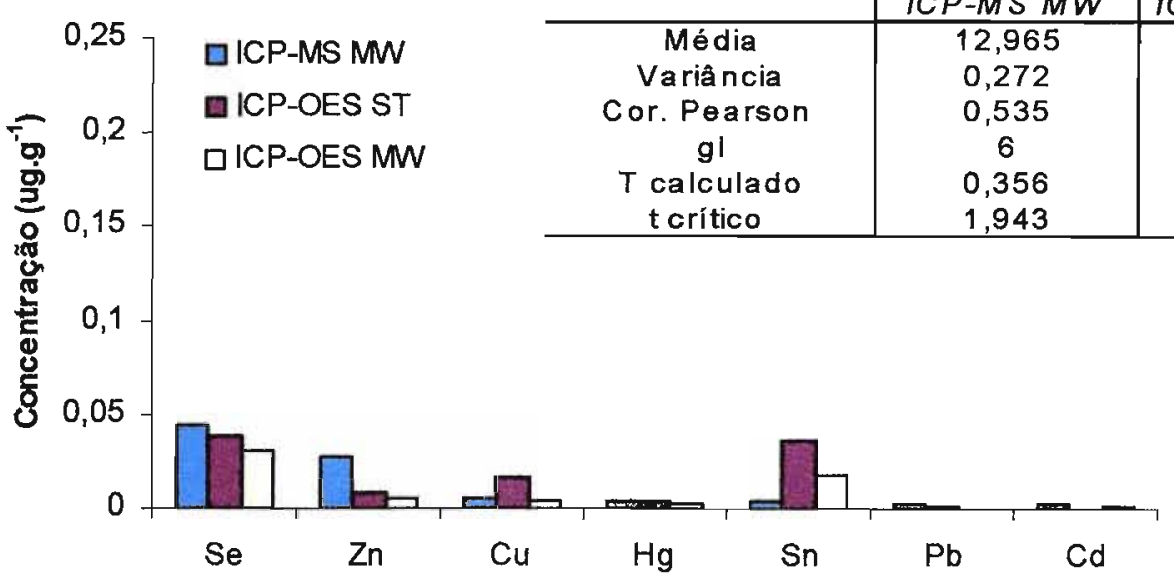

Figura 58-C: Comparação dos resultados dos microelementos para amostra SUC-P1 sem tratamento prévio, com o tratamento em microondas de alta pressão e com o ICP-MS. 


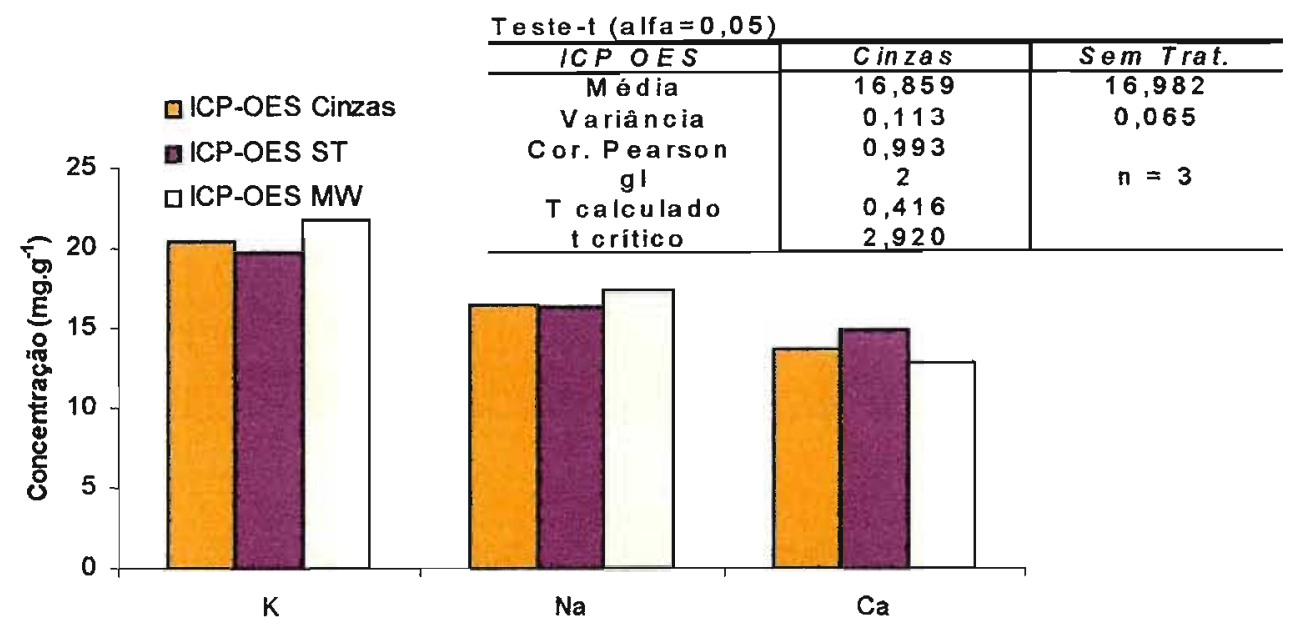

Figura 59-A: Comparação dos resultados dos macroelementos para amostra SACY-P2 sem tratamento prévio, com o Resíduo de cinzas e com o ICP-MS.

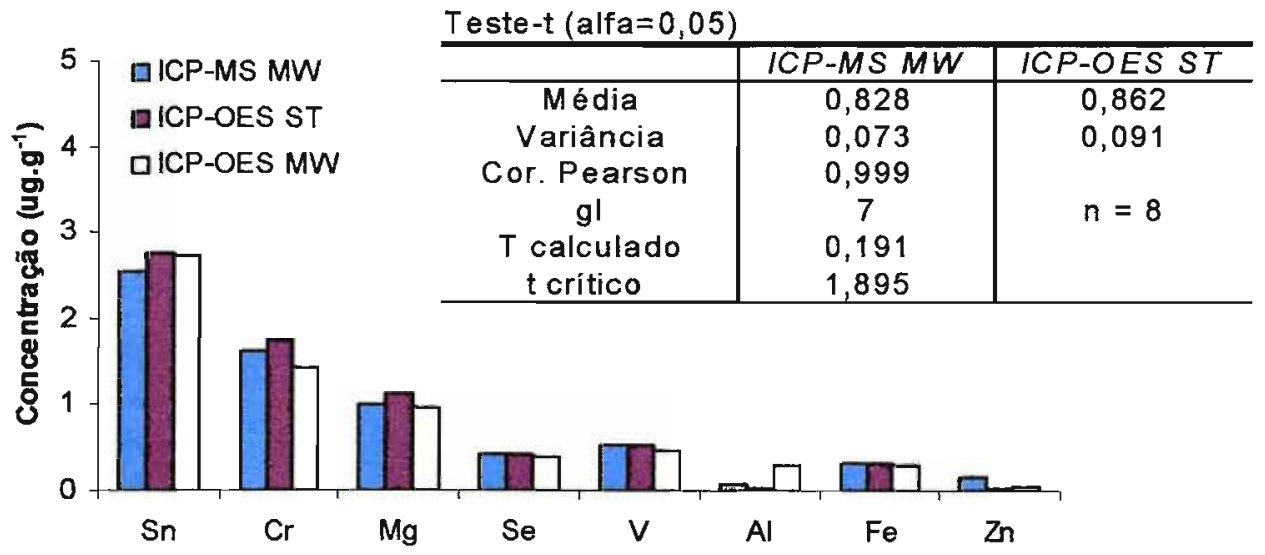

Figura 59-B: Comparação dos resultados dos microelementos para amostra SACY-P2 sem tratamento prévio, com o tratamento em microondas de alta pressão e com o ICP-MS. 


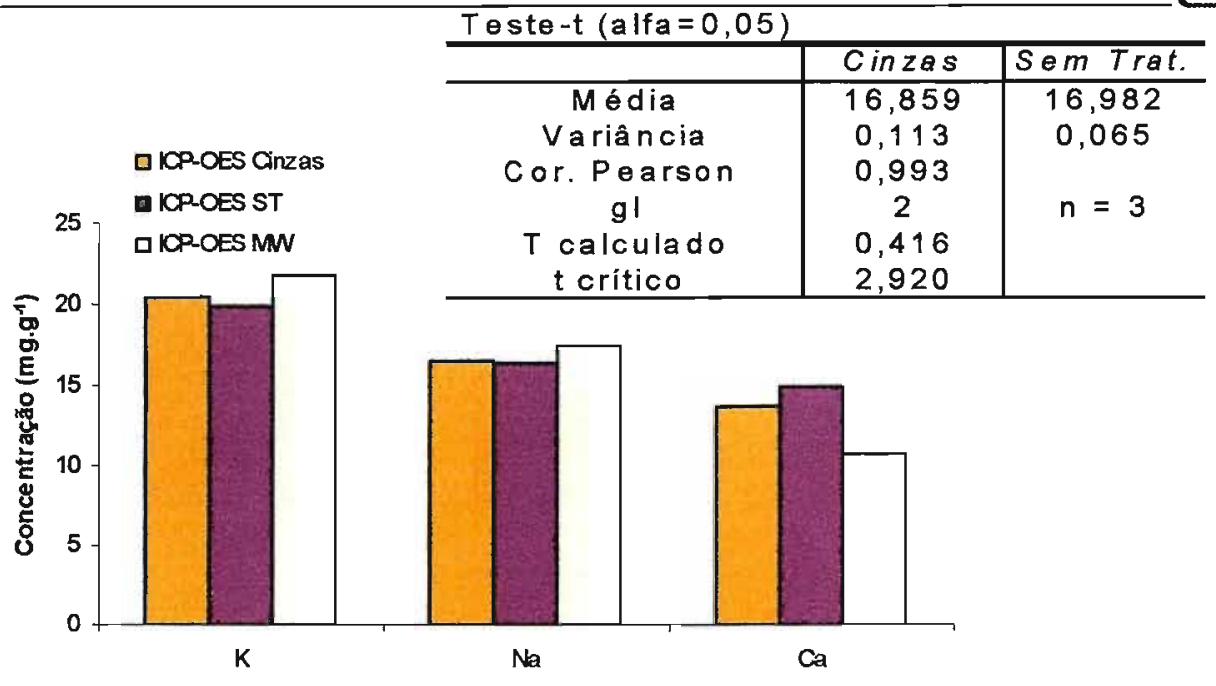

Figura 60-A: Comparação dos resultados dos macroelementos para amostra ASP-L1 sem tratamento prévio, com o Resíduo de cinzas e com o ICP-MS.

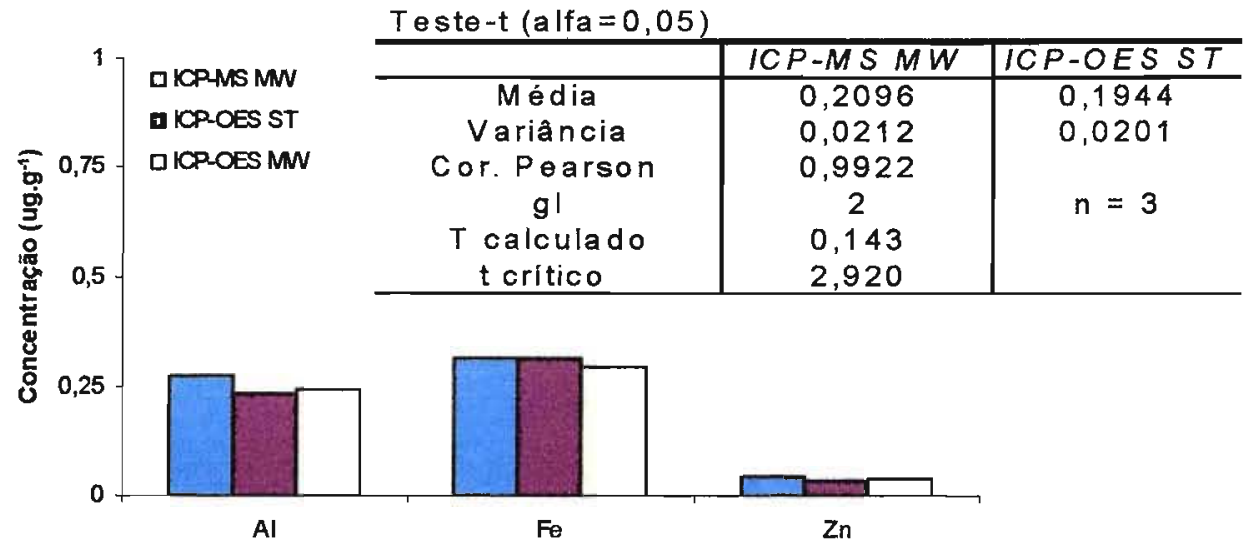

Figura 60-B: Comparação dos resultados dos microelementos para amostra ASP-L1 sem tratamento prévio, com o tratamento em microondas de alta pressão e com o ICP-MS.

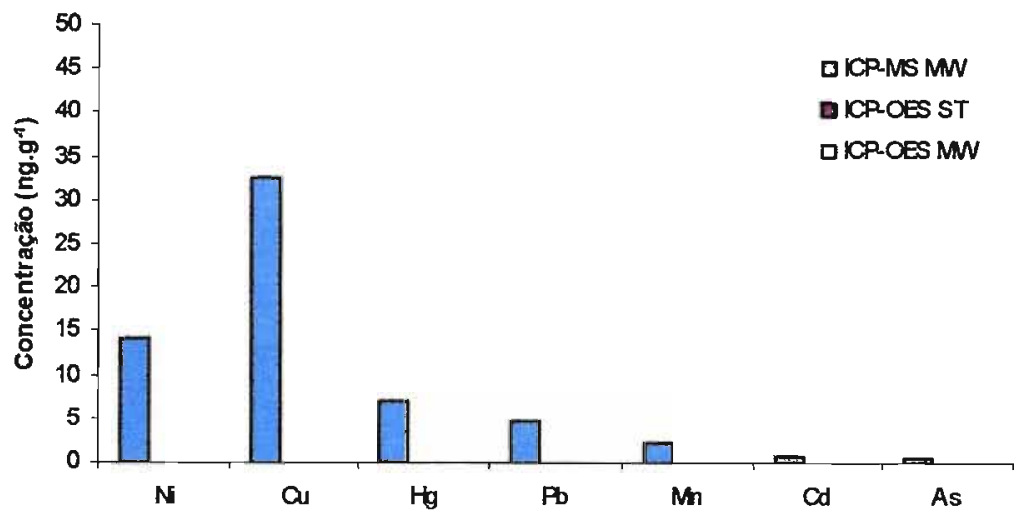

Figura 60-C: Comparação dos resultados dos microelementos para amostra ASP-L1 sem tratamento prévio, com o tratamento em microondas de alta pressão e com o ICP-MS. 


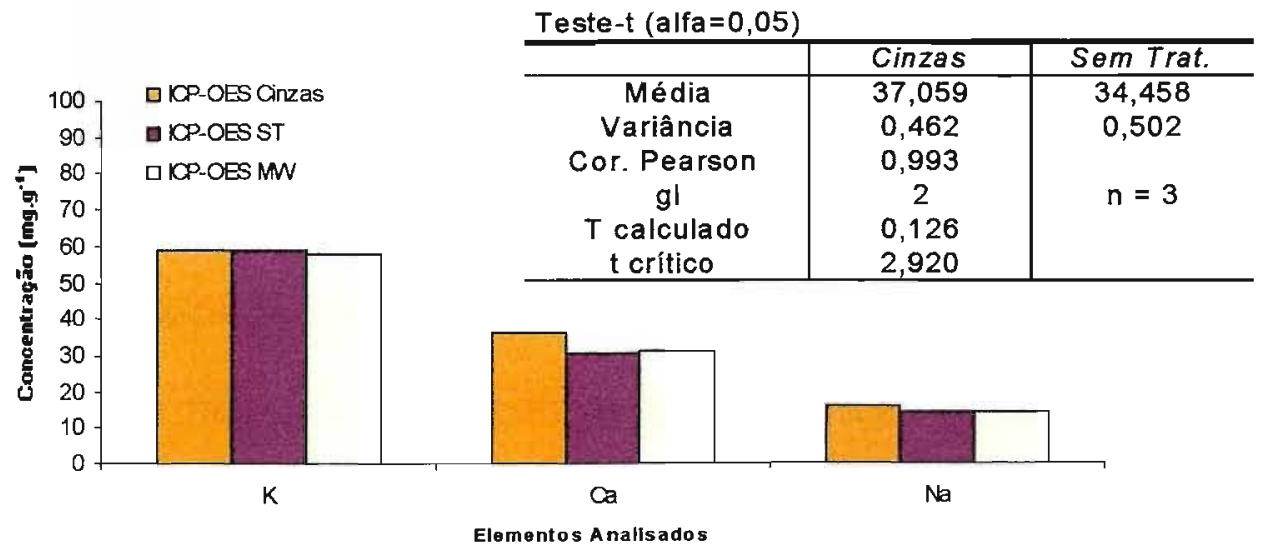

Figura 61-A: Comparação dos resultados dos macroelementos para amostra STE-P1 sem tratamento prévio, com o Resíduo de cinzas e com o ICP-MS.

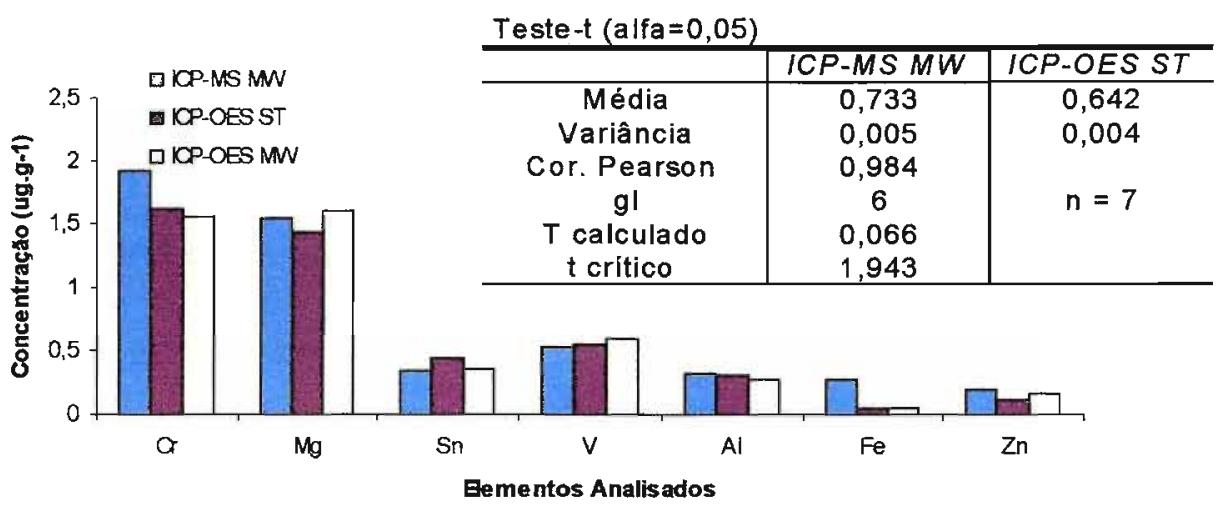

Figura 61-B: Comparação dos resultados dos microelementos para amostra STE-P1 sem tratamento prévio, com o tratamento em microondas de alta pressão e com o ICP-MS.

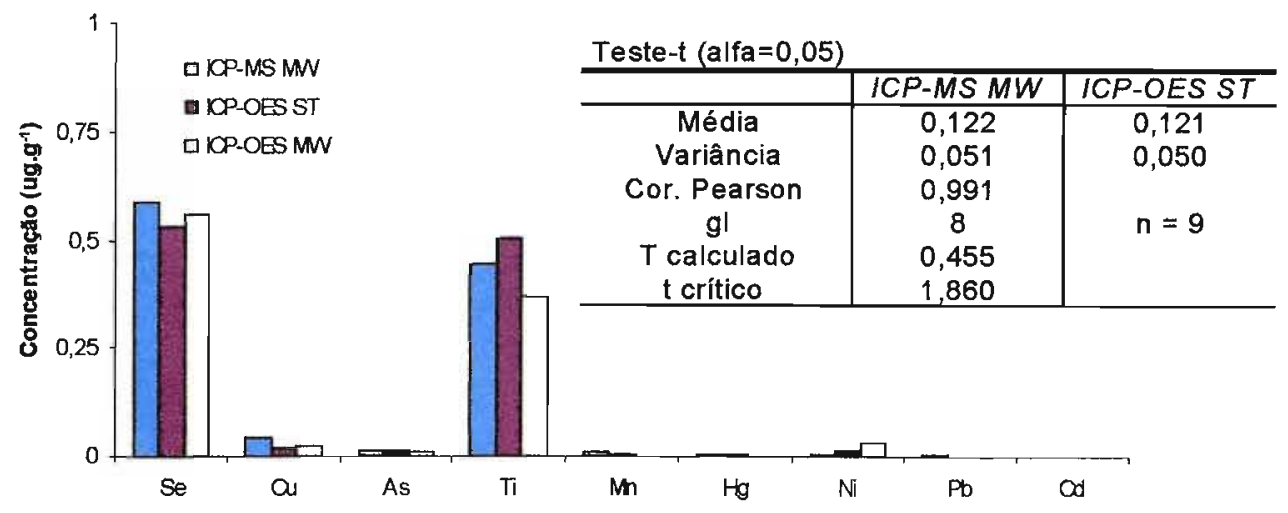

Figura 61-C: Comparação dos resultados dos microelementos para amostra STE-P1 sem tratamento prévio, com o tratamento em microondas de alta pressão e com o ICP-MS. 


\subsection{Determinação de Metais em amostras de Adoçantes em pó:}

Nas tabelas 16 a 19, são apresentados os resultados obtidos para as 17 amostras de adoçante dietético em pó, estudadas utilizando o método de determinação em múltiplos comprimentos de onda. Na figura 62, está o somatório dos elementos tóxicos controlados pela legislação, para as amostras de adoçante em pó.

De acordo com BARUFALDI e STABILE o somatório dos contaminantes inorgânicos presentes em adoçantes com o edulcorante ASPARTAME não devem ultrapassar $10 \mu \mathrm{g} \mathrm{g}^{-1}$ e $20 \mu \mathrm{g} \mathrm{g}^{-1}$ para adoçantes com a SACARINA ${ }^{8}$. Sendo assim, nenhuma amostra excedeu o valor recomendado, apenas a amostra SACY-P2 apresentou as concentrações de metais bastante discrepantes das demais amostras analisadas.

Quanto à comparação com os valores de controle da legislação, algumas amostras de adoçante em pó excederam o limite para os elementos As e $\mathrm{Cr}$ como mostram as figuras 64 e 65 .

As amostras ASP-P9, STE-P1, SUC-P1, SUC-G1, SACY-P1 e SACY-P4 excederam o valor limite da legislação para Arsênio $\left(1,0 \mu \mathrm{g} \mathrm{g}^{-1}\right)$.

As amostras ASP-P2, ASP-P4, ASP-P5, ASP-P7, STE-P2, SACY-P2 e SACY-P3 excederam o valor limite da legislação para Cromo $\left(0,1 \mu \mathrm{g} \mathrm{g}^{-1}\right)$. 


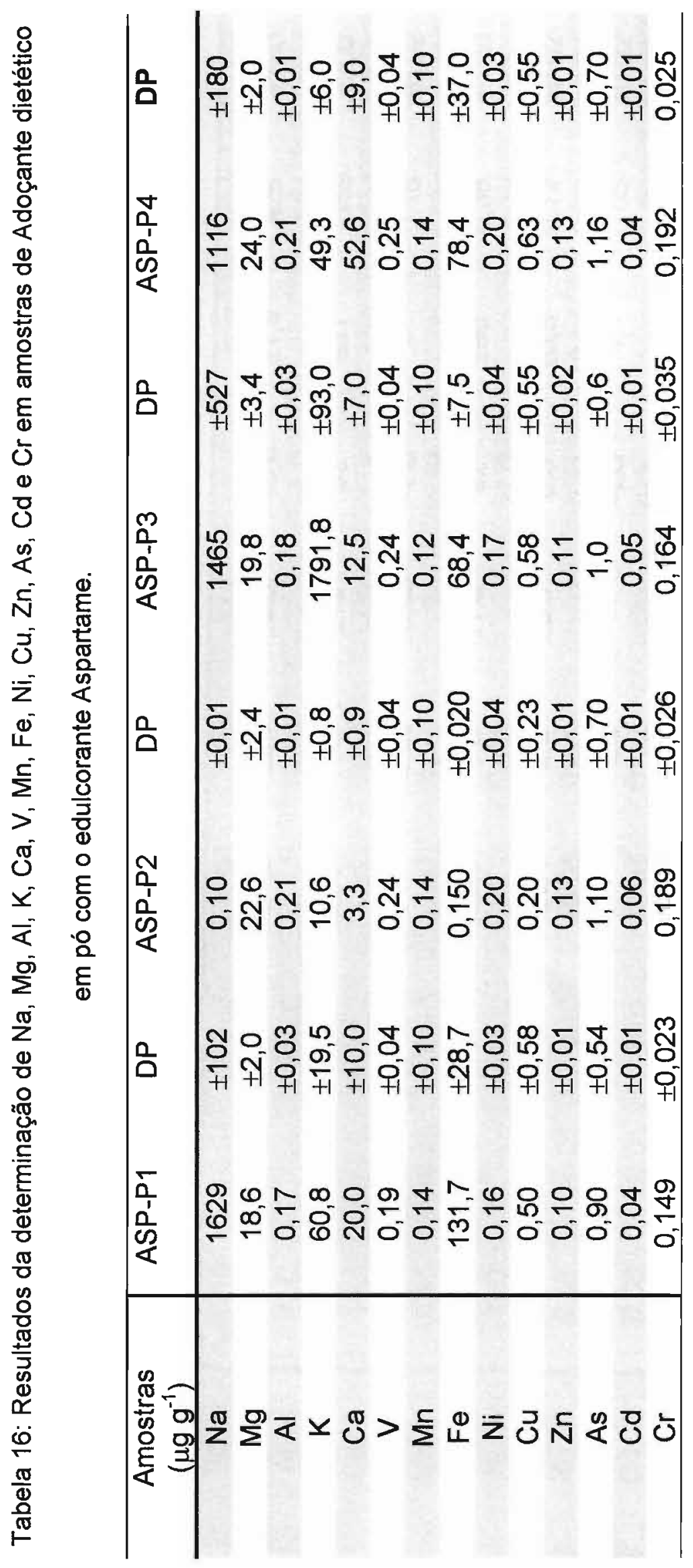




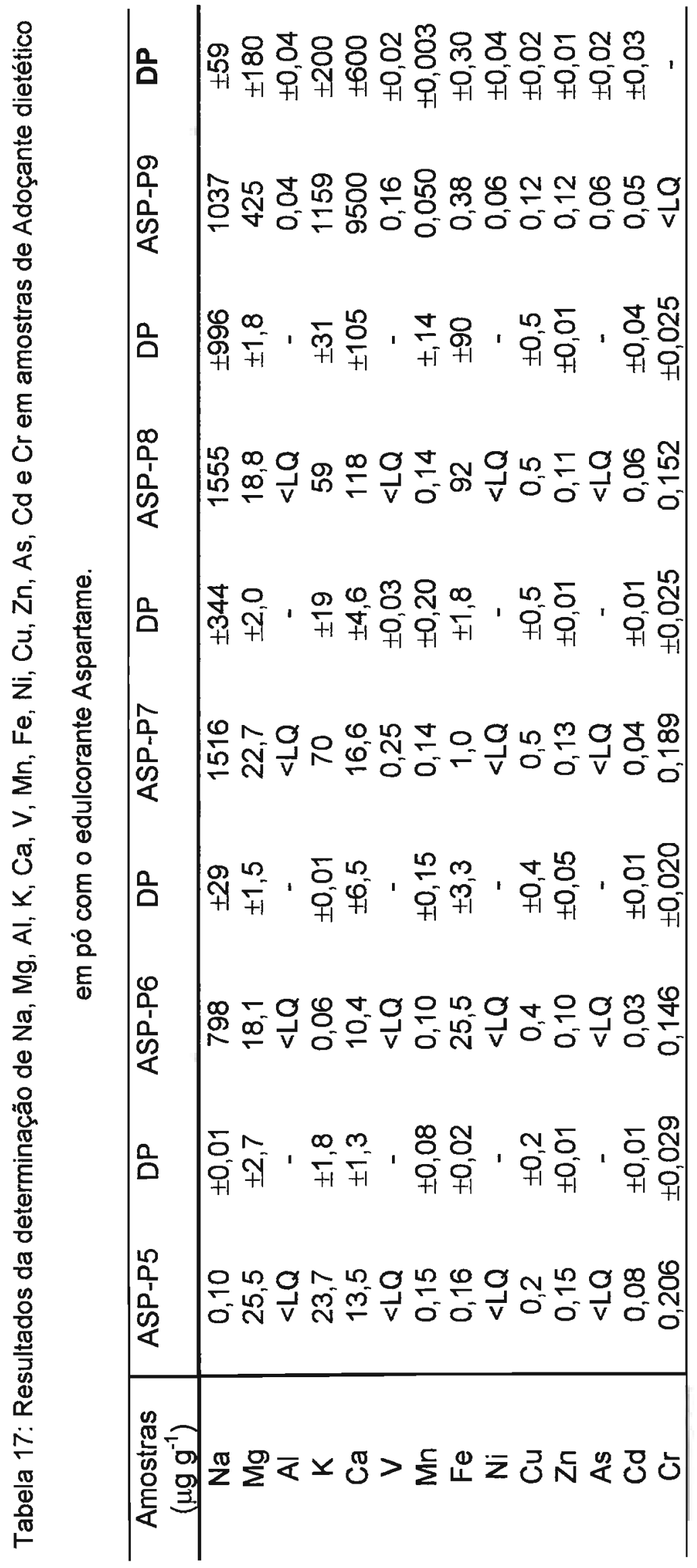




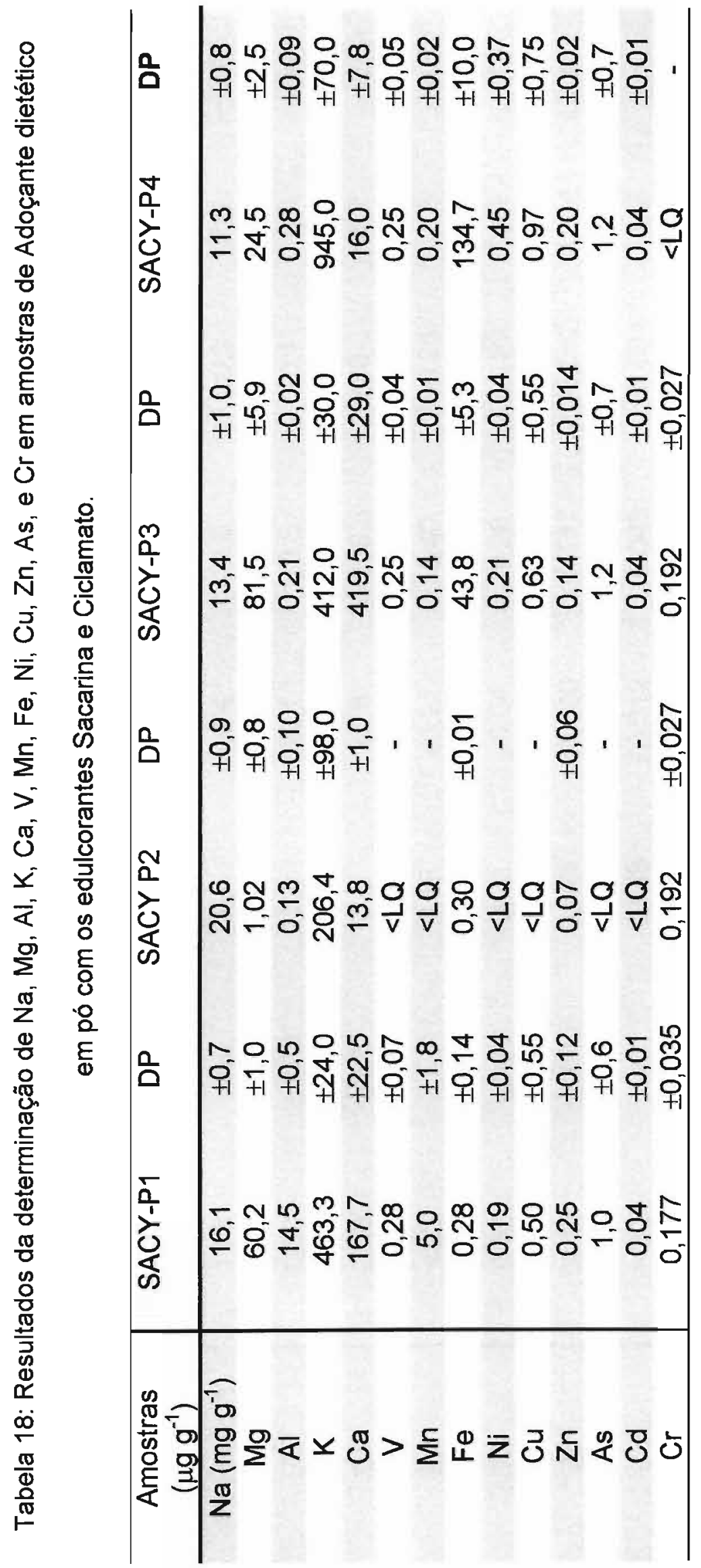




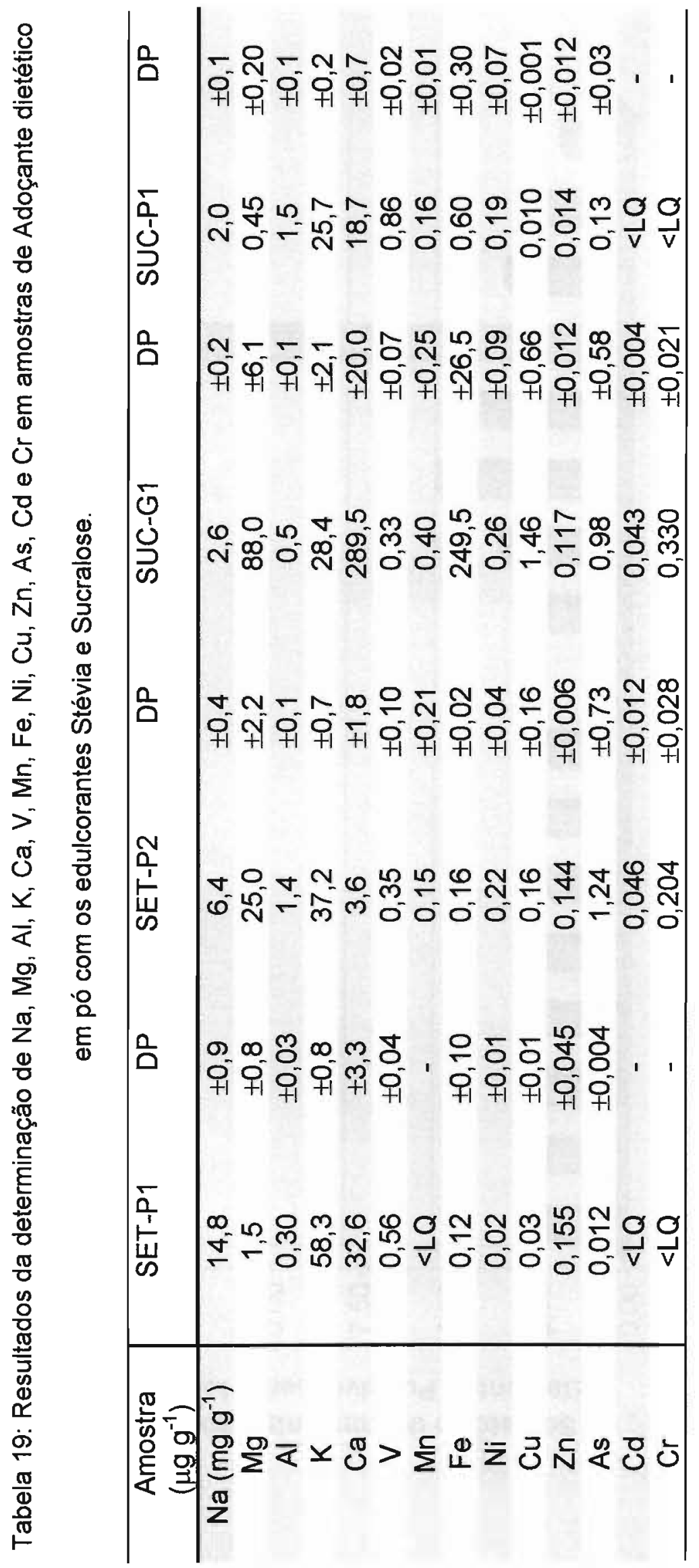




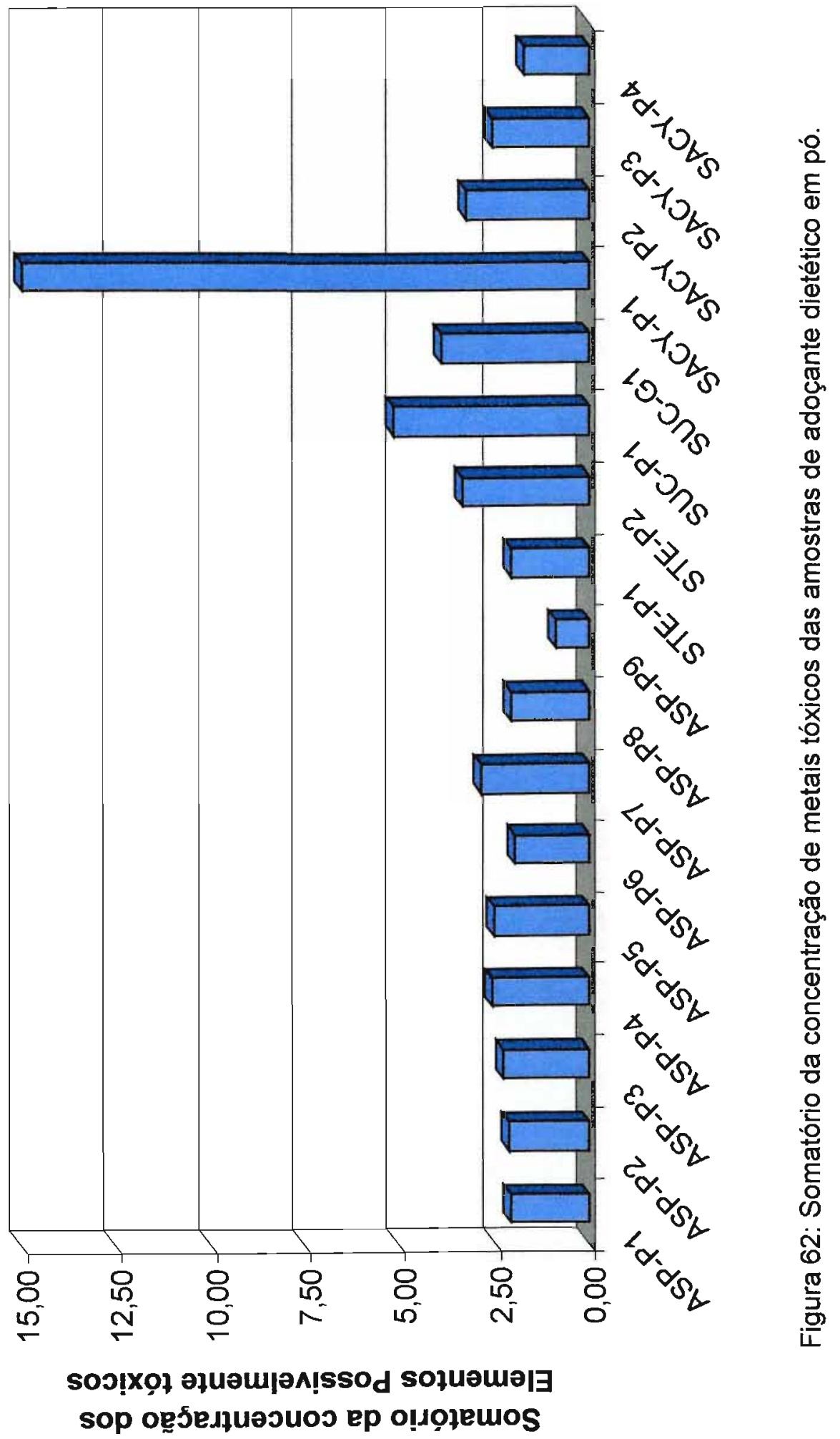




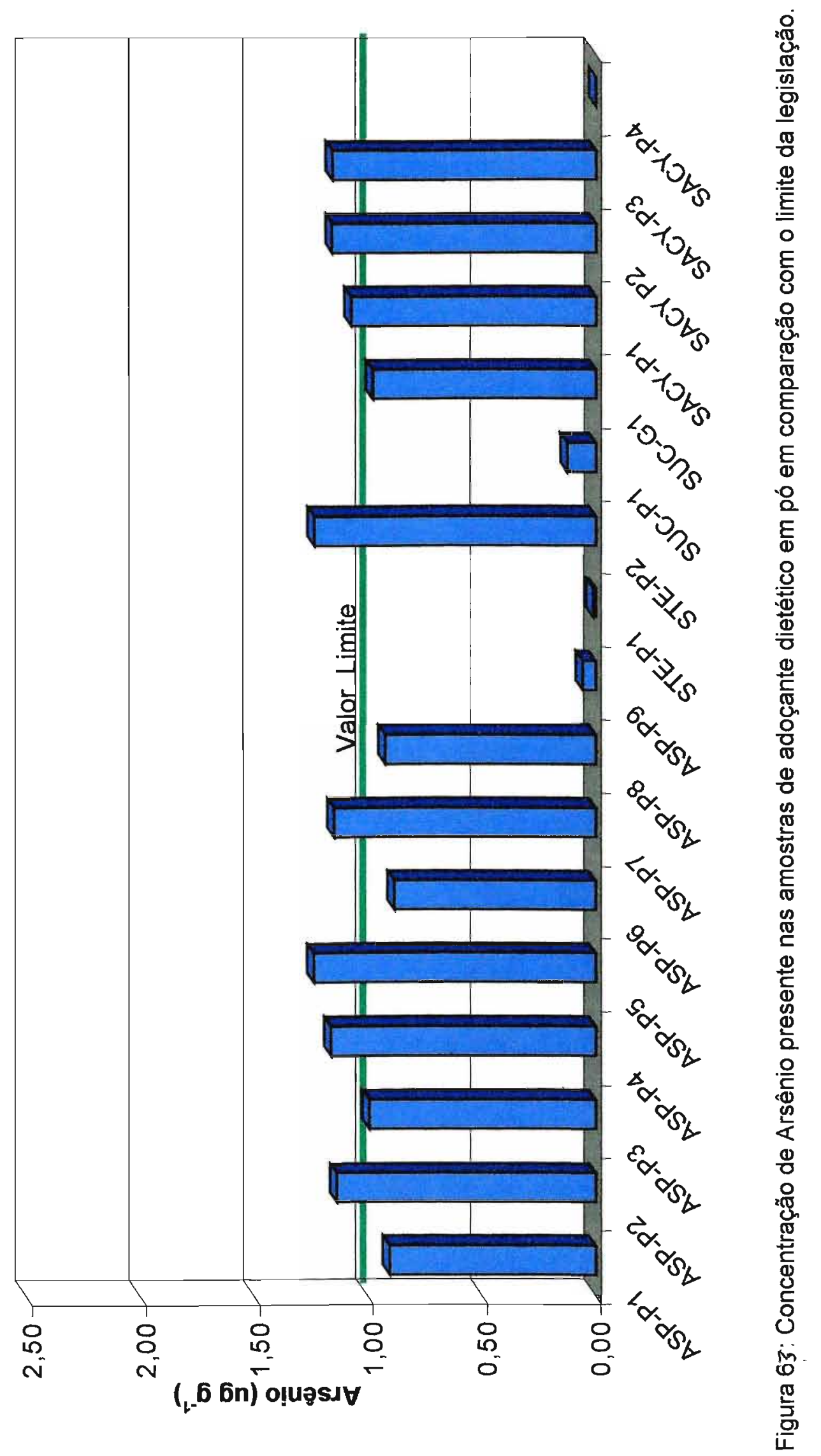




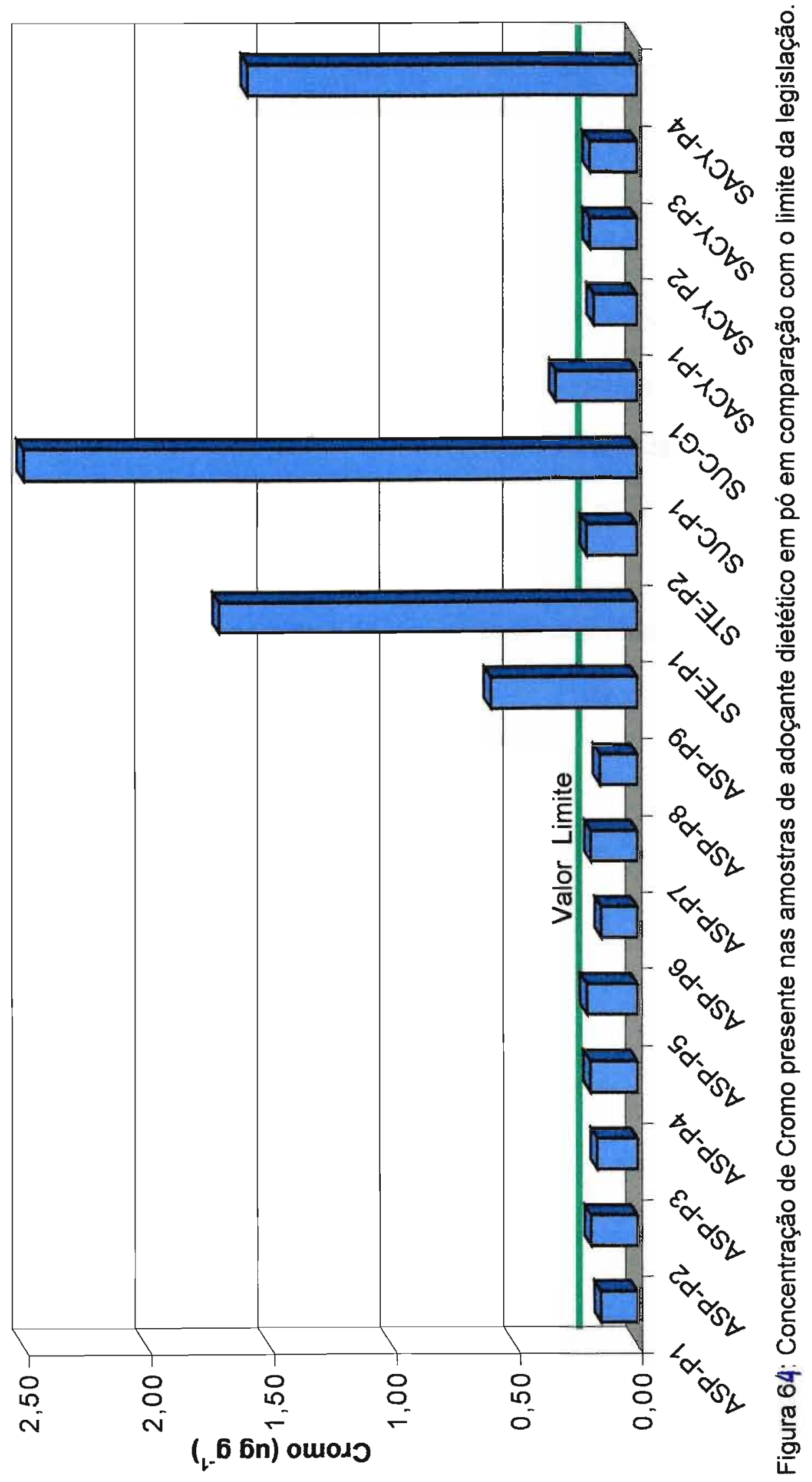




\subsection{Determinação de Metais em amostras de Adoçantes líquido:}

Nas tabelas 20 a 22, são apresentados os resultados obtidos para as 9 amostras de adoçante dietético líquido, estudadas utilizando o método de determinação em múltiplos comprimentos de onda. Na figura 65 , está o somatório dos elementos tóxicos controlados pela legislação, para as amostras de adoçante líquido. Observa-se que nenhuma amostra excedeu $2 \mu \mathrm{g} \mathrm{mL} \mathrm{m}^{-1}$ na soma dos elementos analisados, mostrando a qualidade dos produtos em relação à presença de metais potencialmente tóxicos a saúde humana.

Quanto à comparação com os valores de controle da legislação, apenas duas amostras de adoçante líquido excederam o limite para Níquel como mostra a figura 66.

A amostras ASP-L2 e SACY-L4 excederam o valor limite da legislação para Níquel $\left(0,1 \mu \mathrm{g} \mathrm{g}^{-1}\right)$. 


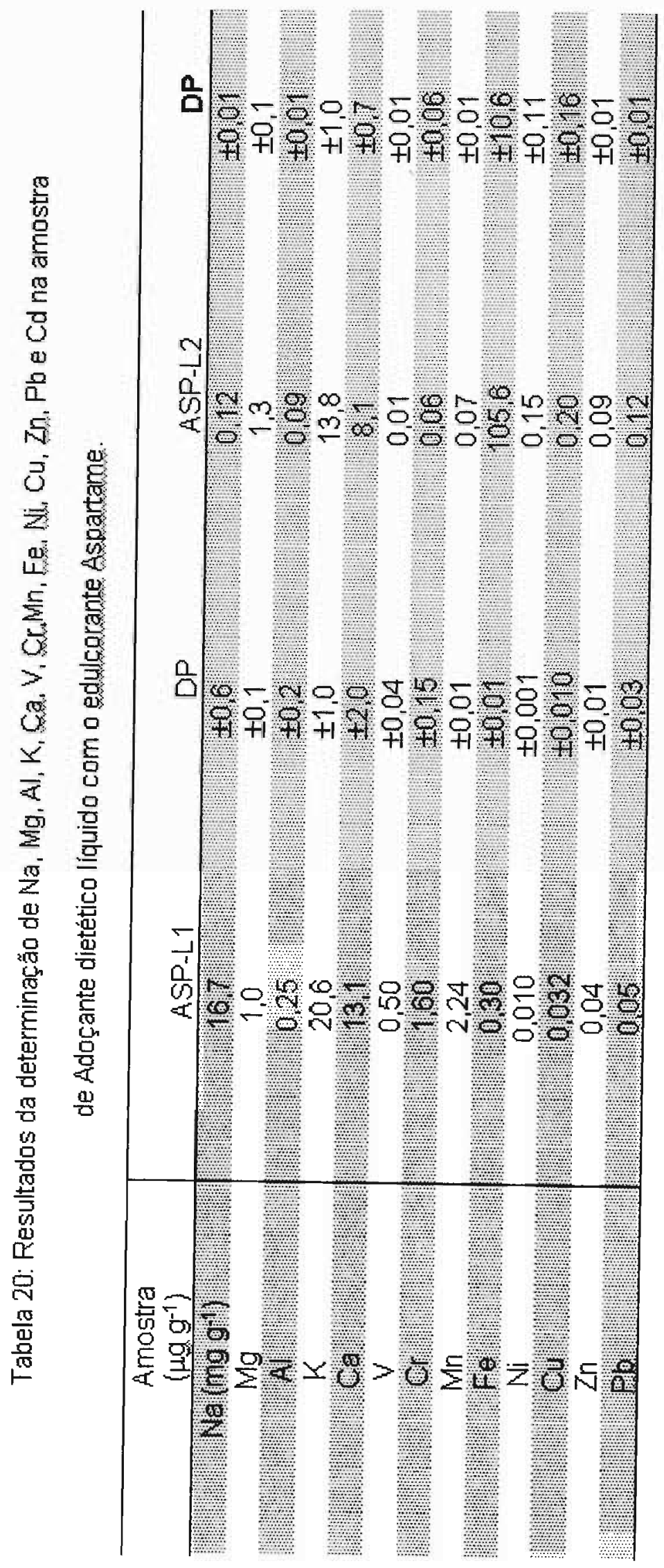




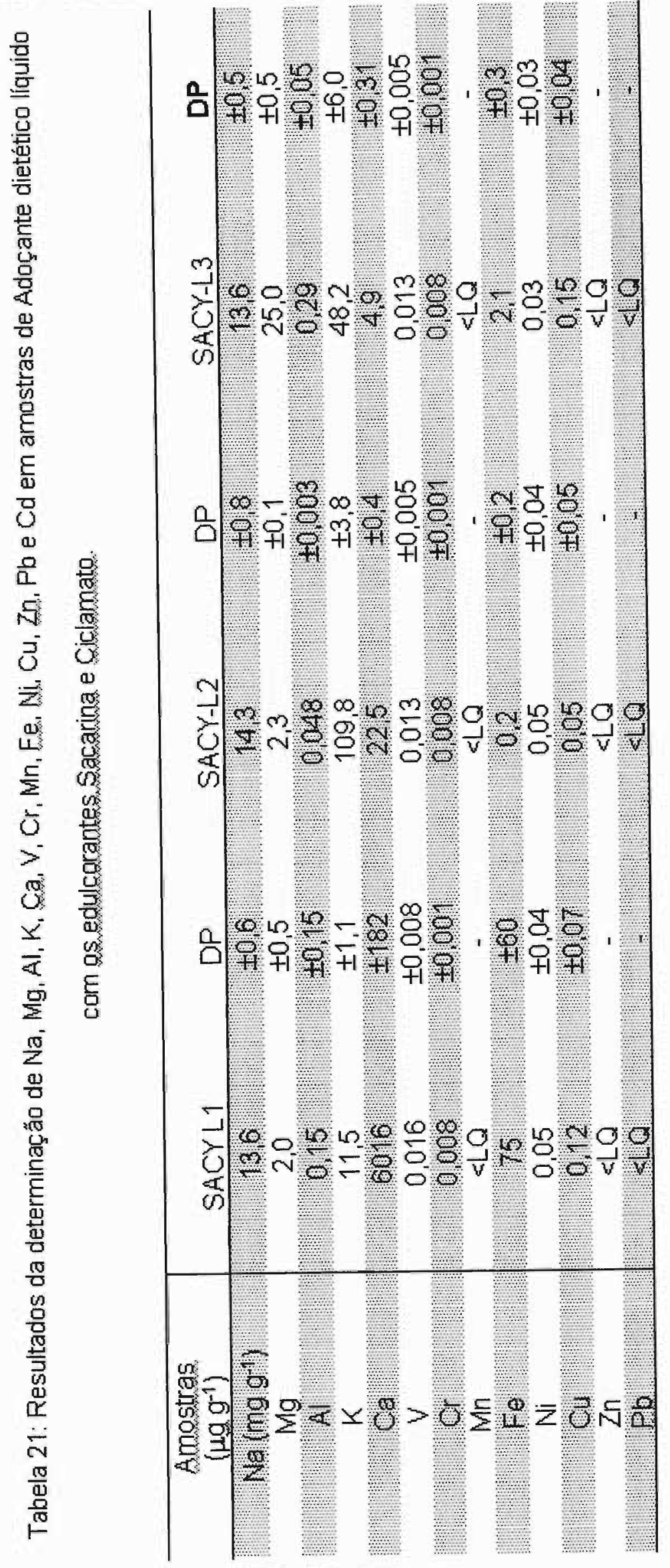




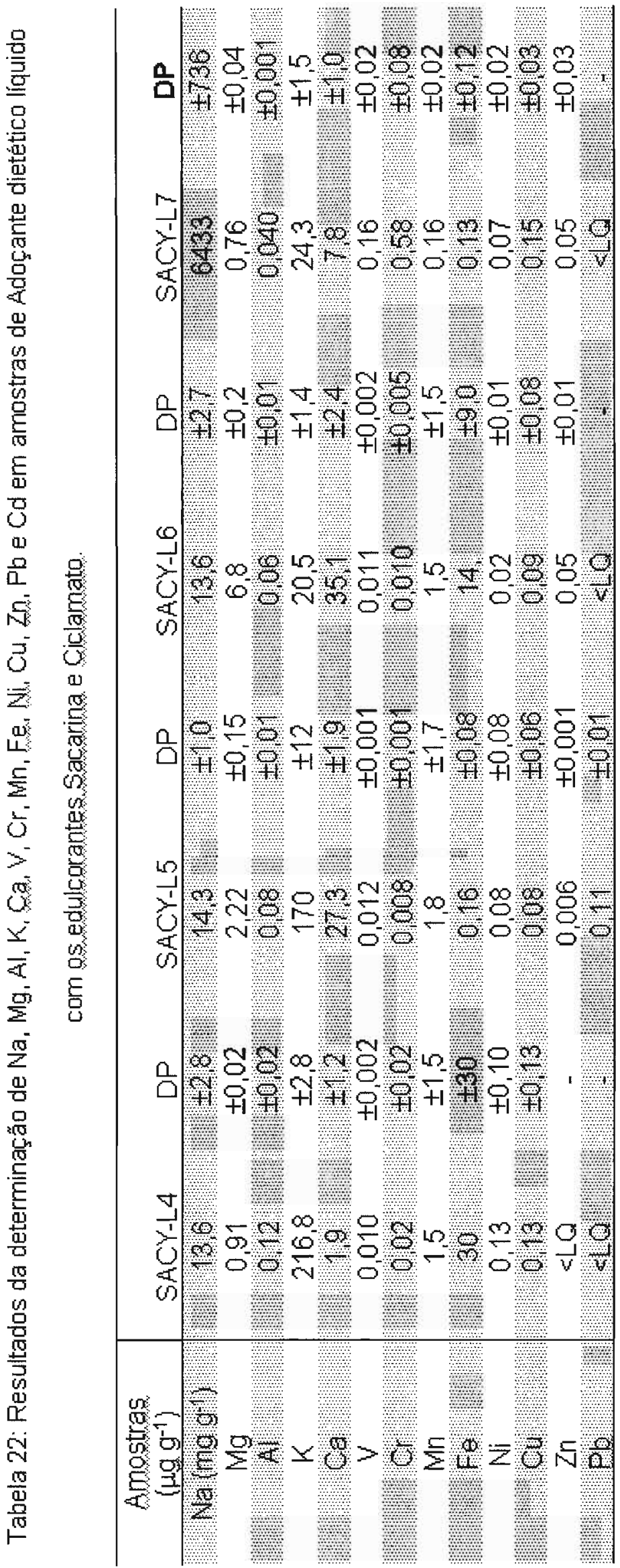




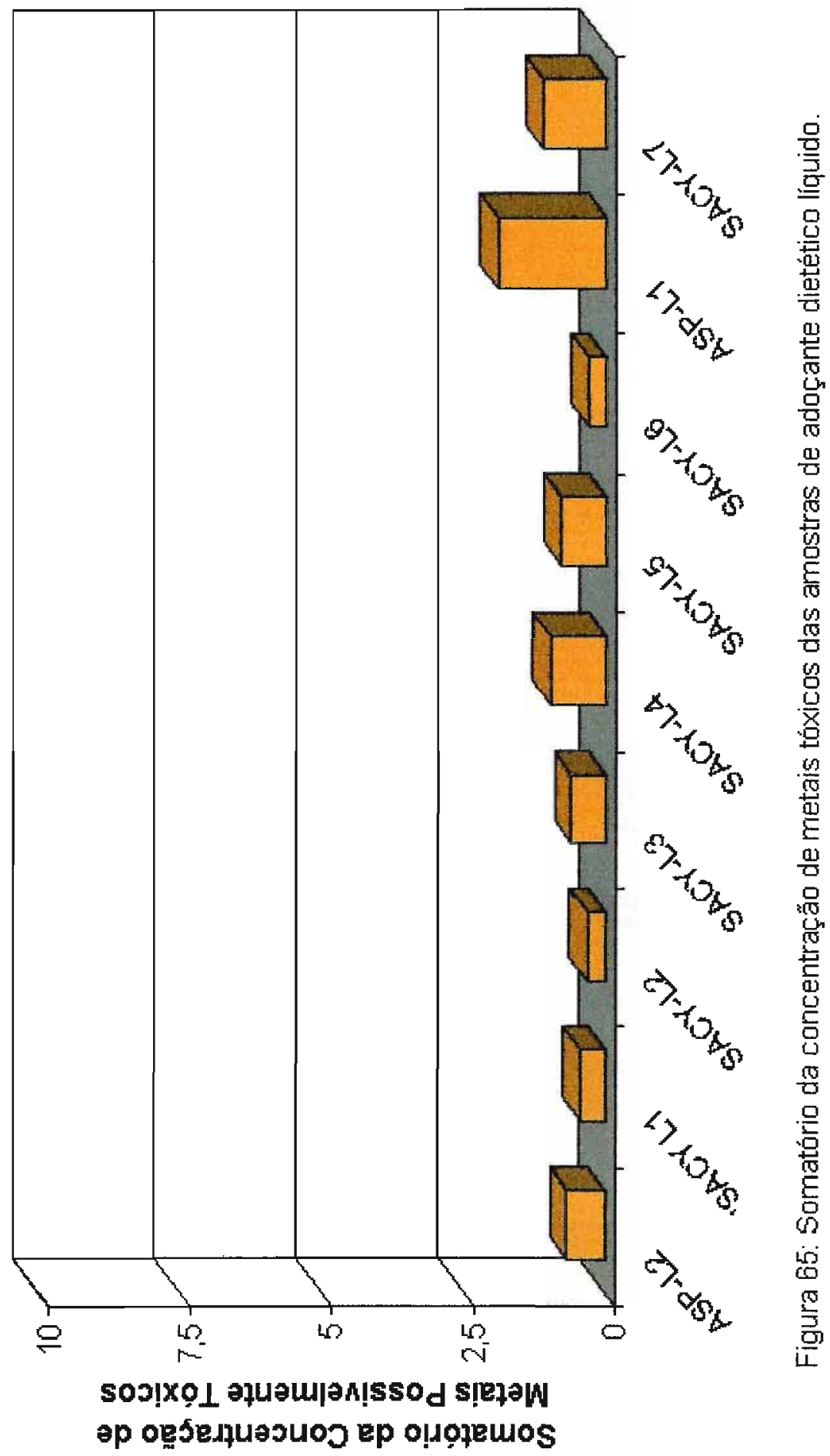




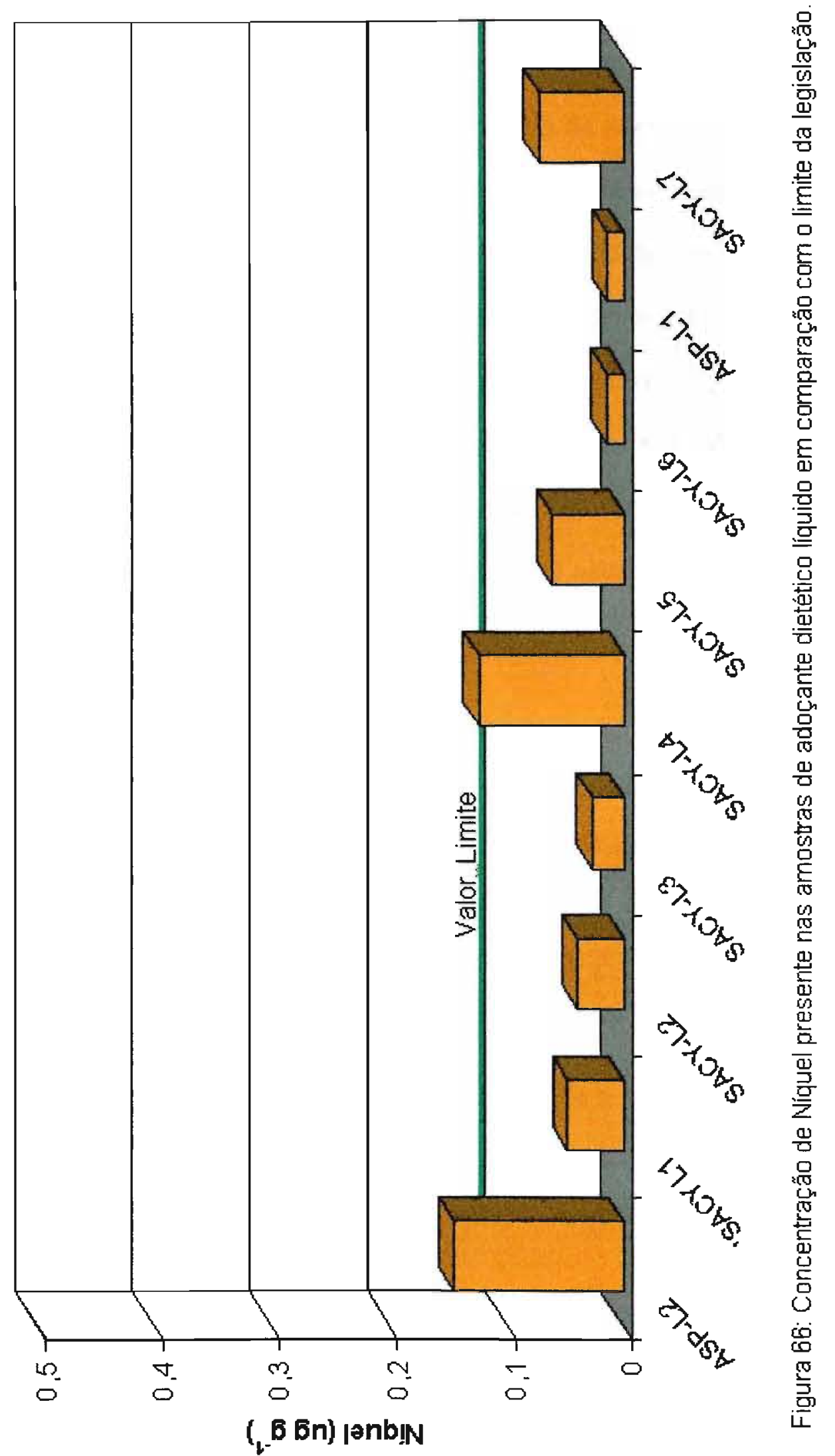




\subsection{IDR de Nutrientes e o consumo de Adoçantes Dietéticos:}

A tabela 23 mostra os valores máximos de $\mathrm{Na}, \mathrm{Ca}, \mathrm{Mg}, \mathrm{Mn}, \mathrm{Fe}$ e $\mathrm{Cu}$ consumidos por um indivíduo adulto que consome $10 \mathrm{~g}$ de adoçante dietético em pó por dia (cerca de 10 envelopes) e a porcentagem que esta ingestão representa em relação a IDR para cada um dos nutrientes analisados. Uma vez que a função do adoçante é restringir o valor calórico da dieta sem incorporar outros nutrientes, não pode haver o consumo não intencional de outros nutrientes.

A tabela 24 mostra os valores máximos de $\mathrm{Na}, \mathrm{Ca}, \mathrm{Mg}, \mathrm{Mn}, \mathrm{Fe}$ e $\mathrm{Cu}$ consumidos por um indivíduo adulto que consome $2,5 \mathrm{~mL}$ de adoçante dietético líquido por dia (cerca de 50 gotas) e a porcentagem que esta ingestão representa em relação a IDR para cada um dos nutrientes analisados.

Tabela 23: Valores máximos de $\mathrm{Na}, \mathrm{Ca}, \mathrm{Mg}, \mathrm{Mn}, \mathrm{Fe}$ e $\mathrm{Cu}$ por $10 \mathrm{~g}$ de adoçante dietético em pó e a porcentagem em relação a IDR destes nutrientes.

\begin{tabular}{c|c|c}
\hline Nutriente & mg/10g de adoçante & \% relativa a IDR \\
\hline $\mathrm{Na}$ & 20,7 & 0,4 \\
$\mathrm{Ca}$ & 4,2 & 0,5 \\
$\mathrm{Mg}$ & 24,5 & 14,2 \\
$\mathrm{Fe}$ & 2,5 & 17,8 \\
$\mathrm{Mn}$ & 42,5 & 1,0 \\
$\mathrm{Cu}$ & 0,1 & 3,0 \\
$\mathrm{Zn}$ & 0,003 & 0,02 \\
\hline
\end{tabular}


Tabela 24: Valores máximos de $\mathrm{Na}, \mathrm{Ca}, \mathrm{Mg}, \mathrm{Mn}$, Fe e $\mathrm{Cu}$ por $10 \mathrm{~g}$ de adoçante dietético líquido e a porcentagem em relação a IDR destes nutrientes.

\begin{tabular}{c|c|c}
\hline Nutriente & $\mathbf{m g} / \mathbf{1 0 g}$ de adoçante & \% relativa a IDR \\
\hline $\mathrm{Na}$ & 167,4 & 0,84 \\
$\mathrm{Ca}$ & 60,1 & 1,88 \\
$\mathrm{Mg}$ & 0,25 & 0,02 \\
$\mathrm{Fe}$ & 1,05 & 1,88 \\
$\mathrm{Mn}$ & 0,05 & 0,03 \\
$\mathrm{Cu}$ & 0,02 & 0,07 \\
$\mathrm{Zn}$ & 0,001 & 0,01 \\
\hline
\end{tabular}

Assim verifica-se que o consumo de adoçante dietético em pó pode interferir significativamente na ingestão dos nutrientes Ferro e Mg. E que o consumo dos adoçantes dietéticos líquidos não interferem significativamente na ingestão de nenhum dos nutrientes analisados.

\subsection{Análise Hierárquica das amostras de Adoçantes Dietéticos:}

A Análise Hierárquica de Agrupamentos AHA (Cluster Analysis) tem como objetivo exibir dados analisados de forma bi-dimensional, de modo a evidenciar os padrões de similaridade no espaço amostral. Os resultados são mostrados na forma de dendogramas, onde a distância entre os pontos reflete a similaridade ou diferença entre as amostras consideradas.

Para efetuar a AHA para as amostras de adoçantes utilizou-se o programa estatístico SPSS (10.0 for Windows) onde foram considerados os valores obtidos 
para as 26 amostras determinadas em triplicata para os 13 elementos analisados, o que faz um conjunto de dados na forma de uma matriz de 78X13.

O conjunto de dados é centrado e re-escalado em função das variâncias dos resultados utilizando o "Ward method", no intervalo dos quadrados das distâncias euclidianas e com padronização Z-scores.

Assim, na figura 67 mostra-se a AHA para os adoçantes dietéticos e observa-se grande similaridade em dois grupos de amostras: no primeiro, os adoçantes líquidos com sacarina e ciclamato apresentam grande similaridade (95\%) e no segundo observa-se um comportamento similar para todos os adoçantes dietéticos em pó excetuando as seguintes amostras STE-P1, SACYP4, SUC-P1, ASP-L1 e SACY-P2, que demonstrou o comportamento mais diferenciado de todo o conjunto. Isso, provavelmente, deve-se a sua apresentação e composição diferenciada, pois em sua fabricação são utulizados $90 \%$ de malto-dextrina para conferir praticidade no consumo, uma vez que sua dosagem seria equivalente à sacarose. 


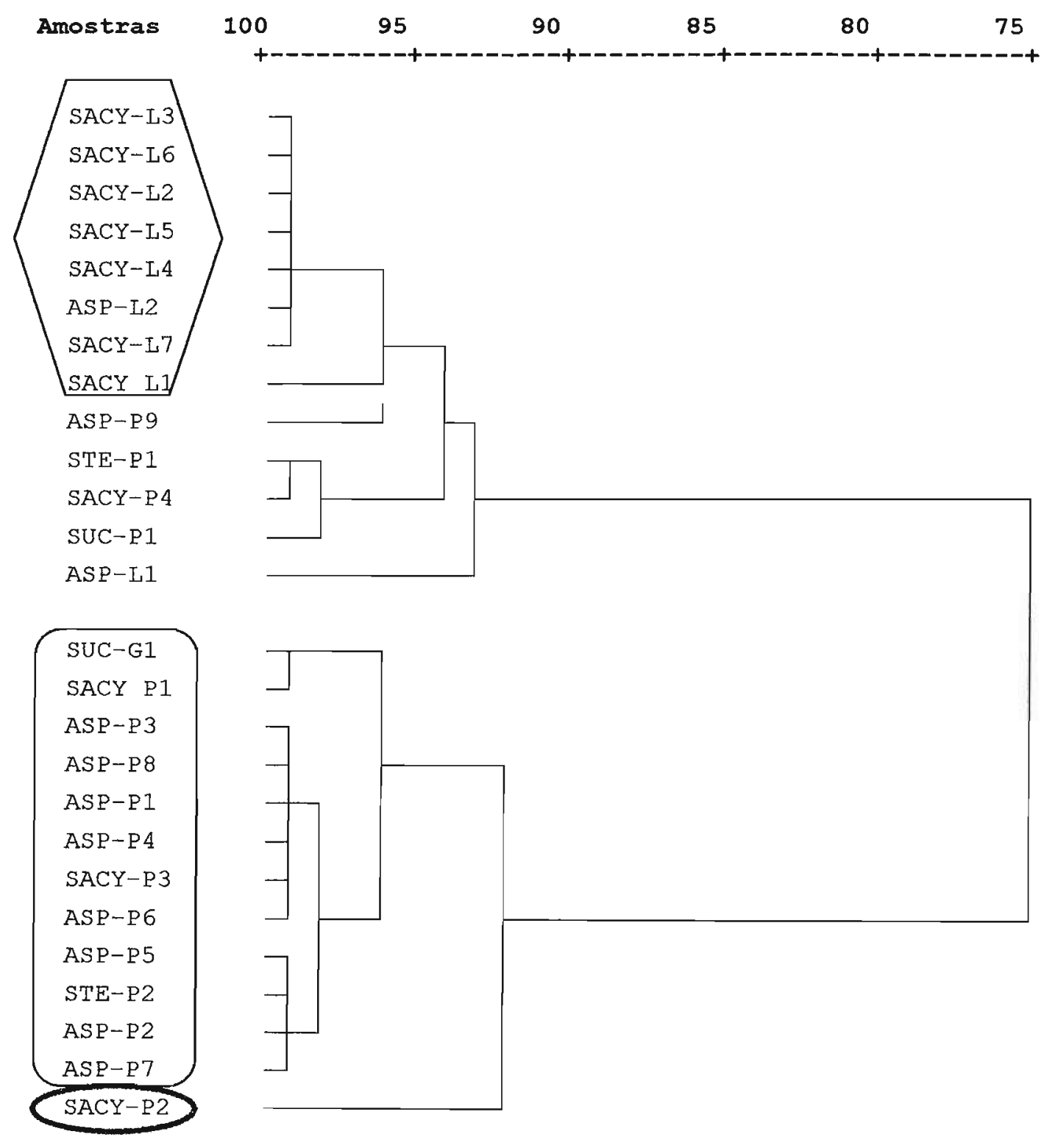

Figura 67: Análise Hierárquica das amostras de Adoçantes Dietéticos. 


\section{CONCLUSÕES}

A técnica de análise elementar por ICP OES atende às necessidades da legislação brasileira para a determinação dos macronutrientes $\mathrm{Na}, \mathrm{K}, \mathrm{Ca}, \mathrm{Mg} \theta$ dos microelementos essenciais $\mathrm{Fe}, \mathrm{Cu}, \mathrm{Zn}, \mathrm{Cr}, \mathrm{Mn}$ e Se e dos potencialmente tóxicos $\mathrm{Al}, \mathrm{Sn}, \mathrm{Ni}, \mathrm{As}, \mathrm{Cd}$ e $\mathrm{Pb}$ em adoçantes sólidos e líquidos,

A possibilidade da análise sem o tratamento prévio da amostra foi confirmada, pois os resultados das determinações por resíduo de cinzas e por dissolução em microondas de alta pressão mostraram-se equivalentes, quando aplicado o teste t pareado para um nível de confiança de 95\%, após o ajuste das condições operacionais do ICP OES.

Uma das vantagens da determinação sem o tratamento prévio da amostra é a rapidez e facilidade de preparar a diluição ou dissolução conveniente à determinação.

O recurso da determinação simultânea do espectro favorece a precisão da determinação, uma vez que vários comprimentos de onda podem ser selecionados sem aumento no tempo ou no custo de análise.

Foi estabelecida condição de análise adequada para 36 linhas analíticas das 74 investigadas para a determinação por ICP OES com vista axial.

O valor do resíduo de cinzas nas amostras de adoçantes dietéticos sólidos analisadas está adequado à legislação, $<4 \%$. 
Nenhuma amostra de adoçante excedeu o valor recomendado para o somatório dos contaminantes inorgânicos (ASPARTAME $<10 \mu \mathrm{g} \mathrm{g}^{-1}$ e SACARINA $\left.<20 \mu \mathrm{g} \mathrm{g}^{-1}\right)$.

Os adoçantes em pó apresentam níveis maiores de metais potencialmente tóxicos $\left(\approx 5 \mu \mathrm{g} \mathrm{g}^{-1}\right)$ que os adoçantes líquidos $\left(\approx 2,0 \mu \mathrm{g} \mathrm{mlL}^{-1}\right)$.

As amostras ASP-P9, STE-P1, SUC-P1, SUC-G1, SACY-P1 e SACY-P4 excederam o valor limite da legislação para Arsênio $\left(1,0 \mu \mathrm{g} \mathrm{g}^{-1}\right)$.

As amostras de adoçante em pó ASP-P2, ASP-P4, ASP-P5, ASP-P7, STEP2, SACY-P2 e SACY-P3 excederam o valor limite da legislação para Cromo $(0,1$ $\left.\mu \mathrm{g}^{-1}\right)$

A amostras de adoçante líquido ASP-L2 e SACY-L4 excederam o valor limite da legislação para Níquel $\left(0,1 \mu \mathrm{g} \mathrm{g}^{-1}\right)$.

O consumo de adoçante dietético em pó pode interferir significativamente na ingesta dos nutrientes Ferro (14,2 \% da IDR) e Mg (17,8\% IDR). E o consumo dos adoçantes dietéticos líquidos não interferem significativamente na ingestão de nenhum dos nutrientes analisados. 


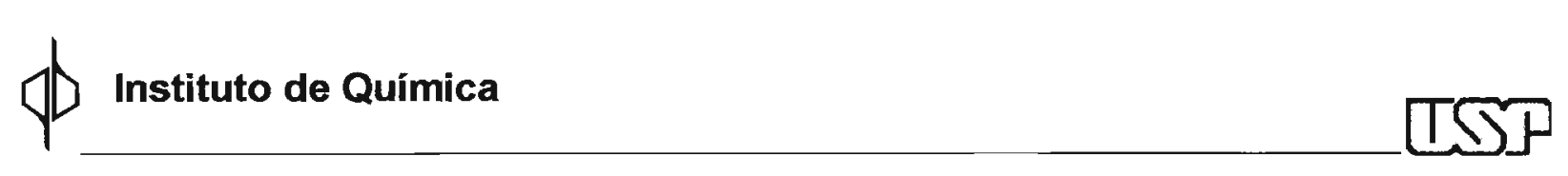

TRABALHOS FUTUROS

- Estudos do uso de padrão Interno em ICP-OES axial para a determinação elementar em matrizes complexas de alimentos.

- Estudos de Padronização interna com múltiplos comprimentos de onda do mesmo elemento.

- Implementar as Análises "Full Scan" e correções adequadas à análise por ICP-OES axial. 


\section{REFERÊNCIAS}

1. MIYAGISHIMA, K. MOY,G.,MIYAGAWA, S. MOTARJEMI, Y., KÄFERSTEIN, F.K., Food Safety and Public Healyh. Food Control. 6, 5, 253-259 (1995).

2. PALAEZ V. A dinâmica Econômica da inovação no campo dos edulcorantes sintéticos. Cadernos de Ciência e Tecnologia. Brasília, 10, 1/3, 93117 (1993).

3. MONTASER, A.;GOLIGHTLY, D.W. Inductively Coupled Plasma in Analitical Atomic Spectrometry. VCH Publishers. Washington DC, 2a.ed. 1992.

4. PIMENTEl M. F.; BaRRos NeTO, B.; ARAUjo M.C.U.; PASQUINI C. Simultaneous Multielemental determination using a low-resolution ICP OES/ diode array detection system. Spectrochim. Acta 52B (1997) 2151-2161.

5. BRASIL, Portaria SVS $n^{0} .29$ Secretaria de Vigilância Sanitária. Diário Oficial da União de 13 de janeiro de 1998.

6. FOOD AND AGRICULTURE ORGANIZATION OF THE UNITED NATIONS/ WORLD HEALTH ORGANIZATION. Codex Alimentarius Comission. Codex guidelines on nutrition labelling. CAC/GL 2-1985. Rome, 33-41 (1985).

7. LAWRANCE, J.F. Enciclopaedia of Food Science Food Technology and Nutrition, Academic Press, 3951-3952 (1993).

8. BARUFFALDI, R.; STABILE, M.N.O. Tecnologia de alimentos Dietéticos. Módulo I: Edulcorantes, Universidade de São Paulo. Faculdade de Ciências Farmacêuticas, 57-62 (1991).

9. AGER, D. J.; PANTALEONE, D. P.; HENDENSON, S. A.;KATRITZKY,A. R.; PRAKASH,I.; WALTERS, D.E. Commercial, Synthetic Nonnutritive Sweeteners. Angew. Chem. Int., 37,1802-1817 (1998), 
10. CRAMMER, B.; IKAN, R. Progress in the chemistry and properties of rebaudiosides. In : Grenby, T. H. Developments in Sweeteners: Elsevier Applied Science, .45-64 (1987).

11. SAKAGUCHI, M. E COL. Esteviosídeo um promissor adoçante natural. Alimentação, 66, 56-68, maio/jun (1983).

12. GRENBY, T. H. Intense sweeteners for the food industry: in overview. Trends in Food Science \& Technology, 2, 7, 2-6 (1991).

13. JONES, J. M. Everything you wanted to know about the safety of acessulfame-K Cereal Foods World, 37, 4, 329-330 (1992).

14. FRANZ, M. et al. Position of the American Dietetic Association : use of nutritive and nonnutritive sweeteners. Journal of The American Dietetic Association, 93, 7, 816-821 (1993).

15. GIESE, J. H. Developing low-fat meat products. Food technology, 47, 1, 114126, (1993).

16. CÂNDIDO, L. M. B.; CAMPOS, A M. Alimentos para Fins Especiais: Dietéticos. São Paulo: Livraria Varela, 1995.

17. DEIS, R. C. Adding bulk without adding sucrose. Cereal Foods World, Dec, 12, 94 (1993),

18. BIRCH, G. G. et al. Chemical and biochemical mechanisms of sweetness. Food Technology, 45, 11, 114-120, (1991).

19. NEWBRUN, E. Dental effects of sugar and sweeteners. In: Kretchmer, N.;Hollenbeck, C. B. Sugars and Sweeteners. Boca Raton: CRC Press, 175-202 (1991).

20. http://www1. uol.com. br/cyberdiet/colunas/010725 nut $\times$ tabela adocantes. ht m acesso em 16/02/2003. 
21. http://www1.uol.com.br/cyberdiet/colunas/010725 nut $\times$ tabela adocantes2.ht m acesso em 16/02/2003

22. BRASIL, Decreto $n^{\circ} .55 .871$. Diário Oficial da União. 29 de maio de 1965.

23. BRASIL, Decreto-Lei n̊.986. Diário Oficial da União. 21 de outubro de 1969.

24. BRASIL, Decreto-Lei $n^{\circ} .74 .170$. Diário Oficial da União. 11 de junho de 1974.

25. BRASIL, Lei n.6.360. Diário Oficial da União. 24 de setembro de 1976.

26. BRASIL, Comunicado nº.08/81. DINAL. 13 de outubro de 1981.

27. BRASIL, Processo $n^{0} .11 .782$. SNVS. de 1980.

28. BRASIL, Portaria $n^{\circ} .14$ da DINAL . Diário Oficial da União. 12 de setembro de 1986 .

29. BRASIL, Portaria $n^{0} .1$ da SNVS. Diário Oficial da União. 07 de janeiro de 1988.

30. BRASIL, Portaria $n^{0} .23$ da SNVS. Diário Oficial da União. 04 de abril de 1988.

31. BRASIL, Portaria $n^{0} .25$ da SNVS. Diário Oficial da Uniăo. 07 de abril de 1988 .

32. BRASIL, Resolução $n^{0} .113$ da SNAD . Diário Oficial da União. 21 de novembro de 1988.

33. BRASIL, Portaria $n^{0} .234$ da SVS. Diário Oficial da União. 21 de maio de 1996.

34. BRASIL, Portaria n.1.549/97 do MS. Diário Oficial da União.

35. MERCOSUR. Grupo Mercado Comum. Subgrupo de Trabajo no. 3. Resolucion no. 36/93. Regulamento técnico MERCOSUR para alimentos envasados. 8 (1993),

36. FOOD ADDITIVE UPDATE. Food in Canada, 53, 3, 16-28, 35-46, (1993). 
37. ORGANIZAÇÃO MUNDIAL DE SAÚDE. Elementos traço na Nutrição e saúde Humanas. Tradução Andréa Favano, São Paulo, Roca, 1998.

38. DUTRA-DE-OLIVEIRA, J. E.; MARCHINI, J. S. Ciências Nutricionais SarvierSão Paulo, 107-162 (1998),

39. GREGER J.L. BAIER M.J. Excretion and retention of low or moderate levels of aluminium by human subjects. Food Chem. Toxic. 21,473-476 (1983). 40. WHO FOOD ADDITIVES SERIES. Toxicological evaluation of certain food additives and contaminants. Cambridge University Press, 24, 113-153(1998).

41. MIDIO, A. F., MARTINS, D. I. Toxicologia de alimentos. Ed. Varela, São Paulo, 295p (2000),

42. PARR R.M. CRAWLEY H. Dietary intake of minor and trace elements: a global survey. International Atomic Energy Agency 1-3, 1990.

43. WHO TECHNICAL REPORT SERIES. Evaluation of certain food additives and contaminants. Geneva:World Health Organization, 776, 1989.

44. BRASIL, Portaria No 33, da Secretária de Vigilância Sanitária, do Ministério da Saúde de 13 de Janeiro de 1998.

45. D. M. CZAJKA-NARINS, Alimentos, Nutrição e Dietoterpia, $8^{a}$. ed., São Paulo Rocca, 113-144 (1994),

46. BENNETT, E.G. Changing metal cycles and human health. Nriagu JO ed. Berlin, Springer-verlag, 345-356 (1984),

47. WHO TECHNICAL REPORT SERIES. Evaluation of certain food additives and contaminants. Geneva:World Health Organization, 837, 1993.

48. WHO FOOD ADDITIVES SERIES. Toxicological evaluation of certain food additives and contaminants. Geneva:World Health Organization, 24:163-219, 1989. 
49. WILLIAMS, D.M. Toxicological evaluation of certain food additives and contaminants. Geneva:World Health Organization, 24:163-219, 1989.

50. OFFENBACHER E. G. et al. Metabolic chromium balances in men. American journal of clinical nutrition. 44:77-82, 1986,

51.BERBERÁ, R. FARRÉ, R. LOZANO, A. Oral intake of cadmium, lead, cobalt, chromium, nickel, manganese and zinc in the Spanish diet, estimated by duplicate meal study. Journal of micronutrient analysis. 6: 47-57 1989.

52. NATIONAL RESEARCH CONCIL. Recommended dietary allowances, $10^{\text {th }}$ ed Washington, DC, National Academy of Scienc, 1989.

53. HAZARDOUS SUBSTANCES DATA BANK. Manganese. National Library Medicine. Canadian Center for Ocupational Health and Safety 2000-4 (nov 2000). 54. BRASIL, Decreto $n^{\circ} .50 .040$. Diário Oficial da União. 24 de janeiro de 1961 , 55. BRASIL, Decreto $n^{0}$.55.871. Diário Oficial da União. 26 de março de 1965. 56. BRASIL, Portaria $n^{\circ} .685$ da SNVS. Diário Oficial da União. 27 de agosto de 1998.

57.PACHIONE, R. Industria do diet engorda as vendas. Revista Química $\theta$ Derivados. http://www.quimica.com.br/revista/gd419/edulcorantes1.htm acesso 16/03/2003.

58. TURCO, D. Mercado saudável ganha fôlego. Revista Distribuição http://www.revistadistribuicao com br/content asp?page $=225$ acesso16/03/2003 59.KRUG, J.F. III Workshop sobre Preparo de Amostras, São Carlos, 2002, $150 p$,

60. HOENING, M., KERSABIEC, A.M. Sample Preparation steps for analysis by atomic spectroscopy methods: Present Status. Spectrochim. Acta 51B 12971307 (1996). 
61. MAGALHÃES, C. E. C., ARRUDA, M. A. Z. Amostragem de Suspensões:

Emprego da Técnica de Análise Direta de Amostras. Química Nova 21(4) 459466 (1998).

62. SING. R. Direct Sample Insertion for Inductively Coupled Plasma Spectrometry. Spectrochim. Acta 54B 411-441 (1999).

63. THIEL, G., DANZER K. Direct analysis of mineral components in wine by Inductively coupled plasma optical emission spectrometry (ICP OES). Fresenius J. Anal. Chem. 357:553-557(1997),

64. BURNS, D.T. et al. Use of the terms "recovery" and "apparent recovery" in analytical procedures. Pure and Applied Chemistry, 74, 2201-2205 (2002),

65. CAROLI,S., FORTE, G., IAMICELI, A. L. GALOPPI, B. Determination of essencial and potentialy toxic trace elements in honey by ICP-based techniques. Talanta 50 327-336(1999).

66. MORGANO, M.A., QUEIROZ, S.C.N., FERREIRA M.C. Determinação dos teores de minerais em sucos de frutas por espectrometria de emissão óptica em plasma indutivamente acoplado (ICP OES).Ciência e Tecnologia de Alimentos. 19, 3 set./dez (1999).

67. FASSEL, V.A. ICP Information Newsletter, 1, 3, (1975) apud BARNES, R. M. Recent advances in emission spectroscopy: Inductively coupled plasma discharges for spectrochemica analysis. CRC Critical Reviews in analytical chemistry, 203 (1978).

68. FASSEL, V.A. ICP Information Newsletter, 1, 267(1975) apud BARNES, R. M. Recent advances in emission spectroscopy: Inductively coupled plasma discharges for spectrochimica analysis. CRC Critical Reviews in analytical chemistry, 203 (1978). 
69. GREENFIELD, S. MCDEACHIN H.M.C.D., SMITH, P.B. Plasma emission sources in analytical Spectrometry-III. Talanta, 23, 1-14 (1976).

70. GREENFIELD, S. MCDEACHIN H.M.C.D., SMITH, P.B. Plasma emission source s in analytical Spectrometry-II. Talanta, 23, 553-562 (1975),

71. GREENFIELD, S. MCDEACHIN H.M.C.D., SMITH, P.B. Plasma emission sources in analytical Spectrometry-I. Talanta, 22, 1-15 (1975).

72. MOORE G.L. Introduction to Inductively coupled plasma atomic emission spectrometry (ICP OES). Analytical Specroscopy Library, 3, Elsevier NY (1989), 73. DENNAUD, J., HOWES, A., POUSSEL,E., MERMET, J.M. Study of ionic-toatomic line intensity ratios for two axial viewing-based inductively coupled plasma atomic emission spectrometrs. Spectrochim. Acta 56B 101-112 (2001). 74. HEITLAND, P. BRANDT, T. ARDELT, D. KRENGEL-ROTHENSEE, K, WIEBERNEIT,N. Trace Analysis in water samples. Aplication Note ICP-4 Spectro Ciros CCD, SPECTRO REPORT

75. TODOLÍ, J.L.; GRAS, L.; HERNANDIS, V.; MORA, J. Elemental Matrix effects in ICP-AES. J. Anal. At. Spectrom., 17, 142-169 (2002),

76. VAN VEEN, E.H.; DE LOOS-VOLLEBREGT, M.T.C. Application of mathematical procedures to background corretion and multivariate analysis in inductively coupled plasma atomic emission spectrometry. Spectrochim. Acta 53B 639-669 (1998),

77.R. KUCHARKOWSKI, D. JANKOVA, E. HERRMANN, A. JOHN. Contribuitions to acuracy improvement of Simultaneous ICP atomic emission spectrometry using multi-line measurements of analyte and internal standard elements Applications for the analysis of permalloy. Fresenius J. Anal. Chem. 361 532-539(1998). 
78. VAN VEEN, E.H.; DE LOOS-VOLLEBREGT,M. T. C. On the use of line intensity ratios and power adjustment to control matrix effects in inductively coupled plasma atomic emission spectrometry. J. Anal. At. Spectrom. 831-838 (1999).

79.SADLER, D.A.; SUN, F.; HOWE, S.E.; LITLLEJOHN, D. Comparasion of Procedures for Correction of Matrix Interferences in the Multi-element Analysis of Soil by ICP OES with a CCD Detection System. Microchimica Acta $126126-311(1997)$

80. HAALAND, D.M.; CHAMBERS, W.B.; KEENAN, M.R.; MELGAARD, D.K. Multi-window Classical Least-Squares Multivariate Calibration Method for Quantitative ICP-AES Analyses. Applied Spectroscopy, 54,9, 1291-1301(2000).

81. J.M. MERMET, Use of magnesium as a test element for inductively coupled plasma atomic emission spectrometry diagnostics Anal.Chim. Acta, 250, 85 (1991)

82. Brasil, Portaria INMETRO n 029, de 10 de março de 1995.

83. FUNK, W.;DAMMANN,V. DONNEVERT,G. Quality assurance in Analytical Chemistry. VHC Publisher, p 40,1995.

84. BUZOIANU,M. ABOUL-ENEIN,H. Y. The tracebility of analytical measurements. Acreditation and Quality Assurance, 2,11-17 (1997).

85. Talanta GSAM

86. NORMAS ANAIÍTICAS DO INSTITUTO ADOLFO LUTZ. Vol 1 Métodos Químicos e Físicos para analises de Alimentos.

87. VASCONCELLOS, L.M.H.; LAURIA, D.C.; SILVA, L.H.C. Relação entre as massas úmida, seca e cinzas em materiais biológicos. Química Nova. 22(6) 1999. 
88. SMITH, F.E.; ARSENALT, E.A. Microwave-assisted Sample preparation in Analitical Chemistry. Talanta, 1207-1268 (1996).

89. TRIPKOVIC, M.R.;HOLCLAJTNER-ANTUNOVIC,I.D. Stud of Matrix effect of esily and non-esily ionizable elements in an Inductively Coupled Argon Plasma-Part 1Spectroscopy Diagnostics. J.Anal.At. Spectrom.8, 349-357(1993). 90. TRIPKOVIC, M.R.;HOLCLAJTNER-ANTUNOVIC,I.D. Stud of Matrix effect of esily and non-esily ionizable elements in an Inductively Coupled Argon Plasma-Part 2 Equilibrium Plasma Composition.J.Anal.At. Spectrom. 8, 359-365 (1993).

91. GOUVEIA, S.T.,SILVA, F.T., COSTA, L.M., NOGUEIRA, A. R.A., NÓBREGA, J.A. Determination of residual carbon by inductively -Coupled plasma optical emission spectrometry with axial and radial view configurations. Analitica Chimica Acta 269-275(2001).

92. C. DUBUISSON, E. POUSSEL, J.L. TODOLI,J.M. MERMET Effect of Sodium during the aerosol transport and filtering in Inductively Coupled Plasma atomic emission spectrometry. Spectrochim. Acta 53B (1998) 593-600. 
Anexo I: Minerais na composição do corpo humano.(Em adulto saudável de $70 \mathrm{Kg}$ )

Macronutrientes

\begin{tabular}{c|c|c}
\hline MINERAL & FUNÇÃO NO ORGANISMO & GRAMAS \\
\hline CÁLCIO & OSSOS E DENTES & 1.100 \\
FÓSFORO & OSSOS E DENTES & 750 \\
POTÁSSIO & ELETRÓLITO INTRACELULAR & 225 \\
ENXÔFRE & AMINOÁCIDOS, PELE E CABELOS & 150 \\
CLORO & ELETRÓLITO & 100 \\
SÓDIO & ELETRÓLITO EXTRACELULAR & 90 \\
MAGNÉSIO & ELETRÓLITO METABÓLICO & 35 \\
SILÍCIO & TECIDO CONJUNTIVO & 30 \\
\hline
\end{tabular}

Micronutrientes

\begin{tabular}{c|cc}
\hline MINERAL & FUNÇÃO NO ORGANISMO & MILIGRAMAS \\
\hline FERRO & HEMOGLOBINA, TRANSPORTE & 4.200 \\
FLÚOR & DE OXIGÊNIO & 2.600 \\
ZINCO & OSSOS E DENTES & 2.400 \\
ESTRÔNCIO & INTEGRIDADE ÓSSEA & 320 \\
COBRE & CO-FATOR ENZIMÁTICO & 90 \\
COBALTO & NÚCLEO DA VITAMINA B12 & 20 \\
VANÁDIO & MIETABOLISMO LIPÍDICO & 20 \\
IÔDO & HORMÔNIOS DA TIREÓIDE & 15 \\
ESTANHO & DESCONHECIDA & 15 \\
\hline
\end{tabular}




\section{Anexo II: Definição de Caloria}

A energia proveniente dos alimentos pode ser expressa em calorias, ou mais corretamente em quilocalorias (Kcal), unidade que representa a quantidade de calor necessária para elevar de 14,5 a $15,5^{\circ} \mathrm{C}$ a temperatura de $1 \mathrm{~kg}$ de água,

O valor energético dos alimentos de baixo valor calórico deverá constar do rótulo do produto, expresso em quilocalorias, de acordo com a portaria da SNVS/MS de 04/04/1988. 


\section{Anexo III: Estudo fatorial $2^{2}$ para a otimização dos parâmetros da análise por ICP-OES.}

Abaixo observa-se o estudo fatorial $2^{2}$ para a otimização dos parâmetros de análise por ICP-OES. Onde foram realizados 6 ensaios em dois níveis para dois fatores (potência, fluxo do nebulizador) e dois pontos centrais e como resposta a razão do BEC entre as linhas iônicas e atômicas do Magnésio.

\section{Desenho Factorial 22 Completo com ponto central 2 Fatores}

Potência RF (1200 a $1400 \mathrm{~W})$

Fluxo do Nebulizador $\left(0,8\right.$ a $0,9 \mathrm{~L} \cdot \mathrm{mim}^{-1}$

Com 2 replicatas no ponto Central

\section{Resposta}

Razão de Intensidade das linhas iônica $(280,270 \mathrm{~nm})$ e atômica $(285,213 \mathrm{~nm})$ do Magnésio.

Razão Mgll/Mgl

\begin{tabular}{|c|c|c|c|c|}
\hline \multirow[b]{2}{*}{ Ensaio } & \multicolumn{2}{|r|}{ Mgll } & & Razão Mgll/Mgl \\
\hline & 1 & 280.278 & $285.21 \%$ & \\
\hline \multirow{3}{*}{1} & Adição & 1120387 & 474121,4 & 2,389 \\
\hline & Branco & 162237 & 8333.39 & \\
\hline & Adição & 259955,8 & 309001 & 0,840 \\
\hline \multirow[t]{2}{*}{2} & Branco & 6658.39 & 732401 & 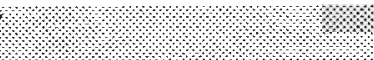 \\
\hline & Adição & 2179502 & 716975,5 & 3,092 \\
\hline \multirow[t]{2}{*}{3} & Brance & 17773,43 & 17926.22 & \\
\hline & Adição & 1106663 & 542355 & 2,074 \\
\hline \multirow[t]{2}{*}{4} & Branco & (: $: .16014 .62$ & 16476.02 & : : \\
\hline & Adição & 1090358 & 499283 & 2,213 \\
\hline \multirow[t]{2}{*}{5} & Branco & $11 / 124$ & $1 / 601,62$ & \\
\hline & Adição & 1109384 & 525041,8 & 2,139 \\
\hline 6 & Branco & 11216.37 & 1158988 & \\
\hline
\end{tabular}


Representação gráfica do fatorial codificado.

Cálculo dos Fatores

Pontos Fatoriais

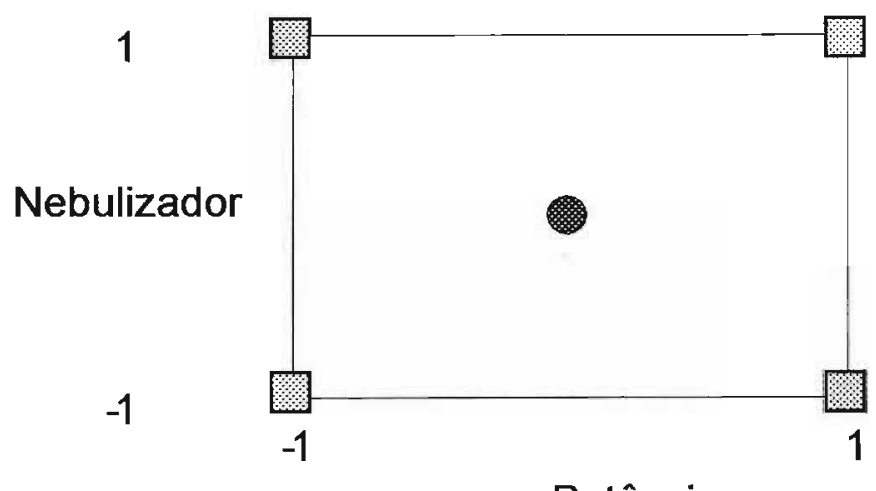

Potência

\begin{tabular}{|l|l|l|l|l|l|}
\hline Term & Effect & Coef & SE Coef & T & P \\
\hline Constant & & 2,0985 & 0,02616 & 80,21 & 0,008 \\
\hline Pot & $-1,2840$ & $-0,6420$ & 0,02616 & $-24,54$ & 0,026 \\
\hline Neb & 0,9690 & 0,4845 & 0,02616 & 18,52 & 0,034 \\
\hline Pot ${ }^{\star} \mathrm{Neb}$ & 0,2660 & 0,1330 & 0,02616 & 5,08 & 0,124 \\
\hline Ct Pt & & 0,0775 & 0,04532 & 1,71 & 0,337 \\
\hline
\end{tabular}

Análise da Regressão

\begin{tabular}{|c|c|c|c|c|c|c|}
\hline Source & DF & Seq SS & Adj SS & Adj MS & F & $P$ \\
\hline $\begin{array}{c}\text { Main } \\
\text { Effects }\end{array}$ & 2 & 2,58762 & 2,58762 & 1,29381 & 472,54 & 0,033 \\
\hline $\begin{array}{c}\text { 2-Way } \\
\text { Interactions }\end{array}$ & 1 & 0,07076 & 0,07076 & 0,07076 & 25,84 & 0,124 \\
\hline Curvature & 1 & 0,00801 & 0,00801 & 0,00801 & 2,92 & 0,337 \\
\hline $\begin{array}{c}\text { Residual } \\
\text { Error }\end{array}$ & 1 & 0,00274 & 0,00274 & 0,00274 & & \\
\hline Pure Error & 1 & 0,00274 & 0,00274 & 0,00274 & & \\
\hline Total & 5 & 2,66912 & & & & \\
\hline
\end{tabular}


Normal Probability Plot of the Standardized Effects

(response is Mgll/Mgl, Alpha $=, 05$ )

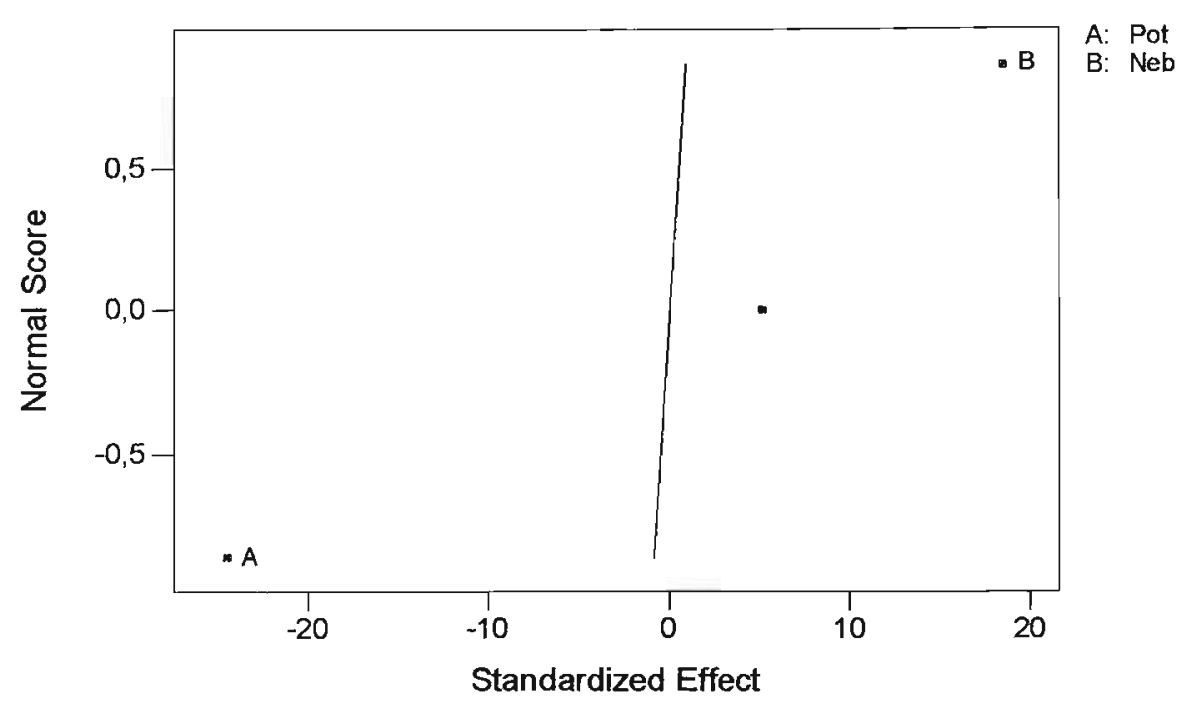

Gráfico Normal das Probabilidades

Pareto Chart of the Standardized Effects

(response is MgIl/Mgl, Alpha $=, 05$ )

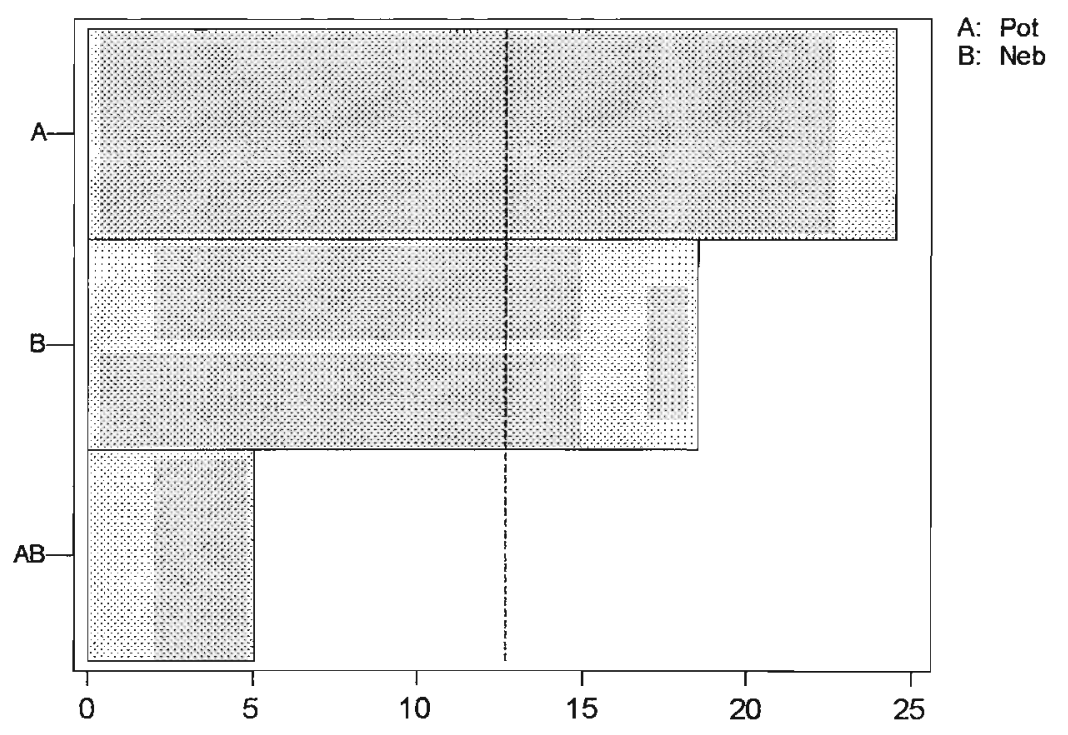

Gráfico de Pareto para os Efeitos 


\section{Interaction Plot (data means) for Mgli/Mgl}

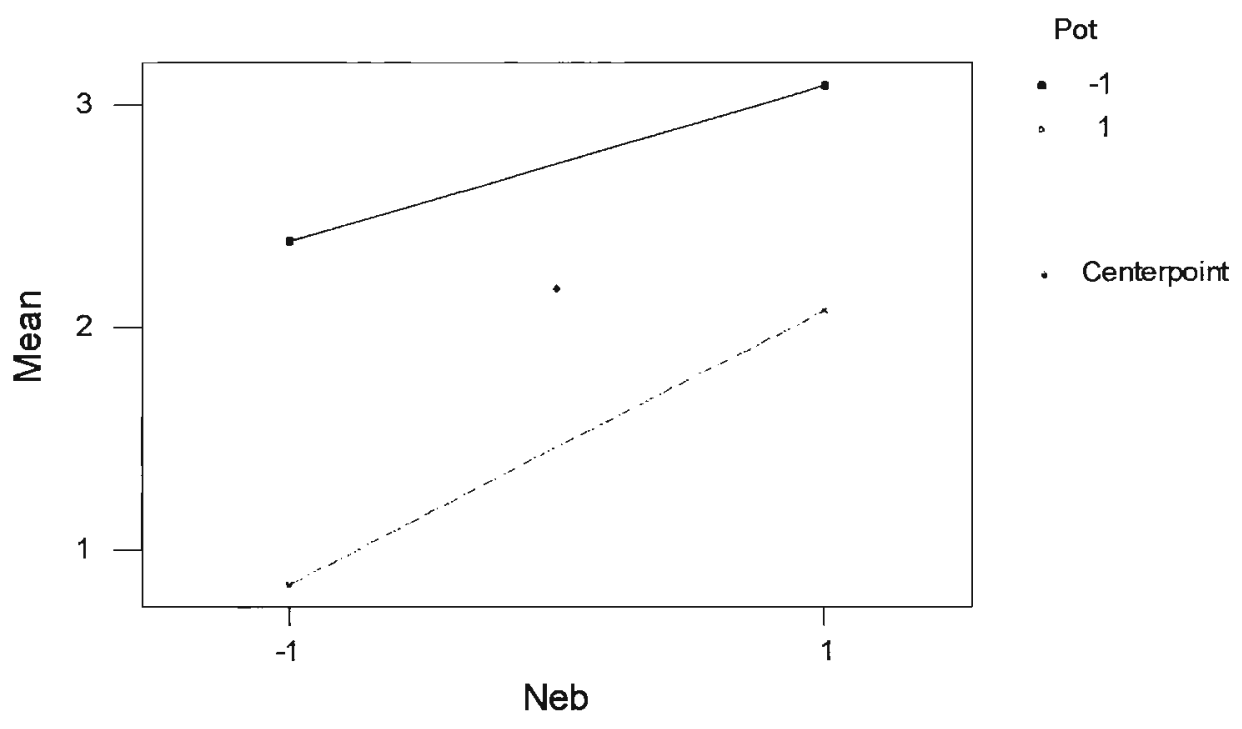

Gráfico de interação dos efeitos

- Centerpoint Main Effects Plot (data means) for Mgll/Mgl

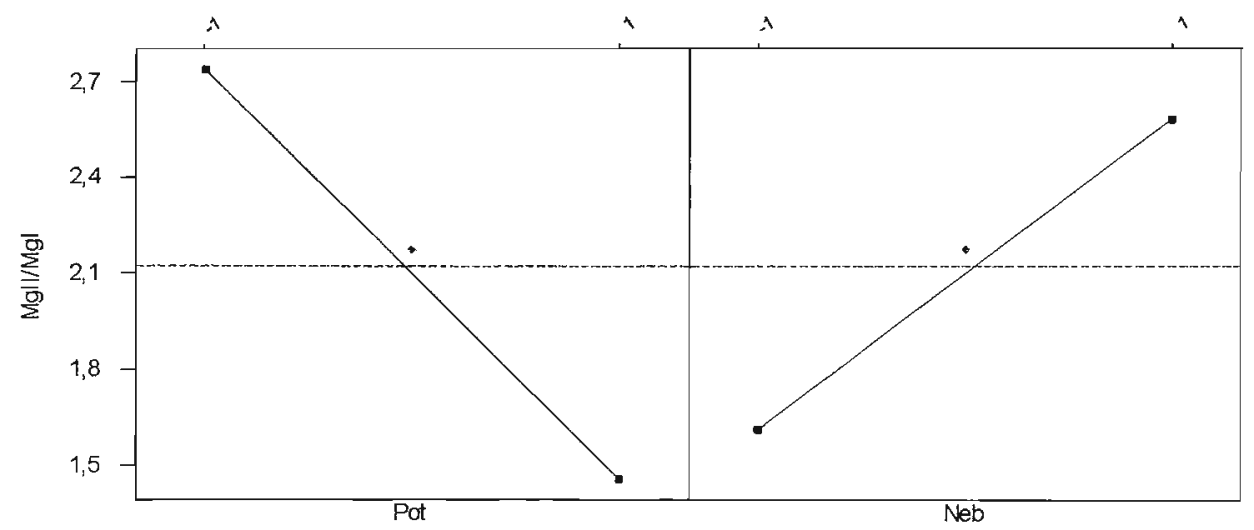

Gráfico dos Efeitos 

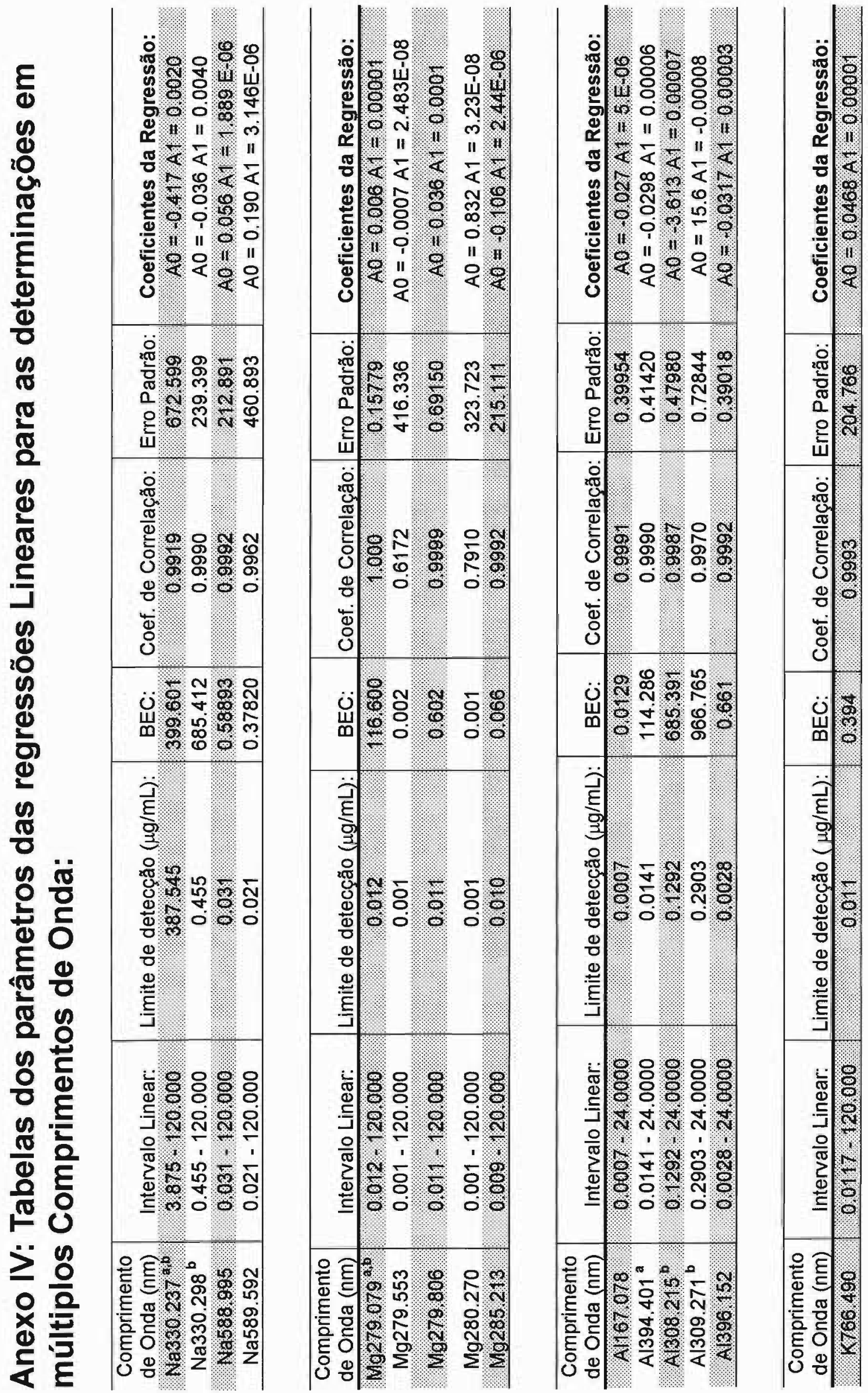


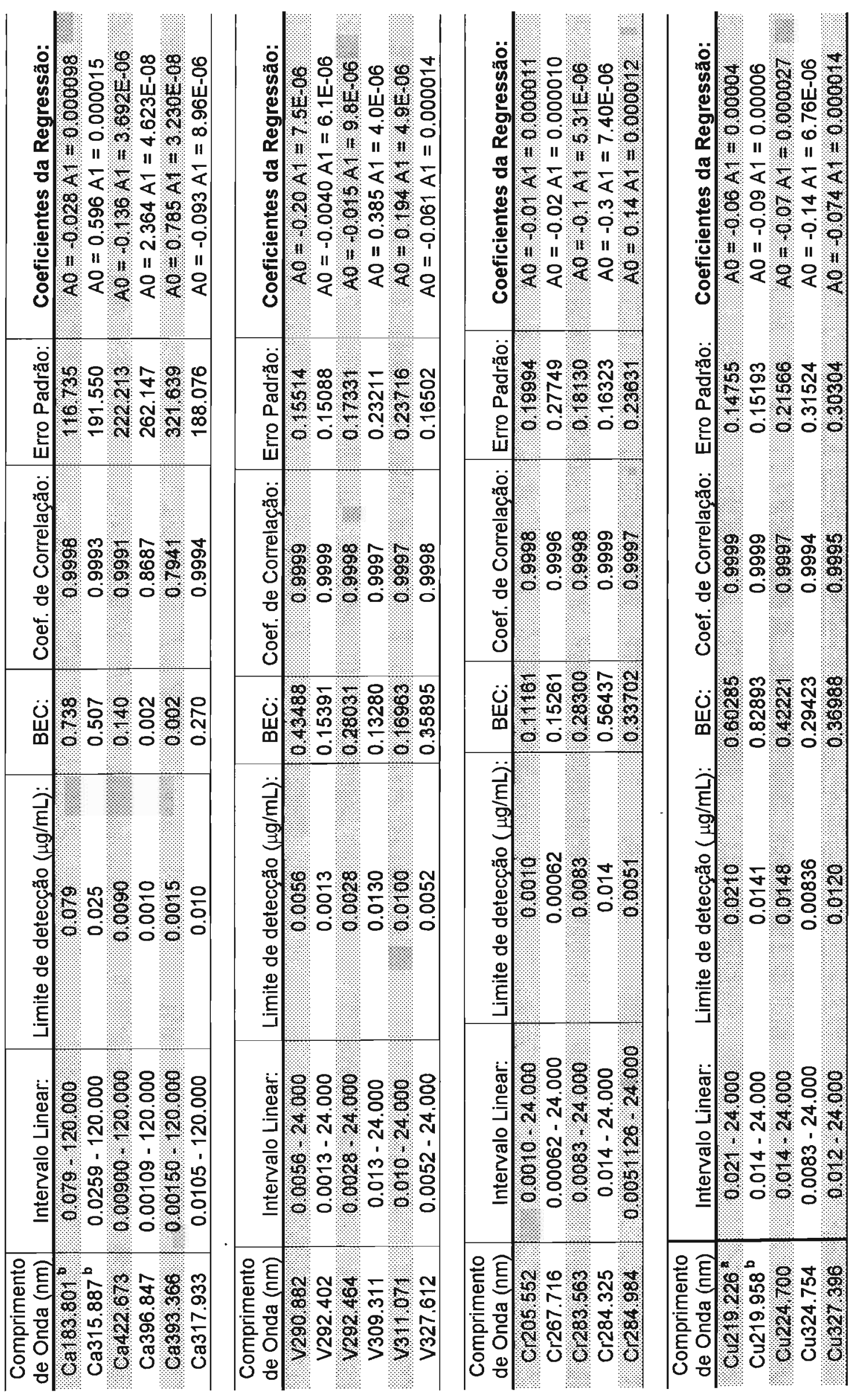




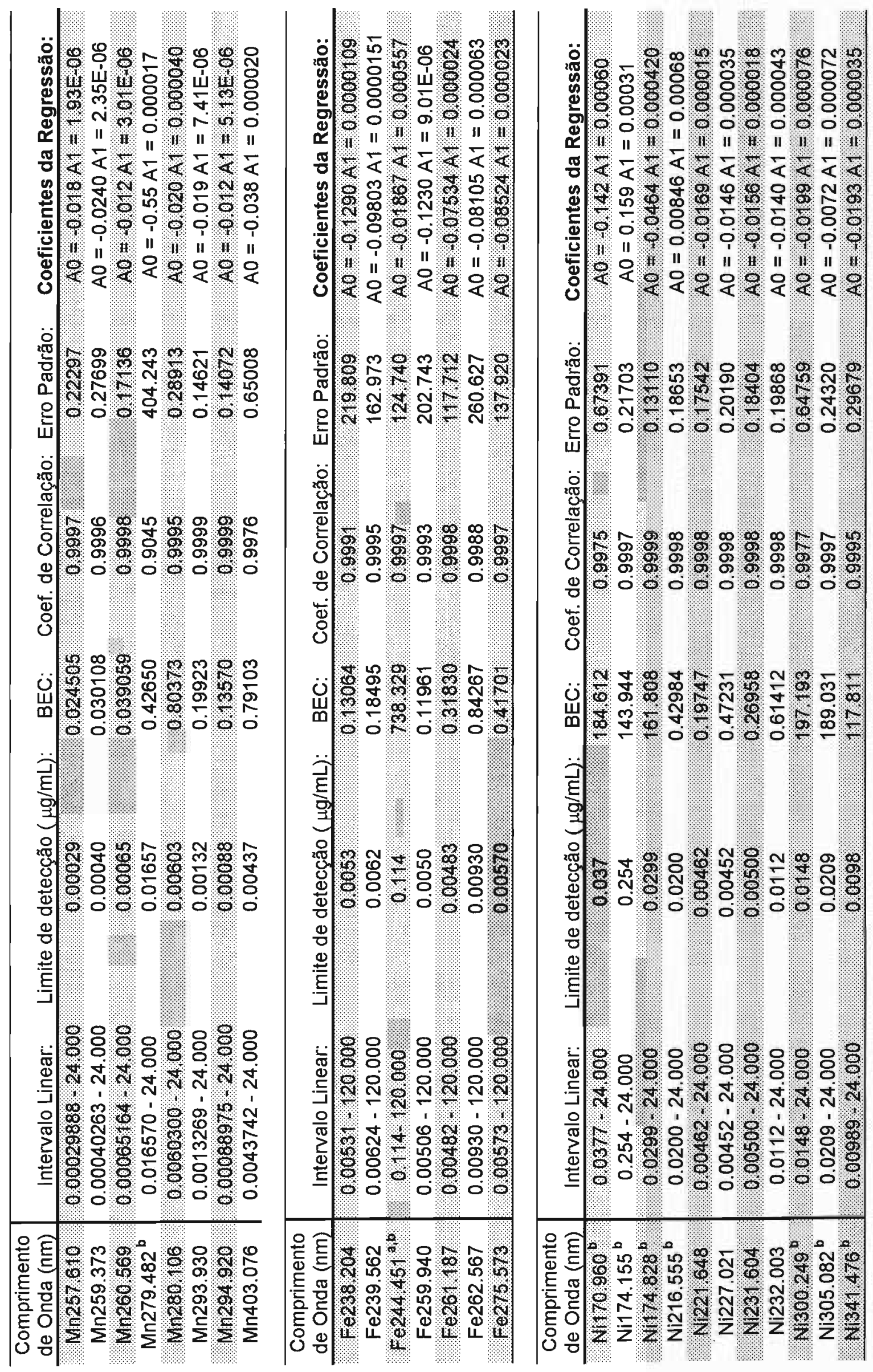



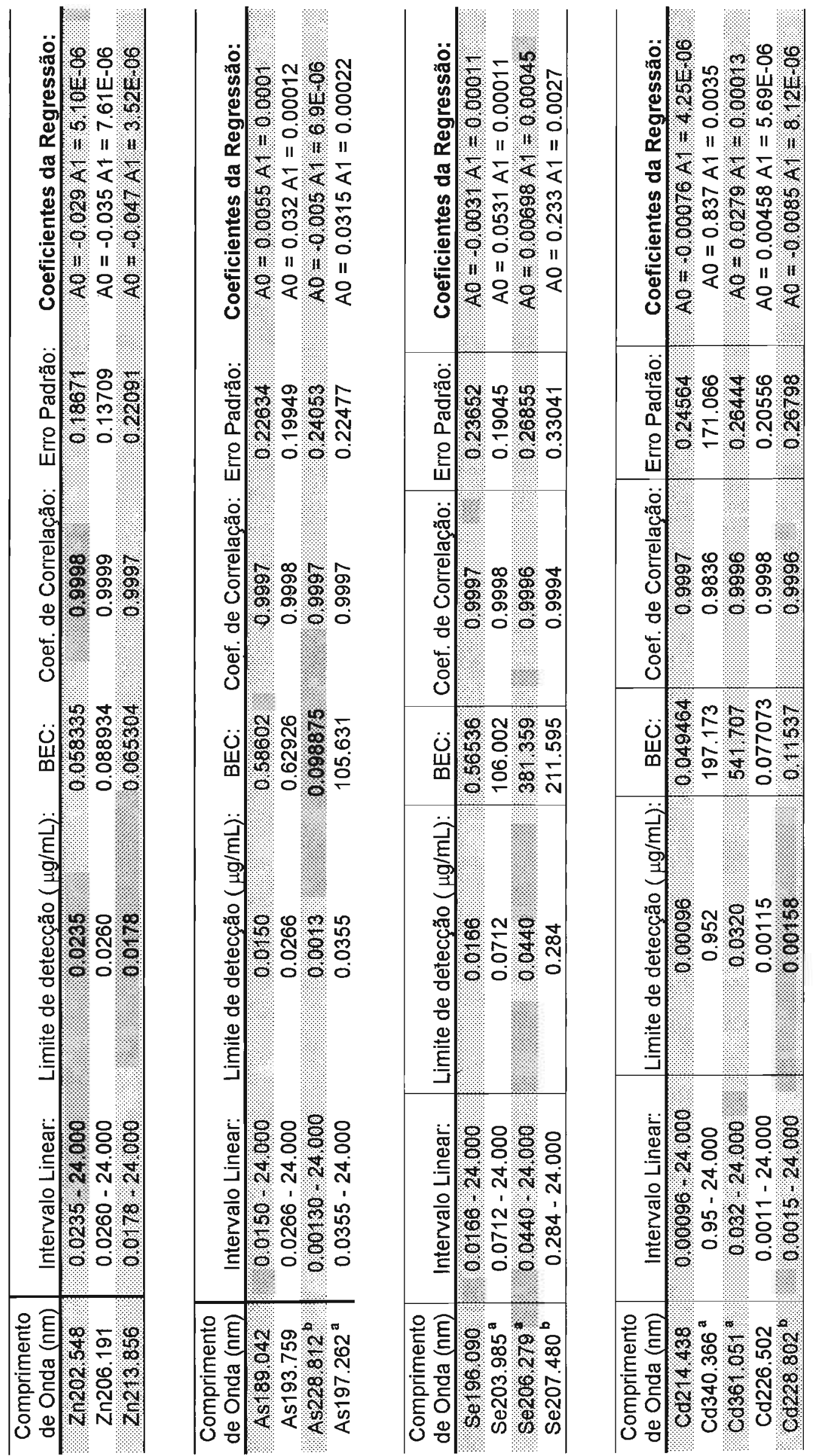


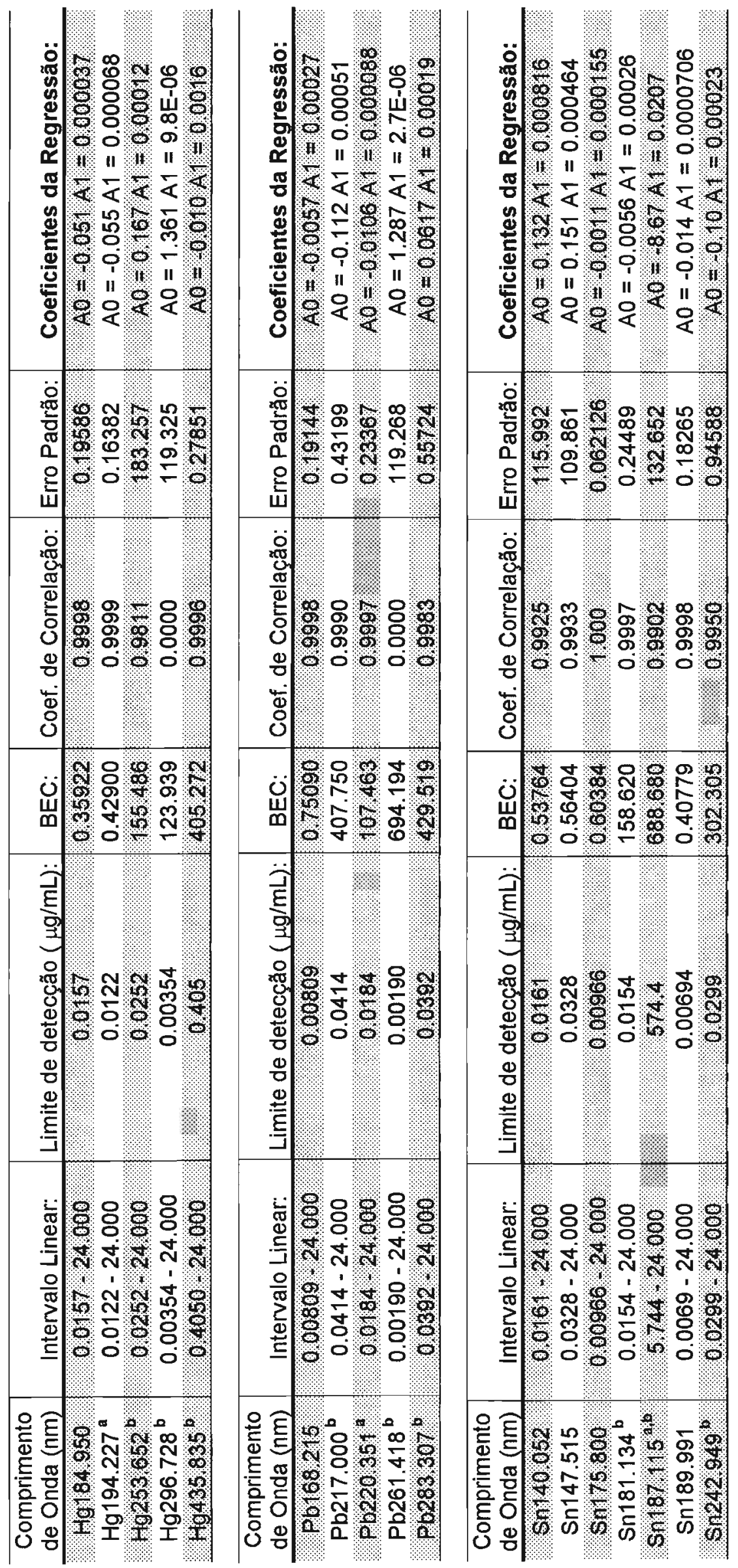




\section{Conc $=A_{0}+A_{1} \times$ Intensidade}

Ao - Coeficiente linear da regressão.

$A_{1}$ - Coeficiente angular da regressão.

LOD - Limite de detecção instrumental

$\lambda$ - Comprimentos de onda

IR - Intensidade Relativa do elemento de interesse.

${ }^{a}$ Linhas espectrais com baixa sensibilidade.

${ }^{b}$ Linhas que apresentaram interferências de matriz ou espectral.

$$
\begin{aligned}
& B E C=\left(C_{1}-C_{0}\right) \times I_{0}-C_{0} \\
& \left(I_{1}-I_{0}\right) \\
& \text { LOD }=3 \delta_{\mathrm{Bco}} \\
& \mathbf{S} \\
& L O Q=10 \delta_{\mathrm{Bco}} \\
& \text { S }
\end{aligned}
$$


Anexo V: Estudo dos Perfis e das interferências espectrais e de matriz.

Verifica-se a presença de um fundo (BG) estruturado para algumas regiões espectrais próximo de $300 \mathrm{~nm}$ independentemente do método utilizado para o prétratamento da amostra.
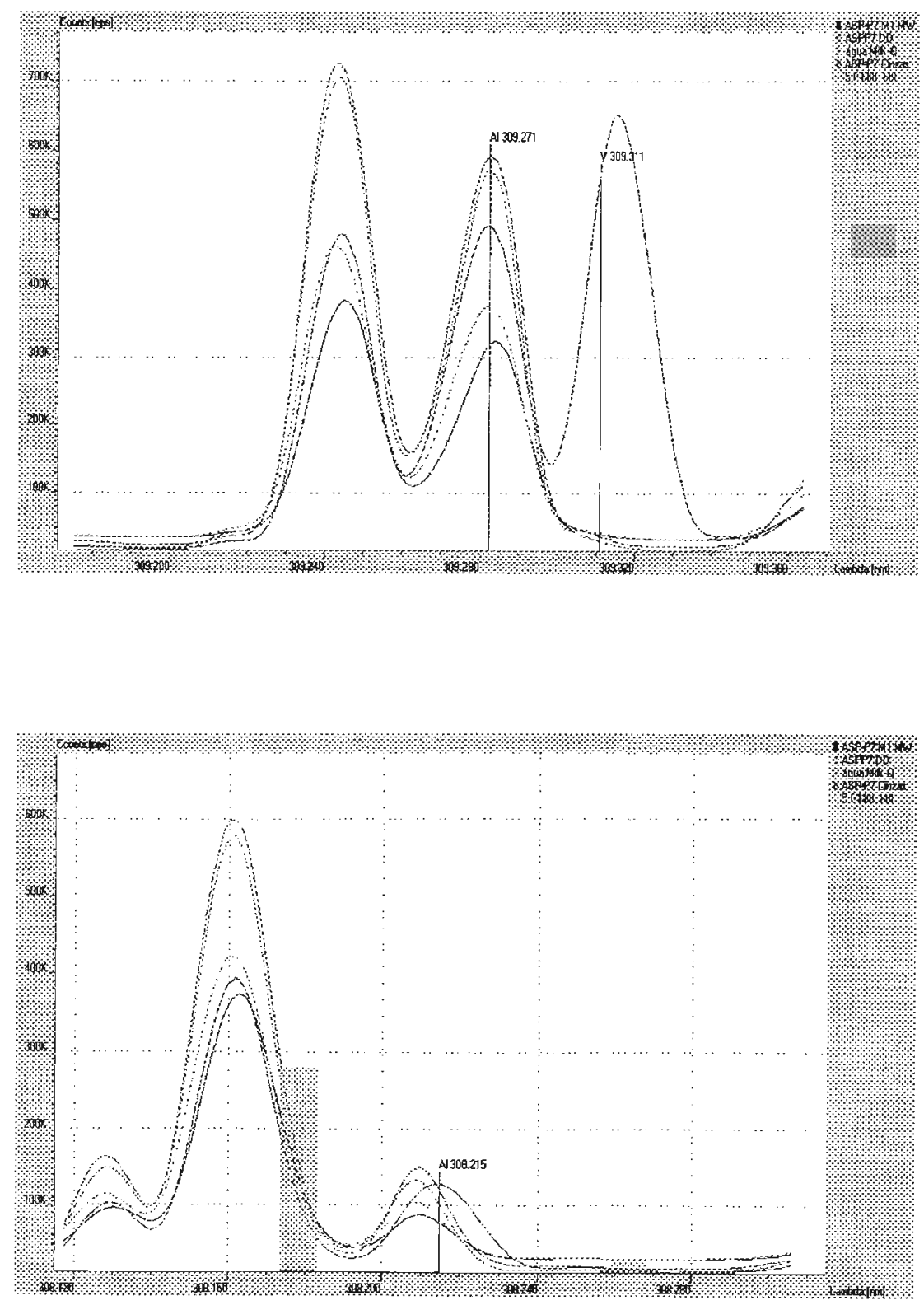
$\phi$
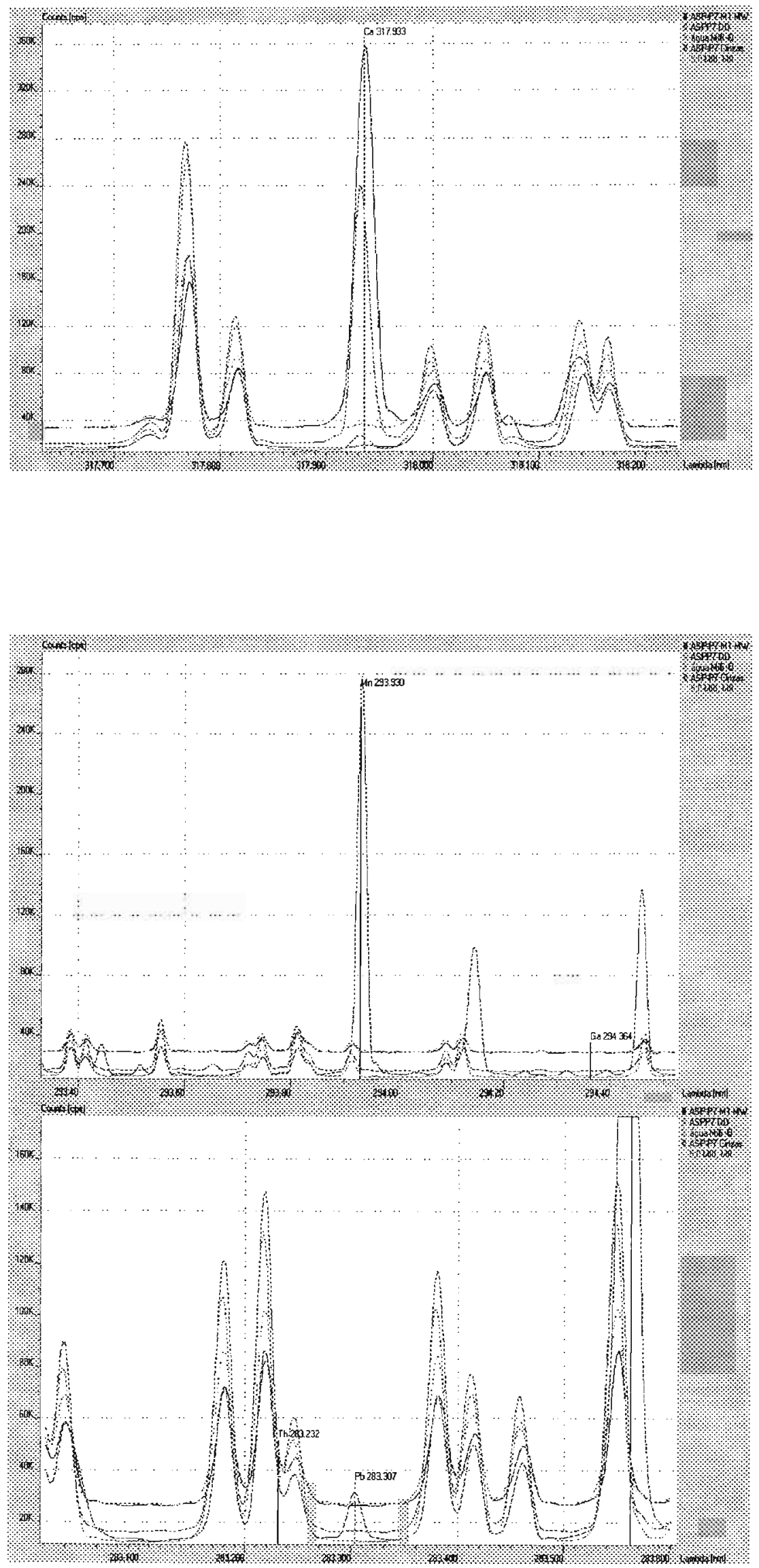
$\phi$
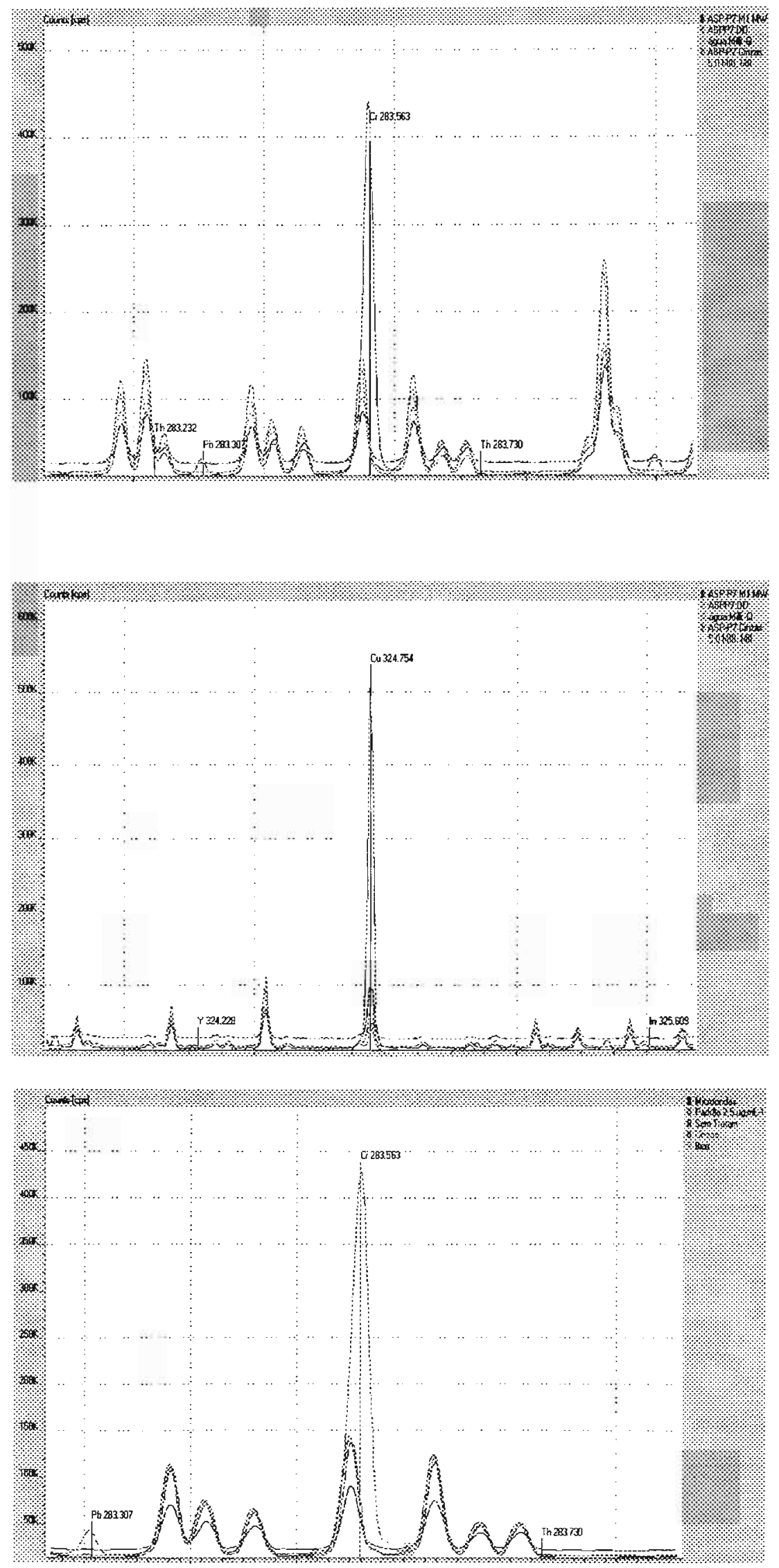
$\phi$

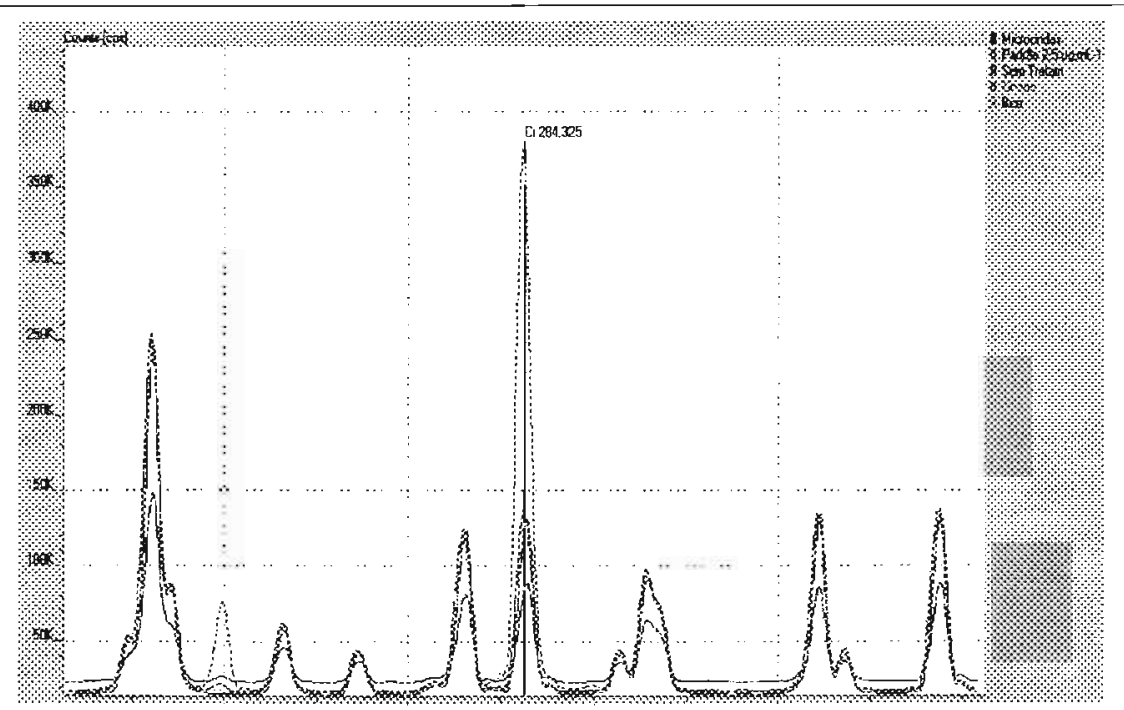

